$$
\text { printed space }
$$

\title{
critically exploring the (re)production of meaning in architecture
}

\section{Matthieu Mereau}

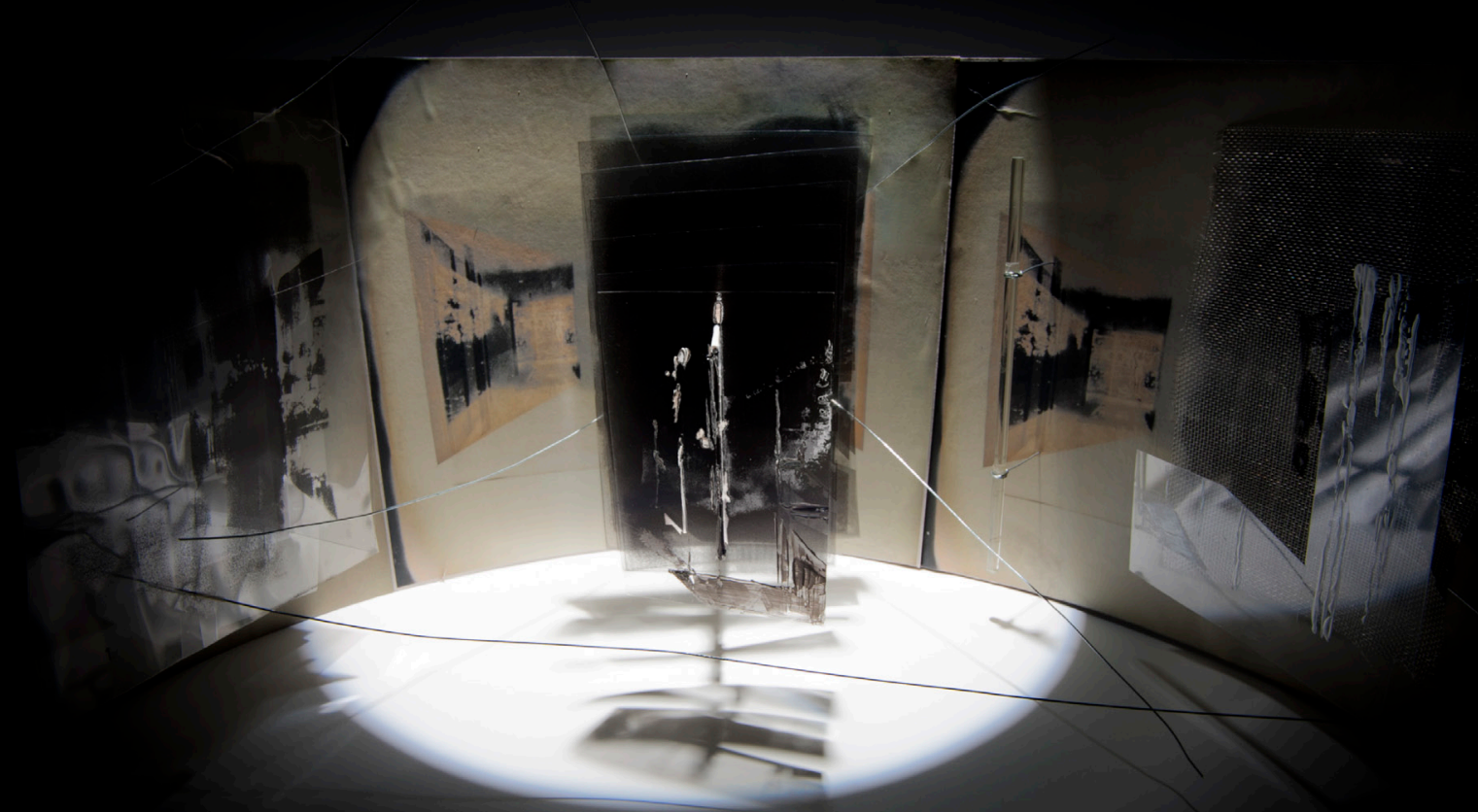





$$
\text { priำกำอ space }
$$

\title{
critically exploring the (re)production of meaning in architecture
}

\section{Matthieu Mereau}

\author{
A thesis submitted in partial fulfilment \\ of the requirements for the degree of
}

MASTER OF ARCHITECTURE (PROFESSIONAL)

at the

SCHOOL OF ARCHITECTURE

of

VICTORIA UNIVERSITY OF WELLINGTON 


\section{abstract}

This research is an exploration of meaning in architecture, considering architectural meaning as cultural production. My thesis expands the notion of architecture from the mere design and implementation of built forms to include consideration of the cultural context in which they are produced. It considers architecture to encompass not only built forms but the interpretations and cultural representations which are assigned to them. These cultural products images, artworks, and media discourse - contribute to the wider social meanings people use to make sense of the world around them.

Meanings in architecture are social creations. They are placed on artefacts by people situated within specific social contexts, and within their frames of thought and experience. My main premise is that institutions of architectural mass media, to a certain extent, shape the frames of reference for mainstream views of architecture, playing a significant role in influencing the meanings people attribute to the various cultural products that make up the field of architecture.

From this premise, this research proposes that the 'media space' of architecture - a space which people abstractly construct as they interpret architectural print media - has potential for architects interested in dealing with the cultural substance of architecture, that is, with architectural meaning.

To explore this idea, this thesis uses theoretical discussions on three themes ('Meaning in Architecture', 'Architectural Media and Representation', and 'the Architecture Culture Industry') to develop a particular understanding of the production of meaning in architecture. Parts of this understanding are strengthened and further developed by case studies of particular works of three architects: 
the journal L'Esprit Nouveau (1920-1925) produced by Le Corbusier; the Sala O exhibit at the Exhibition of the Fascist Revolution (1933) designed by Giuseppe Terragni; and the German Pavilion at the Barcelona International Exposition (1929) designed by Ludwig Mies van der Rohe.

The way these architects engaged with architectural print media to develop the meanings of their work is used as the rationale for a series of architectural design explorations, which attempt to create an architecture open to post-structuralist understandings of meaning. This conceptual 'reconstruction' of Mies' muchpublicised Barcelona Pavilion and the accompanying self-critique becomes my own contribution to the critical media discourse surrounding (or as I argue, constituting) the pavilion.

This research finishes with some conclusions towards a philosophy of meaning in architecture. Its findings critique conventional understandings of the nature of architectural interpretation, and challenge the hegemony of the built form as the site of architectural meaning. Revealing the special focus of the architecture culture industry to be the stimulation of architectural meanings and the spread of particular interpretations in society, my study starts to reassess the role of the architect in contemporary, 'mediatised' culture.

Through approaching architectural print media in more astute ways, architects may begin to explore new forms of architectural meaning, beyond the limits of built form and material existence, and create work within the 'media space of architecture'. 


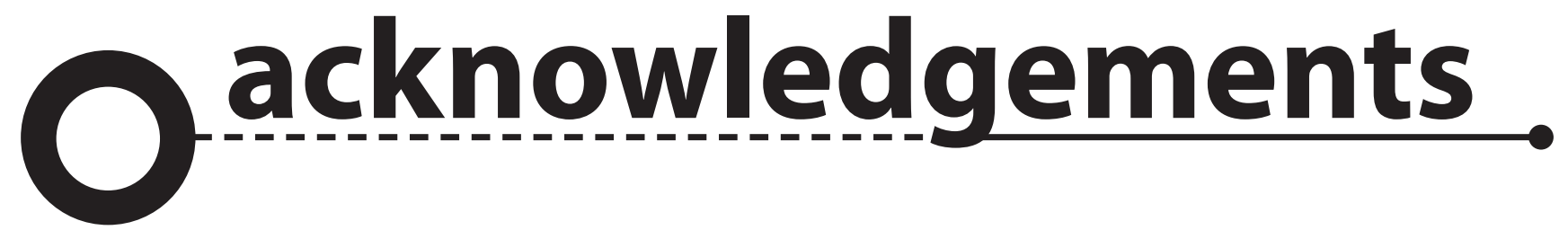

- Dr. Peter Parkes, for his patient, engaging and generous supervision.

- Paul James, for his strategic advice at a crucial moment of the research.

- Cory Manson, Erica Brouard, and Marita Hunt, for being captive guinea-pigs for my untested ideas.

- Sally Apthorp, for being an encouraging sounding-board for my creative experiments.

- Annelies Zwaan, for her baking and banter.

- Charlotte Grieve and Claire Krejcisz, for keeping me smiling during the year.

- The Town Belt, for its quiet walks.

- And my parents, for their unconditional support. 


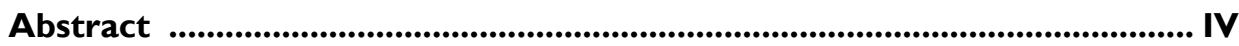

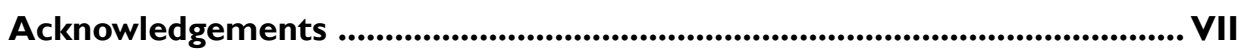

CHAPIES 1:an introduction::::2

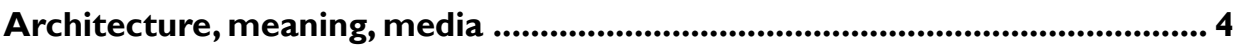

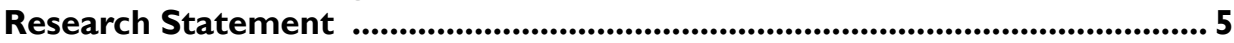

Two small steps to start: theoretical beginnings ...................................................6

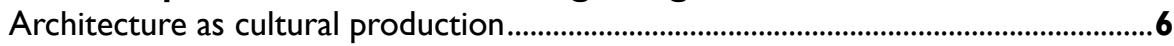

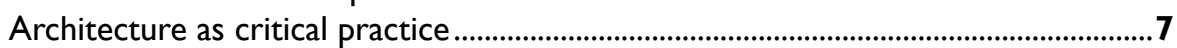

Scope of research ........................................................................................................ 7

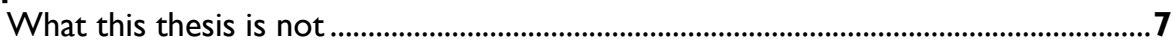

A personal exploration of meaning in architecture.........................................................8

Introduction

14

A dominant model of meaning in architecture:'romantic hermeneutics'... 15

Meaning as truth ..................................................................................................... 15

Meaning as the genius of the artist......................................................................... 16

Meaning as recreating the mindset of the author ...................................................... 17

An oppositional model of meaning in architecture:'post-structuralism' .... 18

Meaning and the object: a critique of the reification of physical objects................. 18

Meaning and possibility: Barthes' "Third Meaning" .......................................................... 19

Meaning and context: girders from New York ……………..................................... 19

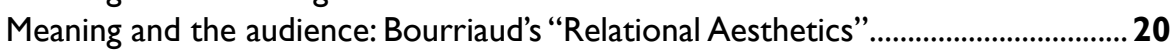

Meaning and visual culture: aesthetic meaning............................................................... 2 I

The place of the post-structuralist architect .................................................. 23

Conclusion and a definition of meaning.......................................................... 25 


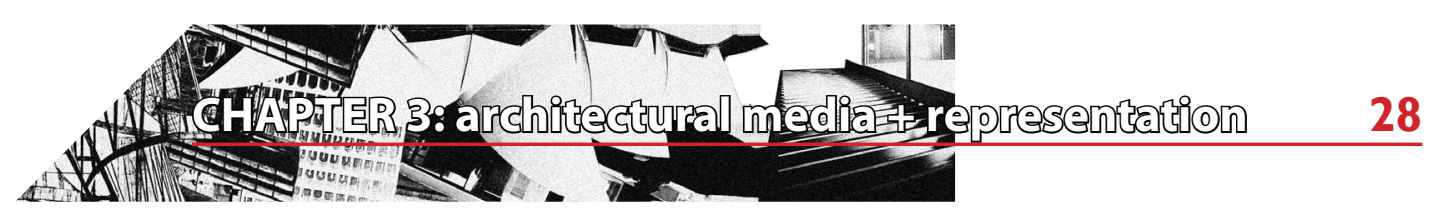

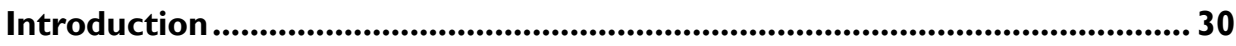

Representation ........................................................................................................... 3 I

The nature of images in architectural media................................................. 31

Photographic images ..................................................................................................... 32

Media influence on architecture ................................................................ 33

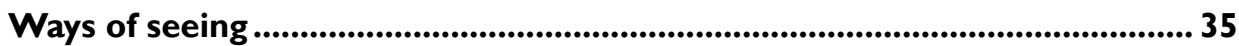

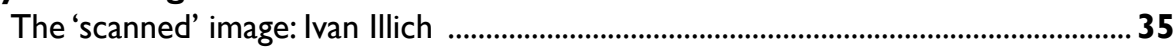

The 'technological' image (of multiple fragments):Walter Benjamin ..........................36

The 'politicised' image: Juhani Pallasmaa, Serge Daney, and Nicolas Bourriaud ........37

The 'mediatised' role of the architect....................................................................... 38

Manipulation of images: fabricated realities............................................... 39

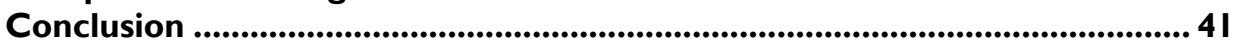

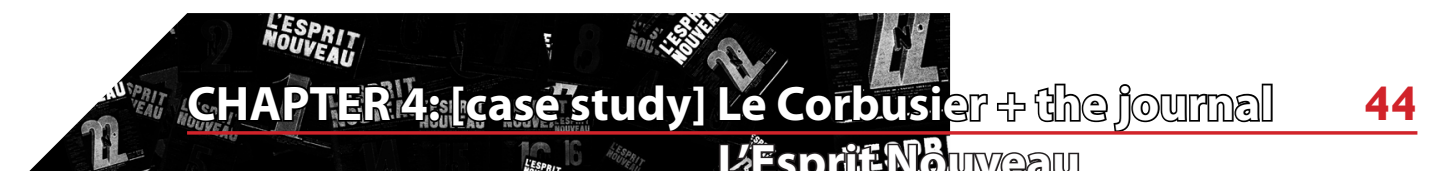

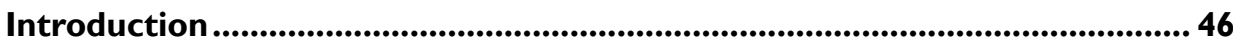

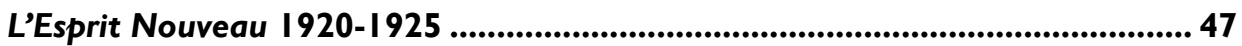

Le Corbusier's techniques of print media............................................................... 49

Appropriation - of imagery ...................................................................................... 49

Juxtaposition —of images and texts..........................................................................50

Manipulation —of images ..............................................................................................52

The image/text relationship.....................................................................52

Publicity and self-promotion .......................................................................................5 53

Print media: a space of architectural production .................................................. 54

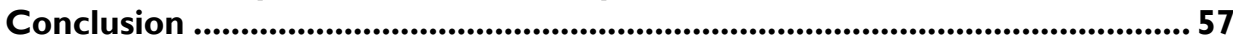




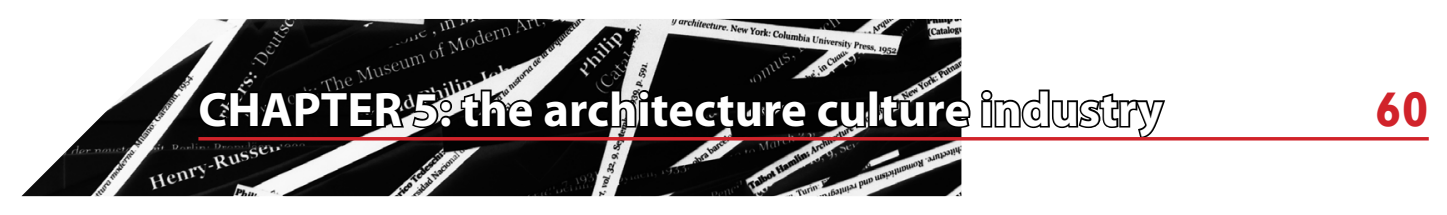

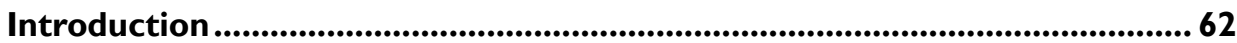

The politics of representation: institutions \& ideologies..................................63

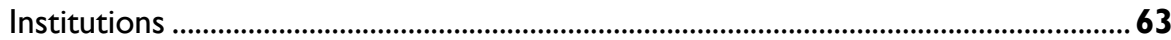

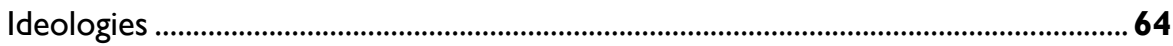

View I: Ideology as mass deception ...............................................................................64

View 2: Ideology as propaganda...........................................................................................6

View 3: Ideology as myth-making.............................................................................66

'Modernism': a product of the architecture culture industry .............................66

Conclusion ..............................................................................................................6 69

CHAPTER 6: [case study] the Exhibition of the Fascists 72

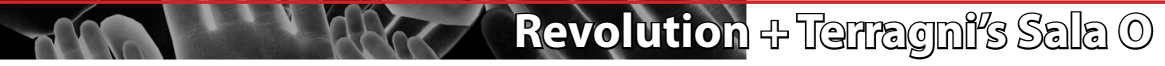

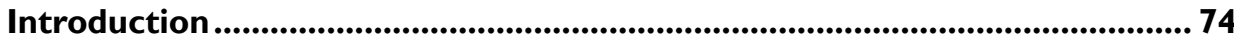

A context for the Mostra .......................................................................................75

Italian Fascism and visual culture ............................................................................ 75

The Mostra della Rivoluzione Fascista (Exhibition of the Fascist Revolution) 75

The exhibition and the architecture culture industry...................................................76

Media as matter: The place of II Popolo d'Italia .....................................................76

Curated collage: production of the exhibition.............................................................77

'Hypervisual dynamism': Giuseppe Terragni's Sala $O$ design ............................... 77

'Montage' in the production of the Sala O.........................................................83

Ideologies in the Mostra and Sala O..........................................................................84

The "unfortunate" question:Terragni and Fascism............................................................ 85

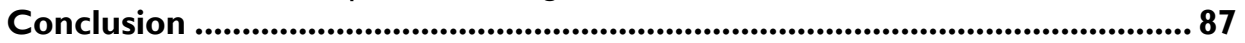


Introduction

SECTION I:The Barcelona Pavilion and Architectural Media \& Representation

Mies and the media space of architectural production ................................ 93

The Berliner Bild-Bericht photographs: A focus ............................................... 94

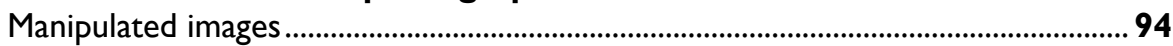

The 'authentic' image?....................................................................................................... 103

The concept of 'montage' or 'collage' in the Barcelona Pavilion................. 103

Problematic plans....................................................................................... 104

The 1929 publication plan of the pavilion................................................................... 104

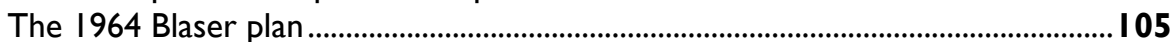

SECTION 2:The Barcelona Pavilion and the Culture Industry

The pavilion and ideology: canonical interpretations ................................. I 07

The 'International Style' exhibition and book ................................................................. 108

The pavilion and ideology: myths................................................................ 108

Myth of the new "free plan" and "free facade" ............................................................ 109

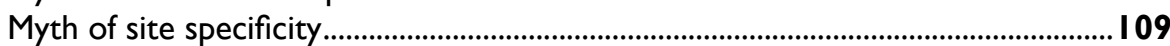

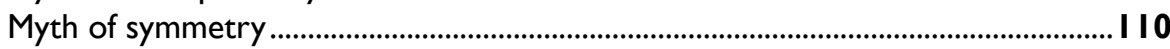

Mies' factual manipulation: misstatements and inaccuracies...................... I I 0

SECTION 3:The Barcelona Pavilion and Meaning

A 'compromised' construction: “architecture" vs. "building" .................... I I 2

Priorities............................................................................................................... I I

Idea and image:The pavilion and dreaming.................................................... I I 3

"architecture" or "architectonic"? ........................................................... I I4

[re]production and [re]construction ......................................................... I I 4

1985 OMA reconstruction............................................................................................ 14

1986 Barcelona reconstruction .............................................................................. I I 5

An "official" reproduction................................................................................................................ I I 5

A physical reproduction....................................................................................................... I 16

A superficial reproduction ...................................................................................................... I / 6

Last words on [re]production/construction ......................................................... 117

Conclusion ....................................................................................................... I I 9 


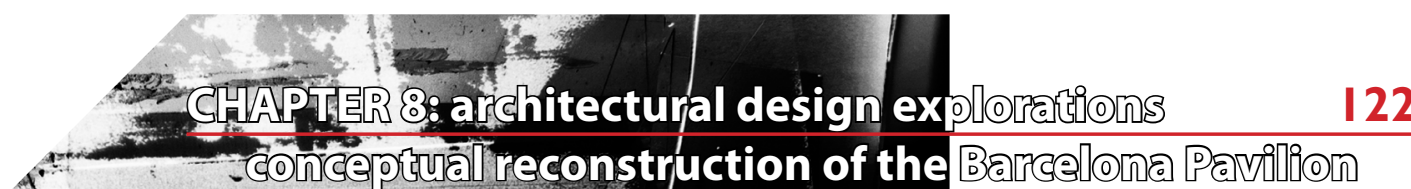

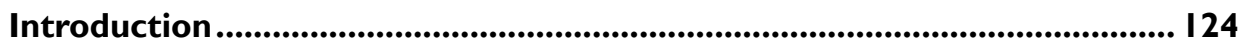

The role of the 'project', and aims of the design process.......................................... 125

Indeterminacy as a part-method................................................................................. 125

Interpretation: retrospective analysis ................................................................. $/ 26$

Reconstructing the Barcelona Pavilion ......................................................................... 127

On the act of reconstruction ........................................................................................... 127

Design criteria for my reconstruction....................................................................................... 127

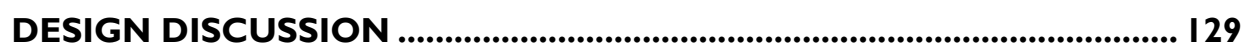

SECTION I:The Publication Exhibition piece

Writing down: Description of the Publication Exhibition piece ........................ 129

Writing out: Intentions for the Publication Exhibition piece ............................ 130

Writing through: Critical Interpretation of the Publication Exhibition piece I 33

The size

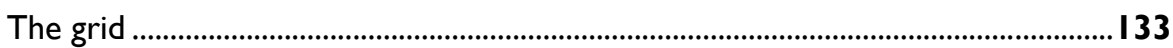

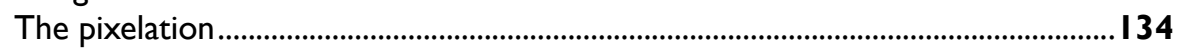

The perspective points.......................................................................................134

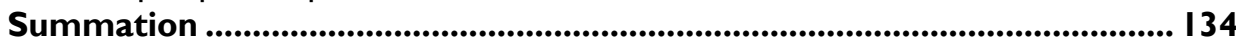

SECTION 2:The September Installation

Writing down and out: Description and Intentions for the September Installa-

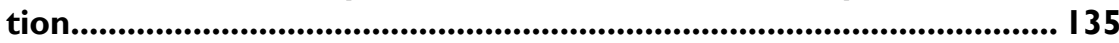

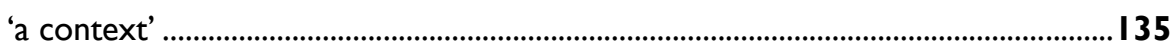

'a project'

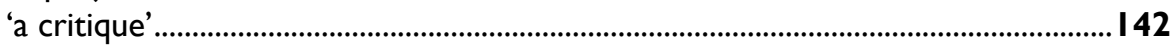

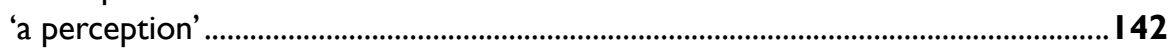

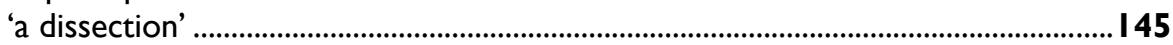

'an apparatus' ......................................................................................................... 145

'a synoptics' ............................................................................................................ 146

Writing through: Critical Interpretation of the September Installation ...... 152

Meanings from processes of reproduction ............................................................... 152

Others' interpretations: the design review................................................................. 152

The installation as the Barcelona Pavilion reconstructed............................................ 155

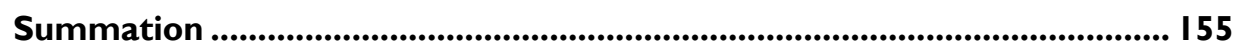

SECTION 3:The 'new work' installation

Writing down: Description of the 'new work' installation................................. 156

Writing out: Intentions for the 'new work' installation................................... 159

The 'synoptics' photos as an image set....................................................................159

The 'synoptics' photos in relation to the Berliner Bild-Bericht prints ....................159

Writing through: Critical Interpretation of the 'new work' installation ........ 160

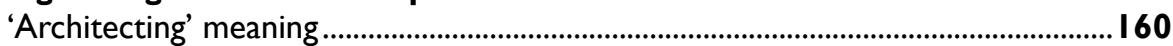

Productive superficiality ..................................................................................161

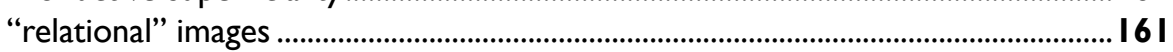

Faceted interpretations: Giedion's anonymous history ……………………………...161

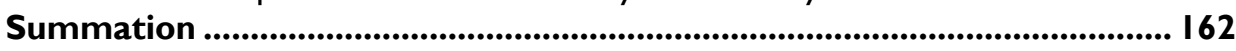

Conclusion: a post-structuralist work of architecture.................................... 163 
Introduction.

168

Significance of this research ..................................................................... 169

Conclusions toward a philosophy of meaning in architecture....................... 170

Last words..................................................................................................................... 173

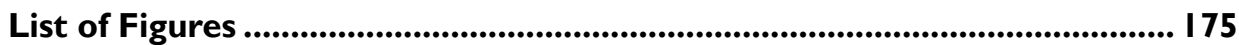

Bibliography .................................................................................................................. 18 


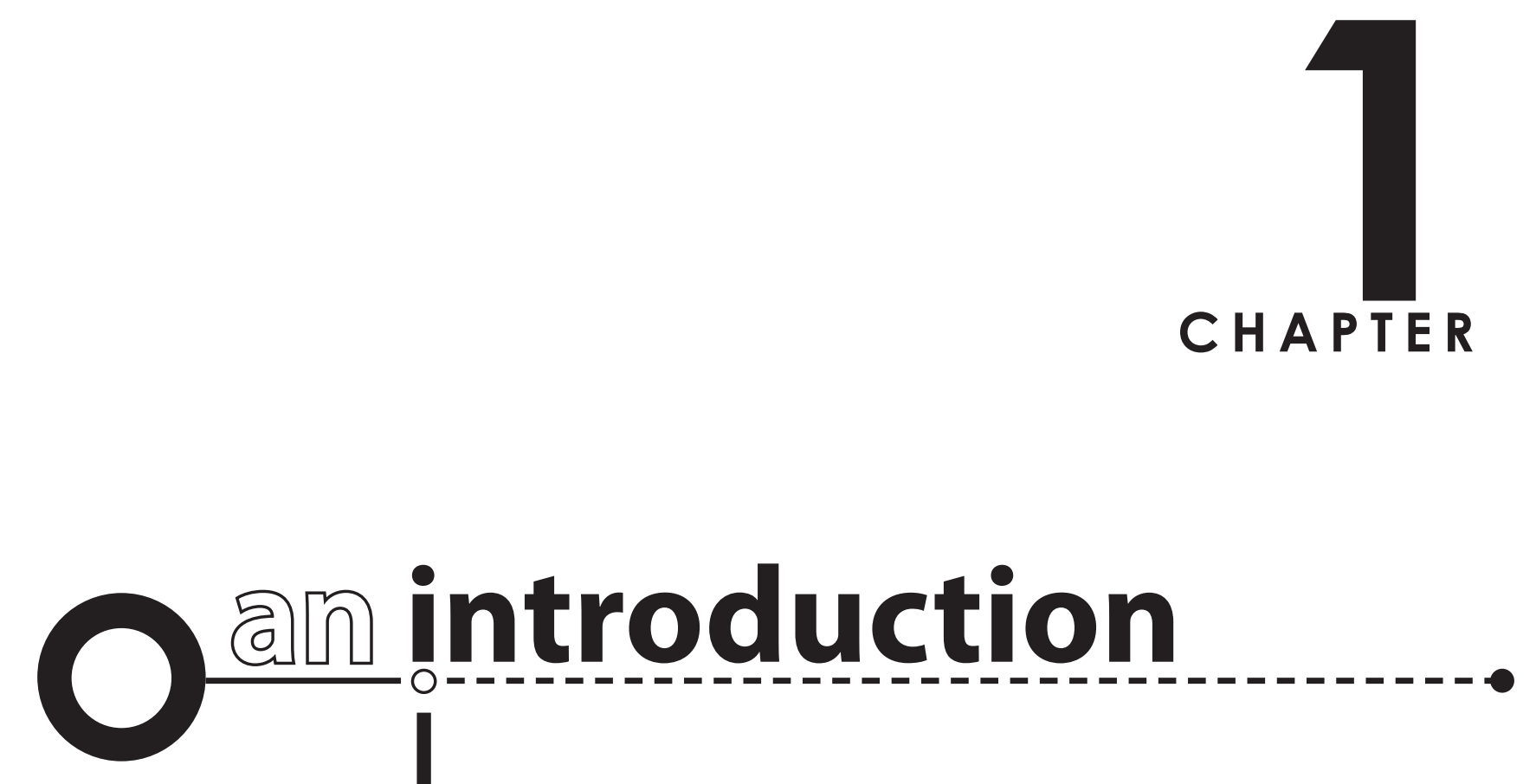

"Everything is architecture."

- Hans Hollein (1968, p. 1).

"And it turned out later that, not being able to build certain things, I could draw them; but not being able to explain them entirely in drawing [...] I had to explain them, so I wrote."

- Le Corbusier (quoted in Žaknić, 2007, p. 117).

"[A] theory is an artefact, more than that, it is a designed artefact, and as such it must be no less well designed than anything else that purports to satisfy our intellect, our sensibilities, and our needs, material or intellectual."

-Panagiotis Louridas (1999, p. 533). 


\section{chapter}

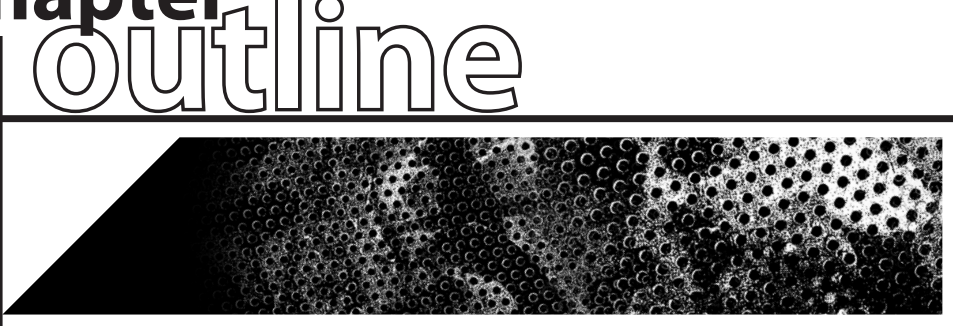

Architecture, meaning, media

Research Statement

Two small steps to start: theoretical beginnings

- Architecture as cultural production

- Architecture as critical practice

Scope of research

- What this thesis is not

- A personal exploration of meaning in architecture

Playing leapfrog:An arrangement for this thesis 


\section{1 \\ CHAPTER}

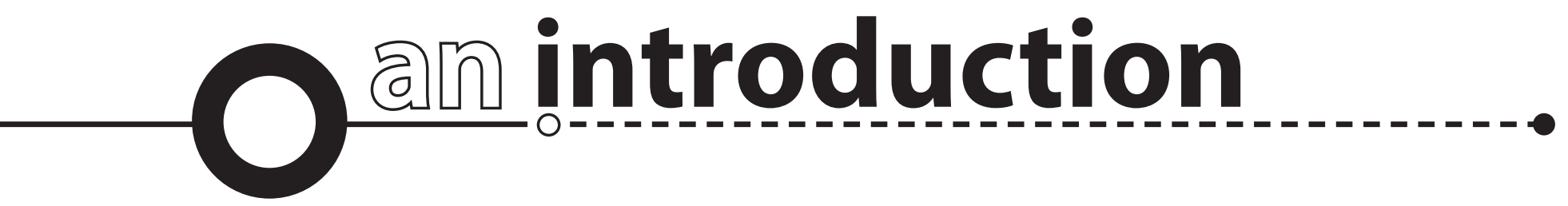

\section{Architecture, meaning, media}

Architecture $^{1.1}$ is an interpretive act. Among the many cultural practices which form people's lives, architecture is one of the most obvious and yet easily overlooked; particularly in regard to people's attribution of meaning to the world around them.'.2 People, when asked to describe architecture are likely to think of important buildings, not acknowledging that it is the attribution of meaning to built forms which gives them this 'importance'; changing them from piles of construction materials assembled in a certain way into products of architecture with cultural significance. Meaning ${ }^{1.3}$, then, is an essential part of architecture, but how architectural meaning arises for people is not widely discussed. In general, people are not used to critically analysing what architecture means for them, or why this might be so, instead often relying unquestioningly on architectural 'experts' to tell them what to think. Architectural mass-media, the vehicle for the production and public dissemination of architectural interpretation, has a significant influence on people's interpretations of architectural meaning. Architectural journals, books and other print media products such as photographs and printed images are key sources for people's own meanings of the architectures they encounter. For example, people's ideas of certain famous buildings are often shaped by particular 'iconic' photographs reproduced again and again in architectural culture. Tourists visiting the buildings in real life often find that its physical reality seems different to that conveyed by these images. The combination of architecture (understood as meaning) and media (understood as processes specialised in the dissemination of meaning) is an extremely powerful one. Brought together by the relational concept of the architecture culture industry, ${ }^{1.4}$ these three areas define the broad scope of this research.
1.1. Defining the concept of what 'architecture' might be is an overwhelming undertaking, fraught with possible contradictions, ambiguities and examples begging to be exceptions to anything one might propose. As such, a well-argued definition of architecture is far beyond the scope of this research. However, for the purposes of establishing some context for this discussion of specifically architectural meaning, I supply the following working statement: In this thesis I understand architecture to be a very broad term relating to meaning associated with the art of designing physically-, visually-, or metaphorically-habitable space.

1.2. Anote on context:This thesis has been written from a context situated within the twentieth and twenty-first century world of Western architecture culture, and also from a viewpoint situating 'modernism' as a key influence on the history of architecture.

1.3. All uses of the word 'meaning' in the text refer to architectural meaning. This thesis is less concerned with specific meanings orinterpretations of architecture, than with its historical being, modes of production, and influence.

1.4. The architecture culture industry is a relational concept describing the way people interact with the vast field of commoditised culture, and is formed by the processes by which cultural 'institutions' employ ideologies to maintain their social standings and promote certain ideas and ways of thinking. (See Chapter 5). 


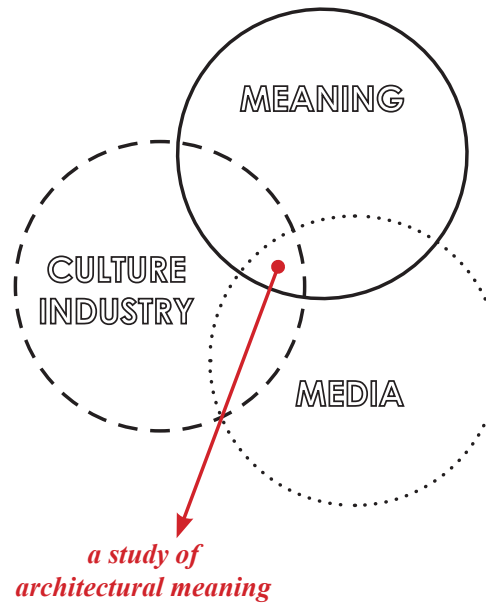

fig. 1.I. The three intersecting thematic areas of my research.

\section{Research Statement}

This thesis critically explores the role of architectural print media in the production of meaning in architecture. It asks how the influence of the architecture culture industry on people's interpretations shifts not only our understanding of architecture as built form but also the role of architects. It seeks to discover how the reproductive dimensions of architectural print media hold potential for a critical exploration of meaning in architecture. In this thesis I propose that an architecture dealing firmly with the cultural substance of meaning can be produced within the media space of architecture, a space which people abstractly construct as they interpret architectural print media.

In the conventional processes of architectural production, the conception, execution, and reproduction of architecture tend to be separate, consecutive moments. But under the critical proposition of this thesis (that architecture can be produced and 'exist' in the media space) this hierarchy is subverted. Conception of architectural ideas and their reproduction feed off and cross each other. This proposition seems to have significant implications for the practice of architecture in contemporary, mediasaturated society. If the physical reality of architecture is a separate entity from that created via the media, architects have the potential to explore a facet of their architectural production (meanings and ideas) in a more astute manner by engaging with media processes. The representational dimension of media offers architects possibilities for architectural meaning which may exceed the limited communicative capacities of physical built forms, further extending and complementing the work involved in trying to achieve the complex reality of construction.

When translated into built form, architecture gets mixed up in the world of phenomena and necessarily loses its purity as concept. Yet significantly, that when this same built architecture enters the two-dimensional space of printed media, it returns to the realm of ideas (Colomina, 1994, p. I 14). The function of media representation is not a static, impartial reflection, a mirror image, of architecture as it happens to be built, but a further opportunity for architects to engage with the substance of ideas. Construction is a significant moment in the architectural process, but by no means its entire end product. Photography and layout can be used to construct another architecture in the space of the printed page. 


\section{Architecture as cultural production}

"In order to know all we can about architecture we must be able to understand each instance of architecture, not as a passive agent of culture in its dominant ideological, institutional, and historical forms, nor as a detached, disinfected object. Rather we must understand it as actively and continually occupying a cultural place - as an architectural intention with ascertainable political and intellectual consequences."

$$
\text { — K. Michael Hays (1984, p. 27). }
$$

This study is situated within an understanding of architecture as a form of 'cultural production' or 'cultural practice'. Architecture is a philosophically complex, conflicting and divergent discipline. Architectural ideas both stem from and feed into ideas of wider society simultaneously. Cultural practices such as architecture are not simply derivatives of culture, but are themselves major elements of its constitution, alongside not only other 'traditional' arts and forms of intellectual production but also all the practices of signification. Although my study is focused on the specialised cultural practice of architecture, a broad definition of culture ${ }^{1.5}$ remains important as is suggests that architecture should still be defined and examined within the widest possible cultural contexts. To this effect, my research has incorporated ideas from architectural theory and history, anthropology, art history, biography, cultural studies, film and media studies, historiography, literary criticism, philosophy, and political studies, amongst others.

A reading of architecture as cultural production makes little distinction between what is built and what is not: after all, what comes to be built is arguably often a matter of good fortune and the availability of finance. And despite most architectural discussion generally focussing on physical buildings as objects, many buildings are not architecture in the sense of significantly forming part of its debates and development. "The discourse of architecture as a specific practice and as an art that expresses and interrogates cultural values misses its target if it concentrates on buildings and projects that lack any original aspiration...those architects who build extensively are not always those with the most critical ideas, and for the most part are not those who debated and generated the inventive thinking which informs their work" (Higgott, 2007, p. 6).
1.5. In this thesis I have used the understanding of the word 'culture' which Raymond Williams gives in his Keywords (1988). Williams describes 'culture' as referring to "the works and practices of intellectual, spiritual and aesthetic development, especially artistic activity. ... [It is a broad and complex term indicative of] the relations between general human development and a particular way of life, and between both and the works of art and intelligence" (p. 90-91) 


\section{Architecture as critical practice}

Given the cultural presences seeking to filter our interpretations of media and architecture, it becomes useful to engage with architecture from a position of critical practice as a tool in the philosophical study of perception and the production of meaning. Critical practice strives to demystify the representations which construct reality for individuals. Demystification in this sense is empowering, creating the conditions whereby languages of critique and possibility develop, enabling people to reflect and take emancipative action against the cultural hegemony of dominant social powers (Dutton, 1996, pp. 159-160). Critical practice aims to achieve a freedom of consciousness that affords an understanding of the articulation between architecture, its representation and its interpretation; an awareness of the relation between what is perceived and what is possible (Porphyrios, 1985, pp. 20-21).

Accordingly, critical architecture lies at the intersection of culture, power and representation and thus contributes to people's identities and how they make sense of the world through meaning (Dutton, 1996, p. 160). The role of the critical architect might therefore be to theorise, consciously and explicitly, the cultural production of meaning in architecture, and to develop processes that reveal how this happens. This is in part the task I have given myself in this thesis.

\section{Scope of research}

\section{What this thesis is not}

To describe the scope and limits of this research it is simplest for me to

1.6. This thesis suggests ways in which architects can start to address these relationships. And, although not a specific focus, it also provides some answers towards why many architects overlook such considerations. (See Chapter 2 in particular for a discussion of certain trends in mainstream architecture culture). state a few things that this thesis is not.

This thesis has not attempted to produce a singular, highly-resolved conventional architectural design project (ie. a building) as the result of its research. It has however engaged with significant ideas of architectural practice, most crucially, the production of architectural meaning. Rather than seek to 'express' these ideas through a physical design, this thesis explores how these architectural ideas come about at all. For, how can architects, as creative practitioners, fully attempt to engage in the processes of cultural production without considering the relationships they have to their 'audience', to the cultural contexts they are situated in, to the ideas they create, the ideas which influence them, or the ideas they inspire? ${ }^{1.6}$

This thesis does not pretend to treat the design project as a scientific 'test'. The design component of this research, although significant in terms of stimulating thought-processes which may not have otherwise occurred, is not considered as a resolved 'end' or 'concluding manifestation' of the research. Neither does it pretend to systematically 'test' the theoretical positions of the research to arbitrarily determine if they are 'correct' or not. Rather, design has been used as an exploration of the ideas assembled 
and arising in the textual research, extending them into a more visual realm of architectural design, and the possibilities or attitudes which this different dimension is able to offer to the written discourse.

This thesis does not pretend to provide fixed answers. Instead, what I have attempted to do is provide a set of arguments, present certain views, and make judgements of their worth in terms of my own frames of reference and understanding. This is why I approach the research as a personal exploration of meaning in architecture, rather than subscribe to a prescriptive attitude claiming to reach 'universal truths'.

\section{A personal exploration of meaning in architecture}

From the outset of this study, I contend that all cultural products are tied to the conditions and context of its production.As such, a critical discussion of architecture, such as this one, is not only a reflection of the original sources, objects, ideas, and buildings it considers, but of the ideologies and ideas of its author. Therefore, it is important to acknowledge that my exploration of architectural meaning is a personal, interpretive one. My written discourse constructs an interpretation rather than attempting to reveal any sort of fundamental 'truth' of meaning in architecture. I have made conscious choices in what I have discussed, emphasising some ideas and sources at the expense of others. However, I have nevertheless attempted to keep my work open to other readings and interpretations, being mindful of ways my research may engage with that of others. Finally, as a result of the particular theoretical understandings I establish for myself through this thesis, it is also important to note openly that certain 'institutions' of architecture culture and of the reader are co-authors of this discussion, inescapably shaping both my frames of reference in writing it, and the reader's own frames of reference in reading and interpreting it.

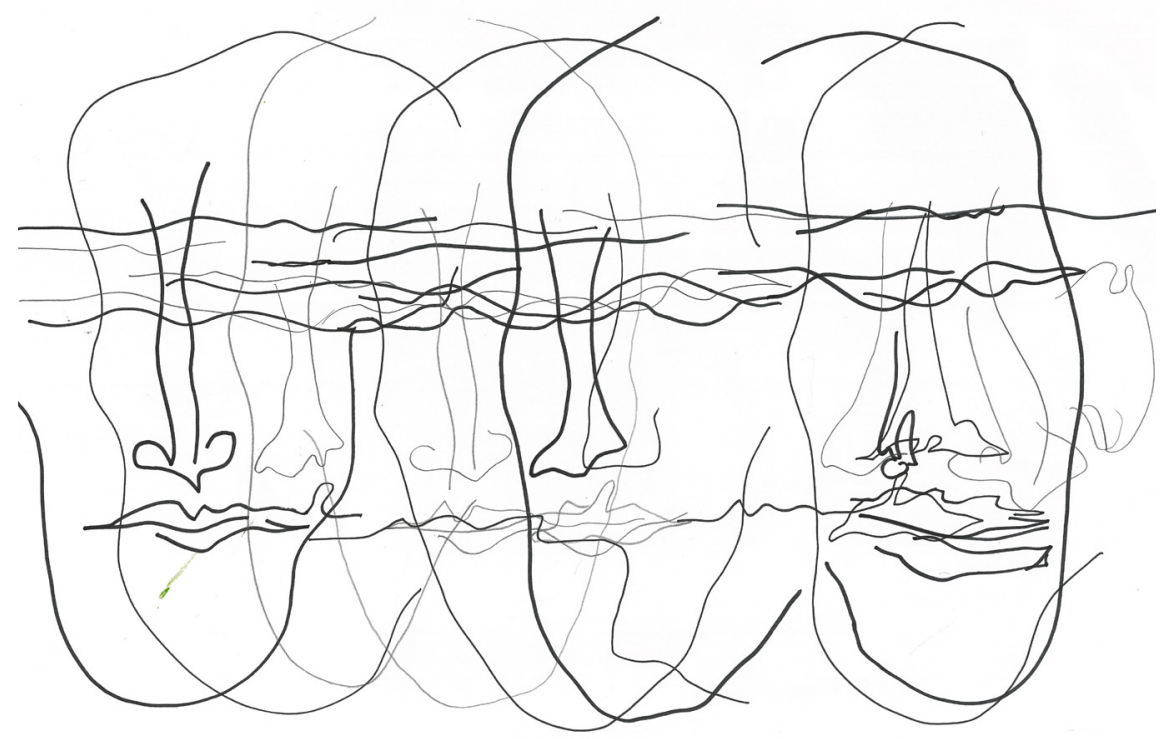

fig. 1.II. Critical interpretations are reflections of the ideologies and ideas of their authors. (Drawing by the author).

The French philosopher Paul Valéry unexpectedly learnt this from his study of Leonardo da Vinci: while Valéry thought he was writing on the genius of Leonardo, he realised that what he wrote was only a reflection of his own mind and the image of the artist which his mind's eye had constructed. "In the end...," Valéry wrote, "I dared to discuss myself using his name and his character," projecting himself onto the study he was creating (Valéry, 1929, pp. 26-27). 
The discussion of this thesis comprises nine chapters, covering three theoretical themes, three case studies, a collection of architectural design explorations, and some conclusions towards a philosophy of meaning in architecture.

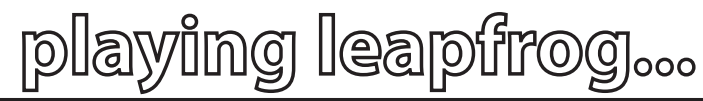

Chapters 2, 3 and 5 cover the themes of meaning in architecture, architectural media and representation, and the concept of the architecture culture industry respectively. They provide a theoretical discussion on each of these areas, and establish particular positions useful in constructing my developing argument.

Chapter 4 is the first of my case studies, focusing on Le Corbusier's involvement with the Parisian journal L'Esprit Nouveau (published 19201925). It examines how the theoretical positions on architectural meaning and media (Chapters 2 and 3 ) can be seen in the production of architectural meaning. I argue that Le Corbusier blurred the conventionally understood limits between architecture and mass-media by using L'Esprit Nouveau as a new space of production, the 'media space of architecture'.

My second case study, discussed in Chapter 6, relates to the themes of architectural media and representation and the architecture culture industry (Chapters 3 and 5). Looking at the Exhibition of the Fascist Revolution (Rome, 1933) and the design by Giuseppe Terragni of the Sala $O$ exhibit within it, I consider how processes of the architecture culture industry can be seen as influential factors in the design of architectural space. I argue that Terragni's Sala $O$ demonstrates a way of practicing architecture which cannot be separated from its representation, revealing architecture's dependence on cultural products such as print material which so significantly influence our perception of architectural meaning.

Chapter 7 comprises my third and final case study, which ties together the theoretical themes of Chapter $\mathbf{2}$ (architectural meaning), Chapter $\mathbf{3}$ (print media and representation) and Chapter 5 (the architecture culture industry). Focussing on the famous Barcelona Pavilion (first constructed 1929), my discussion explores how its architect, Ludwig Mies van der Rohe, 


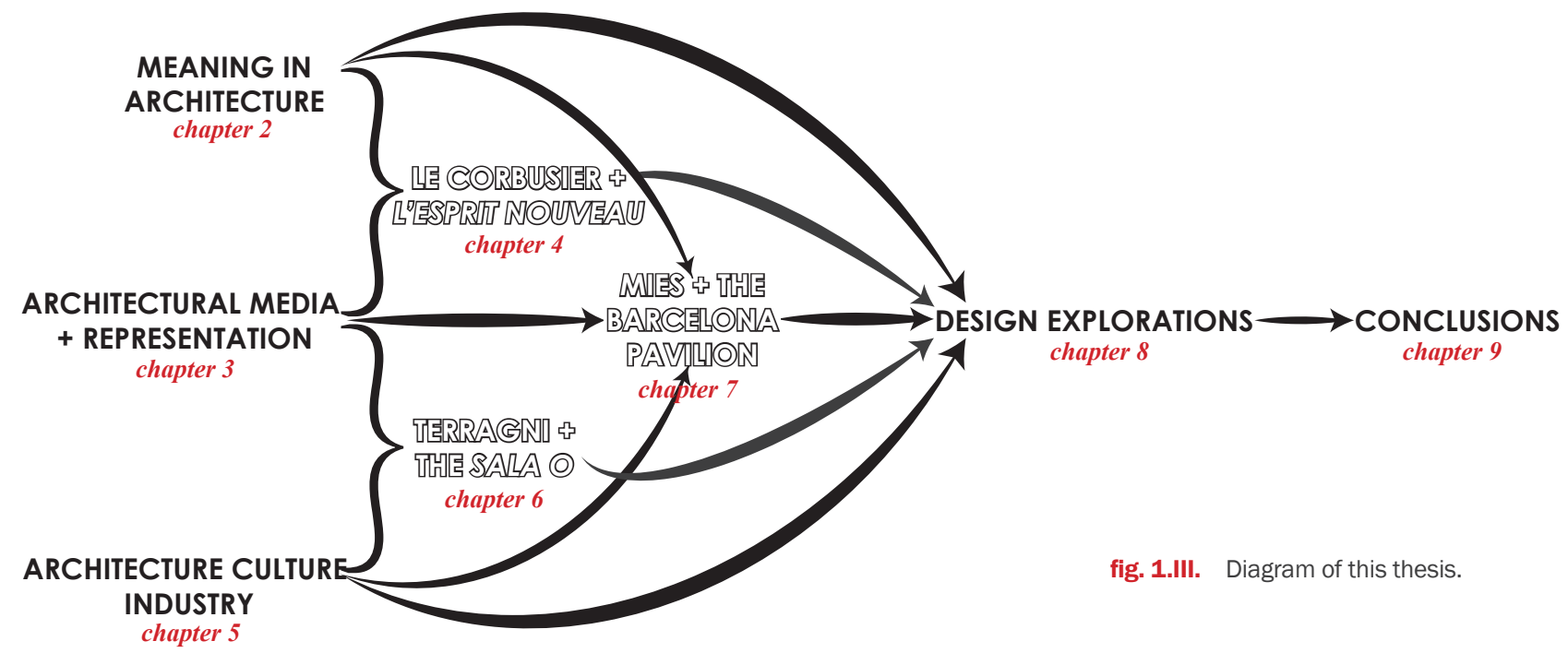

\section{...an arrangement for this thesis}

consciously engaged with the media processes of the architecture culture industry to encourage certain interpretations of his work. I argue that the resulting, highly significant (that is, meaningful) architecture operates almost exclusively in the media space of architecture, distant from its physical built form.

Having established theoretical positions on the three themes, further analysed and developed through the three case studies, in Chapter $8 \mathrm{I}$ focus on the exploration and extension of these ideas via my own project of architectural design: the reconstruction, within the 'media space' of architecture, of the Barcelona Pavilion. A series of design discussions critically interpret my three architectural design explorations (two architectural installations and the proposed design of a third), questioning conventional understandings of the pavilion, and challenging the hegemony of the built form as the site of architectural meaning.

The final chapter (Chapter 9) provides a discussion of the developing conclusions I have been able to make towards a philosophy of meaning in architecture, including indications of new potential for the role of architect this understanding offers. I find meaning to reside in people's heads, not in built forms, and the reification of objects to be, like the idea of 'true' meaning, to be a myth perpetuated by mainstream architecture culture for reasons of social power. Architectural representations are found to be not 'neutral depictions of reality', but ideologically-charged interpretations useful in developing aesthetic meaning as people interpret them.

In engaging with processes of mass media and representation, I argue architects have the opportunity to negotiate a conceptual space in which they can explore questions of architectural meaning for themselves and others. 


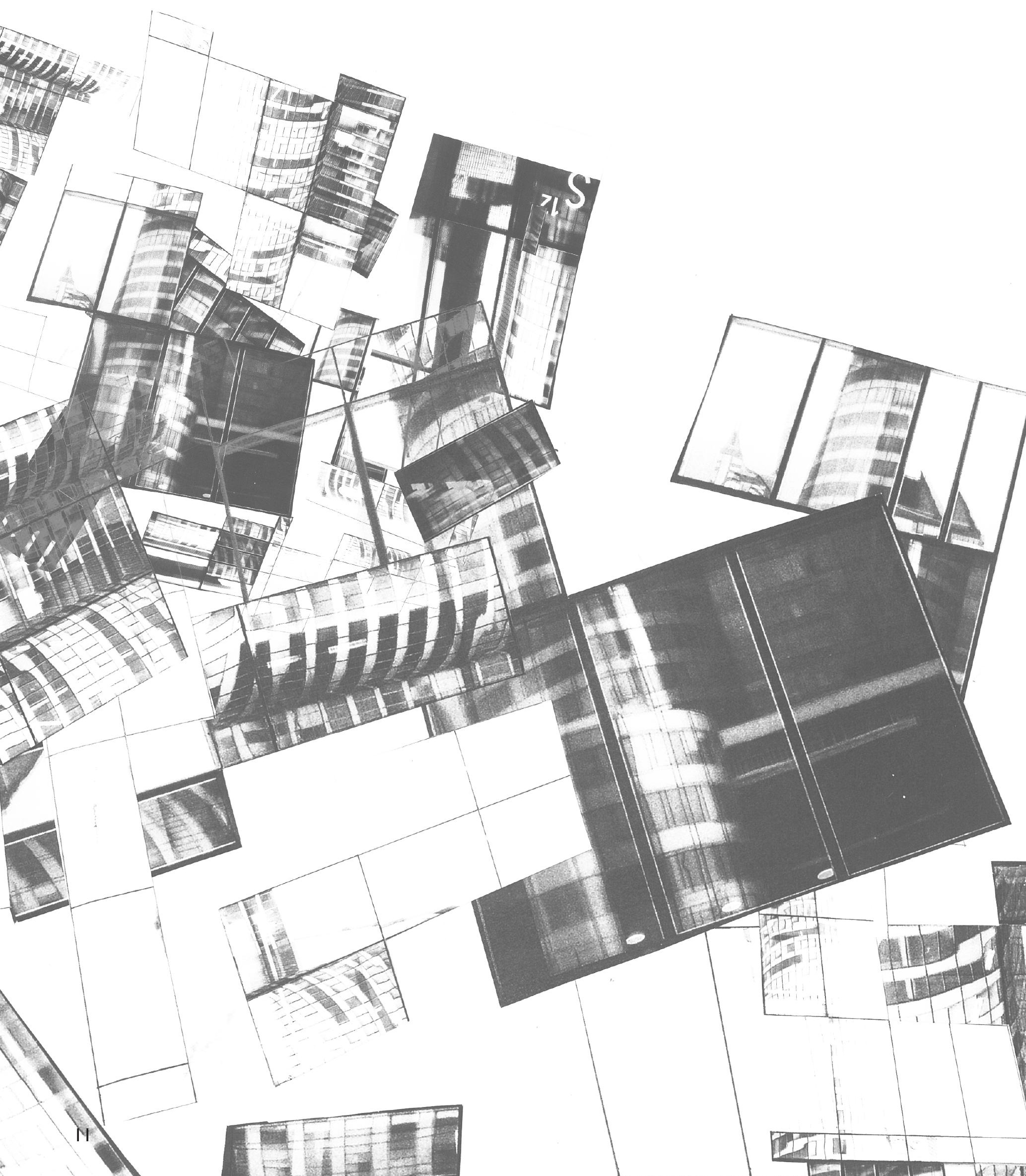




\section{2}

CHAPTER
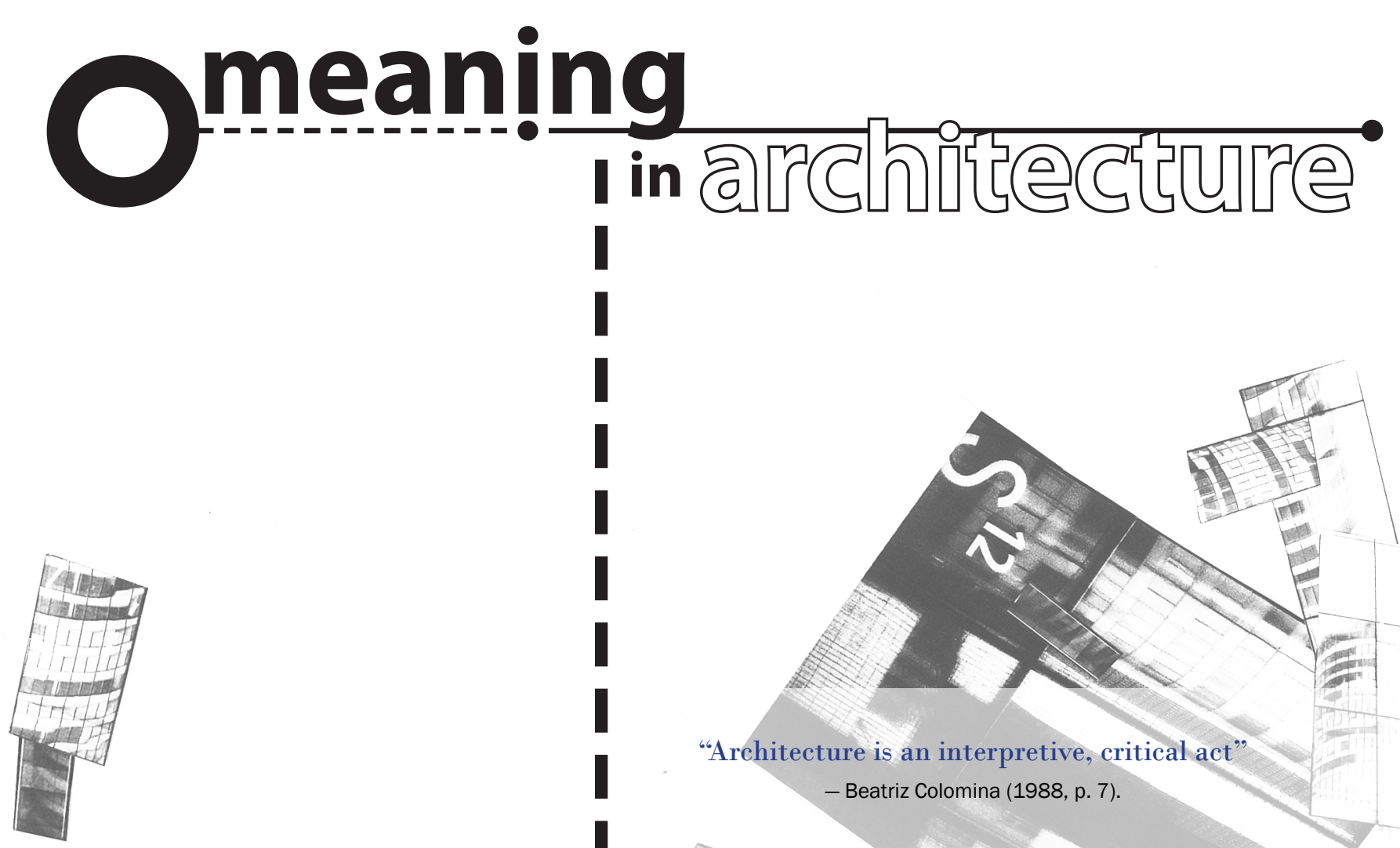

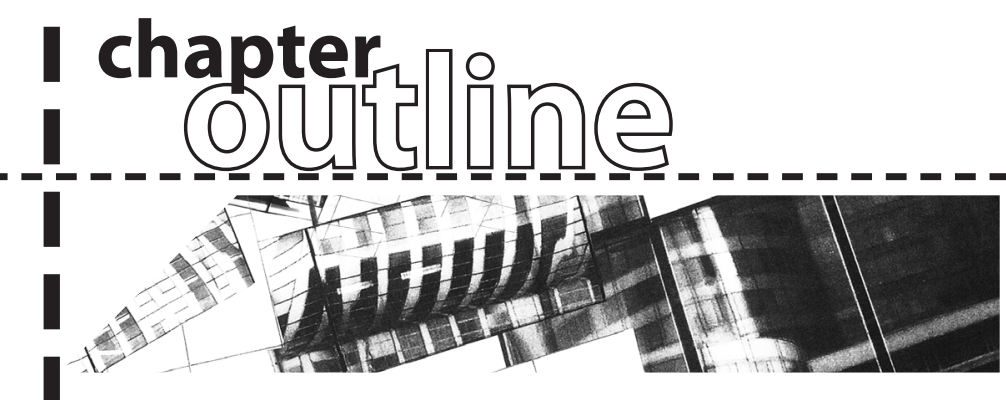

I

$\longrightarrow$ Introduction

- A dominant model of meaning in architecture:

'romantic hermeneutics'

Meaning as truth

- Meaning as the genius of the artist

- Meaning as recreating the mindset of the author

- An oppositional model of meaning in architecture: 'post-structuralism'

- Meaning and the object: a critique of the reification of physical objects

1--.- Meaning and possibility: Barthes' “Third Meaning”

- Meaning and context: girders from New York

Meaning and the audience: Bourriaud's "Relational

Aesthetics"

Meaning and visual culture: aesthetic meaning

- The place of the post-structuralist architect

- Conclusion and a definition of meaning 


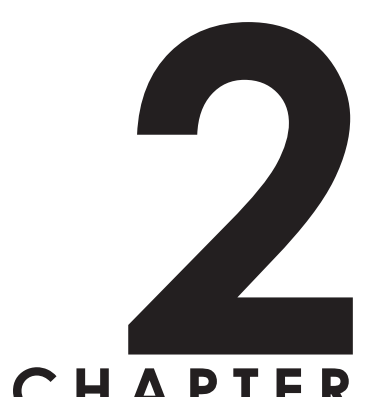

Omeaning

\section{Introduction}

People have tried to conceptualise the production of meaning in culture in various ways. In working towards a philosophy of meaning in architecture, I argue that mainstream architecture culture can be seen to reproduce a deterministic attitude to architectural meaning: mainstream architecture culture treats meaning as being able to be 'retrieved' from works of architecture, the built form acting as a vessel for the communication of the architect's creative intent. Identifying this attitude as romantic hermeneutics, in this chapter I explain and critique this model of understanding meaning, and how it may be seen to underlie many unquestioned practices in architecture culture. Finding it to be problematic on several accounts, I challenge its dominance in architecture culture, instead proposing poststructuralism as a model which is more able to accommodate the way aspects such as context, culture, ideologies, and personal frames of reference influence people's interpretations. I use the freer, more open attitude of post-structuralism to address the shortcomings of romantic hermeneutics, and develop a working definition of meaning for this study. 


\section{A dominant model of meaning in architecture:'romantic herme- neutics'}

The term "hermeneutics" refers to the philosophical study of meaning, that is, the art or technique of understanding and interpretation. Modern hermeneutics has been built on the writings of Friedrich Schleiermacher (1768 -1834), a German theologian and philosopher who moved beyond the traditional task of hermeneutics (the deciphering of sacred texts), to explore the nature of understanding in relation to all human texts and modes of communication. In a seminal book for contemporary hermeneutics, Truth and Method (1975), Schleiermacher's ideas are discussed alongside those of Immanuel Kant by the author, Hans-Georg Gadamer, in his attempt to uncover the nature of human understanding. However, what emerges at the intersection of the ideas of these three German philosophers is an attitude to meaning which may be termed "romantic hermeneutics". Romantic hermeneutics is a model of understanding sharing the base concept of romanticism: the recognition that a cultural work is somehow created from an essential "spiritual source", attributing to the artist higher powers of perception that allow them to apprehend a reality deeper than mere appearances. This 'spiritual source' is conceived of as a "truth" by Gadamer, and as the artistic "genius" by Kant, while Schleiermacher's hermeneutic theory focuses on how the interpreter may 'access' this spiritual reality of the artist. In relation to specifically architectural meaning, I argue that the basic concepts of romantic hermeneutics underlie many understandings of meaning in mainstream architecture culture.

2.1. Gadamer is critiquing the French essayist Paul Valéry, but this idea is essentially post-structuralist, and corresponds to Nicholas Bourriaud's idea of 'relational aesthetics' discussed later in this chapter. With this critique, Gadamer is positioned against post-structuralism as an attitude to meaning.

\section{Meaning as truth}

The critical thrust of Gadamer's book is the legitimisation of the 'truth claim' of the artwork, that is, that the meaning of cultural products is an essential 'truth' which is embedded within them, retrievable only through the act of interpretation. Works of art (including architecture) are considered as independent, already-completed objects, able to be 'successfully' understood through 'appropriate' methods of interpretation. This position is made clear through Gadamer's vehement criticism of the idea that creative works by themselves might be unfinished 'fragments', requiring the presence of a viewer or reader for them to be completed.'. $\mathrm{He}$ asserts that this idea represents "an untenable hermeneutic nihilism" because "every encounter with the work has the rank and the justification of a new production... There is no criterion of an appropriate reaction" (Gadamer, 1975, p. 85). Meaning for Gadamer, then, is a singular 'truth' accessed through an 'appropriate' interpretation, somehow measured against an established 'standard' of validity.

The idea of "truth" has been hugely influential in Western architectural history, ranging from promotion of the Gothic as the only "true" architectural style for Anglican churches in the mid-nineteenth century, 
the "true and honest" expression of Modernist structure, to questions of "being true to the original" arising from the present-day renovation of historic buildings. Architectural libraries are full of books claiming to offer "new truths" about famous buildings, each claiming to come closer to what the original architect was trying to explore. This obsession with architectural truth is largely driven by the architecture culture industry, which is responsible for much of the establishing and promotion of certain interpretations as being more "true" than others. This phenomenon is discussed in more detail in Chapter 5 but it is sufficient at this point to state that the ideology of architectural 'truth' can be considered as one of the main means institutions of architecture culture use to manufacture, maintain and sustain their social power.

\section{Meaning as the genius of the artist}

Gadamer's hermeneutics builds on the philosophical ideas of Kant, particularly Kant's conception of 'genius'. This is the quasi-mystical power of the artist to create 'original' works, a talent for producing ideas of a quality much higher than a 'non-genius' might. For Kant, the act of interpretation is an attempt to understand the 'genius' of the artist through their work. Meaning is a "determinate unchangeable form" (Gadamer, 1975, p. 52) and its production is considered to be historical, having occurred at the point where the creative genius of the artist became manifest in the work:"Genius in understanding corresponds to genius in creation" (Gadamer, 1975, p. 52). For Kant, genius also differentiates the artist from the craftsman, in that the artistic product is complete in itself, not by reference to a purpose (Boyer, 20I I, p. 95).

The 'genius' of the architect is another well-worn pedal in mainstream conceptions of architectural history. The works of architects deemed significant by mainstream culture are frequently described as "masterpieces" and their creators hailed as creative geniuses. Consider for example, mainstream understandings of the works of Frank Lloyd Wright, Le Corbusier, Mies van der Rohe, or even modern "starchitects" such as Frank Gehry and Zaha Hadid. We are repeatedly told through architecture culture of the genius of these individuals as being able to create 'outstanding' works of architecture, and there are even modernday architectural 'pilgrimages' to visit them, seemingly in an attempt to 'absorb' their genius though the experience of the physical architectural object. Apart from the curious parallels between such activities and pagan rituals of the "genius loci", it must be emphasised again that the status of these works and architects arises primarily through certain influences of the architecture culture industry. The particular cases of architects Le Corbusier and Mies van der Rohe are examined in Chapters 4 and 7 in this respect.

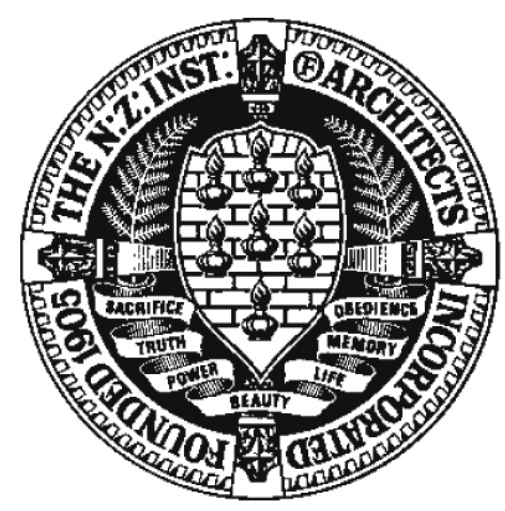

fig. 2.I. Logo of the New Zealand Institute of Architects.

Among the other allegorical "Seven Lamps of Architecture” (Sacrifice, Power, Beauty, Life, Memory, Obedience) featured on the seal is Truth, arguably providing an example of the way mainstream architecutre culture subscribes to the cult of 'true meaning' which is a part of romanitc hermeneutics. 


\section{Meaning as recreating the mindset of the author}

In order to access the meaning (Gadamer's 'truth' and Kant's 'genius') of an object (and it seems to always consider meaning to be embedded in the physical object), romantic hermeneutics recommends certain manners of interpretation. Schleiermacher sees interpretation as being a "divinatory" process of retrieving the "individuality of the speaker, that is, [the mindset of the author" at the point where they produced the work (Gadamer, 1975, p. 164). He argues that by reconstructing the context and reestablishing the mental 'world' the work belongs to, we can recreate the circumstances and processes of its creation, and therefore reach the point required to fully apprehend the 'inner origin' of the artistic work. Meaning can therefore only be produced by the author, within their own particular context, and at the specific moment of creation. For Schleiermacher, interpretation must become a process of re-education in order to access this original 'world' of the author, this being seen in opposition to that of the interpreter. Interpretations deriving from this mindset are seen to be 'correct', whereas others failing or not attempting to understand the position of the author are necessarily flawed and incorrect. This attitude sees authorial meaning as fixed and immutable, inseparable from the conditions of intent embedded within the object, necessitating this oneway 'access' to its contextual 'world' to produce 'valid' interpretations.

In mainstream architecture culture, Schleiermacher's idea of meaning as stemming from the personal 'world' of the architect is reflected to a certain extent in the obsession with the architect's statement. Whether in the form of a written exegesis or the incessant question, "What does your project mean?" mainstream architecture culture often seeks the architect's own interpretations as the 'correct' meaning of their work. The pervasiveness of this way of thinking is suggested even through the way architects are educated. Architecture students are often required to present their interpretation of their work as explanation in the formal event of a design critique. In such a situation, their work is assessed against the student's own interpretation, and how easily their examiners are able to understand their mindset through the design.

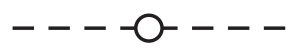

Romantic hermeneutics, then, considers cultural products (such as works of architecture), as imbued with an "original" or "true" meaning, which comes from the creator of the work. Any attempt to interpret works of architecture under romantic hermeneutics is an attempt to bring this hidden truth or message of the architect to light. It privileges the status of the author over the audience, who are treated as passive receivers of meaning following codified rules for its interpretation (prescriptive ways of seeing). 
An oppositional model of meaning in architecture: 'post-structuralism'

There are several issues which arise with romantic hermeneutics as a model for the production of meaning in cultural practice, including architecture. These issues incite a challenging of the reification of objects with meaning, a questioning of the ideology holding the author as the source of meaning, and the disputing of meaning as a fixed, established phenomenon. They also raise discussion on the role of context and the act of interpretation in relation to meaning. Because these issues mostly stem from the way romantic hermeneutics is based on a fixed, immutable and hierarchical relationship structuring the conceptualisation of meaning, it can be called a structuralist approach, which sees the world largely as structural events and overlooking human agency. In challenging romantic hermeneutics, I therefore take a post-structuralist approach to the production of meaning. Post-structuralism is a philosophical understanding opposing structuralist ideas on the relation between meanings as objects, meanings as possibilities, meanings and contexts, meanings and the audience, and the concept of 'aesthetics'. Weaving together ideas from the semiological philosopher Roland Barthes and the art critic Nicolas Bourriaud, the following explanation of post-structuralism works towards understanding the consequently re-defined role of the architect.

\section{Meaning and the object: a critique of the reification of physical objects}

Architectural determinism is a notion which may be seen to characterise much of mainstream architectural theory.2. It is the belief that some sort of an instrumental, determinate and unidirectional relationship exists between a built form and architectural meanings. Buildings are treated as though they actively generate meanings, issuing 'messages' to people. People are treated as passive 'receivers' of such meanings, which are considered to be 'universal' and value-free. Such "deterministic" perspectives on architecture, suggesting that meanings are "delivered" via direct, causal links between object and audience are, in my view, untenable. Contrary to determinism's conception of people as passive receivers of meaning, people do not simply react to their physical environments; they endow them with meaning, they interpret and re-interpret them. Such interpretations are never independent of the social and cultural contexts in which they take place, which form specific frames of reference for the meanings people bring to bear on their worlds. These "frames of meaning", culturally-constituted codes, reside in and arise from the symbolic content that people assign to their social and physical environments over time. Giving rise to people's interpretations of other cultural products, these frames are cultural products in themselves, being definitions of an individual's social and physical circumstances.
2.2. For the following discussion about reification of objects with meaning and architectural determinism, I am indebted to the many conversations I have had with Dr. Peter Parkes, as well as to his Ph.D. (Parkes, 1986) 
2.3. The literary theorist and semiological philosopher Roland Barthes provides an interesting transition between romantic hermeneutics and post-structuralism, eventually offering a flexible understanding of meaning open to different levels of interpretive 'possibility'. Barthes' early works were along the lines of structuralism, including his famous Mythologies (1957), a collection of essays examining the semiology of the process of modern myth creation, and updating the system of sign analysis first developed by the 'founding father' of structuralism, Ferdinand de Saussure (1857-1913). However, his later writings reflect a shift in his thinking, as he started to realise structuralism was limited by Western culture's dependency on beliefs of constancy and ultimate standards. In 1968 he published what is largely considered to be his best-known work, the essay The Death of the Author, which questioned the notion of the author as the source of "ultimate intended meaning', and this has generally been interpreted as a post-structuralist text. $\ulcorner-----\overline{\text { third 'other' meaning }}-\overline{-}$ THE OBTUSE MEANING significance ᄂ - - - - - -

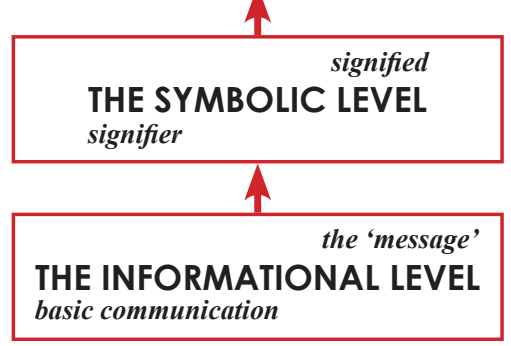

fig. 2.Il. Roland Barthes' three levels of meaning for the interpretation of cultural products (including architecture).
2.4. In his essay Barthes holds the third meaning to exist only in films or other arts which contain images and a narrative. He claims 'simple' photography and figurative painting are unable to assume obtuse meaning due to a perceived lack of 'narrative horizon' or location within a sequence/configuration (Barthes, 1982, p. 331). However, when it comes to architecture or architectural photography, I believe Barthes' contentions may be relaxed: Architecture is about constructed space, and people's inhabitation of it, whether physically and bodily, or visually and conceptually. Even architectural photography is able to be 'inhabited' in this manner, particularly through a series of related views of the same architecture. Any inhabitation of this kind immediately forms part of a mental sequence of spatial use which contributes to the required narrative horizon.

\section{Meaning and possibility: Barthes' "Third Meaning"}

Particularly useful to the discussion of the production of post-structuralist meaning in architecture is an essay by the literary theorist and semiological philosopher Roland Barthes, ${ }^{2.3}$ entitled: The Third Meaning. In it Barthes proposes that our interpretations of cultural products (in his case, photographic stills from an Eisenstein film) have the potential for three different levels of meaning: the informational, the symbolic, and the third, obtuse meaning (Barthes, 1982, Pp. 317-319). For Barthes, the informational meaning is first, being the level of communication or the semiotic 'message' of the image. This is the analogical content of the representation; the scene, object, or landscape which the image 'denotes' for Barthes. The second meaning is symbolic, being at the level of signification. This is the 'obvious' meaning of the image, 'connoted' through different forms of symbolism such as referential symbolism, narrative symbolism, or historical symbolism, which people are able to recognise only via a culturally-shared 'lexicon' of symbols. Barthes' third meaning is much more complex, being at the level of personal significance. This is the emotive evaluation of the image which, for Barthes, escapes description. He can only describe it as obtuse meaning, in that it is "at once persistent and fleeting, smooth and elusive...it provides us with a theory of supplementary meaning..[appearing] to open the field of meaning up totally, that is infinitely" (Barthes, 1982, p. 320).

Barthes' third meaning extends outside the realm of specifiable information, hovering somewhere between the image and its description, between 'definition' and 'approximation'. Necessarily vague, Barthes' idea of the third meaning seems to account for the complex nuances of different people's interpretations of the world around them; different 'possibilities' of meaning. Each one is unique in ultimately indescribable ways, but we can reach a certain level of shared understanding through negotiation of the informational and symbolic levels of meaning. These first and second meanings might be how we communicate ideas in culture, but it is the obtuse meaning which seems to be the way we give these ideas significance.Acting as a sort of catalyst, it can radically shift our original perception of the work, transforming the image or work into a space or field of possibilities and permutations. Specifically for the practice of architecture, I consider it to form part of the subliminal distinction between a building and a work of architecture, a highly personal understanding which may allow us to consider both a rustic wooden shack and a sparkling modern skyscraper (or even merely a representation of either) as offering significance to our culture. ${ }^{2.4}$

\section{Meaning and context: girders from New York}

One of the limitations of romantic hermeneutics is that its proponents treat the context of the work and the context of those interpreting it as fixed. 
Post-structuralism understands context to be a highly changeable factor in the interpretation of cultural products, with people's understandings shifting and altering depending on their contextual 'frames of reference' at any given moment.An example of how the cultural context of objects affects our interpretation might be an experience I had in visiting Christchurch in 2009: walking along the Avon River, I came across an arrangement of twisted metal girders protruding strangely from the riverbank. My initial interpretation of them was (for argument's sake) "free from context", and I found myself arbitrarily focusing on the physical qualities of the girders, noticing that they were rusted and seemed damaged or crushed. It was only later that I discovered that these girders had come from the destroyed World Trade Centre buildings in New York. Having been given this small detail of context in relation to the object, the frame of reference through which I understood these girders shifted dramatically, and I started to make associations between these pieces of metal and the terrorist acts of September $\mathrm{II}^{\text {th }}, 200 \mathrm{I}$ in New York. Although the girders as objects had not changed in the slightest, the sorts of meanings which I started to apply to them were changed by the cultural context I now saw them in. This simplified example of girders from New York indicates how objects, places and times may accrue symbolic meanings though either purposeful or accidental association, becoming "resonant" with meaning and heavy with significance for people as they become embedded in their cultural contexts.

\section{Meaning and the audience: Bourriaud's "Relational Aesthetics"}

The French art critic Nicholas Bourriaud has written several influential texts on post-structural understandings of meaning in art, particularly on the relationship between the artwork and those viewing it. His 1998 book Relational Aesthetics in particular has come to be seen as a defining text for a wide variety of art produced since the early 1990s..5 Given that it is people who make and remake culture in comprehending the world around them, Bourriaud argues that the artwork of particular artists produces open-ended conditions or "relational aesthetics" that invite the viewer to participate in the conceptual construction of the work. In relational art, the work of art operates as a partial object, a 'situation' which can only be activated through the audience's engagement(Bourriaud, 2002, p. 99). This audience is envisaged as a community, the artwork producing intersubjective encounters rather than a 'private' one between viewer and an object. Relational aesthetics therefore understands meaning as elaborated collectively, rather than in the space of individual consumption (Bourriaud, 2002, pp. I5-18).

The concept of relational aesthetics is particularly pertinent to the field of architecture, a highly 'public' art form situated undeniably within a community audience. I contend that as in relational art, the work of

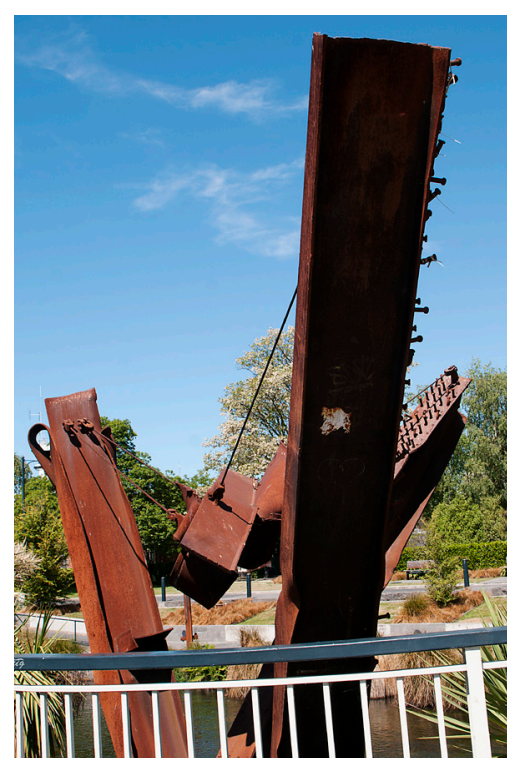

fig. 2.III. Firemen's Memorial, Christchurch, 2009.

The sculpture is constructed of wreckage from the fallen World Trade Centre Twin Towers, New York.

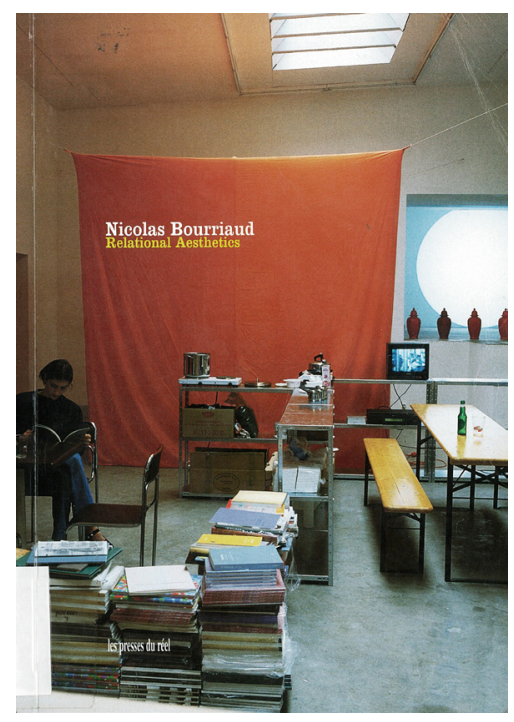

fig. 2.IV. Nicolas Bourriaud, Relational Aesthetics. Cover, Les Presses du réel, 1998.

2.5. See: Bourriaud, N. (2002). Relational Aesthetics (S. Pleasance, F. Woods \& M. Copeland, Trans.). Dijon: Les Presses du réel. (first published in French as Esthétique relationnelle (1998)). 
2.6. This understanding of meaning which I have labelled 'post-structuralism' is also based on Stuart Hall's discussion of meaning, "The Work of Representation", in Representation:cultural representations and signifying practices. (London: Sage, 1997), pp.13-74.

2.7. Perhaps most famously by Juhani Pallasmaa in: The eyes of the skin: architecture and the senses (London: Academy Editions, 1996.) architecture facilitates the production of a social environment in which people come together to participate in shared activity. The experience of architecture may be an emotional, behavioural, or historical response for people, and in taking a position in relation to architecture, people 'complete' the work by taking part in the formulation of its meaning. The notion of relational aesthetics takes this understanding as its foundation, and the power of relational art (and architecture) is in facilitating these processes to occur.

Post-structuralist understandings ${ }^{2.6}$ of the relationships between author/artist and viewer/audience form a striking contrast to romantic hermeneutics. Instead of limiting the production of meaning by considering it solely within the domain of the architect, post-structuralism seeks multiple, wide-ranging interpretations, seeing the strength of a work in the way it is able to cope with layers of accumulated meanings. Where romantic hermeneutical understandings see only a singular, 'essential truth' as the 'innate' meaning of cultural products, post-structuralism acknowledges diverse meanings, some holding more weight in the social contexts of unequal power (which romantic hermeneutics seems to try to pretend do not exist). The dominating and fundamental position of the creator of the work privileged under romantic hermeneutics is challenged and subverted under post-structuralism, leaving room for audiences to develop individual understandings based on the influences shaping their own particular world views.

\section{Meaning and visual culture: aesthetic meaning}

Arguably, since the late eighteenth century, architecture has been predominantly taught, theorised, practiced and critiqued as an art form with a significantly visual focus. Despite this 'hegemony of the eye' being raised and questioned as a critical issue by some scholars of architecture ${ }^{2.7}$, the increasingly visually-oriented development of contemporary culture seems to have further entrenched this emphasis. My study treats this as an inherent condition of architecture, necessitating some discussion of 'aesthetics'. The history of the term 'aesthetics' has layered it with different meanings. Raymond Williams, in his dictionary of cultural terms Keywords (1976), describes how in its English development, the term is strongly linked to developments in thinking about art, being used to refer to questions of visual appearance and effect (Williams, 198I, p. 28). This use represents the separation and distinction under romantic hermeneutics of 'artistic' activity, requiring its own kinds of attention and responses, from other areas of social life. As Williams explains in a later text, "From [its early use as a] description of a theory of perception aesthetics became, in the eighteenth and especially the nineteenth century, a new specialising form of description of the response to 'art' ... [Art] was to be defined by its capacity to evoke this special ['aesthetic'] response... The specializing concept of ['art'] ...in its modern forms, is thus a central example of the 
controlling and categorizing specialization of "the aesthetic"' (Williams, 1977, pp. |49- I50). ${ }^{2.8}$

This particular understanding of aesthetics reveals how it is used under romantic hermeneutics as a conceptual means of securing the hierarchical relationship of artist-genius to passive-receiving audience it relies on for the validity and authority of its meaning processes. The separation of art, architecture and other creative practices from other forms of cultural production (science, language, social formations, politics, etc.) serves as an ideological tool of institutions of mainstream culture, in their attempt to control and limit interpretations of meaning in visual culture. Nevertheless, in critiquing romantic hermeneutics through post-structuralism, I find aesthetics to remain a useful term, albeit given a new definition and understanding. Stemming from the (narrow and limiting) view whereby aesthetics denotes value-specific meanings such as 'beauty', 'style', 'pleasure', and 'taste', aesthetics may be defined as value-laden meanings. As all meanings are value-laden to a certain extent, (there being arguably no such thing as “objective meaning”), aesthetics may therefore be extended to refer to any meaning associated with visual culture. This understanding of aesthetic also has the potential to move beyond mere form (physical objects) to include print media material, and other things which people 'consume' with their eyes: photographs, images, and text. As discussed, the way we place meaning on objects of visual culture is influenced by the particular cultural context and individual factors of perception people have, and cannot be reduced to diametric oppositions of 'beauty' or 'ugliness', 'tastefulness' or 'kitsch'. Attempts to impose external hierarchies of value on the interpretations people make of objects must be seen as political acts of cultural manipulation, a theme informing the argument of Chapter 5.

As the rest of my study will explore, the interaction of visual culture and architecture is crucially important, and particularly in the case of print media, offers possibilities for meaning which are nonexistent or limited in physical objects and built forms (buildings). In short, architectural meaning is a form of aesthetic meaning.
2.8 .

In keeping with the thread of romantic hermeneutical understandings of the separate and distinct role of the artist, 'aesthetic responses' are seen as deriving directly from the 'art-object' itself. Cultural products, such as works of architecture, are viewed predominantly in isolation from their social, historical and political contexts, their intrinsic 'aesthetic properties' - rendering the objects 'beautiful', 'desirable', etc. - being assumed to reside in the properties of the physical object. In this sense, the 'aesthetics' of romantic hermeneutics becomes a branch of 'instrumental knowledge', a means by which culturally-defined 'experts' (for example, artists, architects, and institutional critics) can manipulate values people place on creative works, seeking to control their interpretations and prescribe qualities for their appreciation. Here too, "aesthetics takes on a central role in commodity production, in the manufacture, marketing and consumption of 'art' works as commodities, as objects of exchange value" (Parkes, 1986, pp. 86-87). 
With the challenging of romantic hermeneutics as an appropriate model to understand meaning in the production of architecture comes a change in the status and role of the architect. Where once the architect was considered to be the source of artistic meaning, and able to impart this meaning into the physical works they created, now such clear boundaries and power structures are discarded. Under post-structuralism, the architect is now only one of many factors influencing the creation of cultural products, and the way these products are introduced to and situated within architectural culture. The role of the architect within processes of the architecture culture industry is an ongoing topic of exploration throughout this research, but some initial points can be made to start:

People encounter buildings every day, and even without the benefit of an architectural education, form interpretations of their meaning (consciously or subconsciously). This is clear in people's ability to put built architecture to whatever use is necessary: they do not need the architect to tell them how to use certain spaces (Goldberger, 2009, p. 172). In some cases, 'popular' interpretations of architecture can come to dominate the cultural conception of certain works (Krier, 2009, p. 3I). For example, large buildings often attract imaginative nicknames like Wellington's "Beehive" (government building) and "Cake Tin" (sports stadium), Norman Foster's "Gherkin" (office tower) in London and the Beijing "Bird's Nest" (Olympic stadium). Appropriative interpretations (such as nicknames) indicate how architects cannot control the meanings which people attribute to architecture, but also bring architecture into the realm of general acceptance.The attribution of meaning to things is how people make sense of the world around them, and they can do so continually and naturally, without need for any external agents or aids in cultural interpretation.

The meanings of architecture are also never fixed or static. Changes in architectural meaning are illustrated most clearly in cases where an architecture's original purpose is overhauled completely, layering a new 'story' of the building over the old, for example the conversion of an old church to a set of apartments. Traces of earlier meaning may survive through shared stories of architectural history, just as new ones accumulate in their original place. Older meanings are not more significant than newer ones, each set of interpretations relating to the particular cultural context which influenced it. Therefore, the 'original' meanings of the architect in the creation of the work do not hold greater significance in themselves for others' interpretations of the work. 


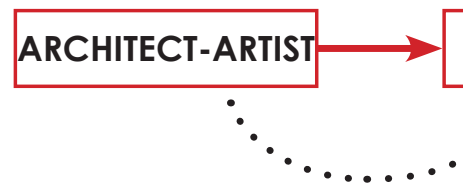

infuses meaning into

\section{WORK OF
ARCHITECTURE}

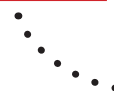

imparts the architect's meaning to

produces

is interpreted by

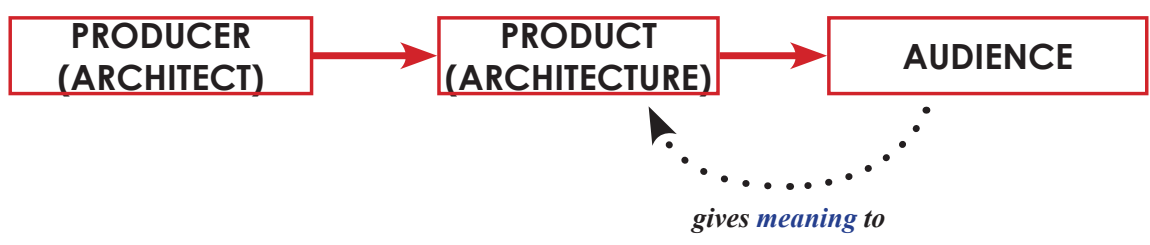

While these points appear to emasculate their traditional role, the poststructural architect may still produce and create exactly the same sort of designs for built forms as always. Post-structuralism is a way of thinking about meaning, not a prescriptive design 'style'. The differences that poststructuralism brings for the architect lie in the conceptual understanding of how their work will be interpreted, and where the boundaries lie between their ideas and those of others. The work remains the means by which the architect can explore their own ideas; they must simply shift their thinking away from the problematic conception of being able to control the way others attribute meaning to the work. Crucially, the architect is also recognised as an interpreter of their own work: in practicing architecture, they may engage with their work as any other person might, applying meanings based on their particular cultural frames of reference and context. In effect, they can 'stand on both sides of the wall': they can create, and they can interpret their creation. Instead of treating them as rarefied individuals mystically infused with creative 'genius', an ideological attitude inherently focussed on preserving social hierarchy and cultural power, a post-structural attitude recognises architects as active human agents, making personal interpretations of the world around them via the activity of their cultural production. fig. 2.V. A romantic hermeneutical understanding of meaning-production in architecture.

fig. 2.VI. A post-structuralist understanding of meaning-production in architecture. 


\section{Conclusion and a definition of meaning}

While this discussion of architectural meaning (for reasons of expediency) has treated the production of meaning as an abstract process, able to be analysed in a detached manner divulged from its content, ultimately I consider meaning to emerge in an intuitive manner from a series of practices embedded in the ways of life we pursue. As such, meaning becomes an extension of ourselves in much the same way that we think of tools as being adapted to suit our specific purposes.

The 'tool' of romantic hermeneutics currently used by mainstream architecture culture in many practices seems fundamentally ill-equipped to deal with modern-day divergences and contradictions of meaning and the recognised complexities of interpretive processes. Using a different conceptual 'tool', that of post-structuralism, the controlled, fixed binary oppositions of structuralism and the validity of authorial pre-eminence are questioned. My understanding of post-structuralism holds that meaning arises from "discourse" or negotiation rather than the substance or content of individual objects. It rejects the idea of a work having a single purpose, a single meaning, or one singular existence. Instead, every reader tends to create a new and individual purpose, meaning, and existence for a given work. Meaning is not considered "true" or "false" but as relevant to each individual according to their own frames of reference.

This freer, more open attitude of post-structuralism seems to address the shortcomings of romantic hermeneutics, and has influenced my own definition of meaning, which I will be using throughout this research. I hold that meanings in architecture are social products, interpretations of culturally-produced environments, and are made by active human agents, in specific cultural contexts. They are personal interpretations which people attribute or place on objects separately according to their own cultural frames of reference. 


\section{conclusion summary}

- Romantic hermeneutics is the model of meaning production which mainstream architecture culture tends to follow. The understanding of meaning it provides is problematic, particularly in regard to its conception of meaning as being fixed and embedded within physical objects.

- I challenge this mainstream conception with the oppositional approach of post-structuralism, which takes into consideration the way context, culture, ideologies, and personal frames of reference influence people's interpretations.

- Post-structuralist thinking informs my working definition of meaning in architecture: Architectural meanings are social products made by humans as active agents interpreting cultural objects in specific contexts. They are personal interpretations which people place on objects according to their own cultural frames of reference. 


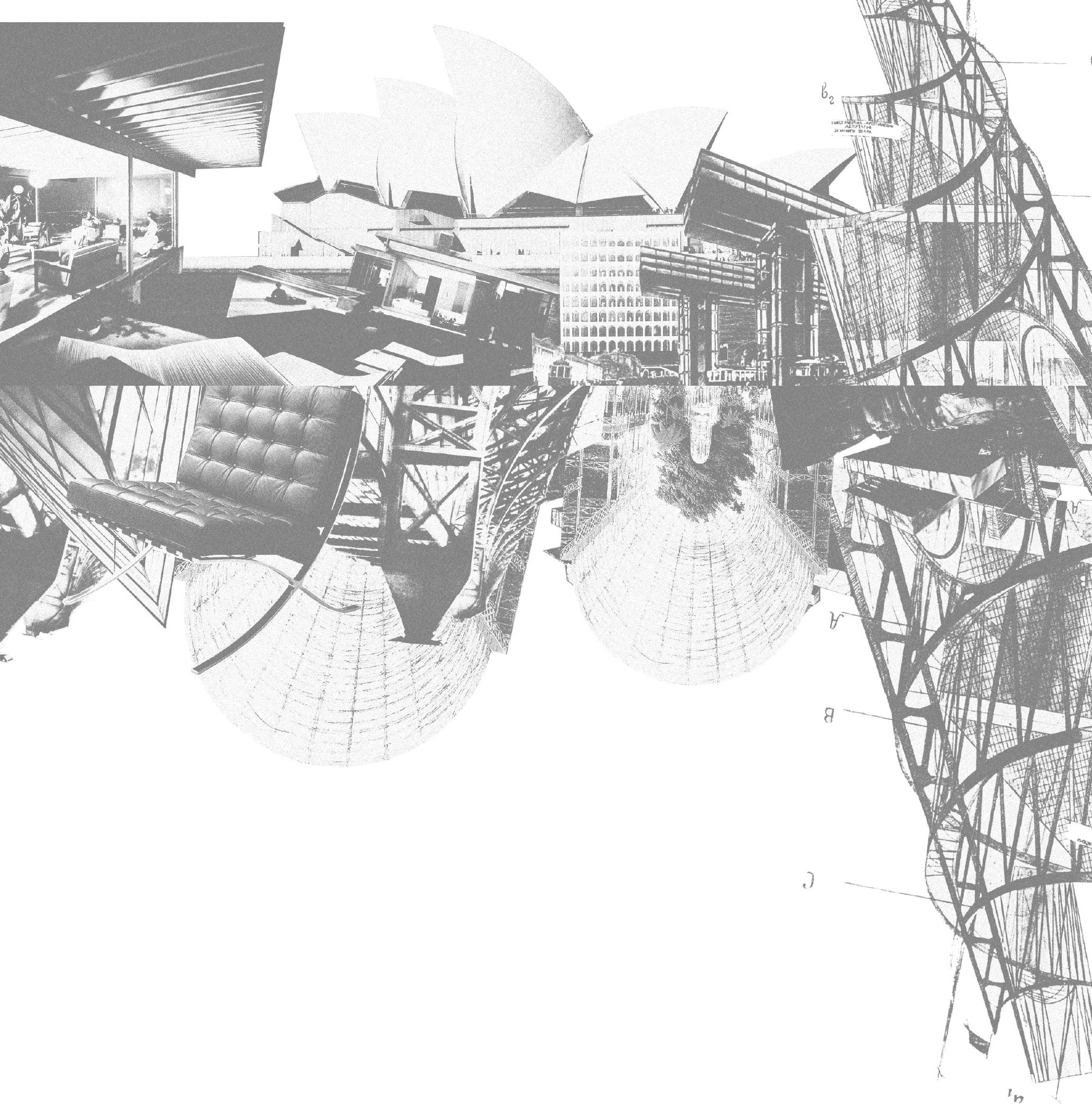




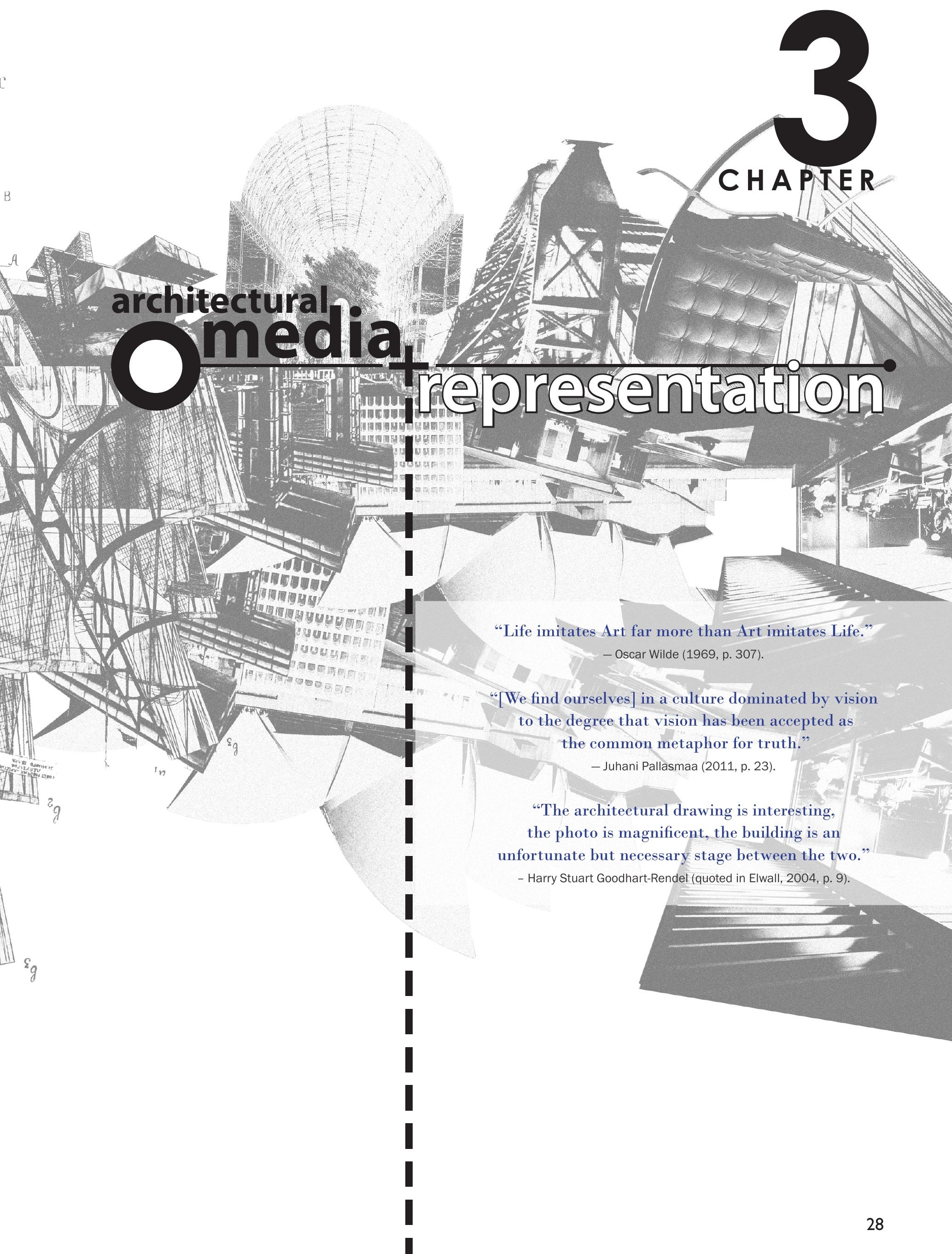



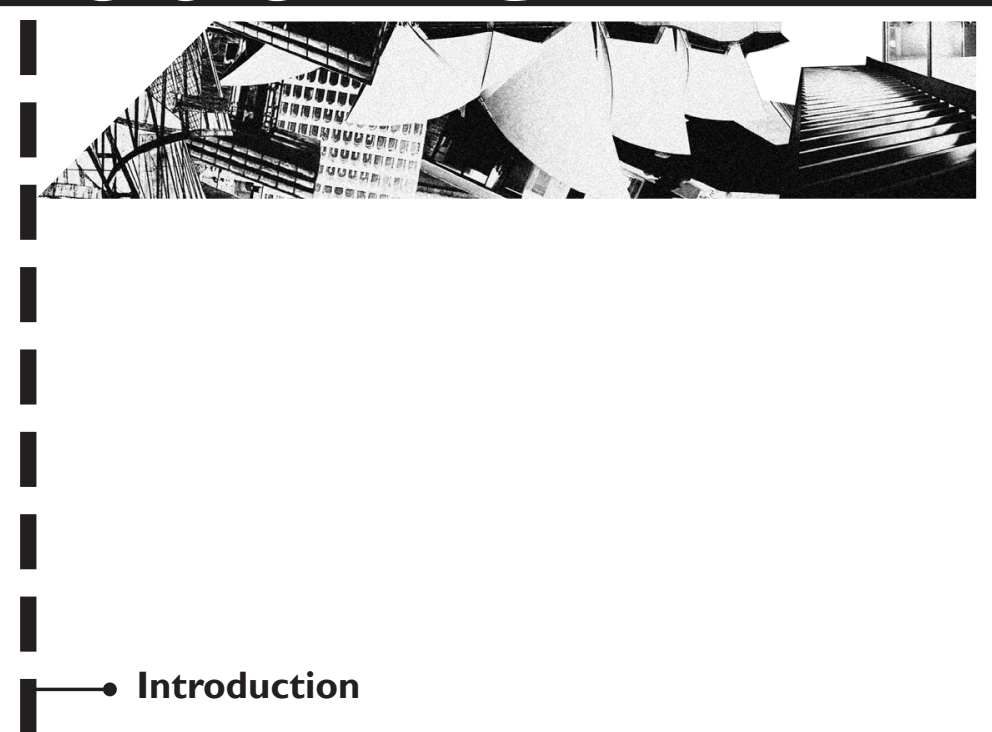

Representation

The nature of images in architectural media

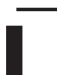

Photographic images

- Media influence on architecture

$\longrightarrow$ Ways of seeing

-.-.. The 'scanned' image: Ivan Illich

[--.-. The 'technological' image (of multiple fragments): Walter Benjamin

- The 'politicised' image: Juhani Pallasmaa, Serge Daney, and Nicolas Bourriaud

$\longrightarrow$ The 'mediatised' role of the architect

$\longrightarrow$ Manipulation of images: fabricated realities

$\longrightarrow$ Conclusion 


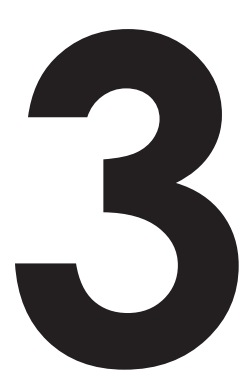

CHAPTER

\section{architectural

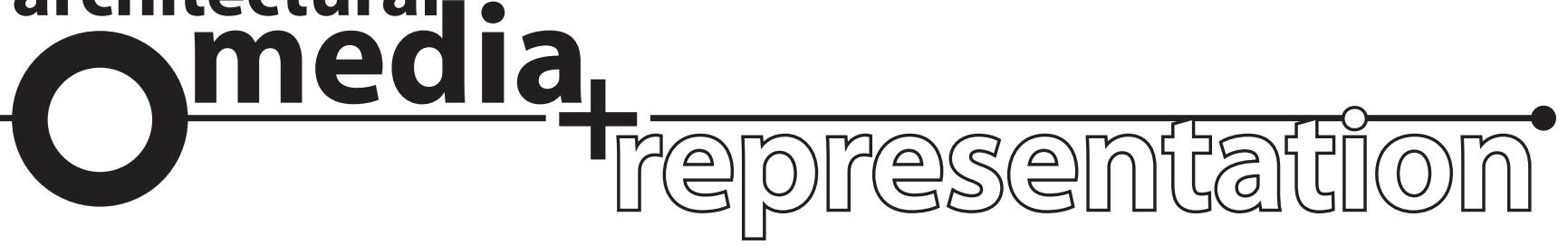

\section{Introduction}

The concept of representation, one of the central practices which produces culture, occupies an important place in what has been called the "circuit of culture" (Du Gay, 1997). It has been described as the production of meaning through a signifying practice, "the link between concepts and language which enables us to refer to either the 'real' world of objects, people or events, or indeed to imaginary worlds of fictional objects, people and events" (Hall, 1997, pp. 5, 17). This chapter considers the contribution media and representation make to architecture culture. Architectural media and representation are significant cultural practices through which people communicate, helping them share thoughts and ideas. In relation to the media influence on architecture, I first discuss the nature of images in architectural media, then focus in particular on photographic images. Mechanically reproduced images have given rise to different attitudes to 'seeing' among visual theorists and cultural philosophers, and this chapter interprets some of these as the 'scanned' image, the 'technological' image, and the 'politicised' image. The spread and influence of media has arguably changed the role of architects, arguably shifting their traditional domain of influence into a 'mediatised' space of fabricated realities, made possible through the suggestive power of manipulated media images.

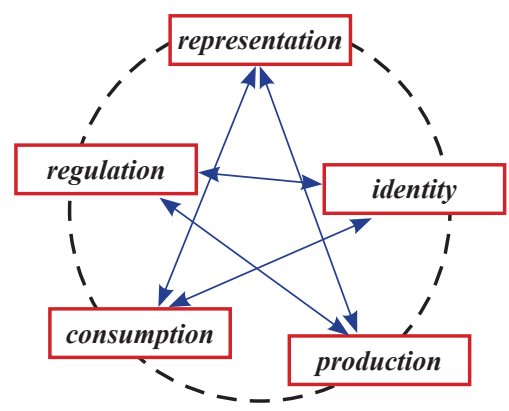

fig. 3.I. The circuit of culture. Diagram based on that in Hall, 1997, p. 1. 


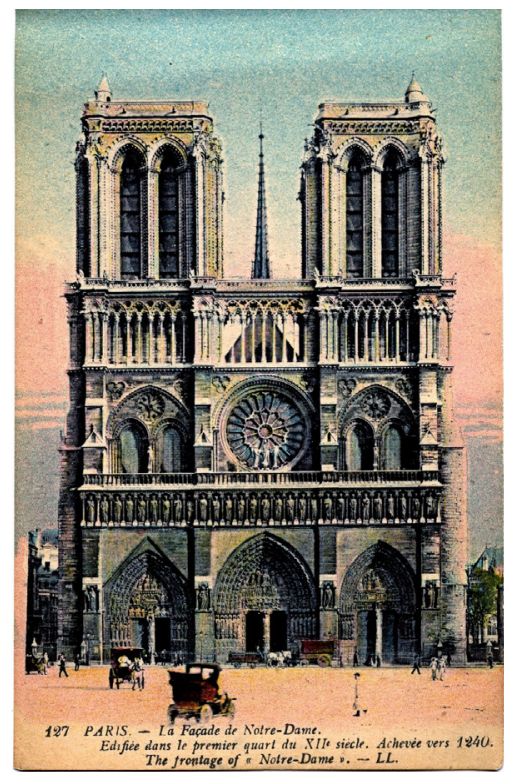

fig. 3.Il. Early twentieth century picturepostcard featuring Notre Dame de Paris.

Victor Hugo's much quoted paragraph entitled "ceci tuera cela" ("this will kill that") in his novel, Notre-Dame de Paris (1831), prophesised the death of architecture as it was replaced by the new medium of mass communication, the printed page. Hugo lamented the end of architecture as "the book of stone, so solid and durable," was made to "give way to the book of paper, which was more solid and durable still" (Hugo, 1978, p. 189). However, I would argue that the new media have not displaced architecture because of their great strength and durability, as Hugo predicted, but for exactly the opposite reasons: because they are fast, fleeting and easily dispensable.

Picture postcards like the oneabove provide a particularly apt example: Hugo's 'stone book' (the cathedral of Notre Dame) is reproduced in a fast, fleeting and dispensible media format, yet one which has the potential (in being sent to an unsuspecting audience all around the world) to have a much wider and far-reaching influence than the actual stones themselves.

\section{Representation}

The discussion in Chapter 2 critiqued the mainstream understanding of meaning in architecture culture, identifying it as romantic hermeneutics. Mainstream understandings of the processes of representation and reproduction may also be aligned with romantic hermeneutical thinking: if the material or 'natural' characteristics (their physical 'reality') is what constitutes objects, then their meanings seemingly arise from the innate 'essence' within them. Representation considered through romantic hermeneutics is therefore a passive process of communicating this 'pre-determined' meaning to a receptive audience. However, Chapter 2 explained the untenability of romantic hermeneutics for this research, replacing it with a post-structuralist understanding whereby meaning is viewed as being produced and constructed through people's acts of interpretation. The oppositional view employed in this thesis understands representation as a primary, constitutive process, not merely a reflection of the world after the depicted event occurred.

\section{The nature of images in architectural media}

Due to the seemingly limitless production and commodification of images, the term 'image' is often taken merely as a shallow and fashionable surface of visual communication and artistic representation. Given an instantaneous and fleeting character, this disparaging attitude is particularly strong in mainstream architecture culture, where an 'architecture of the image' commonly refers to creating a seductive and memorable configuration with a visual bias.

The constantly developing technologies of representation open up new means of monitoring, recording, analysing and depicting countless aspects of reality. The industrial production of images has made them present almost anywhere and available to nearly anyone.

Images are produced and used constantly for purposes of information, education and entertainment, as well as for commercial, ideological and political manipulation, and artistic expression. Our physical world, cityscapes and natural settings, as well as our inner mental landscapes are, in effect 'colonised' by the image industry.Arguably, instead of being neutral depictions of reality, architectural images suggest new realities that are often more 'real than the existing physical and human worlds. As Richard Kearney suggests, "now the image precedes the reality it is supposed to represent...reality has become a pale reflection of the image" (Kearney, 1994, p. 2). 'Reality' itself is philosophically a highly disputable notion, but considering the 'virtual' realities evoked through the 'constructed' imagery pervading contemporary life, it has arguably never been as ambiguous and groundless as today. 
It is interesting to consider how new modes of architectural experience reframe architecture within today's predominantly visual culture. ${ }^{3.1}$ With the world presented to them by the media, people experience architecture within a technologically expanded visual field, not just as objects in continuous space but also as fragmented assemblies in intermittent space. For example, photographs in architectural journals show sequences of highly composed views of buildings, requiring readers to mentally edit these images together into an abstract collective whole in the space between the pages.

\section{Photographic images}

Although photographs freeze buildings and cities into still images, photographs themselves are mobile, portable images that can be transported anywhere."Reproduced images [seem to] have unpredictable lives of their own" (Schwarzer, 2004, p. 24). They are able to be transported outside the established contexts and practices which the objects they depict are tied to. Media reproductions of architecture enable an "aesthetic replay", an optical inhabitation of built settings unaffected by the passage of time or boundaries of space (Schwarzer, 2004, p. 24). The impact of photographic representations of architectural space has been so transformative that even when in the presence of an actual building, people often seem to perceive it through the lens of the images they already know, trying to match it to the representations they have in their heads..$^{3.2}$

Mitchell Schwarzer's book Zoomscape: architecture on motion and media (2004), reflects on moving or imagistic transformations of architecture, as seen from different modes of transport but also through cameras. He sees architecture considered through such a 'zoomscape' to have the potential "not only to concentrate space but also to disperse and rearrange it within time, not only to fix place but also to relocate and redefine it" (Schwarzer, 2004). This idea emphasises the catalytic nature of representation, being able to provide completely new ways of perceiving and understanding previously familiar things. More than presenting, it re-presents, re-producing parallel architectures in people's minds.

Despite technological processes facilitating the production of images, including the ability to make hundreds of copies from a single film negative or digital image file, reproductions are still connected to some sense of their original subjects. Photography in particular, uses traces of the real to fabricate new realities. It appropriates the light reflected off physical objects, capturing it on light-sensitive paper and then uses it for distinctly non-physical, abstract means. Although one might not be able to take a photograph of an idea, a photograph may be able to suggest it.
3.1.

A note on visual culture: Representation is a conceptually dense cultural practice. As the art historian W. J. T. Mitchell writes, it is "a complex interplay between visuality, apparatus, institutions, bodies and figurality" (Mitchell, 1994, p. 16). Indicating the factors underlying visual culture and making possible the capacity of representation to stimulate meaning, each of these concepts requires its own explanation: 'Visuality' refers to the visual register in which the image and visual meaning operate. 'Apparatus' refers to the technological means by which images are produced and circulated by mass-media, which are increasingly sophisticated and complex in our world of digital printing and electronic reproduction. 'Institutions' refer to the organised social relations of image-making and circulation, which today are often large scaleand corporate instructure, global their scale of operations. 'Bodies' reminds us of the presence of the viewer, spectator, observer, as the necessary 'other' in the circuits of visual meaning, which make meaning possible. Finally, 'figurality' reminds us of the image's privileged position in relation to representing or 'figuring' the world to us in pictorial form. Because of the strongly visual aspect of its perception, architecture culture is implicated in the processes and developments of visual culture.

3.2. For example, visiting several famous buildings in Europe, 2010, I was bemused by crowds of tourists clamouring to take snapshots from certain vantage points, until I realised these were locations which approximated the 'canonical' views of the buildings reproduced again and again in books, postcards and touristic guides. 
Photography has become one of the main means of communication in architecture culture. Today, in architecture schools, students are largely exposed to architecture through lecture slides and illustrated printed texts. In architectural practice, photography contributes to the working process through site photos, promotional imagery, product catalogues, and style magazines. Photographs are the primary means of introducing architecture to the general public and of stimulating interest and desire for architecture. Tourist guides, large-format books, housing and travel magazines all transform architecture into consumer objects for a mass audience.

The German philosopher Walter Benjamin discussed the encounter of viewers and photographs. He considered photography as harbouring 'image-worlds': geyser-like eruptions of images triggered by the act of viewing, produced in part in the audience's unconscious (Benjamin, 2008a, p. 272). Through its hidden capacity of association he saw photography as providing a reforming of perception. Agreeing with Benjamin's sentiment, Juhani Pallasmaa contends that the quality and richness of an architectural image arises more from the wealth of associative images and meanings that it evokes than from the details of the architectural form it may depict (Pallasmaa, 20I I, p. 75).

\section{Media influence on architecture}

One question which arises from the current discussion is to what extent media shapes architecture, or architecture shapes media? The boundary between the media as a 'reflective' medium versus 'manipulative' medium is decidedly blurred.

A common theory in the history of architecture links each 'great' period in building history to a specific construction technique. For example, ancient Greek architecture with trabeation, Roman with the arch, through to modernism with reinforced concrete. However, with the invention of mechanical printing processes in the fifteenth century, print media also started to influence developments in architecture (Carpo, 200I). Until the Renaissance, the only way to see a building was to visit it in person. Buildings could not travel, so people had to. But with the invention of the printed image in the early sixteenth century, the architectural historian Mario Carpo argues this new media provided a growing library of architectural treatises to help architects in exploring the possibilities of their design processes (Carpo, 200I, pp. 6-7). Explaining how this new technology affected architecture culture, Carpo gives the example of the Renaissance theory of the five architectural orders (Tuscan, Doric, lonic, Corinthian, Composite), promoted in particular by Sebastiano Serlio in the fourth part (I537) of his treatise, The Seven Books of Architecture. Carpo considers this architectural design theory to be a media-savvy response consciously 
developed in response to the new means of communication, the printed illustration (Carpo, 200 I, p. 6). Forming a standardised catalogue of graphic components that were interchangeable with each other and repeatable - what Benjamin would have called "designed for reproducibility"- the system of the five Renaissance orders was not so much about the massreproduction of the same physical architectural components, as it was about the mass-reproduction and spread of a set of related architectural ideas. This use of print media to promote architectural ideas rather than architectural techniques is a subtle distinction helping to guide the focus of my research, which remains concerned with processes of architectural meaning over architectural matter and material substance.

Photography as a medium can also be seen as an influence on architectural 'style'. Photography reduces architecture down to plays of shadows and light. Modernist architecture replaced surfaces decorated using historicist ornament with surfaces articulated by the play of shadow and light. Architectural photography of early modernist buildings highlighted these aspects of the designs, encouraging the modernist aesthetic of expansive glazing and flat, white walls which photographic representation was able to 'showcase'. Arguably 'conditioning' both architects (in their designs inspired by modernist architectural photography) and the viewing public (through the idealisation of these aspects of modernist architecture), this use of photography is a clear example of the power architectural media has to influence architecture culture through different representation techniques, ${ }^{3.3}$ arguably becoming one of the specific 'construction' techniques available to the contemporary architect.

The art historian Lynda Nead suggests that creative practices (art, architecture, etc.) can be understood as a discourse, ${ }^{3.4}$ a specialised form of cultural knowledge consisting of "the concatenation of visual images, the language and structures of criticism, cultural institutions, publics for art and the values and knowledge made possible within and through high culture" (Nead, 1988, p. 4). With this understanding, creative practices become not just certain kinds of visual products but the knowledge, institutions, subjects and other cultural practices which work to define certain cultural products as important and others as less so.The vehicles for collecting and sharing discourse among different people are media products, and printed representations comprise a significant part of the media's communicative role. The importance of cultural discourse becomes the importance of ideas spread via the media. In focussing on cultural production as ideas, I am considering architectural media and representation not in terms of the buildings they refer to, or even in terms the particular visual properties of certain images, but as the meanings we place on either as interpretations of cultural production. On the cover of her collection of essays, This is not architecture (2002), Kester Rattenbury illustrates her title with a photograph of the Barcelona Pavilion, one of the most famous examples
3.3. An example could be the development of colour photography and printing processes, which allowed new qualities of architecture to be represented for the first time in print media. For instance, interest in the work of Mexican architect Luis Barragán mushroomed after a 1976 retrospective at New York's Museum of Modern Art, where theaccompanying catalogue's colour reproductions conveyed the bold polychromy of Barragán's architecture to a wide audience for the first time. In addition, the revival of interest in Art Nouveau architects such as Antonio Gaudíand Victor Horta can arguably be attributed in part to colour photography, which is betterabletoshow their profuse use of graphic decoration than black-and-white (Elwall, 2004, p. 198). In examples such as these, technologies of reproduction can be seen as important influences on the shape and spread of certain architectural ideas.

3.4. Meanings have complicated relationships to practices and cultural production, being able to give a quick pencil sketch some of the gravitas of a skyscraper, as well as reduce these overwhelming physical entities down to a set of ten letters on a page. With this in mind, the term 'discourse' is useful to replace the narrow notions of 'text' because it blurs and refuses the conventional distinction between thought and action, ideas and practices. 


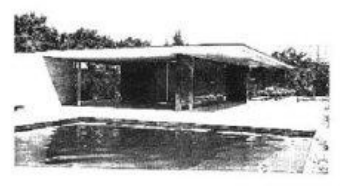

this is not architecture fig. 3.III. Kester Rattenbury (ed.), This is not architecture. Cover, Routledge, 2001.

3.5. All media products can be seen to have a bias, a limitation. Through this, the culture industry producing and influencing media material expresses aspects of reality over others. It filters reality and at the same time reconstructs reality for people. Refer to Chapter 5 for my discussion on the architecture culture industry.

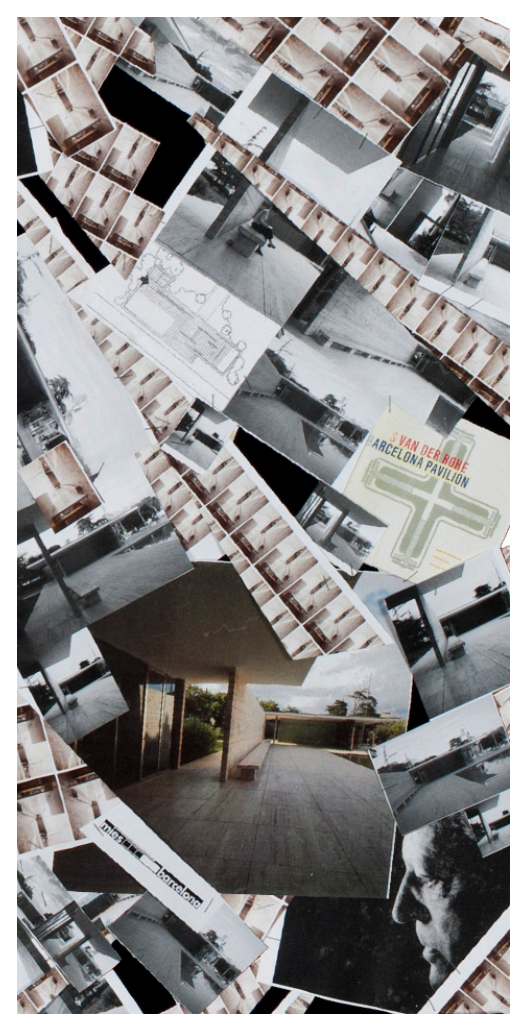

fig. 3.IV. Collage of print media material on the Barcelona Pavilion: a representation of bildwelt. of modern architecture in the world. In her introduction, she explains: "Of course this is not architecture. This is a picture. This is a book. Yet it is almost impossible to conceive that a photograph of the Barcelona Pavilion, on the front of an architectural book, is not architecture. [...] It's hard to accept that...what you're looking at is a representation and not the thing itself. [Especially with the Barcelona Pavilion,] the representation is almost more definitive than the thing itself"(Rattenbury, 2002, p.xxi). For Rattenbury and many others, it appears the distinction between 'architectural representation' and 'architecture' is open to debate, now having a seeming equivalency. What allows this to occur is the particular ways of seeing which modern architectural media and representation techniques develop and encourage. ${ }^{3.5}$

\section{Ways of seeing}

The rapidity and multiplicity of images have changed the relation of human eyes to images. Considering meaning to arise according to romantic hermeneutics affects the way people see things. Traditional aesthetic perception defines images as sorts of buffers between viewers and objects, and is focussed only on perceiving such objects as 'finished' and closed entities. In contrast, post-structuralist ways of seeing consider objects to be in a state of only partial completion, an open-ended product which is able to "foster new fields of reference" (Bourriaud, 2002, p. 100). These ways of seeing embrace a much wider range of art forms, and are able to cope with the changes in visual culture stemming from a 'hyper-inflational' system of imagery. Some of such 'ways of seeing' proposed by theorists of visual culture include the 'scanned' image (Ivan Illich), the 'technological' image (Walter Benjamin), and the 'politicised' image (Juhani Pallasmaa, Serge Daney, and Nicolas Bourriaud), all understandings which subvert the traditionally placid contemplation of images favoured by mainstream architecture culture.

\section{The 'scanned' image: Ivan Illich}

In Guarding the Eye in the Age of Show, the Austrian philosopher Ivan Illich proposes that the "universe of pictures" which has surrounded people since the invention of perspectival representation can be understood as a merging of images and the perception of reality. "Since the sixteenth century...the eye [has been]...but the instrument by which images are imprinted...This identification of vision with inward visualisation must be recognised as a crucial achievement of European modernity" (Illich, 1995, p. 5I). He goes on:"[The German word weltbild signifies]...'the image of the world'...In the nineteenth century... it was used in opposition to 'worldview'. Bildwelt is [a] very new [term]...It suggests a 'universe of pictures' by which I am surrounded and which hide from me the world of raw things. [Both words issue] from the wedding of image and vision. Their opposition 
suggests the transition from the visualisation of the world to the reduction of the world to a picture" (Illich, 1995, p. 5I). Illich claims the Renaissance image "formed within the gaze" is replaced by modern technology with an image formed by 'scanning', a mesmerising 'show' substituting an artificiallyprovided 'objective reality' in place of active image-formation in the minds of viewers (Illich, 1995, Pp. 50-5I). Essentially bemoaning the death of individual imagination, Illich cautions against our isolation from "the world or raw things", the un-mediated experiences which refreshingly stimulate our independent 'world-views' and ways of seeing.

\section{The 'technological' image (of multiple fragments): Walter Benjamin}

Despite their apparent overexposure in any discussion on new media, reproduction, and the change in status from the 'autonomous' work of art to one integrated into the fabric of everyday life, the writings of Walter Benjamin remain significant, even for the simple fact that his essays themselves have been produced and reproduced repeatedly in the very manner which they discuss. The process of reproduction allows things which were created just once to be produced for everyone. But for Benjamin, the "once does not matter": the individual item counts for less than the replication of the prototype (Benjamin, 2008b), Benjamin's own easily-read and widely referred-to essays seeming to demonstrate his very dictum:"The work reproduced becomes the reproduction of a work designed for reproducibility” (Benjamin, 2008b, p. 24).

In his famous essay, The Work of Art in the Age of its Technological Reproducibility (first published 1936), Benjamin was concerned for the relation between the original and the reproduced work of art. The reproduction of the work of art removed the 'aura' of uniqueness which the classical 'cult' of authenticity bestowed on the original work of art (Benjamin, 2008b, PP. 2I-25). With the mass reproduction and representation of cultural products, Benjamin argued that to ask for the 'original' product makes no sense. Questioning the effects of mass media techniques on processes of cultural production, Benjamin's essay can be seen to neutralise a number of 'traditional' concepts used to support the hegemony of romantic hermeneutics as a model defining the production of cultural meaning, such as 'creative genius', 'eternal value' and the mysterious 'aura' of the artwork.

For Benjamin, the technologically-reproduced image (in his case, via the camera) revealed a new way of seeing. Just as psychoanalysis had opened up the realm of the psyche to 'new' ways of thinking, he considered mechanical photography to form an equivalent analytical practice for the visual realm. (Benjamin, 2008b, p. 37): both these innovations isolated and made analysable things which had previously floated unnoticed on the broad spectrum of perception. "Through the camera," Benjamin claimed,

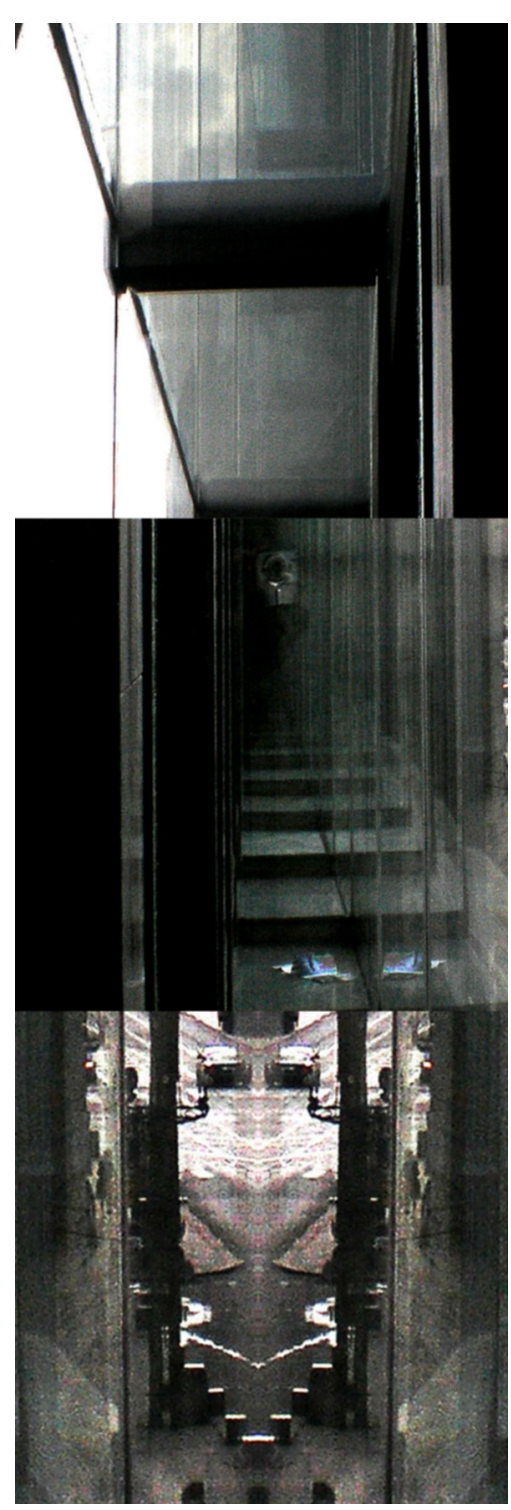

fig. 3.V. Cropped photo-fragments, suggestive of the 'technological' image. 


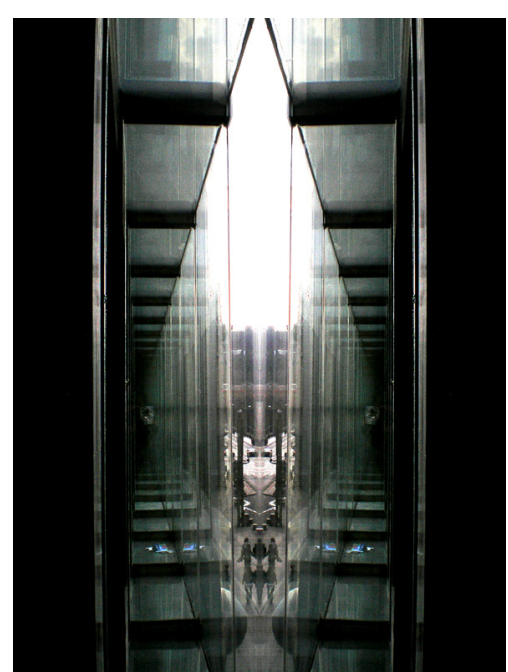

fig. 3.VI. Window reflections in mirrored glass. Prague, 2010.

This is the source photograph for the photo-fragments on the previous page. The fragments provide only a hint of the whole image, requiring viewers to tap into what Benjamin calls their 'optical unconscious' to form some interpretation of them.

3.6.

Benjamin's ideas have been criticised for their technological utopianism: the broad conviction that certain properties of technological media as such hold within them the potential for social change (Jennings, 2008, p. 13). He ignores the view that technologies of mass media and reproduction are only processes used by humans, treating these mechanisms and abstract concepts as active agents. This 'deterministic' aspect of Benjamin's thinking must be rejected, as under the post-structuralist understanding of meaning proposed in Chapter 2 , it is people who are active agents in the production of meaning, using and interpreting the effects of such technologies through placing certain meanings on the resultant products. "we first discover the optical unconscious" (Benjamin, 2008b, p. 37). This was particularly evident for Benjamin in the photographic technique of the close-up or cropped image. "With the close-up," he observed, "space expands... a space informed by human consciousness gives way to a space interwoven with the unconscious" (Benjamin, 2008b, p. 37). Offering new potential to the object or image depicted, Benjamin's understanding of these photographic techniques acknowledges the power of the fragment for people's attribution of meaning to cultural objects. Technological frames encourage us to imagine what is beyond their limits: the cropping of a photograph creates possibilities by concealing, allowing unexpected answers to emerge from the viewer's mind might not exist if they were shown the unaltered scene.

Walter Benjamin conceived of two different roles an artist might take in their relationship to the production of meaning in their work: the surgeoncameraman and the magician-painter. Whereas the latter maintains in their work a "natural" distance from reality, embracing the "total view" in terms of the pictures they produce, the surgeon-cameraman penetrates deeply into the web of reality, producing pictures composed of multiple fragments assembled under new modes of seeing. Thus, Benjamin argues that the representation of reality through film and camera is incomparably more significant for contemporary ways of seeing than painting, since it offers a perspective reconfiguring the world according to a simultaneous collective reception. 3.6

\section{The 'politicised' image: Juhani Pallasmaa, Serge Daney, and Nicolas Bourriaud}

Juhani Pallasmaa understands there to be two opposing ways in which images can be related to the audience viewing them: images used to dictate, manipulate and condition 'the audience', and images that emancipate, empower and inspire (Pallasmaa, 20 I I, p. 2I). The first type is exemplified for Pallasmaa by political and consumer conditioning, narrowing down, confining and weakening the freedom, choice and individuality of viewers by attempting to focus and channel their attention and awareness into a prescribed pattern of interpretation. In contrast, the second type is exemplified by poetic and artistic images, which seem to open up, fortify and liberate viewers by encouraging personal imagination, emotive interpretation and affect.

There is a fine line between an image's power to display an idea and its potential for propaganda. Serge Daney has written on the shifting balance between these as more rapid and intensified forms of media proliferate. He identifies two attitudes of images: Firstly, the "Show/See" attitude, representing for him an essential 'democracy of the image' through the 'sharing' of ideas with its viewing audience. The show/see image therefore 
has a relational message or meaning, being based on the encounter of work and audience. However, Daney's second attitude, the "Promote/Receive" image has a prescribed message or intent, only stimulating homogeneity and propaganda. ${ }^{3.7}$

Creative practices are dependent on and influenced by available technology. The appearance of major innovations in representational technology, for example photography, clearly alters relations between people and the world, and also methods of representation as a whole. Creative practices such as art and architecture may form a critique of production methods and human relationships produced by the technologies of the day. They do this by reproducing them, shifting them into a different mode or place, so we start to see them from a different perspective. This is referred to by Bourriaud as "the Law of Relocation", saying critical creative practice stems from the shifting of art from one technology to another (Bourriaud, 2002, pp. 66-67)

What is important to remember, I suggest, is that any cultural product, including images and works of architecture, do not in themselves possess any political power. Richard Kearney's explanation of how the philosopher Jean-Paul Sartre understands the image supports this idea: "It is not the image that is persuasive, erotic, or disgusting. It is we who persuade, excite and disgust ourselves by the very act in which we construct the image [...] An image is an unreality which has no qualities unless given by us" (Kearney, 1991, p. 70, original emphasis).

\section{The 'mediatised' role of the architect}

With the production of architectural material shifting away from their direct control, the architect, supposedly the very figure of mastery as creator of space, also becomes a troubled spectator of their own work. The idea of architects as the final authorities, undivided subjects indisputably in charge of their work becomes a suspect illusion. Arguably, the role of architects becomes constructed, controlled, and fractured by the work. The architectural media transform spaces conceived by the architect into representations immediately open to a myriad of interpretations, appropriations, associations, and observations. Manipulated by this new construct of media, architects are both inside and outside the media-object, and are not simply its authors. In a time where the proliferation of images encourages our tendency to scan rather than read, to glance rather than perceive, our responsibility as practitioners of a discipline so intrinsically tied to the making of images becomes to question the implications of our tendency to equate mediated experience with human experience, pictures of things with the things themselves.
3.7. Serge Daney. Persévérance (Postcards from the cinema), Editions P.O.L. (1992), p.38

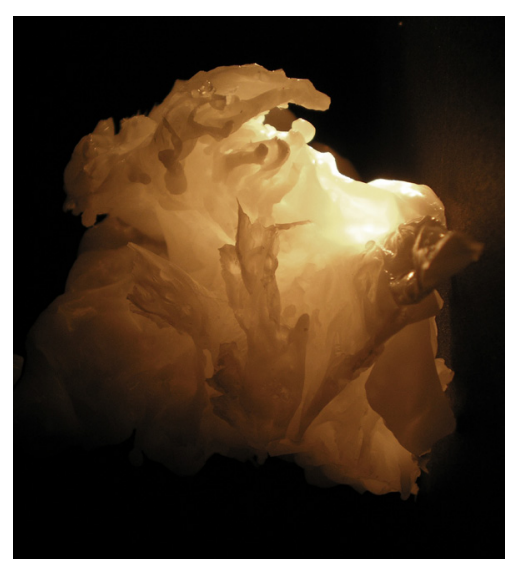

fig. 3.VII. Photographic study of a wax form.

It is important to remember that the evocative qualities that some images and objects appear to have are culturally-influenced values which people project onto them, rather than 'innate' characteristics. 
Jürgen Habermas, the German philosopher, claimed that design is a form of communicative action, and therefore that communication (representation) is a form of design (Habermas, 1984). This claim is perhaps supported by the observation that architects design using far more expressive forms of representation than the very restricted and proscribed forms of communication required to convey the information necessary to construct the design in three dimensions (Staub, 20 I I, p. 58). The act of representation and image-making is an important aspect of the role of the architect. As the Finnish architect Juhani Pallasmaa writes, "the most existentially and experientially rooted architectural experiences impact our minds through images which are condensations of distinct architectural essences. Lasting architectural experiences consist of lived and embodied images which have become an inseparable part of our lives" (Pallasmaa, 20 I I, p. I I). However, Pallasmaa claims that architects need to criticise the exploitative imagery of contemporary consumer culture, the forceful architecture of the image for example, and at the same time defend poetic and embodied images, underlining its central role in all artistic experience and thought (Pallasmaa, 20II, p. 12).

Jonathan Hill claims that "the reputation of [the contemporary] architect is, in part, dependent on his or her ability to generate a good photograph. If an architect is successful the same image is published throughout the world, to be copied by other architects with little regard to cultural or social differences"(Hill, 2003, p. 21). Hill's distillation of the practice of architecture to the marketing of design and images as mass-produced commodities seems to have grounds among much of contemporary 'global' architecture.

\section{Manipulation of images: fabricated realities}

With the ubiquity of the mechanical reproduction of images, many people's perceptions are informed by mainstream cultural impressions of technology as a 'guarantee' of fidelity to the original. However, this impression is often used to present people with fabricated realities of architecture which do not or could not exist as they are represented in architectural print media. Architectural photography can create an idealised moment, filtering the visual abundance of direct experience down to a distilled perfection of the image. "Architectural photography prepares you only for the optimum condition, the best time of day, best position, the standard view, the authorized take, the truth against which all other views will seem irredeemably poor approximations," writes architectural critic Janet Abrams (Abrams, 199I, pp. 77-78).

While Chapters 4 and 7 provide detailed examples of the way manipulated images have been used by certain architects (Le Corbusier and Mies van der Rohe respectively) to promote certain ideas about their architectural work, 
it is important to clarify here that photography's "regime of truth"(Hall, 1997, p. 49) is deeply embedded in mainstream architecture culture. However, this attribute need not be considered in a negative light, being simply the result of an ideology of perception, and able to be overcome with critical interpretation. Further, the case studies on Le Corbusier, Mies van der Rohe, as well as the Design Explorations discussed in Chapter 8, endeavour to explain how people's ability to fabricate realities from print media material can be used in a productive (as opposed to a deceptive or exploitative) sense. Most importantly, it is imperative to observe that there is no such thing as the 'neutral' representation or image.
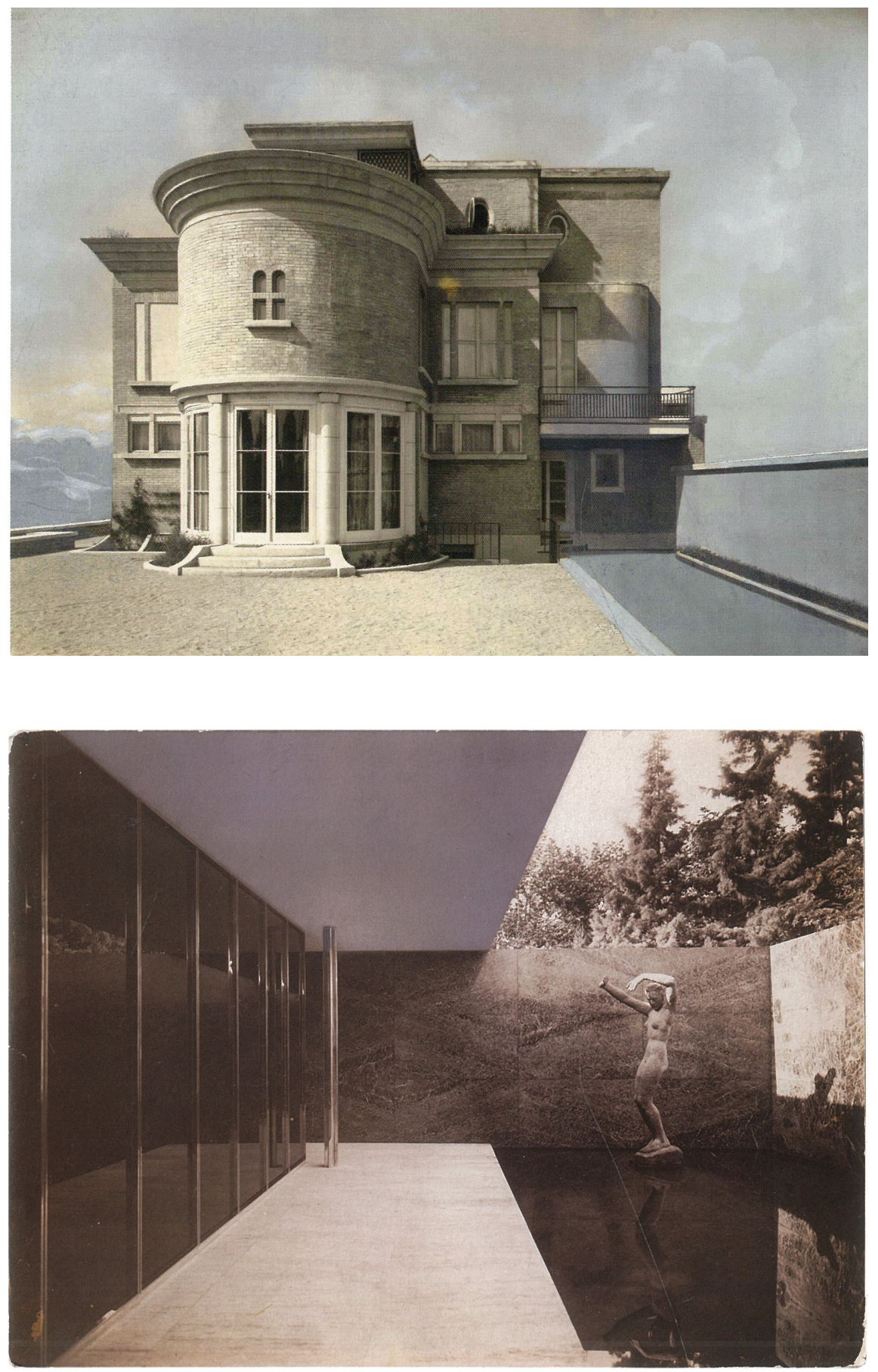

fig. 3.VIII. Manipulated photo of the Villa Schwob, designed by Le Corbusier (1916).

fig. 3.IX. Manipulated photo of the Barcelona Pavilion, designed by Mies van der Rohe (1929).

Both these photographs have been visually altered by their respective architects, changing the view from what would be physically possible to see in reality.

The 'fabricated realities' of these two photographs (among others) are discussed in Chapters 4 and 7 respectively. 


\section{Conclusion}

With the advent of technical reproduction, all images and representations simultaneously take place in two realities, their power being derived from this very tension between the real and the suggested, the perceived and the imagined. In the act of interpreting a work, representations shift from a physical and material existence into a mental and imaginary reality in people's minds. Similarly, even built architecture occupies two realms simultaneously: the reality of its tectonic and material construction, and the abstracted, idealised and spiritual dimension of its artistic interpretation. These two realities maintain a dynamic and dialectic relationship. Perhaps it is no longer possible to separate architecture from the medium through which it is presented and reproduced, that it is no longer a question of reality and representation, but of the relationship between one kind of existence and another.

People's cultural frames of reference inform different ways of seeing. How people see is inseparable from what they see, and the technologies that structure vision are inseparable from the built environment that people perceive using them. Media techniques take advantage of some of these ways of seeing. They make us think that architectural representations are objective documentations of reality, not techniques in themselves. They convince us to look "through" their surface to the objects which they refer to, and in doing so change the way we might interpret the original in the flesh.

Print media reproductions of architecture idealise it in a way, allowing us to optically inhabit buildings unaffected by the passage of time or boundaries of space. A set of photographs can focus our attention onto the smallest of building details, and at the same time show us the skyscraper they make. Architectural representation therefore has the potential not only to concentrate space but also to disperse and rearrange it within time, to relocate, reconstruct, and redesign it. As Walter Benjamin asserted, "The work of art reproduced becomes the work of art designed for reproducibility” (Benjamin, 2008b, p. 24). 


\section{conclusion summary}

- Architectural representations are not 'neutral depictions of reality'.

- The spread of images in modern culture has prompted different ways of seeing.

- Media techniques take advantage of some of these ways of seeing.

- Architectural images are often 'seen' through scanning, perceived as fragments, and employed as tools in the inherently political act of cultural production.

- This understanding of architectural media shifts the potential of the role of the architect to include being a skilful user of media material, expanding the possibilities of their physical designs.

- The act of representation can therefore be understood as an act of design, engaging with people's imaginations to fabricate personal architectural realities.

Near the end of his famous "Work of Art" essay, Walter Benjamin described built architecture as the art form that is perceived unconsciously, in a state of distraction (Benjamin, 2008b, p. 40). Given the endless flow of images which permeates contemporary culture, this status must surely also apply now to print media: Images constitute much of people's cultural environments, as buildings become images, and images become a kind of building, 'occupied' like any physical space. Representations designed for their reproduction in print media have become one of the raw materials of an architect's craft, with the power to be attributed with meaning just like any built masterpiece. The following chapter explores the potential of these ideas through the work of Le Corbusier, an architect who, I argue, clearly understood the role images and media played in cultural production. 


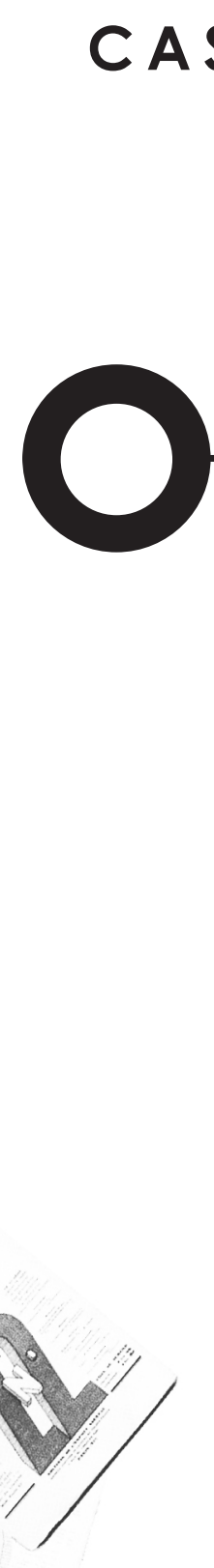

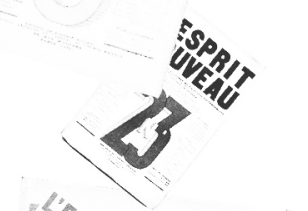

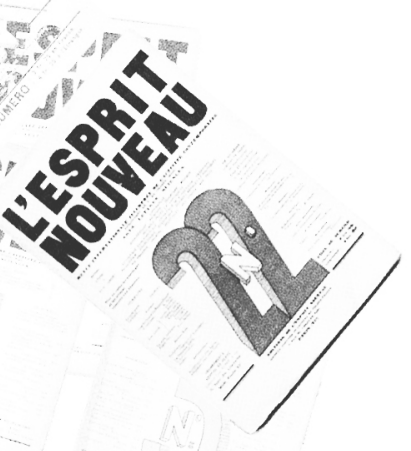

sis

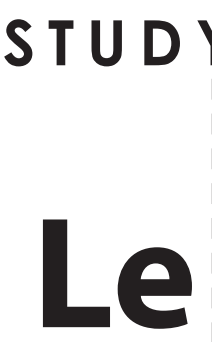

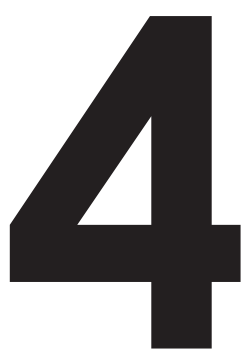

CHAPTER

Corbusier

\section{the journal}

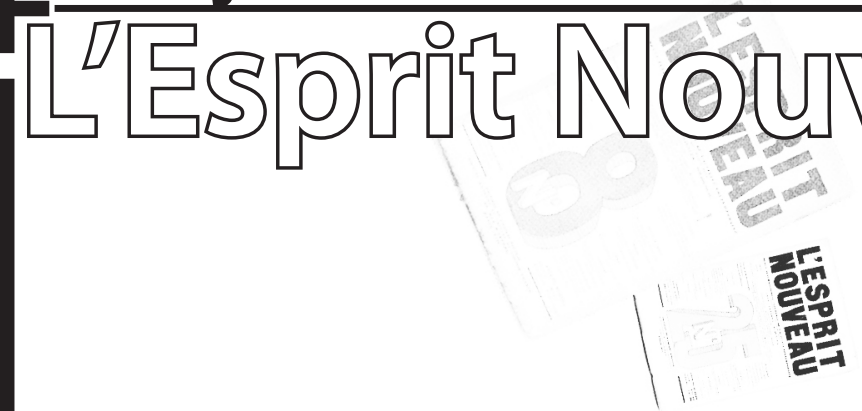

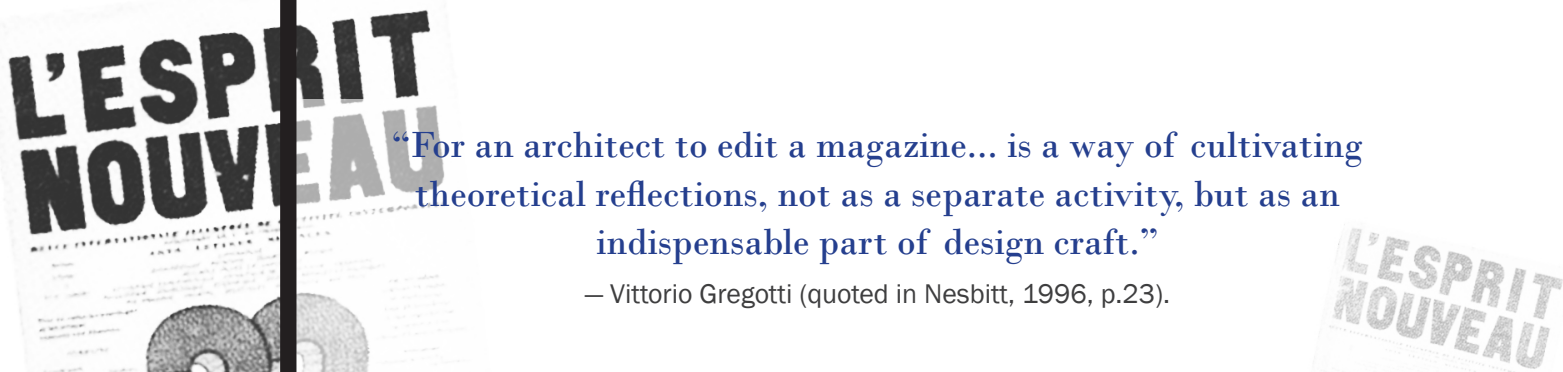

"[A] Mirror of Thought. Architecture is a system to think with... and [can] become the expressive verb of a milieu." - Le Corbusier (1925, pp. 5,74).

\section{NOLIEA} worthwhile which is not transmittable."
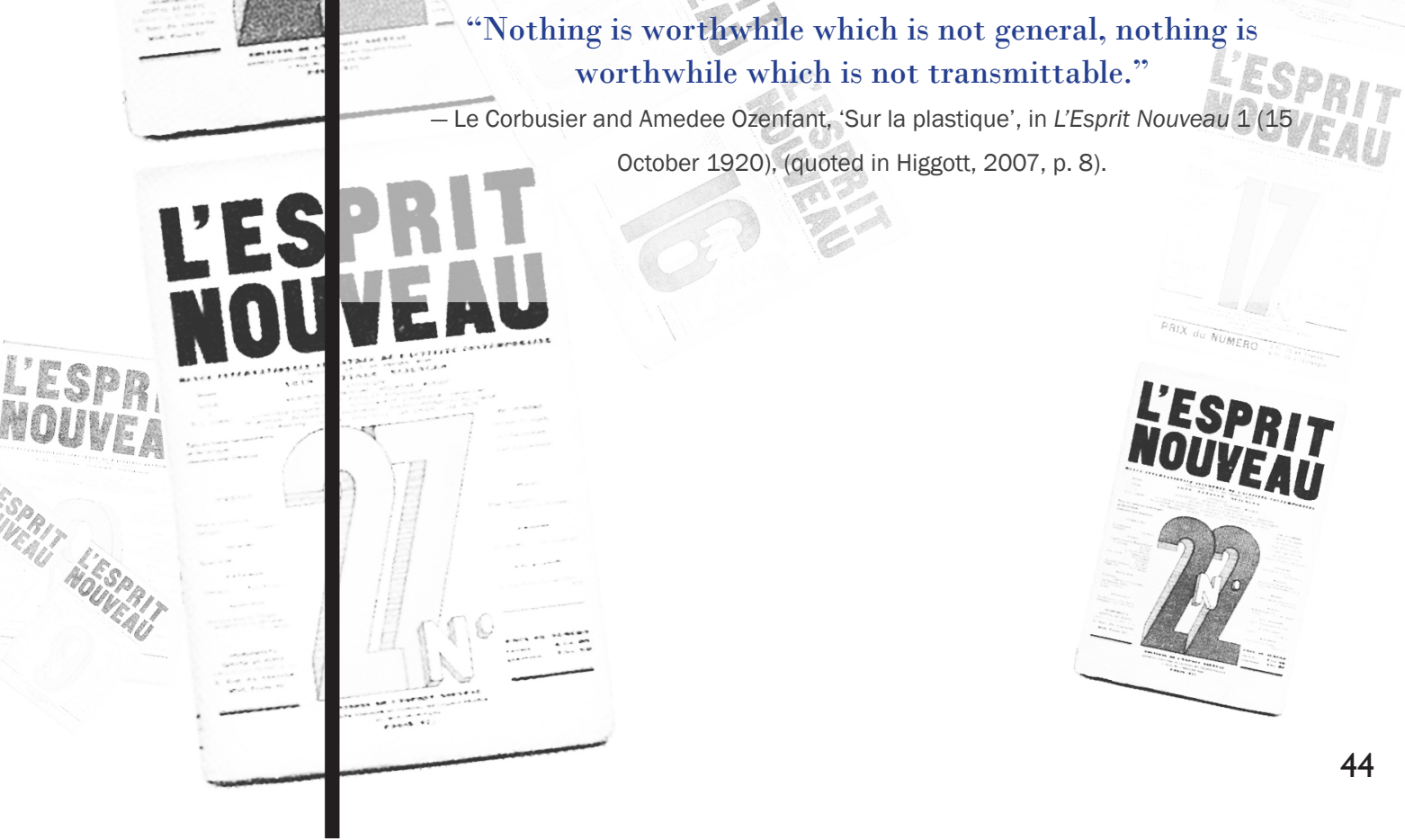


\section{Introduction}

L’Esprit Nouveau 1920-1925

Le Corbusier's techniques of print media

Appropriation -of imagery

- Juxtaposition-of images and texts

-.-. Manipulation —of images

- The image/text relationship

- Publicity and self-promotion

Print media: a space of architectural production

\section{Conclusion}




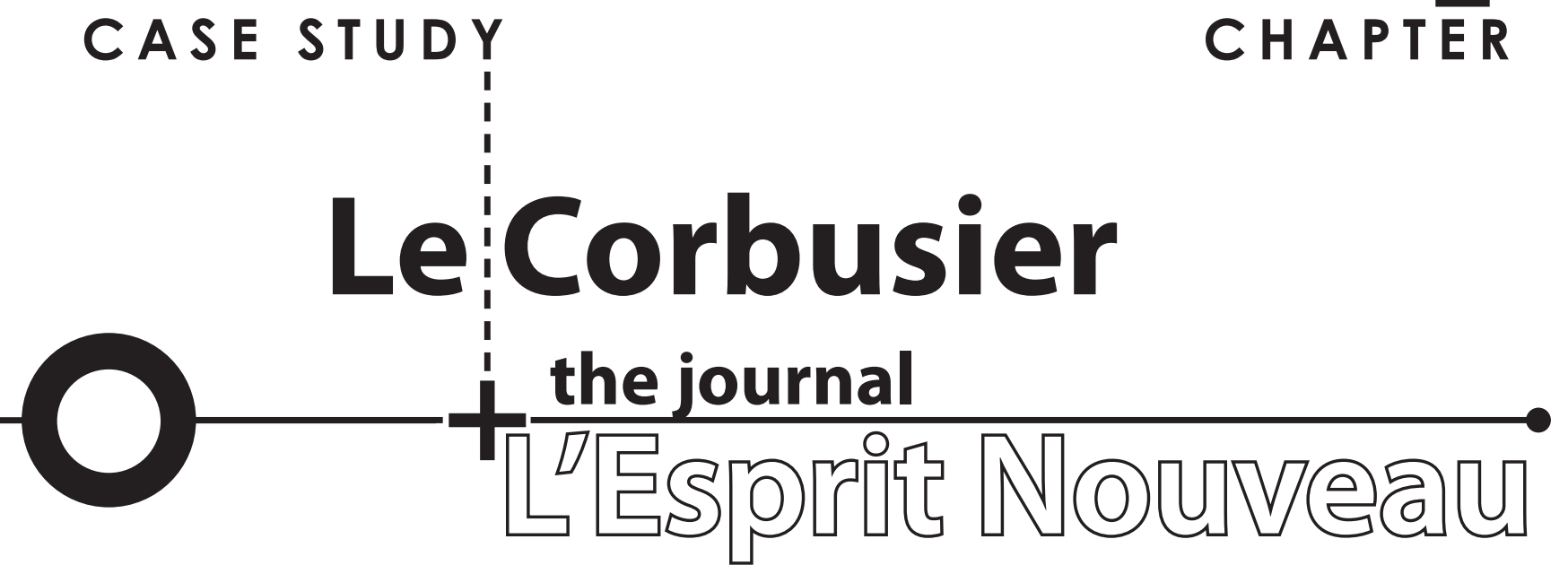

\section{Introduction}

Having established an understanding of how meanings are attributed by people to cultural products (Chapter 2), and discussed the place of architectural media and representation in regards to architectural meaning (Chapter 3), I now turn, in the first of my case studies, to an examination of how these theoretical positions can be seen to be present in mainstream architecture. The editorial and publishing activities of the Swiss-born architect Le Corbusier ${ }^{4.1}$ provide significant examples of how an architect's engagement with processes of print media may be useful for the practice of architecture (built or otherwise).

Le Corbusier ${ }^{4.2}$ has been claimed to be the first architect (but certainly not the last) to understand the role of the media in producing rather than simply representing architectural ideologies. He published profusely, and his books and articles attempt to persuade his readers to adopt a new aesthetic appropriate for a new future, that of the machine age. He was not only a "man of letters" but a man of the media, utilising available means of expression to make his work known, to express his ideas publicly, to contribute to the cultural production of the twentieth century via manifestos, expositions, and in particular, printed media.

The focus of this case study is on Le Corbusier's blurring of the conventional boundaries between architecture and mass-media by practicing simultaneously as an architect and also as the editor of a journal, L'Esprit

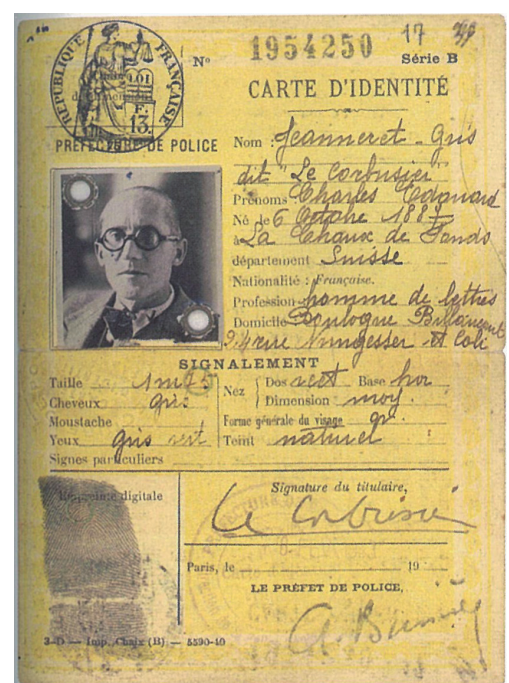

fig. 4.I. Le Corbusier's French identity card.

The importance of Le Corbusier placed on published discourse is perhaps revealed by the identity card he received in 1930 when he became a naturalised French citizen: Under 'Profession' , Le Corbusier, later hailedas one of the 'masterarchitects' of the twentieth century, simply noted "homme de lettres" (man of letters) (Boyer, 2011, p. 20).

4.1. Born Charles-Èdouard Jeanneret in 1887, the name Le Corbusier was a pseudonym he adopted first for signing articles in the journal L'Esprit Nouveau, then as his name for his architectural work from 1925 onwards, and finally as a signature on his paintings from 1928 onwards.

4.2. See Beatriz Colomina, Privacy and publicity: modern architecture as mass media (1994). 
4.3. Le Corbusier's writings suggest he conceived of architecture as a deeply structured analogical model linking togetherdifferentlevels of thoughtonarchitectural design, urbanism, decorativeartsand painting (Boyer, 2011, p. 37).

4.4. "Domain de L'Esprit Nouveau" (signed “L'Esprit Nouveau”), L'Esprit Nouveau 1(1920), no pagination. (Quoted in Boyer, 2011, pp. 44-45)
Nouveau, which was produced in Paris between 1920-1925. This journal was used by Le Corbusier to publish his ideas of modernism in industrialised everyday life.

In his editorial work for L'Esprit Nouveau, Le Corbusier borrowed many print media techniques from modern advertising, taking advantage of their ability to suggest certain meanings to help promote his architectural ideas. His use of appropriated imagery, juxtaposition, and image manipulation demonstrate his adept engagement with print media processes of the architecture culture industry. Le Corbusier used images produced using these techniques not to 'illustrate' the written text; rather, they construct a new, 'slippery' text or message in the mind of the reader.Aiming to influence people's construction of meanings on his project of modernity, such media techniques also acted as a means of self-promotion, Le Corbusier consciously using L'Esprit Nouveau to generate publicity for his architectural work and ideas. Finally, I argue that Le Corbusier's involvement in producing and publishing L'Esprit Nouveau demonstrates his use of print media as a new space of production, the "media space of architecture" playing a useful role in the development of architectural meaning.

\section{L'Esprit Nouveau 1920-1925}

In 1920, Le Corbusier formed a new journal in collaboration with the painter Amédée Ozenfant and the writer Paul Dermée. Entitled "L'Esprit Nouveau", the review espoused their doctrine of "Purism", a synthesis of the arts placing painting, architecture and all aesthetic expressions on the same level. ${ }^{4.3}$ Guiding the editorial direction of the journal was the motto the "spirit of the machine", a spirit of construction and synthesis driven by "pure conception". ${ }^{4.4}$ The aim of L'Esprit Nouveau was to affirm the existence of this constructive spirit in contemporary culture.

Le Corbusier's editorial strategies were fundamentally different from other art periodicals circulating since the end of the $19^{\text {th }}$ century. With the experience of L'Esprit Nouveau, he came to understand the press, the printed media, not only as a medium for the cultural diffusion of something previously existing but also as a mode of production with specific characteristics, rules, limitations and power. 

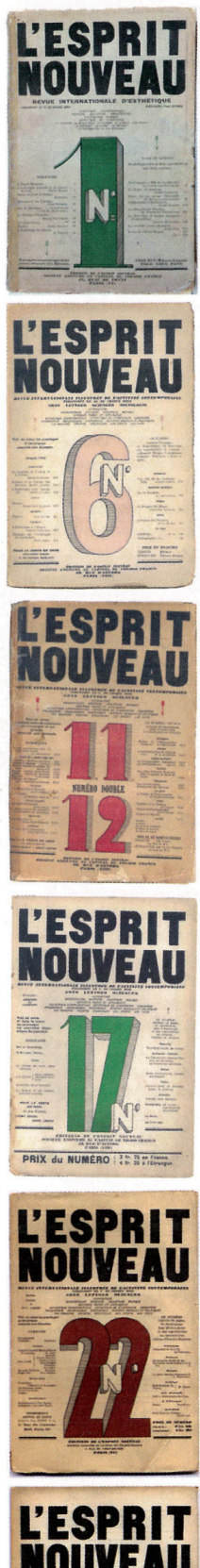

$01 \mathrm{E}$

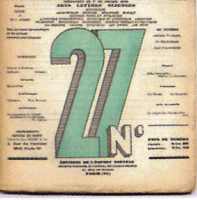

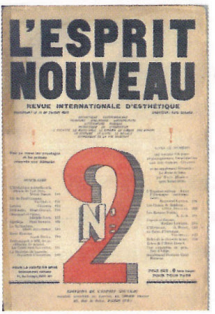
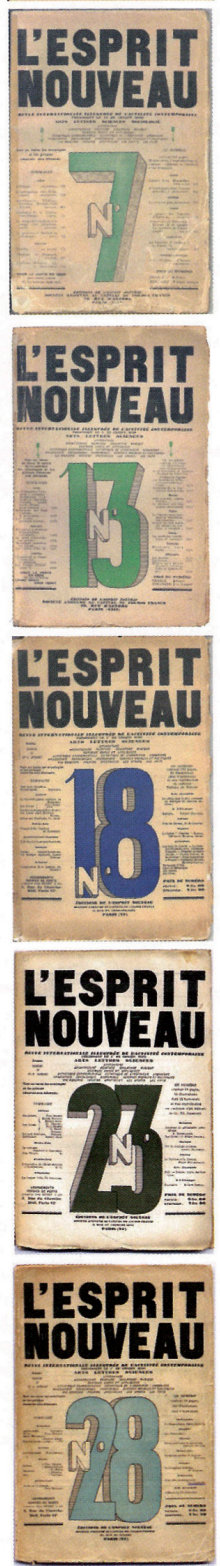
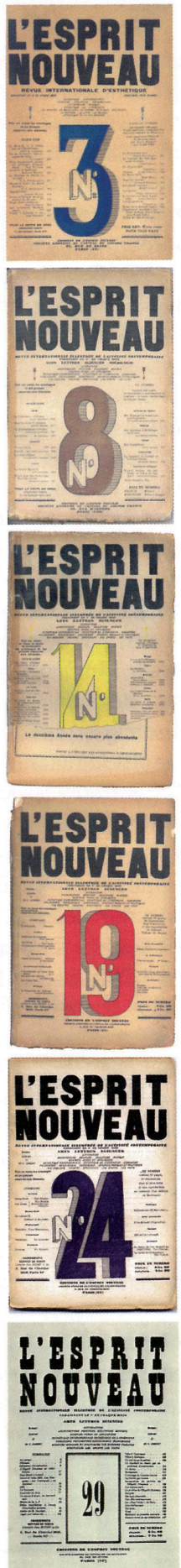
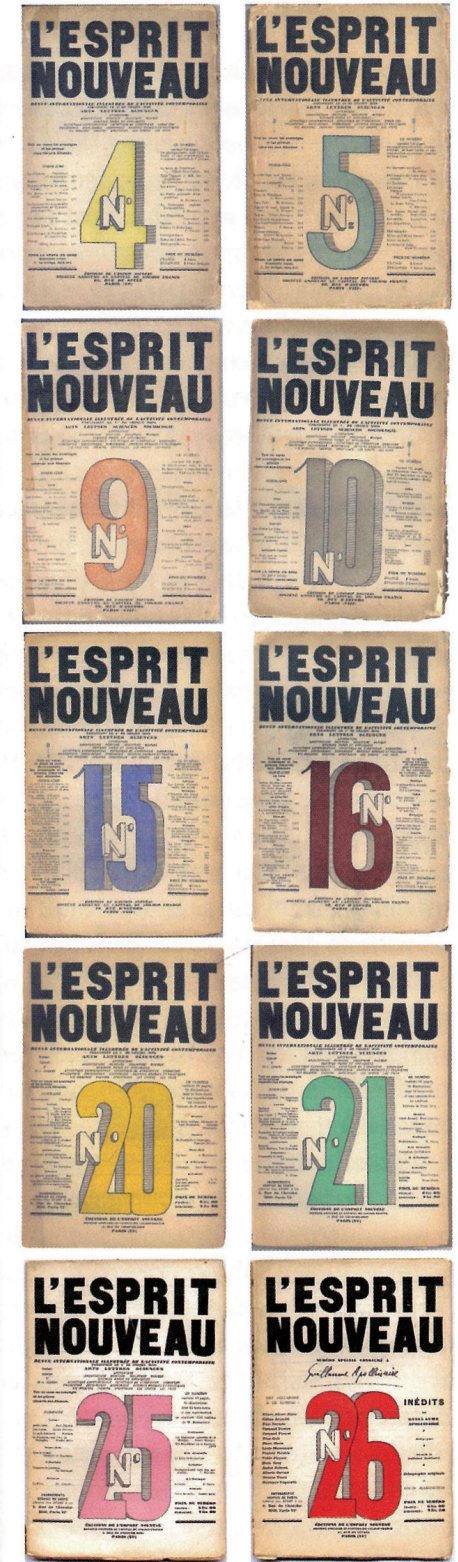

fig. 4.Il. L'Esprit Nouveau, all covers 1920-1925.

Twenty-eight issues of L'Esprit Nouveau were published between October 1920 and January 1925, and these can be divided into three distinct periods of editorial control:

- Issue 1 (October 1920) - Issue 3 (December 1920):

During which time Paul Dermée was editor-in-chief, and the journal focussed on aesthetics and literature. His editorial direction did not fit with what Ozenfant and Le Corbusier sought to achieve, and after the third issue he was dismissed.

- Issue 4 (January 1921) - Issue 17 (June 1922):

This second period was characterised by Le Corbusier and Ozenfant as acting editors, both being actively involved in directing the content of each issue. Their use of overlapping pseudonyms in this period creates issues in identifying exactly who wrote each article. [For example, when they wrote together they sometimes used their own names, Amédée Ozenfant and Charles-Èdouard Jeanneret, and at other times used pseudonyms such as Julien Caron or Vauvrecy. Articles signed by Saugnier, de Fayet, or Dr. Saint-Quentin seem to have been written by Ozenfant, while Jeanneret seems to have written independently as Paul Boulard, or a version of his great-grandfather's name Lecorbésier, which he adapted into Le Corbusier. Some articles on architecture are signed Le Corbusier-Saugnier, making it unclear how much Ozenfant contributed to them. (refer to Boyer, 2011, pp. 272-273; and de Heer, 2009, p.193 (Appendix II))]

- Issue 18 (November 1923) - Issue 28 (January 1925)

After a hiatus of one year and four months due to financial struggles, the journal resumed publication, this time with Le Corbusier firmly in charge. In this third period, the journal's look was also restyled to take greater inspiration from the "new machine age". 


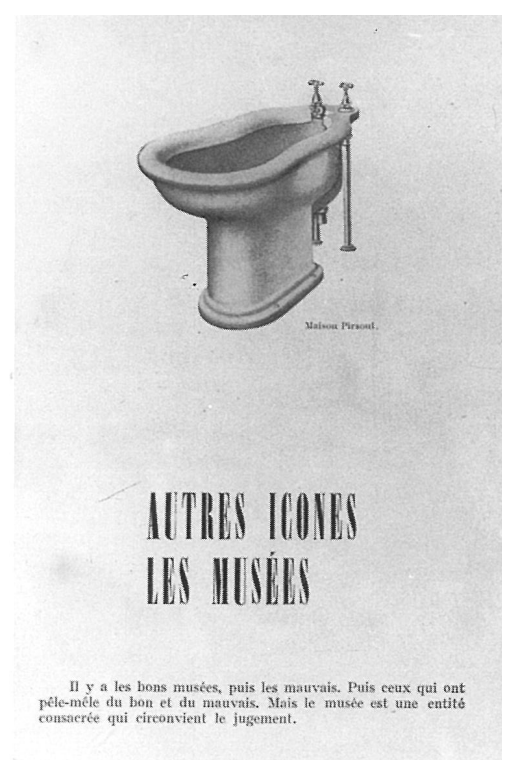

fig. 4.III. Page from L'Esprit Nouveau 20 (1924)
4.5. Appropriated photographic or drawn images were presented as expressions of precision and clarity. These include images of American grain silos and factories, airplanes, steamships and automobiles. By 1922 the typewriter, typed page and printed page were being used in L'Esprit Nouveau as emblems of "a new clarity and precision", rotary generators of "an internal elegance", and "a new morality, the morality of The Good Job" (Boyer, 2011, p. 283). Le Corbusier also appropriated images of small mass-produced goods, ranging from pipes to purses, all put to new uses as "the inescapable consequence of mechanism; objects ofall kinds which are presented to us in impeccablygood order" (L'EspritNouveau 21 (March 1924), quoted in Christopher Green, Cubism and its enemies: modern movements and reaction in French art, 1916-1928 (New Haven: Yale University Press, 1987), p.211).

\section{Le Corbusier's techniques of print media}

Arguably due to his activities as both a designer and a painter, Le Corbusier was particularly interested in the visual impact of his books and publications. Le Corbusier was meticulous about the design of the page layouts, how typographic formats make reading more efficient, the qualities of the images used, and the promotional materials of his publishing. His engagement with the processes of print media production through use of certain techniques from modern advertising - juxtaposition, appropriation, and manipulation - reveal an understanding of the significant influence media products can have in shaping people's interpretations of architectural meaning and concepts. Through careful employment of these techniques, Le Corbusier took advantage of the media's ability to advance certain ideas over others, using it as a tool of self-promotion, enhancing his public persona and career, and eventually becoming known as one of the most important architects of the twentieth century.

Appropriation - of imagery

Modern advertising often utilises 'borrowed imagery' to reinforce the messages it seeks to promote. Le Corbusier employed this technique, appropriating images and elements of printed advertising in assembling issues of L'Esprit Nouveau, taking them out of their original contexts and shaping them to fit into new ones to explore some of his ideas in the journal.

Advertisements of filing cabinets manufactured by Roneo, office furniture produced by Or'mo, suitcases and trunks from Innovation can be seen as a sort of theme or leitmotif in issue after issue. Their repetition, often in the same page position and order, could be seen as metaphors for the standardisation and simplification that Le Corbusier was advocating ${ }^{4.5}$ (Boyer, 20I I, p. 282).

In L'Esprit Nouveau, some of the images used to illustrate the texts were deliberately taken from catalogues of companies whose advertising helped finance the review, including Omega, Innovation, Hermès, Peugeot, and Voisin, provoking questions about the context of interpretation. A page from L'Esprit Nouveau 20 provides an interesting example of Le Corbusier's use of appropriation. To illustrate the head of the article "Autres icons: les musées"("Other Icons:The Museums"), Le Corbusier uses an image of a bidet taken from the catalogue of the manufacturer Maison Pirsoul. In the use of plumbing fixtures, as well as the obvious challenge to the institutions of mainstream art ("les musées"), this example is directly comparable to Marcel Duchamp's Fountain by R. Mutt of 1917. Le Corbusier seems to have not only appropriated imagery, but also appropriated the concept of Duchamp's notorious 'ready-mades': Duchamp's artwork is a mass-produced object turned upside down, signed, and sent to an art exhibition. Le Corbusier's "raw material" is an advertising image, taken from an industrial 
catalogue and placed in the pages of an art journal. In both cases, it is the incongruity of the new context which can be seen to give the work its impact.

I would argue that using this technique suggests Le Corbusier was acutely aware of the prevalence of reproduced images such as photographs and cinema, which since the turn of the century had gradually replaced tasks once reserved for painters. Images from illustrated magazines and the newspapers now opened up contemporary consciousness, extended understanding and filled people's minds "with new wonders small and large." ".6 "Many of Le Corbusier's illustrations allow the force of the image to dramatise his words, short-circuiting the slow process of verbal description" (Boyer, 20I I, p. 30)(added emphasis).

The architectural historian Beatriz Colomina claims that the imagery in the pages of L'Esprit Nouveau derived from advertising sources is considerably more pervasive than from strictly architectural sources (Colomina, 1994, p. 153).With this in mind, the presence of this unorthodox publicity material seems to suggest a shift for Le Corbusier, away from the conventional interpretation of architectural media, and by extension the conventional limits of architecture as a field. Moving from considering architecture as an internally-focussed exchange between members of the same cultural institutions (for example, building designers), he seems to approach it as a more open dialogue with an emerging reality, namely the culture of advertising and mass media, the relation of architecture to the culture of the consumer age. ${ }^{4.7}$

\section{Juxtaposition -of images and texts}

Le Corbusier was also acutely aware of the strength of ideas that can be produced through the juxtaposition of images and of images with writing. His use of illustrations in L'Esprit Nouveau (and in the books of the later Esprit Nouveau imprint ${ }^{4.8}$ ) is characterised by surprising combinations of images, juxtaposing apparently unrelated items on the same page or facing pages. Ancient temples are compared to automobiles (Vers une architecture), the church of Hagia Sophia in Istanbul is connected to a child's drawing (L'Art decorative), and a plan of Paris is placed next to the Great Wall of China (Urbanisme). ${ }^{4.9}$ These unexpected juxtapositions seem to aim to reveal not the distinctions but possible connections between the images - the stronger the contrast, the more powerful the provocation of certain ideas, rather than acting as mere visual illustrations of the text.

A clear example of the correlative associations which Le Corbusier encouraged readers of L'Esprit Nouveau to make based on the juxtaposition of different images are his advertisements for the luggage company Innovation. Le Corbusier wrote copy (text used in advertisements) for at least

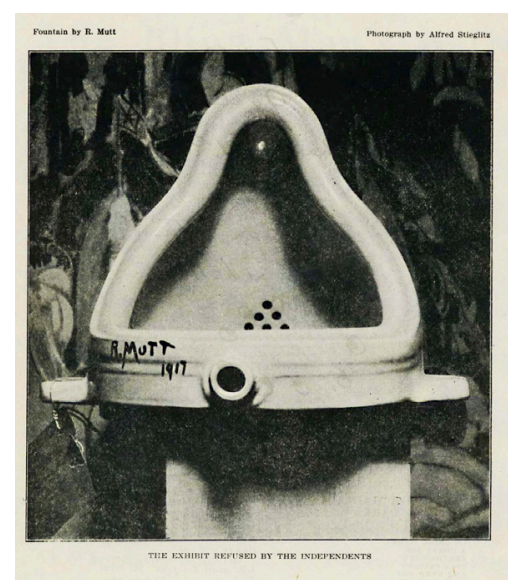

fig. 4.IV. Marcel Duchamp, Fountain by R.Mutt (1917).

4.6. Le Corbusier, "Sainte Alliance des Arts majeurs ou le Grand Arten Gésine”, La Béte Noire (1 July 1935). Foundation Le Corbusier shelfmark X1-12-91. (Quoted in Boyer, 2011, p. 30)

4.7. The idea of industry, mass production and reproduction, breaks the traditional continuity of the concept of 'craft', inverting the relationship between producer and product. Production in a "consumer society" develops, as Adorno and Horkheimer noted, according to a logic of its own reproduction. The main mechanism by which this is accomplished is the "culture industry", the vehicles of which are mass media: cinema, radio, publicity, and periodical publications. (refer to Horkheimer \& Adorno, 2002) (see also Chapter 5 for a more in-depth discussion of the role of media in modern culture).

4.8. The journal L'Esprit Nouveau ran for five years, and then spawned an imprint of the same name hosted by publisher George Crès, the first five volumes of the series (Vers une architecture (1923), L'Art decorative d'aujourd'hui (1925), La peinture moderne (1925), Urbanisme (1925), and Almanach de l'architecture moderne (1925) were reprints of articles from the magazine.

4.9. Vers une architecture, p.106107; L'Art decorative d'aujourd'hui, p.150151; Urbanisme, p.168-169. 

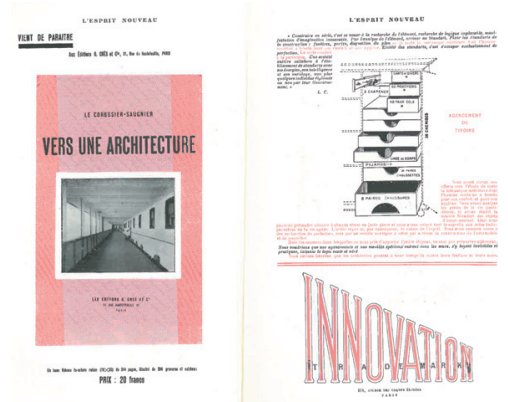

fig. 4.V. Spread from L'Esprit Nouveau 19 (1923).

4.10. Nancy Troy, Modernism and the Decorative Arts in France (New Haven: Yale University Press, 1991), p.216. (Quoted in Boyer, 2011, p. 282) twelve advertisements for Innovation (Boyer, 201 I, p. 282). This company held a patent on a system for hanging rather than folding clothes in a trunk, and the text Le Corbusier wrote for an ad declared it was "the most scientifically studied and the most solidly constructed trunk that has ever existed"4.10 subtly associating it with the technical aspects of building and construction. He placed one of his Innovation ads opposite a page on which an ad for his forthcoming book Vers une architecture appeared. Beneath the image of a set of drawers he wrote, "We have devoted ourselves to the search for perfection, driven by a motivation analogous to that which achieved the construction of the automobile and the ocean liner," strategically linking not only Innovation luggage to modern technological advances, but also his architectural ideas. With copy like this, Le Corbusier manages to juxtapose the developments of modern industrially-produced products with his own architectural proclamations, both elements also mutually supporting their individual claims to 'innovation'.

The sampling of imagery from Le Corbusier's daily environment - news clippings, advertisements, excepts from sales catalogues, etc. - and their juxtaposition within the page layouts of L'Esprit Nouveau can be critically considered in several ways. Catherine de Smet sees this technique as being related to the contemporary art practices of the day: the avant-garde collages and explorations of artistic modernity through the detritus of industrialised everyday life. But she also proposes that these page layouts could be considered from the "picturesque" magazine tradition, which "juxtaposed heterogeneous images and revelled in a pell-mell effect, making a metaphorical allusion to the architectural space of a "bazaar"' (de Smet, 2005, p. 72).

Another perspective on Le Corbusier's rhetorical use of juxtaposition is offered by Reyner Banham. He criticises Le Corbusier for not being consistent with his ideas, claiming that Le Corbusier's placement of antithetical images side by side generates ambiguous meanings (Leatherbarrow, 1993, p. 220). As an example, Banham describes how Le Corbusier's juxtaposed concept house:machine is used sometimes to treat the house as a utilitarian tool and product of "mere" engineering, sometimes as a beautiful object to be revered, and sometimes as something spiritual and ineffable. However, I would argue that this ambiguity was consciously sought by Le Corbusier: in allowing for different readings and varying interpretations, Le Corbusier created arguments flexible enough to be applied in many different situations, leaving himself room to twist his arguments into new forms to avoid them being rejected outright and integrating his work into the contemporary conditions of production. In doing so, he was able to establish and maintain his social standing as part of the avant-garde cultural elite, seeking to achieve its own historical legitimisation. 


\section{Manipulation - of images}

Le Corbusier's printed works are mostly made from a continuous editing of found and appropriated images. Almost invariably, Le Corbusier transformed and manipulated these photographs. Beyond removing them from their original context, he painted on them, erased their details, and reframed or cropped them. The images he published in his journals were images which were worked on, chosen, composed, or as I will argue, constructed images.

For example, in photographs of his Villa Schwob house published in L'Esprit Nouveau, he airbrushed out the garden pergola, removed vegetation in the garden, and modified the vestibule, windows and doorway steps to make it appear to fit the 'purist' aesthetic he was promoting with the journal. In cases such as this, it becomes evident that for Le Corbusier, any representation which better reflected his concept took precedence over the faithful documentation of the actual built work.

But manipulating images was, for Le Corbusier, arguably more than just a tool of visual 'propaganda'. In fact, as Colomina details, Le Corbusier actively engaged in manipulating photographic prints, postcards or printed images as an integral part of his creative architectural process, using them as visual precedents and ways of thinking about his own work (Colomina, 1994, pp. 90-100). For example, he made reproductions of certain images he liked, drawing and redrawing them by hand seemingly to 'enter' and 'inhabit' them. Colomina suggests that these manipulations are Le Corbusier's response to the explosion of images in mass media: each manipulation is not simply a mis-representation of the photographic subject, but a "careful [purist] reduction of everyday objects to essential forms" (Colomina, 1994, p. 93). Processing these images in this exclusive manner seems to be Le Corbusier's act of resistance to a passive reception of imagery in the face of an increasingly industrialised visual culture. The preformed image thus enters Le Corbusier's creative process, but in an interpreted form.

\section{The image/text relationship}

In his task of producing print media material to promote his version of modernism, Le Corbusier was keenly aware of the special relationship created between image and text on the page. In the publicity brochure that Le Corbusier prepared for his book Vers une architecture, he wrote: "This book derives its eloquence from the new means; its magnificent illustrations hold next to the text a parallel discourse, and one of great power." 4 .II Seemingly influenced by Le Corbusier's famous statement in L'Esprit Nouveau that a "house is a machine for living", the French essayist PaulValéry called a book a "machine for reading" (machine á lire), ${ }^{4.12}$ writing that there are two virtues of a book: It can be read from word to word and

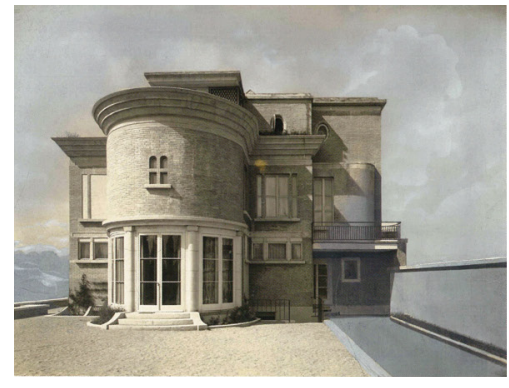

fig. 4.VI. Manipulated photograph of the Villa Schwob, as published in L'Esprit Nouveau 6 (1921).

Note the over-painted area at bottom right obscuring the garden pergola.

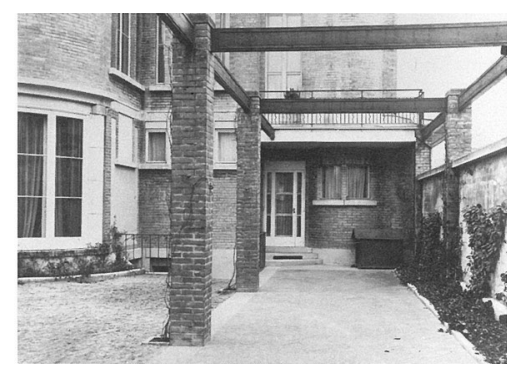

fig. 4.VII. Villa Schwob, detail of the pergola. Original photograph (c.1920).

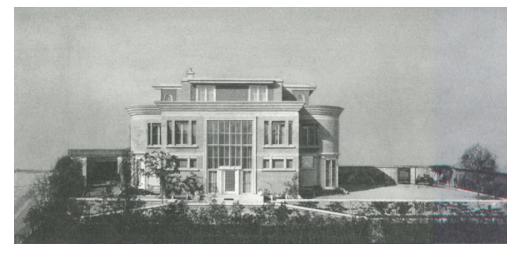

fig. 4.VIII. Manipulated photograph of the Villa Schwob, as published in L'Esprit Nouveau 6 (1921).

Note the lack of site context.

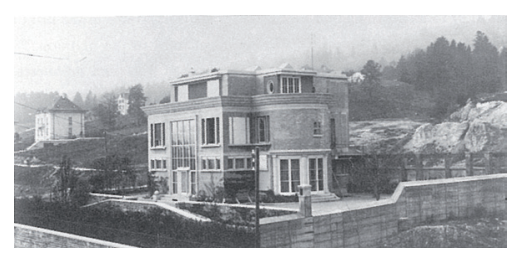

fig. 4.IX. Villa Schwob, showing hillside site context and neighbouring houses. Original photograph (c.1920).

4.11. Publicity brochure for Vers une architecture. Fondation Le Corbusier, shelfmark B2 (15) (Quoted in Colomina, 1994, p. 119)

4.12. Paul Valéry, "Les deux vertus d'unlivre" (1926), ArtsetMétierGraphiques 12 (14 September, 1927): 3-8. (Quoted in Boyer, 2011, p. 30) 
4.13. “In LeCorbusier's books, images are not used to 'illustrate' the written text; rather they construct the text"(Colomina, 1994, p.119) (See also p.148).

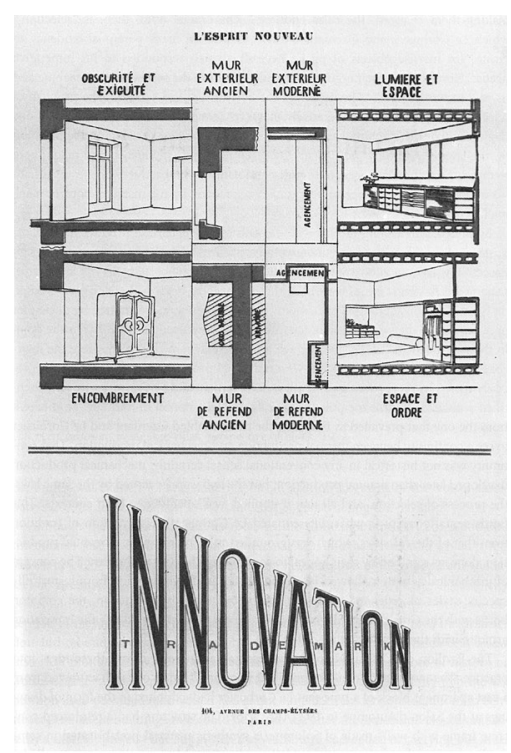

fig. 4.X. Advertisement for the Innovation luggage company, featuring an architectural drawing by Le Corbusier. L'Esprit Nouveau 20 (1924). line to line, a linear progression establishing a chain of mental reactions in the reader. But a page is also an image to be seen, allowing an immediate and simultaneous gaze to run over the arrangement of images and words. In L'Esprit Nouveau, Le Corbusier retrieves this analogy, and mixes these virtues. He encourages us to 'read' his images and 'look' at his texts.

Through the relation, not only of images with other images, but of images with certain words and texts, Le Corbusier engaged with the imaginative potential of his readers to form associations of ideas and interpretations, and therefore stimulate new ways of seeing. Unlike the "representational" use of imagery in traditional books, where the image is subordinate and passively consistent with the written text, Le Corbusier's arguments are created in terms of the never-resolved tensions he constructs between image and text. ${ }^{4}$. Meaning in these situations arises from a conceptual collision of these two elements: a "collision of fragments corresponding to the experience of culture in the media. Thus Le Corbusier's work in L'Esprit Nouveau becomes a critical comment on the conditions of culture in our time"(Colomina, 1994, p. 128), and reveals the abstract "media space" of the production of architectural meaning.

\section{Publicity and self-promotion}

There are perhaps several reasons why Le Corbusier engaged in writing, editing, and publishing print media such as L'Esprit Nouveau. As I have argued, Le Corbusier used this media material as a creative tool in his architectural production, using it in an attempt to construct certain ideas and concepts. But he also used his print media as a means of self-promotion. The use of modern advertising techniques such as juxtaposition, appropriated imagery, and image manipulation in Le Corbusier's editorial strategies differentiates the journal L'Esprit Nouveau from other art periodicals of the day. As Colomina writes, "what is radically different in L'Esprit Nouveau is the blurring of limits between the content of the magazine and publicity"(Colomina, 1988, p.237). Whereas art periodicals published since the end of the $19^{\text {th }}$ century commonly contained an advertising section at the rear, in L'Esprit Nouveau Le Corbusier integrated advertising features into the fabric of his articles, encouraging us to make narrative links between editorial content and advertorial display. Part of the strategy behind this radical reorganisation was to better promote his own ideas on architecture, urbanism, and the arts. His guiding concept of Purism aimed for a synthesis of all creative activities and their integration with the processes of industrialised everyday life, and the format and arrangement of the journal can be seen as an attempt at achieving this.

Le Corbusier attempted to convince, persuade, and re-educate his readers on the validity of his new 'language' of modern architecture, using print 
media to defend his position and overcome criticism or other obstacles to the acceptance of his ideas. He used it to give witness to his existence, his creativity, and as a record of his attempted synthesis of the arts. Preparing for his participation in the Exposition Internationale des Arts Décoratifs in 1925, he utilised the review to publicise his arguments and promote the name Le Corbusier (the persona he would use exclusively from 1925 for all architectural matters), publishing images of his own building designs, which he often used to illustrate articles expounding his own theories on architecture and modern life (Boyer, 20I I, p. 275). ${ }^{4.14}$ Sometimes an image of built work by the architect was placed in the advertisement of a company that had been involved in its construction. 4.15 And at other times, sometimes Le Corbusier inserted images of his unbuilt or theoretical projects into such advertisements, conferring a degree of legitimacy on them beyond that which publishing already conferred. ${ }^{4.16}$

In borrowing the rhetoric and persuasive techniques of modern advertising for his own theoretical arguments, and through his manipulation of actual advertisements to incorporate his own vision, Le Corbusier blurred the limits between text and publicity. He did so deliberately and consciously, with the intent to persuade the audience of his ideas in the most effective way possible. “L'Esprit Nouveau,' he announced in a publicity brochure sent to industrialists, "is read calmly. You surprise your client into calmness, far from business, and he listens to you because he doesn't know you are going to solicit him."(quoted in Colomina, 1994, p. 185) The blurring of limits between publicity and content in L'Esprit Nouveau was effective not only for the advertised products, but also for the dissemination of the review's theories. $^{4.17}$

\section{Print media: a space of architectural production}

The way Le Corbusier used the techniques of modern advertising to advance his architectural ideas suggests that he treated print media as more than just a 'reflective' medium, in both the visual and contemplative senses, for presenting reality and representing his work. ${ }^{4.18}$ Instead, I propose along with several architectural historians, that he used print media as a new space of production, the "media space of architecture".

Beatriz Colomina's analysis on the place of mass media in early modernism is useful in regards to this idea.Through examining the place of media in Le Corbusier's work Colomina identifies his understanding of the media not only as a medium for the cultural diffusion of something previously existing but also as a context of production with its own autonomy (Colomina, 1994, p. 104). Christine Boyer, in her book on Le Corbusier's writings, would also seem to agree with this analysis: Boyer argues that the fifty or so books Le Corbusier wrote and assembled, as well as the outpouring of
4.14. The line between publicity and self-propaganda is a fine one. The architectural historian M. Christine Boyer contends that L'Esprit Nouveau was a product of wartime propaganda, writing that "though the devastation of [the First World] war never appeared in its pages...Ozenfant and Jeanneret, along with other contributors to the magazine, were steeped in the nationalistic and propagandistic jargon of wartime and postwar France" (Boyer, 2011, p. 272). She identifies certain key words (such as "precision", "purity", and "order", "equilibrium" and "harmony", "utility", "efficiency" and "the elegant solution", "universalism", and "collectivity") as "force-words", ideologically-loaded terms repeated again and again as the foundation for Le Corbusier's claim for the new post-war order required by a society of mass-production culture (Boyer, 2011, pp. 39, 272).

4.15. For example, advertisements in Almanach de l'architecture moderne (1925) for the companies Summer and Eubolithfeature photographs of LeCorbusier's Pavillion de I'Esprit Nouveau.

4.16. Le Corbusier's project of the Immeubles-Villas is but one example of this: The image in the Almanach text and in the accompanying advertisement is the same. The advertising context conflates the realm of ideas with that of built reality, especially since the Immeubles-Villas do not actually exist.

4.17. Colomina argues that this lack of separation between theadvertising and editorial content meant that every time readers of L'Esprit Nouveau were confronted in another context with, for example, a Roneó advertisement, they might associate it with Le Corbusier's ideas (Colomina, 1994, p. 192).

4.18. Le Corbusier's engagement with print media as a creative practice could also be attributed to the difficulties he encountered in his early architectural career (practicing as Charles-Èdouard Jeanneret) in Switzerland. Not having much success as an architect in his native country, Jeanneret moved to Paris and started a new architectural career (under the adopted name Le Corbusier), closely intertwined with his media activities. 
4.19. Expressing the analogy he saw between page layout and architecture, Le Corbusier eventually extended his definition of the word 'architecture' to cover "the art of building [as well as] the typographical art of newspapers, periodicals and books" (Corbusier, 1954, p. 9). Le Corbusier seems to have treated his print material as extensions of the visual and intellectual field of his architecture, architectural historian Catherine de Smet suggesting that Le Corbusier's engagement with print media thus encouraged a constant back-and-forth movement in his work between textual space and visual perception (de Smet, 2005, p. 7). letters, notebooks, and articles he committed to pen and paper, should be considered as creative endeavours with a direct relationship to his architecture and artistic expressions (Boyer, 20I I, p. 23).

In manipulating the images he selected for use in L'Esprit Nouveau, Le Corbusier seems to make a special distinction between the 'real', physical space which a visitor might occupy in his projects, and the space of the page (media representation): he is not concerned that the latter correspond directly with the former. As Colomina writes, "When [the]...built architecture piece enters the two-dimensional space of the printed page it returns to the realm of ideas. The function of photography is not to reflect, in a mirror image, architecture as it happens to be built. Construction is a significant moment in the process, but by no means its end product. Photography and layout construct another architecture in the space of the page" (Colomina, 1994, pp. II4-I I8). In the conventional processes of architectural production, conception, execution, and reproduction are separate, consecutive moments. But in the elliptical course of Le Corbusier's creative process this hierarchy is completely subverted, with conception of architectural ideas and their reproduction feeding off and crossing each other. This has significant implications for the practice of architecture in modern, media-saturated society. If the physical reality of architecture is a separate entity from that created via the media, why concern oneself with trying to achieve the complex reality of construction when concerned with an architecture of meaning?

For Le Corbusier, architecture is a conceptual matter to be resolved in the 'purity' of the realm of ideas (von Moos, 1979, p.299). When translated into built form, it gets mixed up in the world of phenomena and necessarily loses its purity. Yet significantly, that when this same built architecture enters the two-dimensional space of the page it returns to the realm of ideas (Colomina, 1994, p. I 14). Le Corbusier considered the function of media representation to not simply be a static, impartial reflection, a mirror image, of architecture as it happens to be built, but a further opportunity for an architect to promote their ideas. Construction was a significant moment in the architectural process, but by no means its end product. Photography and layout constructed another architecture in the space of the page. 4.19

The media space of architecture has an important role to play in the development of architectural thought. Colomina claims that there is a trend in architectural history which demonstrates that periods where architects get less 'real' built project work are periods of great theoretical advancement for the discipline, pointing to the "provocative" architectural theories developing during the economic slumps of the 1920s (when L'Esprit Nouveau was published) and also later in the 1960s and '70s (Weder, 2007, p. 13). She sees print media as inseparable from the practice of architecture: 
"Publications are one of the most important sites in which architecture is produced" (Weder, 2007, p. 14), and the case of Le Corbusier and the productive relationship he established with the publication of L'Esprit Nouveau would seem to bear witness to this statement. . $^{4.20}$

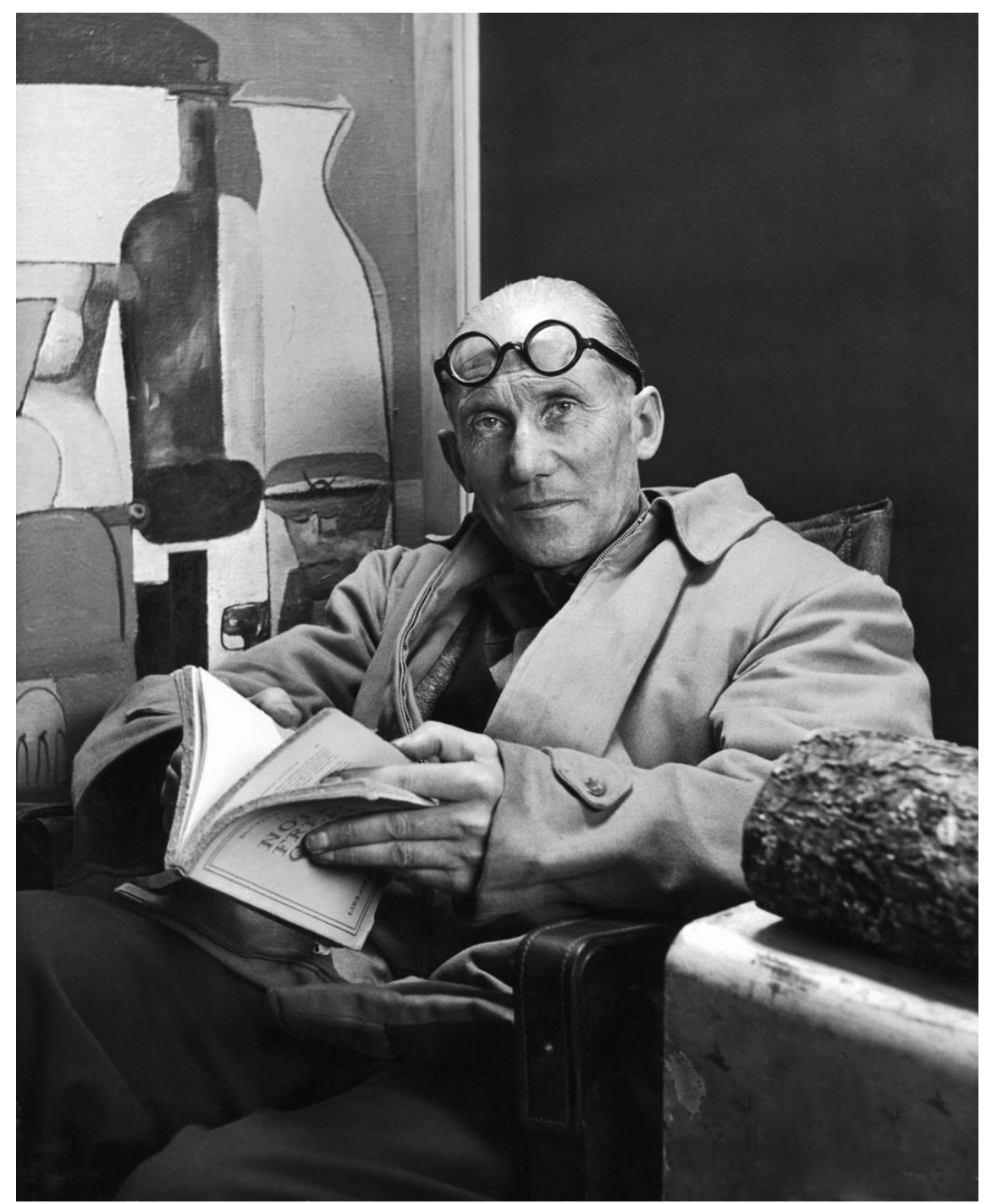

4.20.

L'Esprit Nouveau, a printed media product, was used by Le Corbusier to work out the modern aesthetic he would promote for the rest of his career: "cubes of white raised on pilotis, walls punctuated with horizontal strips of industrial windows or la fenêtre en longuer, flat roofs, and roof gardens - although its codification into five points of modern architecture would not appear until the end of the 1920s" (Boyer, 2011, p. 276).

fig. 4.XI. Le Corbusier reading at home in Paris, 1946.

The buildings designed by this self-described 'man of letters' number less than sixty, whereas he produced over fifty architectural books.

These numbers alone seem to reveal the important place print media occupied in Le Corbusier's architectural production. 


\section{Conclusion}

In examining Le Corbusier's architectural thinking through his publishing activities in the journal L'Esprit Nouveau, the focus of his interest becomes clear: the development of a new architecture related to contemporary conditions of production. As this chapter has discussed, this involved an embracing of the mechanisms that sustained that production: advertising, mass media, and publicity. Le Corbusier's employment of print media techniques to promote his architectural ideas shows his identification of an important conceptual shift regarding the function of culture and the perception of the exterior world by the modern individual in the very existence of the printed media. The media space of architecture is revealed as a highly productive realm for the exploration of architectural meaning by individuals, including architects. Springing partly from the invisible connection bridging image and text on the page, and partly from the abstract space of associative imagination in reader's minds, the media space of architecture appears as a critical, crucial influence on architectural meaning. With the potential to significantly shift the role of the architect, this space may operate independently from physically-constructed built form, in ways which recognise the culturally-attributed meanings of people as the essence of architectural production. 


\section{conclusion summary}

- Publishing is the public communication of ideas, interpretations.

- The activity of publishing provides access to the media space of architecture, which is productive for promoting architectural ideas.

- Published representations of architecture are constructed images with a complex relation to the physical reality of the views they present.

- Therefore publishing can be seen as an alternative way of practicing architecture, in parallel or in opposition to construction of built forms. 
Hans Bernouilli: 'Der Pavillon dec
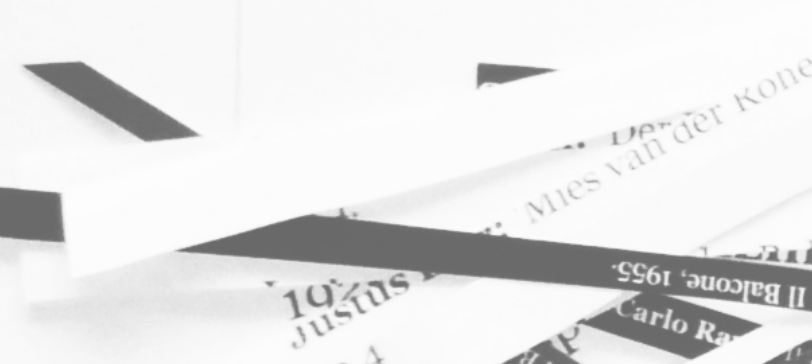

\section{ter.}

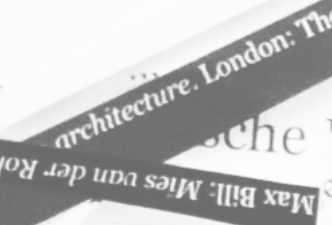

al:

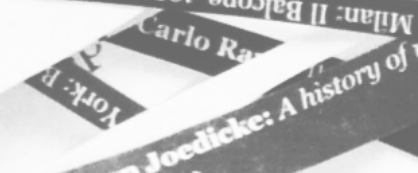

Harber

eutscher "

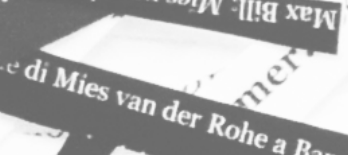

nspavillon a

auf der Internat 1110

ano Zeti: Storia dell architettura moderna. Turin: Einaudi, 1950.
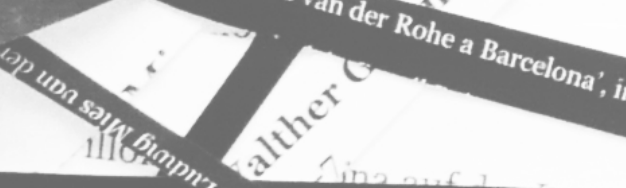
- iv
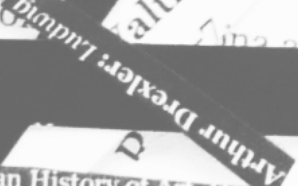

Talbot Hamlin: (ed.) Forms and functions
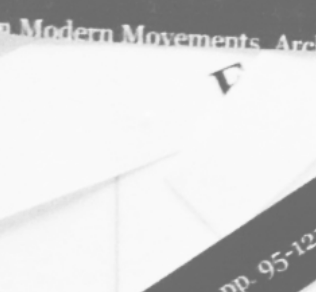

r
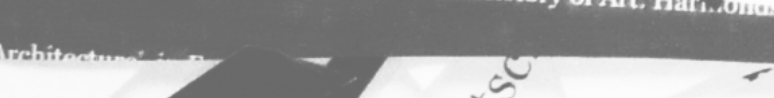


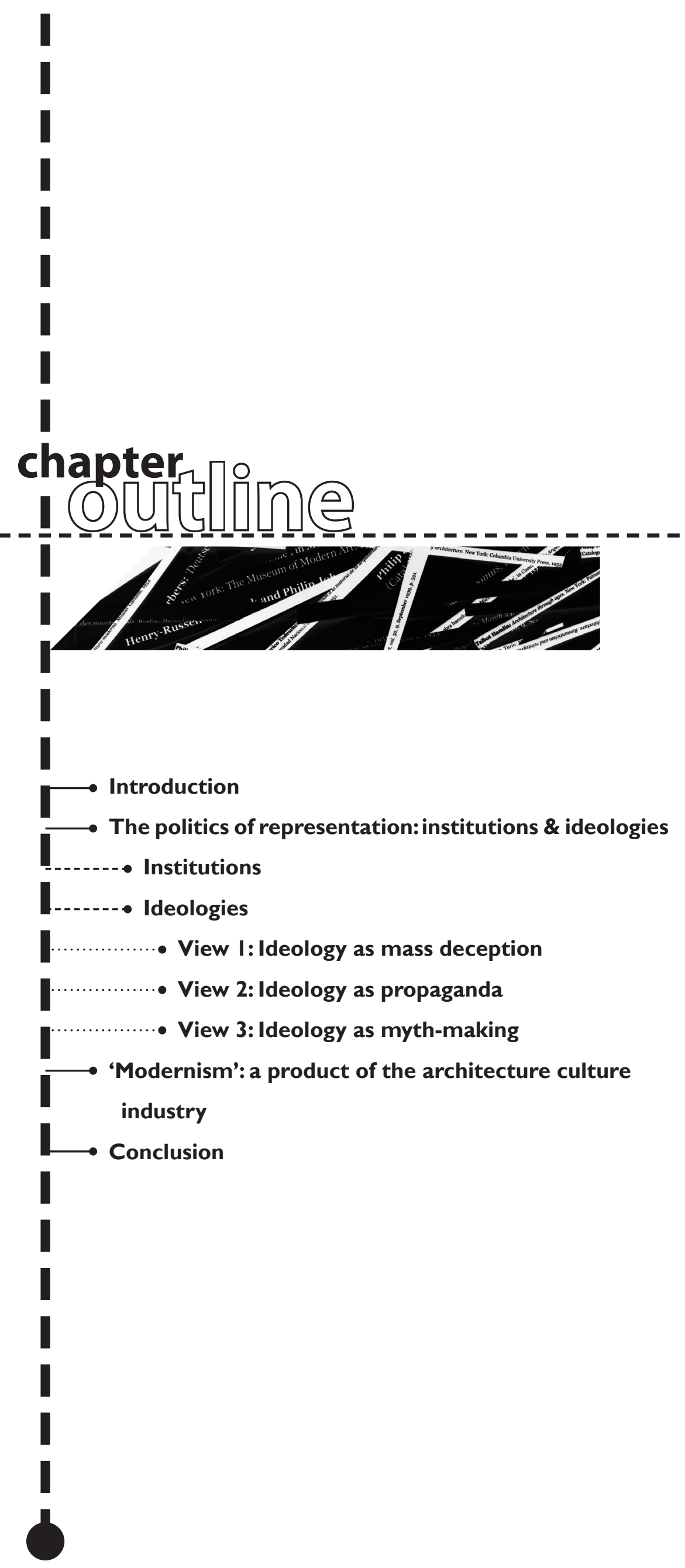




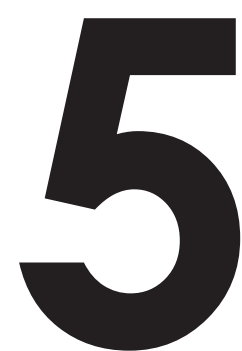

CHAPTER

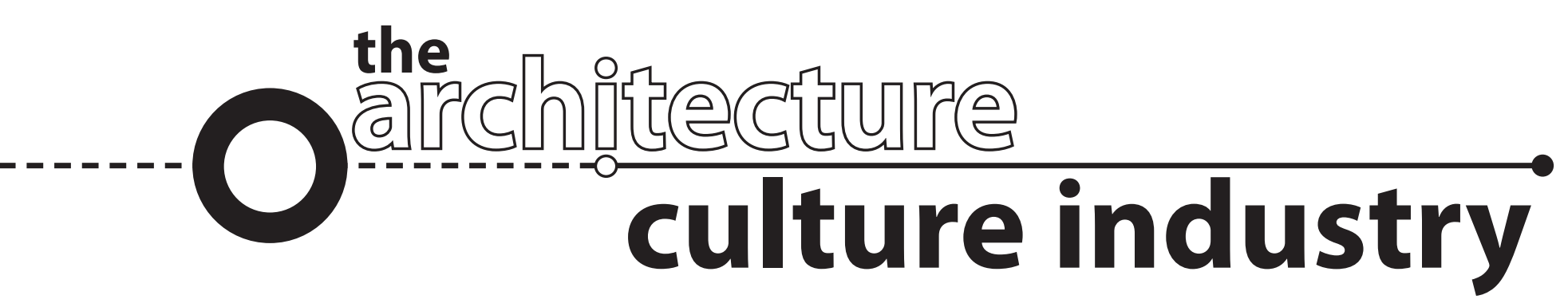

\section{Introduction}

The discussion of this chapter completes - along with meaning (Chapter 2) and architectural representation (Chapter 3) - the trio of themes establishing the context of this research. With the argument of my thesis taking architecture as a form of cultural production, I turn now to an examination of the concept of the 'architecture culture industry', a theoretical position helping to organise and understand some of the complex factors involved in the cultural practice of architecture. The term 'culture industry' (first coined by critical theorists Max Horkheimer \& Theodor Adorno) refers to the production of commodities (images, objects, built forms, etc.) as the principle of a specific form of cultural production. ${ }^{5.1}$ It is a relational concept describing the way people interact with the vast field of commodified culture. Conceived as an intersection of so-called institutions and their ideologies (mass deception, propaganda and myth-making), the idea of the

5.1. See Max Horkheimer and Theodor Adorno. Dialectic of Enlightenment: Philosophical fragments. (Stanford, CA: Stanford University Press, 2002) (first published in German, 1944). plicated reasons behind what, why, and how things (including buildings and ideas) are presented to the public in the media. It also holds that cultural production is inherently tied to politics, institutions utilising ideologies to influence people's interpretation of cultural products and thereby maintain positions of social power. This idea is examined through the architecture culture industry's 'packaging' of early twentieth century architectural history under the label "modernism". 
5.2. For example, the institutions of photography are defined and brought into being by clear legal and economic determinants: privacy laws, copyright, saleability of the image, film-developing equipment, etc.

5.3. Ideologies may be considered as bodies of beliefs, values, or associations informing people's attribution of meaning to cultural products. Ideologies of photography, for example, emergeat the intersection of other ideologies of art, photojournalism, modern image-making, the gaze, etc, and are most evidently constituted in photography by images idealising their subjects (Watney, 1999, pp. 150-151).
5.4. For example, the institutions of photography dictate the type, format and even the brand of film stock to use in a camera. They influence the subject matter, composition and framing of the photographic scene and once the film is developed and printed, they influence where the photographs will be displayed (e.g. in an art gallery, pinned to someone's bedroom wall, or reproduced in a magazine), how it is shown (e.g. framed under glass, hung on white walls; or closely cropped and digitally manipulated to form the background for a print advertisement), as well as how the audience is to look at it (e.g. in a state of reverent contemplation of artistic merit; or in a manner conducive to the commercial message of the advertisement).

\section{The politics of representation: institutions \& ideologies}

The concept of cultural 'institutions' represents the organised elements of society (which may be influential individuals or groups of people) concerned with particular areas or aspects of cultural production. In the field of mainstream architecture, those cultural bodies which promote particular architectural ideas (such as published architectural theorists, magazine editors, or even civic urban design panels) can each be labelled an 'institution'. In an essay on photography, the art historian Simon Watney identifies two ways in which the influence of institutions can be felt. First, certain institutions affect the production of cultural products, generating particular types of cultural practice. ${ }^{5.2}$ Second, institutions produce and reproduce ideologies, 'frames of thinking' which define and limit thought. These are based on values and are often intent on realising specific interests, achieving and exercising social power. Such frames can and often do influence people's interpretations of cultural products. ${ }^{5.3}$ To paraphrase the artist Victor Burgin, we need to consider not only the representation of politics, but also the politics of representation.

\section{Institutions}

An institution can be defined as the normal term for any organised element of society (Williams, 198I, p. 169). As Watney points out, we cannot study the way people attribute cultural products with meaning without addressing the institutional structures acting on them and the way these institutions use these mediums (Watney, 1999, p. 143). To do so would be to over-emphasise the conditions surrounding its reception over consideration of its production, and prevent us from understanding the uneven, shifting, and highly unstable power of cultural mediums that results from each individual's unique interpretation of the product.

In this view, the institutions of media tend to 'reveal' certain ideas as socalled 'truths'. The technology of media is employed to inscribe these institutional 'approved interpretations' into the very appearance of the world, exploiting the uninformed public's general acceptance of media products as 'true' reflections of reality. Subscribing mostly to romantic hermeneutical understandings of meaning, mainstream institutions of the architecture culture industry suggest what people should look for in its products, and how to interpret them..$^{5.4}$ Crucially, the institutional uses of photography often make us think photographs are 'truthful' pictures, not photographic techniques in themselves..$^{5.5}$

The institutions comprising the culture industry ensure a self-preserving social order.Their self-appointment as 'arbiters' of meaning gives them the ability to establish, maintain and advance their positions of social power.Allocating more weight to the ideas (sympathetic to institutional agendas) of 
certain people, cultural institutions often rely on 'experts', rarefying meaning and contributing to the cult of 'fact' and 'objectivity'. The institutions of (architectural) media promote themselves as passive presenters and transferors of information, obscuring the reality of media production being loaded with intensely subjective conditions. In 'buying into' the unquestioned authority of institutions of the architecture culture industry, people submit to relationships of dominant social power over them, revealing all acts of architectural media (cultural) production as political acts to some extent. The significance of the concept of a "politics of representation" lies in the challenging of cultural practices as merely reflective of, and subservient to, political struggles taking place in other (non-discursive) environments.

\section{Ideologies}

Culture as an industry allows institutions of media to fabricate ideologies, frames of meaning. In simple sociological terms, an ideology is a belief system, a practice of signification in which people give meanings to things in certain ways. It applies meanings to its products, and presents these artefacts to consumers as if these meanings emanate from their very core. Through this 'reification' of objects, the culture industry can influence the way people think about things, providing them with systems of thoughtassociation and steering their interpretations in particular directions. Such ideologically-driven meanings are often very limited in scope and rely on manipulative techniques to stimulate people to think about and appreciate cultural products in specific ways, as discussed in Chapter 4. Many authors writing on the ideologies of the culture industry seem to align ideologies with manipulation of people's ability to interpret cultural products. The views of different authors can be arranged according the effect level of this manipulation, ranging from a view of general 'mass deception'; a more targeted view of ideology as 'propaganda'; and down to a specific view of ideology as constructing 'myths' about aspects of each institution of the culture industry. These three understandings of ideology will now be examined:

\section{View I: Ideology as mass deception}

The first view of ideology sees it as a broad-ranging influence affecting the culture industry at the high level of 'civilisation'. The book Dialectic of Enlightenment (first published 1944), by the philosopher-sociologists Max Horkheimer and Theodor Adorno, has become a core text in the area of Critical Theory, critiquing Western civilisation as a whole. The authors argue in a chapter on the culture industry that an analysis of mass media shows the "regression of enlightenment to ideology", graphically expressed in mediums such as film and radio. They saw the powers controlling media as manipulating its output to present its acts of "mass deception" as "enlightenment". 5.6
5.5 An architectural photograph provides us with a conflict of perception: We look at the image and our gaze tries to pierce the surface of the photo, attempting to read the scene as if we were standing in the location of the camera itself. We project ourselves into the depicted scene, and our mind attempts to assemble all the spatial information available into a 'real' arrangement. However, this (ideologicallystimulated) response forgets or ignores the photograph as a constructed object in itself. The way the view is framed, angled, the lighting, the arrangement of the furniture, every element of the scene has the potential to have been considered, altered and manipulated from how it would normally be perceived in real life. Technical aspects (created and controlled by institutions), such as depth of field, exposure, and focus can in themselves and together dramatically shift the way a scene looks. Combined with more artificial alterations to the photo after it has been taken (such as cropping, colour manipulation, airbrushing or overpainting to mask undesirable elements), institutionally-directed manipulations may further distance the photographic scene from the on-location scene.

5.6. A note on Horkheimer and Adorno: While Dialectic of Enlightenment has been highly influential in 20th century philosophy, sociology, culture, and politics, inspiring especially the broad-ranging cultural reforms of the 1960s and '70s "New Left", its core argument cannot be isolated from the historical circumstances in which the work was originally produced, namely, the rise of National Socialism in 1930s-40s Germany, state capitalism, and mass culture as entirely new forms of social domination. However, while the more overtly political views of Horkheimer and Adorno must be understood as a reaction to the heavyhanded manipulation of mass media by the Nazi state, their arguments are important in demonstrating the underlying relationship between culture and politics, perhaps even going so far as to propose politics itself as a form of cultural production. 


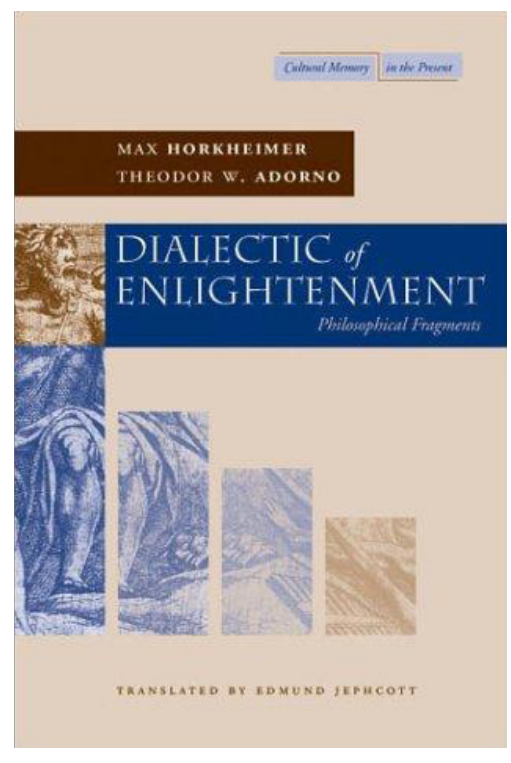

fig. 5.I. Max Horkheimer \& Theodor Adorno, Dialectic of Enlightenment, (first published 1944).

Cover of the 2002 edition, Stanford University Press.

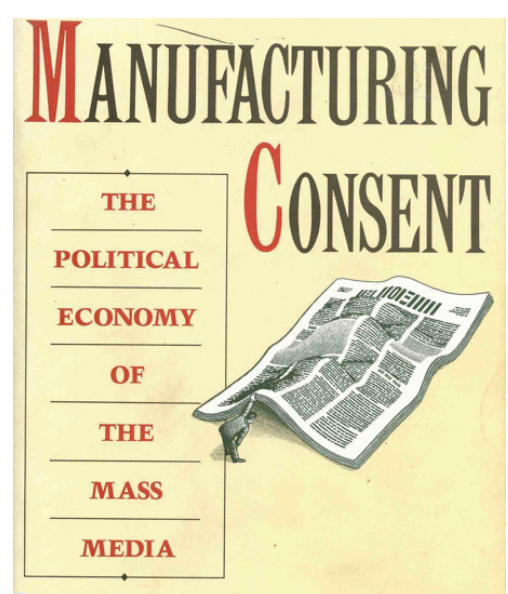

\section{EDWARD S. HERMAN AND NOAM CHOMSKY}

fig. 5.Il. Edward Herman \& Noam Chomsky, Manufacturing Consent. Cover, Pantheon Books, 1988.
Horkheimer and Adorno's view of the culture industry is of a unified and homogenised entity, a cultural mechanism producing "dreamless art", in the form of easily digestible, already-classified material to fulfil the public's "dreamy idealism" for free, rational thought or 'enlightenment' (Horkheimer \& Adorno, 2002, p.98). They saw the culture industry to produce media material in cyclical patterns of content, using 'special experts' to imprint a state of mind repressing the imaginations of the audience: an ideology effecting mass deception. They write, "the whole world is passed through the filter of the culture industry", media being focussed on mechanically duplicating the real world; or rather, the real world is considered an extension of the 'world' the media creates via its processes (Horkheimer \& Adorno, 2002, p.99). Essentially, the authors argue that via its secret ideologies of mass deception, the media substitutes a highly mediated and manipulated simulacrum of reality in place of a self-enlightened and self-aware one.

\section{View 2: Ideology as propaganda}

A second, related, view of ideology sees it as a more targeted policy of manipulation, termed 'propaganda'. The conception of cultural influence put forward by Herman \& Chomsky in their book Manufacturing consent: the political economy of the mass media (1988) shares similarities with Horkheimer \& Adorno's understanding. Both see the culture industry as making use of several 'filters' to implement a "propaganda model" of mass media, based on these authors' belief that the culture industry exists "to mobilize support for the special interests that dominate the state and private activity, and that their choices, emphases, and omissions can often be understood best, and sometimes with striking clarity and insight, by analysing them in such terms" (Herman \& Chomsky, 1988, p.xi).

Such media 'filters' used by the culture industry to facilitate its propaganda include its self-justification (the discounting of individual 'connoisseurship' and expert knowledge as "arrogance", while simultaneously relying on 'experts' which it approves itself), and the penalising of any opposition (The use of "flak" as a means of limiting criticism of its processes). These filters to media activity can be seen to act on mainstream architectural discourse, especially in New Zealand. For example, any public critique of architectural works is often met with rebuttals questioning the critic's authority or qualification to have such opinions. Further, serious, hard-hitting architectural critique is largely absent; perhaps due to fear of upsetting someone the author may know in New Zealand's small, closely-interconnected professional architectural communities.

Thinking about architectural media in terms of propaganda (albeit a very watered-down version of propaganda compared to the overtly proselytizing media of Horkheimer \& Adorno's 1940s Germany) is useful to reframe 
of our view of media. Instead of accepting its products as simply "reporting" the facts, it makes us consider media products in a more motive-driven 'interpreting' light: they are concerned with stimulating the production of meaning, of placing 'facts' of situation into a cultural context to achieve some sort of intended significance.

\section{View 3: Ideology as myth-making}

A third way of considering the use of tightly-focussed ideology in the culture industry is its effect of cultural myth-making, this being ideology acting on specific aspects of culture.The French cultural philosopher and semiotician, Roland Barthes, looked at cultural production in light of its myths, and his work is considered to be a key precedent of modern cultural studies. In his essay "Myth Today" (first published in French in Mythologies, 1957) he extended linguist Ferdinand de Saussure's system of sign analysis by adding a second level of meaning where signs are elevated to the level of myth. Barthes applied this 'mythological' model of meaning to a wide variety of French cultural products (including red wine, soap powders, and the sport of wrestling), in an effort to understand their ideological function in maintaining the economic and political hegemony of the bourgeoisie of his day. Barthes describes the function of ideology in this context as transforming "[the] reality of the world into an image of the world, History into Nature" (Barthes, 1999, p. 57). "What the world supplies to myth is an historical reality, defined...by the way in which men have produced or used it; and what myth gives in return is a natural image of this reality" (Barthes, 1999, P. 58). In other words, 'mythological' ideology works to 'naturalise' what is in fact humanly constructed. Myths are therefore interpretations of events by groups seeking to bolster their own cultural dominance. 'Mythology' thus becomes both the process by which these events are made to connote something beyond their overt meaning, and the study of such interpretations underscoring their ideological functions.

\section{'Modernism': a product of the architecture culture industry}

An example of the architecture culture industry's influence on architectural culture can be seen in the various packagings of architectural history of the early twentieth century into 'isms', chiefly Modernism. From the 1930s until the 1970s, mainstream architectural history was dominated by a small number of highly influential books on modern architecture that provided architects with introductions to figures, movements and themes deemed important by those writing them.Additionally, they provided ideological "narratives of epochal identity" subtly approved by the architecture culture industry through publishing and disseminating them (Mertins, 20 I I, p.5). Some of the books establishing the canon of modernism for mainstream architecture culture include Nikolaus Pevsner's Pioneers of Modern Design (1936); Sigfried Giedeon's Space, Time, and Architecture (I94I);

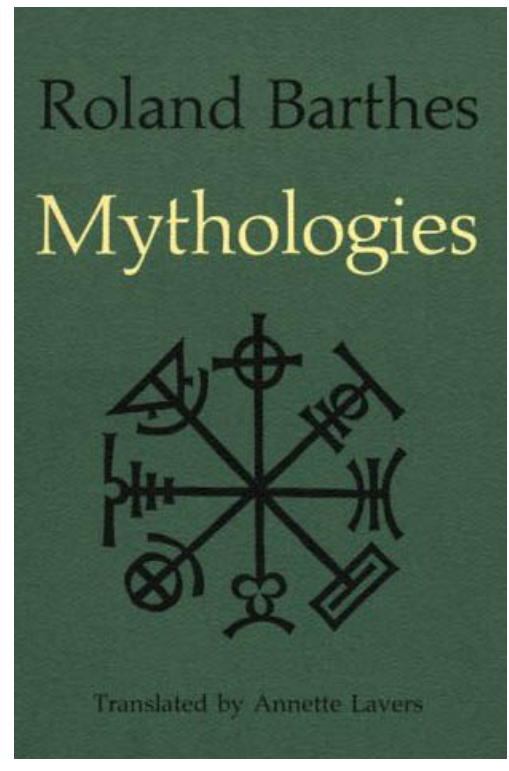

fig. 5.III. Roland Barthes, Mythologies (trans. Annette Lavers). Cover of the 1st English edition. Paladin, 1972. 
5.7.

Pevsner's book was still being read in the 1960s, although Giedion's 1941 book had supplanted much of its original impact. Gideon's much weightier and dramatic account was biased to favour certain key architects, Gideon proclaiming modernism's final fulfilment being reached only in the work of his friend, Le Corbusier. Reyner Banham was a student of both Pevsner and Gideon; while Benevolo's widely published and republished book extended many general points of Gideon's history. Given the internallinks between these influential books, the understanding they give of architecture arguably starts to become particularly homogenous and canon-like.

5.8. Such architectural historians include, among others, Joseph Rykwert (The First Moderns, 1980), Manfredo Tarfuri (The Sphere and the Labyrinth, 1980) and Kenneth Frampton (Modern Architecture: A Critical History, 1981).

5.9. The Sala O exhibit design (1933) by Giuseppe Terragni in fact comprises the second of my case studies, in Chapter 6.

5.10. Colomina's writing of the late 1980 s and early ' 90 s informed the initial beginnings of my research.
Reyner Banham's Theory and Design in the First Machine Age (1960); and Leonardo Benevolo's Storia dell'archittetura moderna (History of Modern Architecture) (1960) ${ }^{5.7}$ Although these books differed significantly in what they took to be the origins of modernism, its defining traits and pivotal figures, they may still be considered complementary in that they supported the culture industry's codification of modernism as a "monolithic construct" (Mertins, 20I I, p.6). Presenting modernism as unified historical phenomenon, influential texts such as these enhanced each other in promoting a related set of interpretations presented as facts.

From the 1980s a younger generation of historians began to offer alternate readings of modernism, introducing greater complexity and theoretical depth to the discussion of modern architecture. ${ }^{5.8}$ The 'pantheon of heroes', key figures promoted as significant to modern architecture, was expanded to include architects who had not previously fitted into the culture industry's "master narrative" of modernism's progress (such as Alvar Aalto, Erich Mendelsohn, and Giuseppe Terragni $\left.{ }^{5.9}\right)$. But these alternative histories also looked for contradictions in and contestations of the master narrative, where the myths it had channelled into obscuring its operations of power started to become unstuck. For example, Beatriz Colomina was one of the first architectural historians to focus on how the discourse of modern architecture, and modern architecture itself, was shaped by the new media of photography, film and print in the 1920 s. 5.10

The architecture culture industry's promotion of modernism as a way of packaging architectural history shows that the production of architecture depends on its disciplinary apparatus, textuality and context: the architecture culture industry. Every new cultural product is composed in some way by this industry, and is, in turn, constitutive of it. 


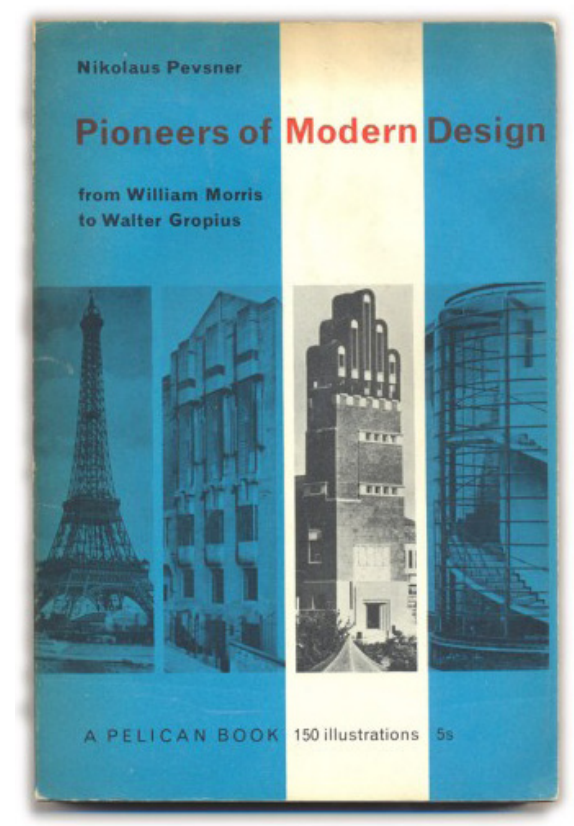

fig. 5.IV. Nikolaus Pevsner, Pioneers of Modern Design, (first published 1936). Cover of the 1961 edition, Penguin.

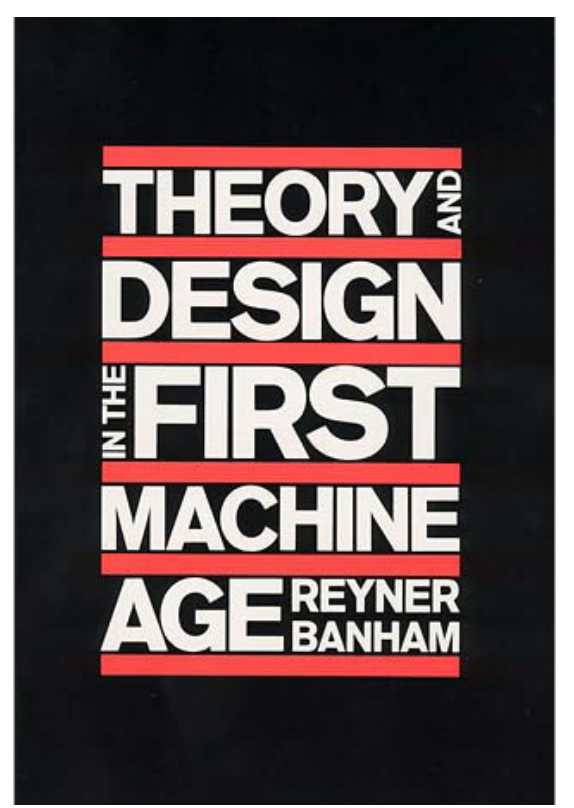

fig. 5.VI. Reyner Banham, Theory and design in the first machine age, (first published 1960). Cover of the 1980 edition, MIT Press.

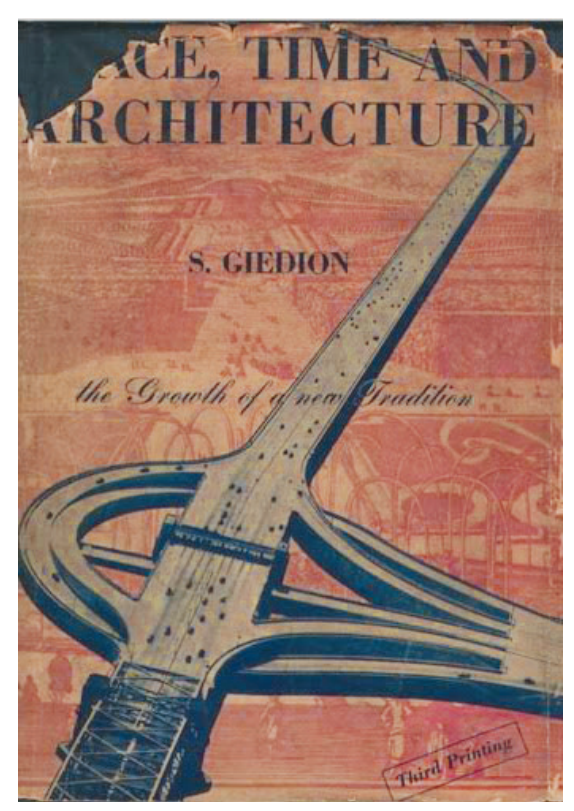

fig. 5.VII. Sigfried Giedion, Space, Time and Architecture, (first published 1941).

Cover of the 1943 edition, Harvard University Press.
Modern Architecture (first published in Italian 1960).

Cover of the 1977 edition, MIT Press. 


\section{Conclusion}

Considering products of media as relating to the concept of the 'architecture culture industry' is useful in understanding the various factors influencing the cultural environment in which architecture is produced, represented, discussed and interpreted. Discussing the institutions and ideologies which comprise this culture industry allows us to analyse the way they interact and affect people's interpretations of its products.

Considering the ideological nature of mass media is important to dispel the widely-accepted 'myth' of the neutrality of media: the general public tend to read books, articles and magazines as if they were truth, without questioning what is being presented to them, how it is being presented to them, and what is not being presented to them. The difference between the physical reality of the situation or object and how it is portrayed or presented in the media can be powerfully significant. If we accept the photographic scene as a true reflection of reality, we blatantly buy into a mythical version of reality, giving the creators of this reality (the architectural mass-media/culture industry) extraordinary social power to shape our world view.

However, in being aware of the nature of the architecture culture industry, we can mitigate the effects of the acts of mass deception it presents us by recognising them as such: as particular interpretations of meaning, individual fragments of our collective understanding of the world. The significance of industry-produced media representations in the study of architecture is their special capacity to embody categories of knowledge which are simultaneously productive (in that they stimulate, incite, and encourage their own continued reproduction) and coercive (in being used to influence meanings outside of themselves): “...fragments of ideology, activated by mechanisms of fantasy and desire within a fragmentary history of images” (Watney, I999, p. I59). 


\section{5.}

- Ideologies of cultural institutions influence our interpretations of cultural products.

- They do this to promote specific ideas/agendas.

- One of these main agendas is the ideology of media being "true" or "objective", which works to mask the way they manipulate or influence our interpretations.

- Because architects produce cultural products, we are part of our own institutions, and have our own ideologies which influence our work. But we also need to be aware of the other parties which act on our work once it is produced and released into culture: other institutions and their ideologies who use the work of architects for their own agendas. 


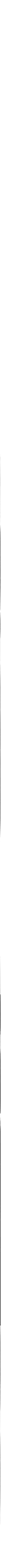


CASE STUDY

CHAPTER

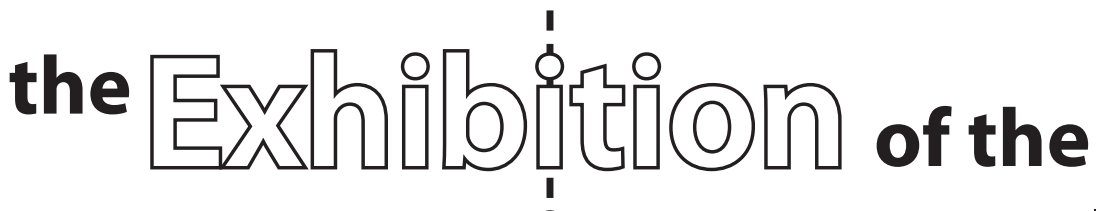

Fascist Revolution

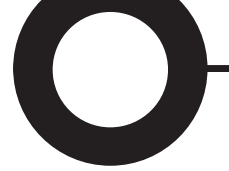

"Il Fascismo fa la storia, non la scrive."

(Fascism makes history rather than writes it)

-Benito Mussolini (quoted in De Frede, 1983, p. 122).

"The consolidation of the Fascist historic imaginary was predicated entirely on the institutionalization of a historic mode of representation at all levels of Fascist visual culture."

- Claudio Fogu (2005, p. 35), (original emphasis). 
Introduction

- A context for the Mostra

- Italian Fascism and visual culture

- The Mostra della Rivoluzione Fascista (Exhibition of the Fascist Revolution)

- The exhibition and the architecture culture industry

- Media as matter:The place of II Popolo d'Italia

- Curated collage: production of the exhibition

- “Hypervisual dynamism”: Giuseppe Terragni’s

Sala $O$ design

- 'Montage' in the production of the Sala $\mathrm{O}$

- Ideologies in the Mostra and Sala O

- The "unfortunate" question:Terragni and Fascism

- Conclusion: Lessons from Terragni and the Mostra 


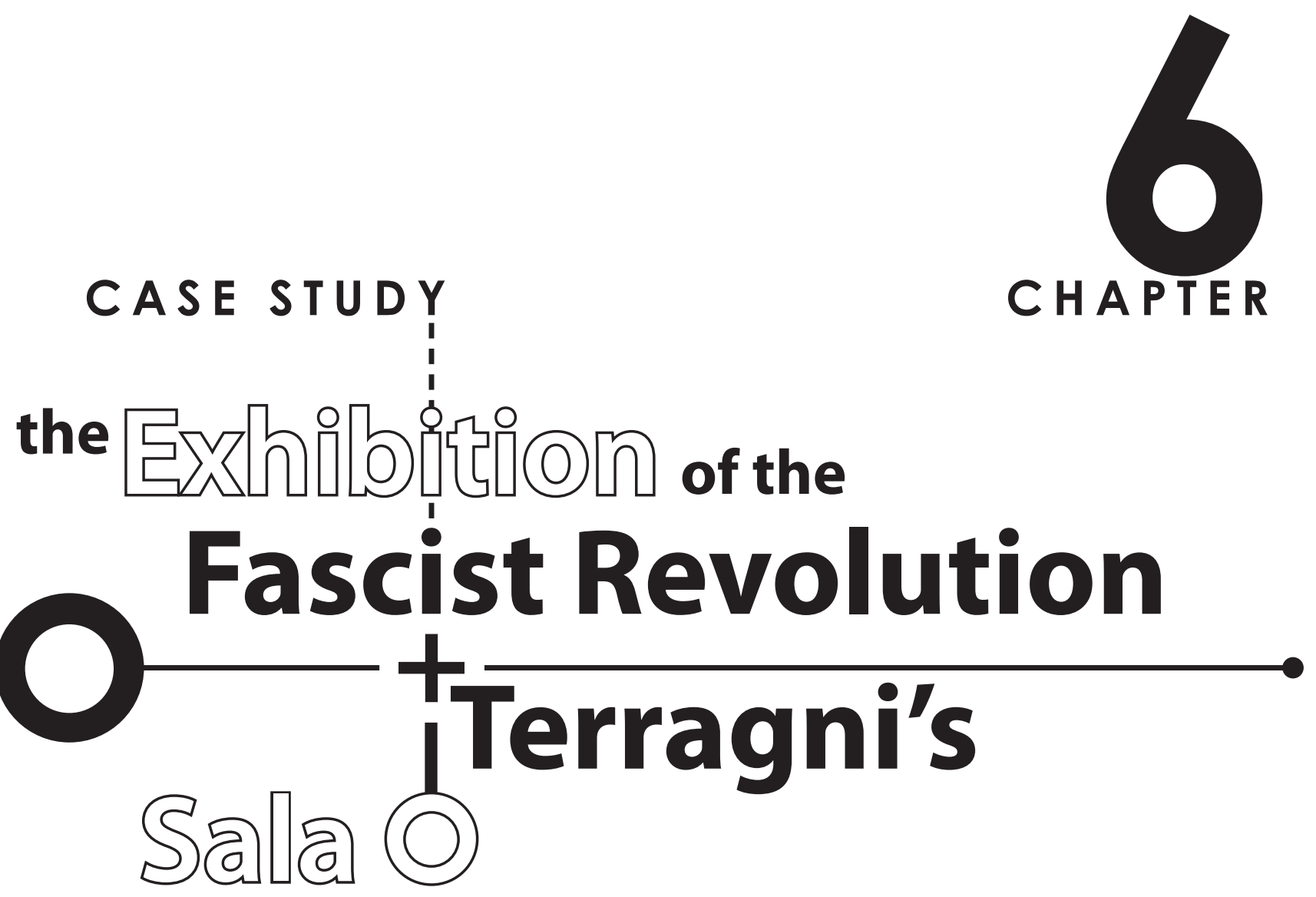

\section{Introduction}

As discussed in the previous chapter, the architecture culture industry comprises of a vast array of institutions involved in the promotion and dissemination of architecture. The ideologies which the institutions foster have a significant influence on the development of architectural meaning for individual people. People's understanding of architecture can be seen to be manipulated by the processes of the culture industry.

This chapter is a case study considering how these processes can be seen as influential factors in the design of architectural space, considered through a discussion of the 1933 Mostra della Rivoluzione Fascista (Exhibition of the Fascist Revolution) in Rome, and the design by Giuseppe Terragni of the "Sala O" exhibit within it.The Mostra della Rivoluzione Fascista, held in Rome in 1932 was the first major exhibition to illustrate the patrimony of the Fascist state. This carefully designed interior environment chronicled the most important events in the history of Fascism, from Italy's intervention in World War I to the March on Rome in 1922. Discussion of the intent of the Mostra, its production, and the particular case of the Sala $O$ exhibit as part of the overall plan helps provide an understanding of how the institutions and their cultural ideologies manifest themselves through artefacts such as the architectural design of an exhibition.

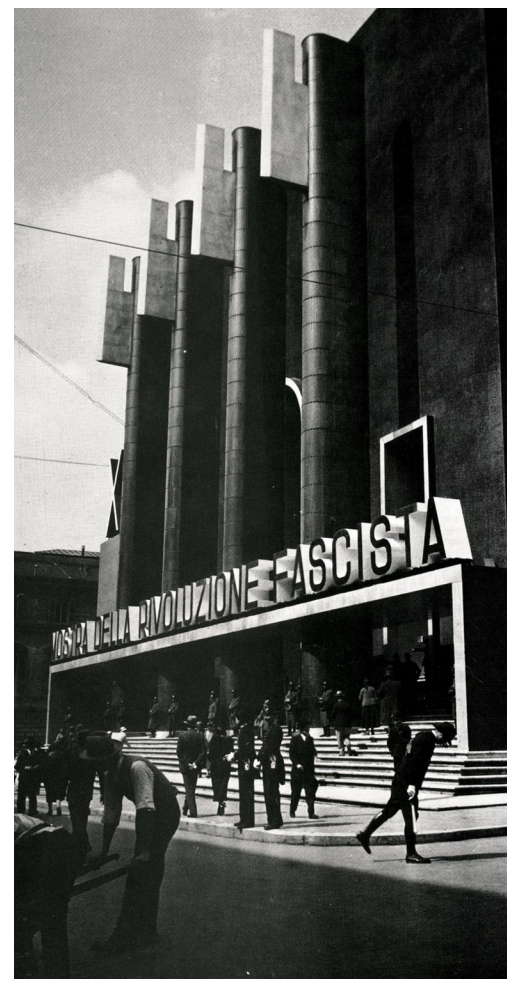

fig. 6.I. Exhibition of the Fascist Revolution, 1933.

Entrance facade designed by Adalberto Libera and Mario de Renzi. 
6.1. Quoted in Fogu 2005, p.40. With the opinion that the exhibition made revolutionary ideas "palpable", Sarfatti reveals a deterministic attitude to questions of meaning.
6.2. Key aims of the Fascists were to restore nationalist pride, re-start the economy, increase productivity with labour controls, remove economic business controls, and impose law and order. Behind these aims were cultural ideologies of Italian national imperialism, authoritarianism and the single party state (eventually manifesting itself through Mussolini's dictatorship), militarism and social interventionism.

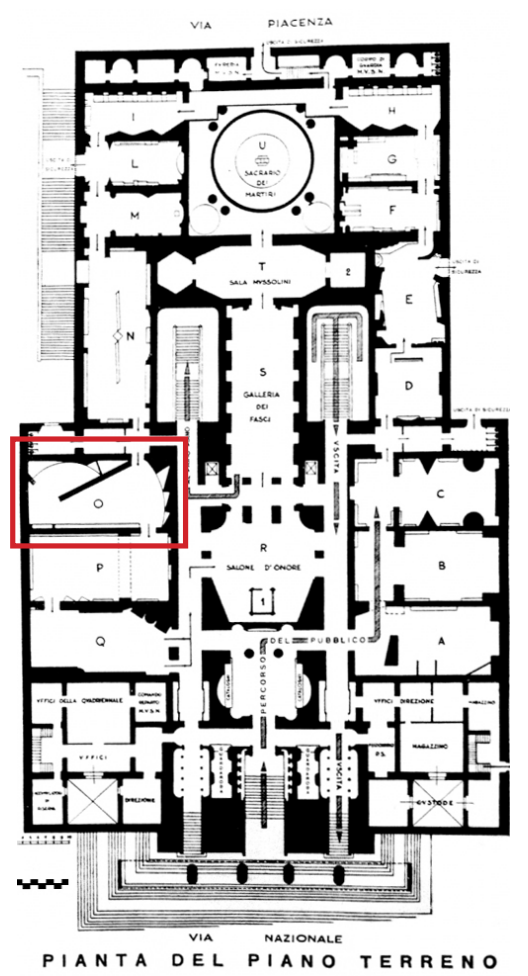

fig. 6.II. Exhibition of the Fascist Revolution, 1933. Plan of the exhibits (the Sala O is identified in red).

\section{A context for the Mostra}

"What opened in Rome is not simply 'the exhibition' (la mostra), but something greater; it is 'the demonstration' (la dimostrazione) of the Fascist Revolution. And here I employ the verb 'to demonstrate' in its literary and figurative, as well as its mathematical and physical meanings. This show makes the Revolution plain, palpable, and intelligible, while at the same time providing proof, a definitive proof of the experiment's success, by calculation and figure. It took Fascism to revolutionise Italy in depth, before such an artistically revolutionary - and at the same time so very Italian and Fascist - idea could even be conceived."

— Margherita Sarfatti, 1933.6.1

\section{Italian Fascism and visual culture}

In the fragile economic, political and social environment of 1920s Italy resulting from the traumas of the First World War, the Partito Nazionale Fascista (National Fascist Party) led by Benito Mussolini emerged as the most dominant political force in Italy. With the Fascist 'March on Rome' of 1922, Mussolini staged a coup d'état, assuming the government of Italy. Central to the regime's success in gaining power and attempts towards achieving its revolutionary aims $\mathrm{s}^{6.2}$ was its conscious engagement with institutions and processes of cultural production. The Fascist regime exploited the power of the visual at every turn, in public spectacles, theatre, cinema and photography, as well as in built architecture.A distinctive visual culture exploiting echoes of Italy's historic roots as the centre of the Roman Empire, and its synthesis with contemporary concepts of modernity was an important tool employed by the Fascists in their attempt to legitimise their regime and promote their political and social ideologies. Exhibitions, too, were used to powerful effect by the Fascists, as 'media events' created by the intersection of art, architecture, performance and propaganda.

\section{The Mostra della Rivoluzione Fascista (Exhibition of the Fascist Revolution)}

The Exhibition of the Fascist Revolution (the Mostra) took place in Rome for several months during 1933, as part of the celebrations of the tenth anniversary of the Fascist March on Rome. Installed in the Palazzo delle Esposizioni in Rome, the exhibition was divided into two sections. The first was a documentary-chronological section in the galleries around the perimeter of the Palazzo's plan. Fifteen rooms, (labelled A - Q) illustrated the revolution from the foundation of Mussolini's newspaper II Popolo d'Italia (November 1914) to the climactic historic event of the March on Rome (October 28, 1922). The second was a central non-chronological section, composed of four larger rooms (labelled $R-U$ ) dedicated to ceremonial themes of honour, fascist martyrdom, and the explicit symbolism of Fascist ideology. The rooms were designed individually by artists and architects from diverse backgrounds and movements, but were linked by a common 
approach to the exhibition material of print media products: the concept of montage "[gave] the whole event its most exquisite and distinctive visual character" (Neppi, 1932, p. 338, cited in Stone) (my translation). The use of this media-derived technique will be addressed at a later point in this chapter.

\section{The exhibition and the architecture culture industry}

The focus on print media as the material and matter of the exhibition reveals its close ties to the architecture culture industry and the press of the day. In fact, print media material formed much of the substance of the exhibition, with Mussolini's newspaper II Popolo d'Italia being a significant subject and conceptual inspiration in the exhibition. This, along with the use of the media technique of 'montage', and the direct use of print media material in the construction of the exhibition suggests a reciprocal relationship between architecture and media as cultural products. In his essay on the role of publications in architecture, Brian McLaren has suggested that, "perhaps [this exhibition and the printed media material that accompanied it] signalled a change in the status of architecture, which meant, in the words of [Victor] Hugo, 6.3 'the human race has two books, two registers, two testaments: masonry and printing"'(McLaren, 1992, p. 103).

\section{Media as matter: The place of II Popolo d'Italia}

Described by some historians as Fascism's most successful cultural event, the exhibition combined the talents of thirty-four artists and architects, and ten storiografi (eyewitnesses/historians) who were invited to create an exhibition encouraging Italians and foreigners alike to experience and participate in the regime's representation of itself. The organisers centred the exhibition on a unique protagonist: not Mussolini in person, nor Fascism in general, but Mussolini's newspaper the Popolo d'Italia (Fogu, 2005, p. 44). "In the Popolo d'Italia the organizers correctly identified the perfect representational means to give visual form to the idea of Fascist historic agency" (Fogu, 2005, p. 44). Phrases, mottoes, and entire passages of editorials from the newspaper were reproduced in photographic or sculptural form and were plastered on the exhibition's walls and ceilings. Even the Popolo d'ltalia typeface was used for such purposes, forming an almost direct 'spatialisation' of this mass-media organ. At the same time, the original articles (in newspaper form) were displayed next to documents of the events to which they referred, underlining the documentary narrative of the exhibits. In this way, the distinctions between document (original) and commentary (interpretation) were first eliminated and then progressively inverted via architecture: in the Mostra, the original historical documents ended up functioning as interpretive commentaries to the 'spatialisation' of Mussolini's words embodied in the Popolo d'ltalia. ${ }^{6.4}$

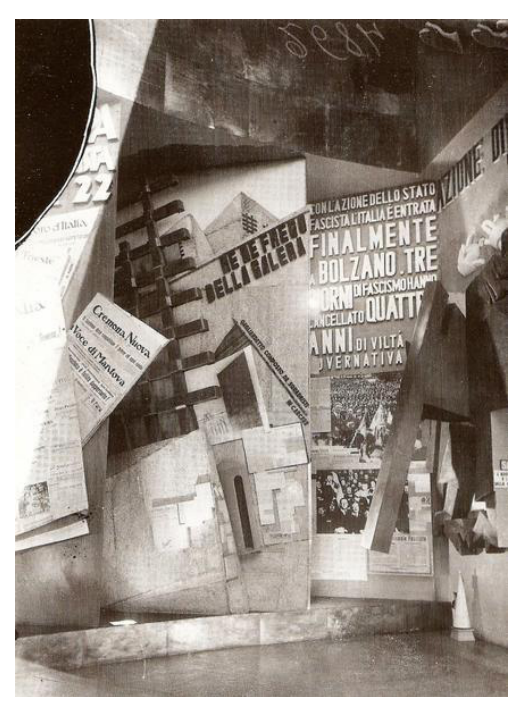

fig. 6.III. Sala O, 1933. Collage entitled "Me ne frego" ("I do not care") combining slogans and text from the /I Popolo d'Italia newspaper.

6.3. McLaren quotes Victor Hugo's Notre-Dame of Paris (1831), translated by John Sturrock (New York: Penguin Books, 1978), p.200.

6.4. The importance of this institution of mass media, the Popolo d'Italia newspaper, to the officially sanctioned history of Italian Fascism as presented in the exhibition was made clear in the final, symbolic sequence of rooms $R-U$. As part of the climax of the exhibition, the visitor, having finished the promenade through the chronological exhibits of the Fascists, found themselves in the first of the final four rooms, arranged along the central axis of the building. The focal point of this Salone d'Onore (Hall of Honour) was a reconstruction of Mussolini's first office at the Popolo d'Italia. Nicknamed the covo (den), it was encased in a tabernacle-like structure with eight columns, each formed from authentic print rollers of the original Popolo d'Italia printing press. Quite literally, the tools of mass production and reproduction created the architectural space, the ideology of the Popolo d'Italia being revealed as one of the essential materials constructing the Fascist regime. 


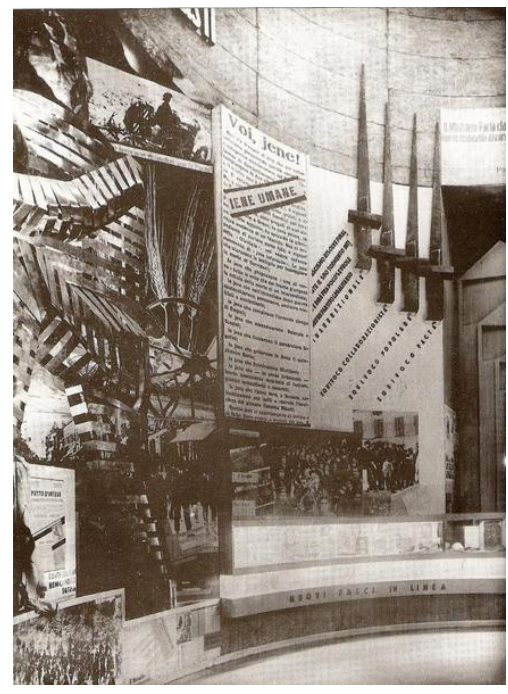

fig. 6.IV. Sala O, 1933. Collage entitled "lene umane" ("Human hyenas") using material from II Popolo d'Italia.

\section{Curated collage: production of the exhibition}

One of the key impressions the organisers of the exhibition wanted to give was the persistent support of the Fascist regime from all parts of the Italian public. To this effect, the exhibition was 'collaged' together from material gathered from a seemingly wide variety of sources. II Popolo d'Italia listed this material as "...important and significant memorabilia, photographs, autographs, relics, newspapers, [and] publications," some 18,400 items being sent from all over Italy (Jan 5, 1932). Despite these items eventually being highly filtered and used in a predetermined curatorial direction, the large number of contributors (prefects, federal secretaries, museums, libraries, and private citizens, all identified through captions and contribution credits) gave the impression that the exhibition was the product of many different people. In utilising the public to return mass media back to an arm of the institutions which originally disseminated it, the curated spatial 'collage' of the Mostra arguably demonstrates the self-referential nature of the culture industry. The link between print media, political ideology, and architecture was most dynamically explored in the contribution of the architect Giuseppe Terragni to the Mostra.

\section{'Hypervisual dynamism': Giuseppe Terragni’s Sala O design}

The exhibit in the room marked Sala O (Room O) on the plan of the exhibition, designed by the Italian Rationalist architect Giuseppe Terragni, formed part of the most dramatically compelling exhibits in the later sequence of rooms covering the proper "revolutionary" period between March 1919 and October 1922. It fit into the organisers' rhetorical strategy for the exhibition by continuing to reproduce Mussolininan phrases and mottoes, blurring the distinction between document and commentary. Being a part of an intensifying sequence of unity of figurative, verbal, and architectural language, this room also helped make the Fascist interpretation of history present to the viewer.

Terragni's design for the Sala $O$ was characterised by a dynamic sense of movement, impetus and energy. Compared to the tightly controlled, orthogonal, and often symmetrical arrangements of the other rooms, even the plan of the Sala $O$ started to reveal this vitality: Cut diagonally in plan by a wall and surrounded by semi-circles of angular display cases, the Sala $O$ was an energetic mass of interconnecting photomontages, collages, and cut-outs. Composed using strong diagonal lines, these techniques manipulated frenzied images of the social, political and economic crisis leading to the March on Rome, October 28, 1922. 


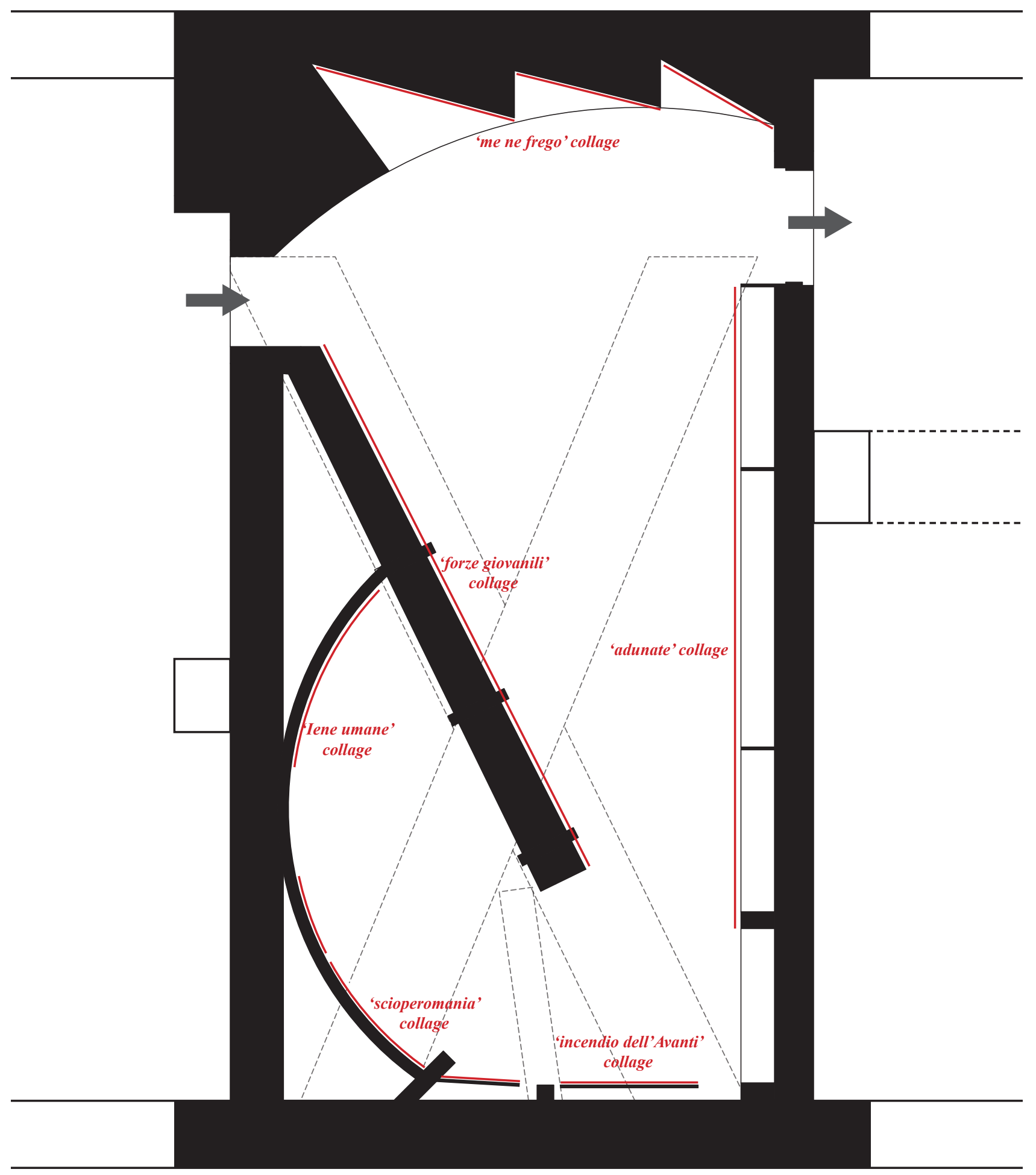

fig. 6.V. Plan of the Sala O, designed by Giuseppe Terragni. Rome, 1933. (author's own drawing). 

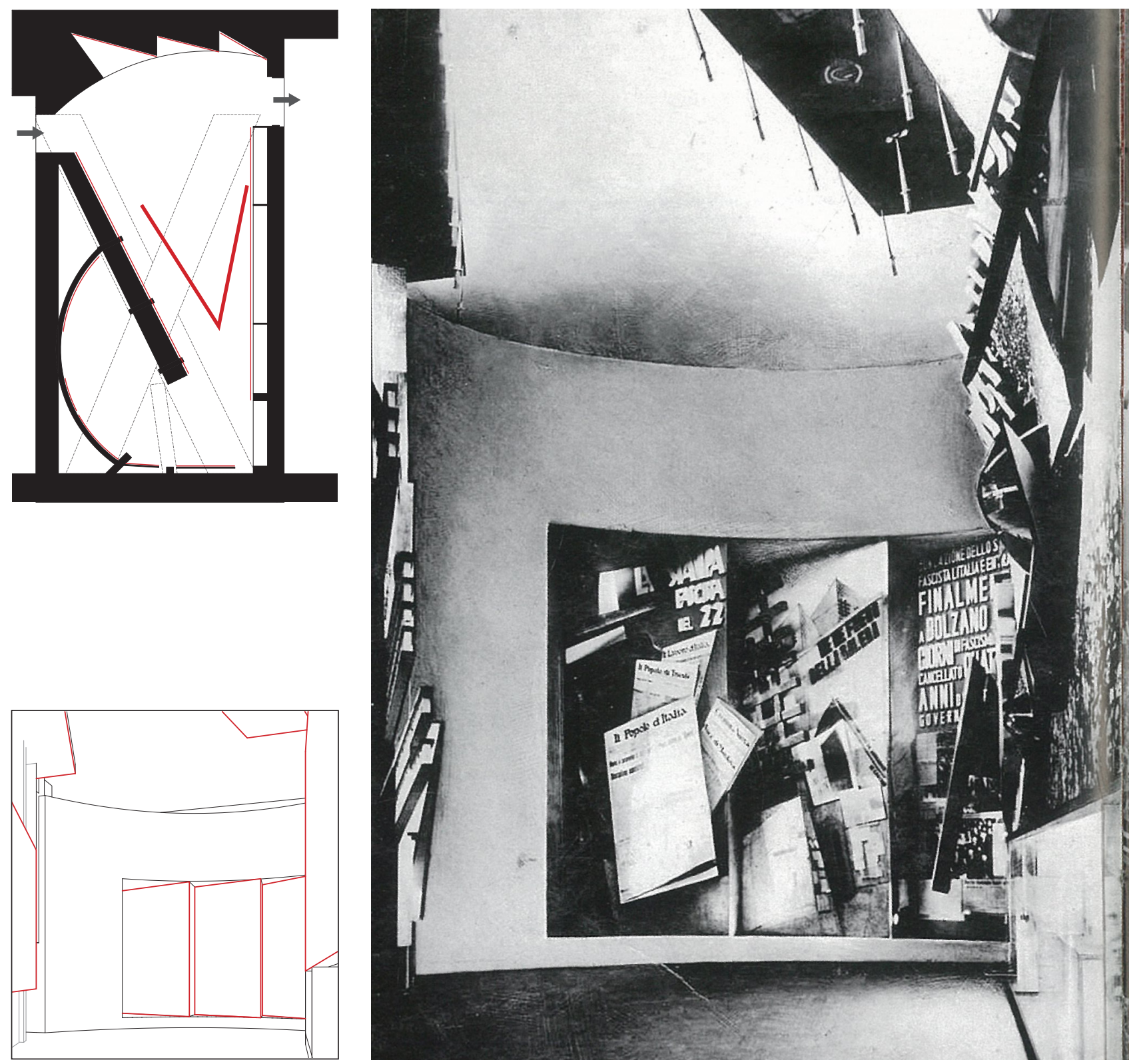

fig. 6.VI. Sala O, 1933.

View towards the "Me ne frego" collage. 

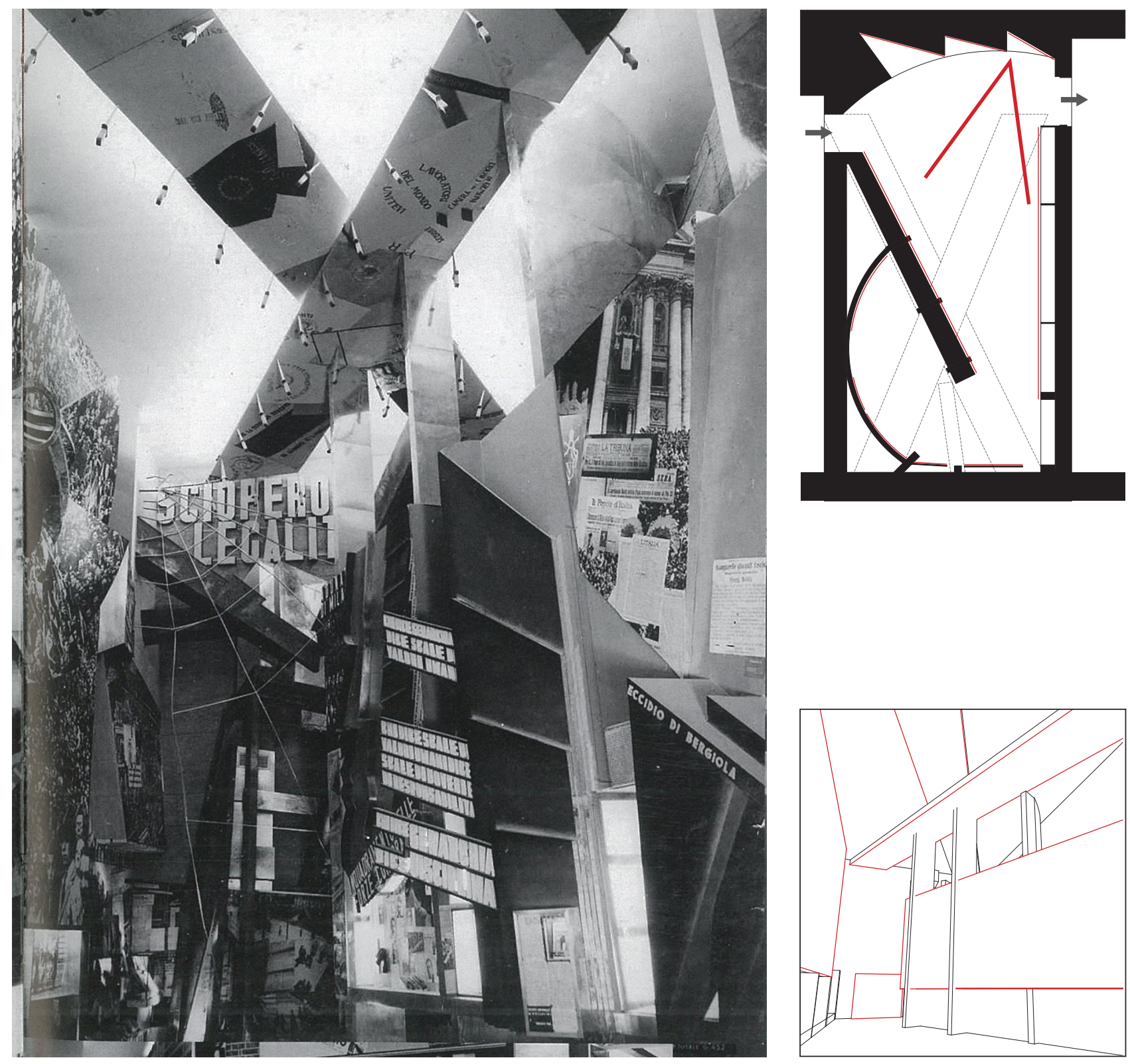

fig. 6.VII. Sala O, 1933.

In the centre foreground is the "forze giovanili" collage.

Note the ' $X$ ' crossing the ceiling, and overwhelming mass of visual material.

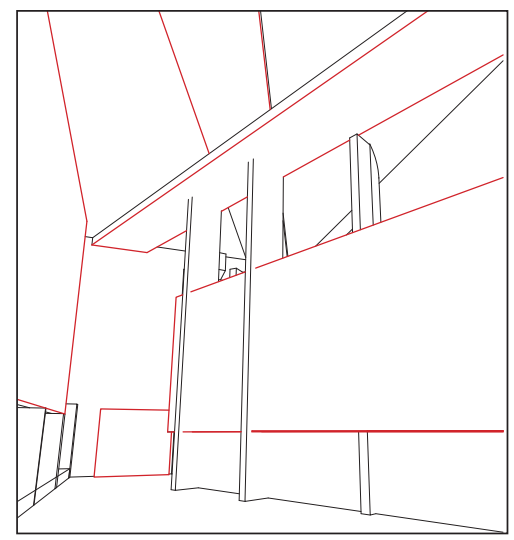



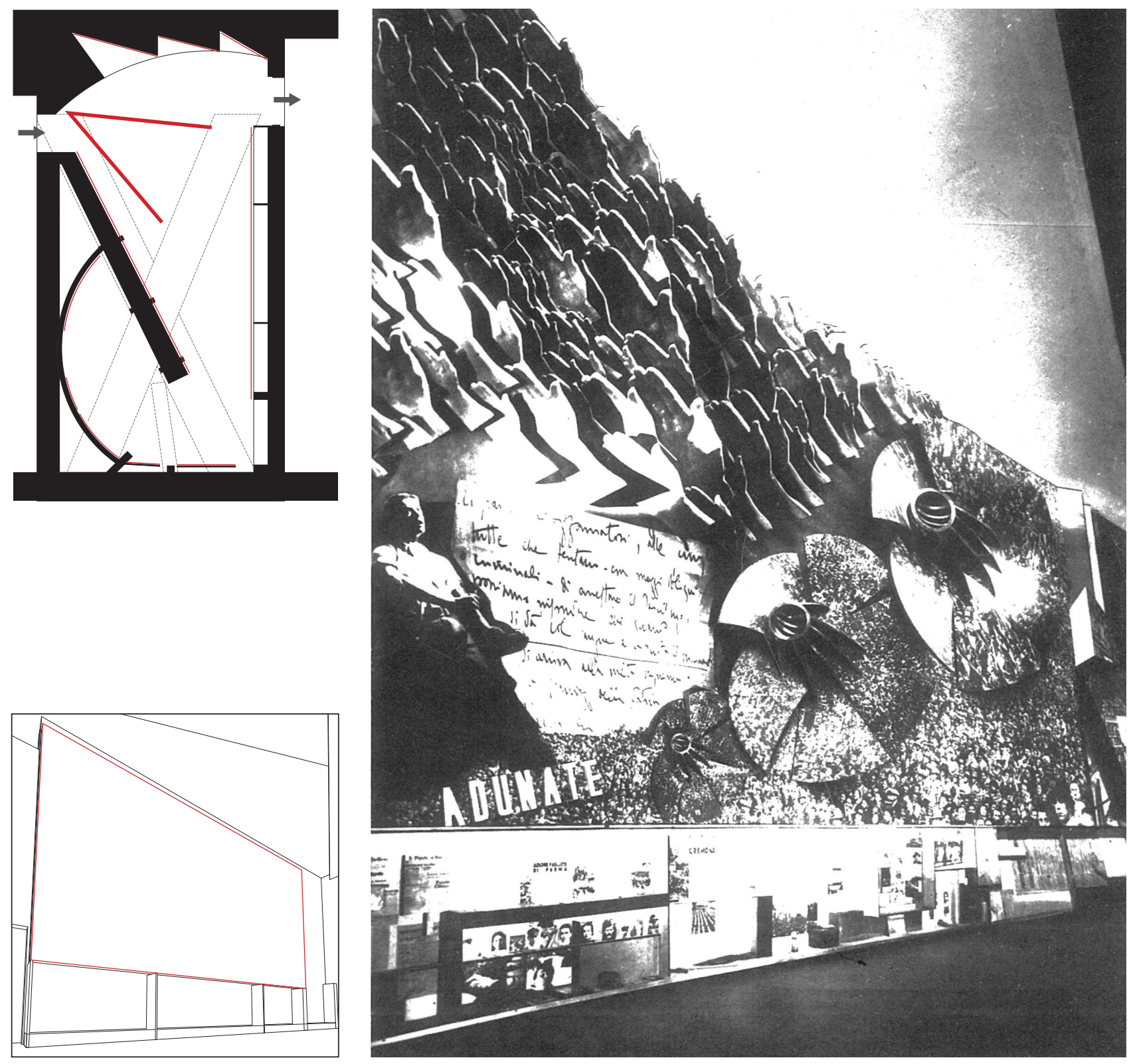

fig. 6.VIII. Sala O, 1933.

View towards the "Adunate" photomontage. 

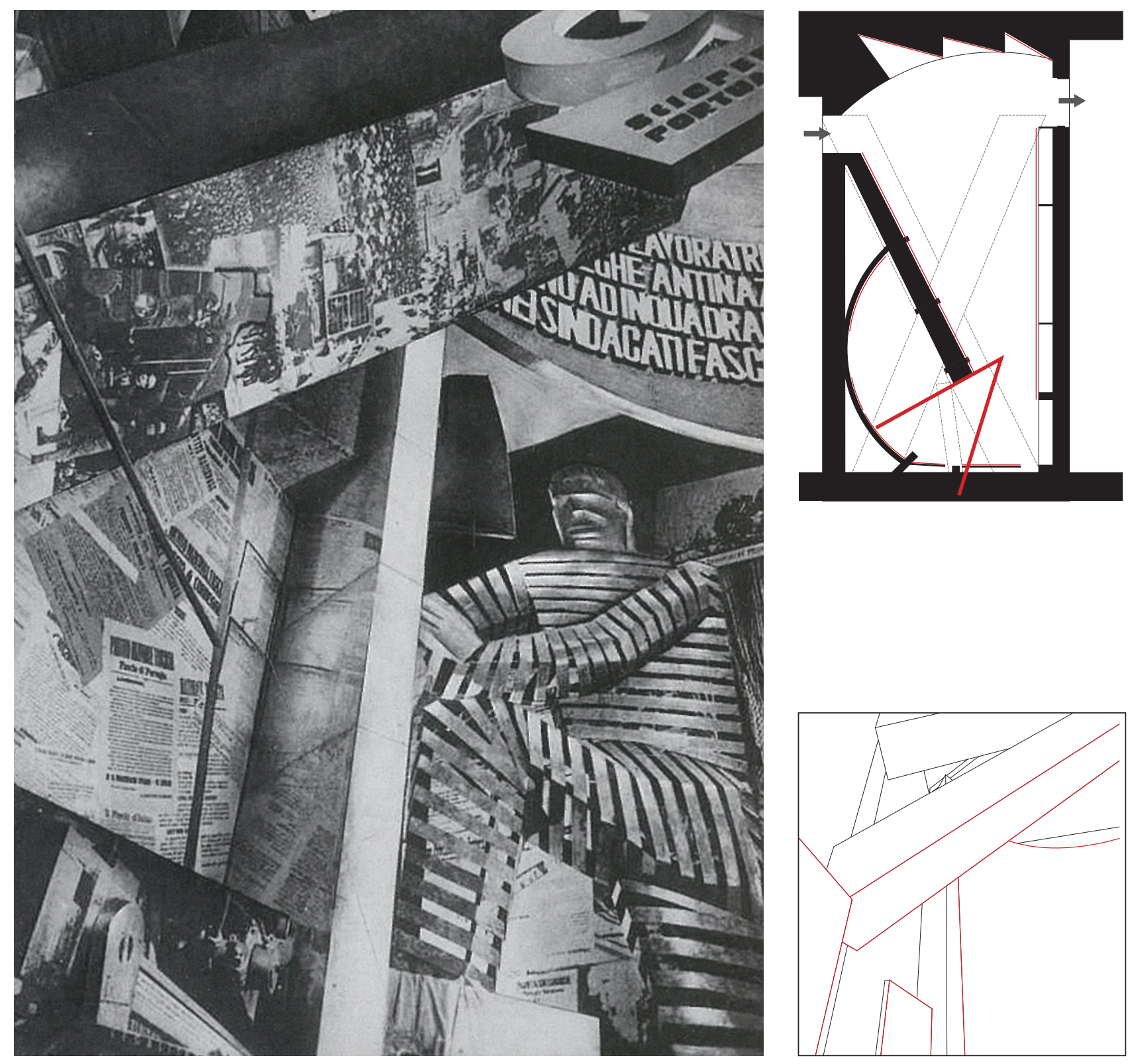

fig. 6.IX. Sala O, 1933.

The prisoner-figure is part of the "scioperomania" collage. Note the dynamic arrangement of media material.

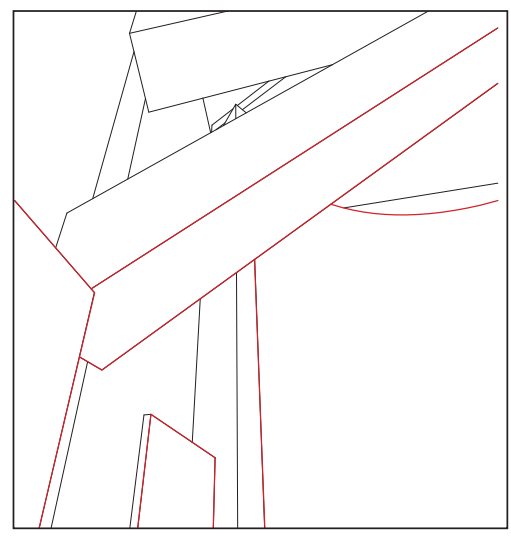




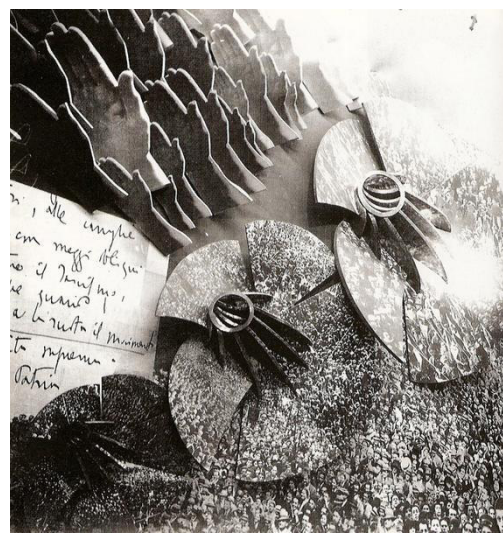

fig. 6.X. Sala O, 1933. Detail of the "Adunate" photomontage.

6.5. Adunate translates from Italian as "assemblies" or "gatherings", but also interestingly as "assemblages", perhaps a pun on the method of photomontage and collage used in its creation.

6.6. X="Decennale", for the Decennale fascista, celebrations for the tenth anniversary of the Fascist March on Rome which the Mostra was a part of.

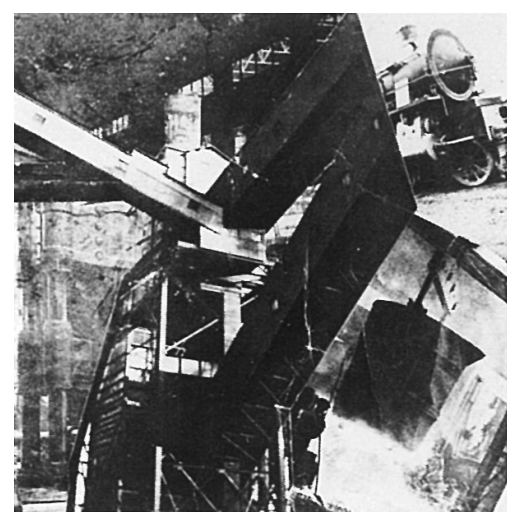

fig. 6.XI. Giuseppe Terragni, photomontage (date unknown).

6.7. Refer to Sergei Eisenstein's theory of 'intellectual montage' in his collection of essays on film, (1949). Film form: essays in film theory (New York: Hartcourt, 1949), p.82
One side of the diagonal wall told the story of the actions of Fascist militia in 1922, using clippings and artefacts. Above the display hung a series of merging silhouettes in which Mussolini's black profile fused with the silver outline of Italy, underlined by the words "Inquadramento delle forze giovanili" ("Shaping-ground for the forces of youth"). This conflation of Italy-Mussolini-Fascism symbolised the emergence of the institutions of the nascent Fascist state from the disarray of the Italian government, and further emphasised the personality of the Duce (Mussolini) as the catalyst. Once the visitor moved past this wall they were faced with a ceiling-high figure standing ominously in a corner of the room. Composed of a prisonsuit of metal strips, this diorama used the power of newspaper headlines to proclaim this empty shell of a body as:"Il lavoratore irretito dalla scioperomania" ("the worker trapped by strike mania"),

In further contrast to the sombre, heavy rooms that preceded it, Terragni designed the Sala $O$ using a range of shiny and reflective materials. These materials not only helped intensify the visual experience of the viewer, but by drawing the viewer's reflection into the space of the representation, it also disintegrated the boundary between spectacle and spectator and in this way helped confound or blur their sense of self-identity before the viewer reached the dominant figurative element in the room: a huge photomontage called "Adunate". 6.5 Starting with a collaged mass of anonymous faces, the visitor's reflection was captured by waves of shiny metal cut-outs, conceptually adding them to this swarming crowd. One of Mussolini's mottos, (“... with blood the wheel is set in motion...”) was dynamically reproduced in an enlarged handwritten scrawl, and visualised by three wheels/turbines that seemed to spin with the energy of the collaged crowd flowing against their blades. The almost literal revolution of the turbines transformed the gathered masses into a stylised sea of plaster hands, all pointing upwards in a disembodied Fascist salute. Drawing the visitor's eye up towards the ceiling, they brought attention to a gigantic black $X$ hanging over the whole room, symbolising the present day. ${ }^{6.6}$

\section{'Montage' in the production of the Sala 0}

Terragni's methods of production, dynamic compositions, abstract imagery, and emphasis on 'forward-looking' aspects such as industrial processes, has led the Sala $O$ design to be interpreted by many critics as being influenced by futurism, cubism, and the Russian avant-garde. In particular, the 1920s Soviet theory of 'montage' ${ }^{6.7}$ seems to strike a useful chord in the interpretation of Terragni's Sala $O$ design: Describing the aesthetic collision of separate elements and the resulting overlay of independent thoughts, the term 'montage' could express the essential basis of the Sala $O$ exhibit. Photographs of its production show that it was a process not unlike assembling a large photomural: texts were cropped and collaged with images in "a simulation of the assemblage of images and text in the space of the 
pages of a magazine" (McLaren, 1992, p. 104). McLaren compares the production of the Sala $O$ to the photomontages of the Dadaist artist Raoul Hausmann, in that they were 'assemblies' or 'constructs' of media material. Terragni's preparatory studies for the design included photomontages of images of industrial buildings, powerful machinery and churning locomotives. Elements of these studies seem to be echoed in the Sala $O$ through its deep recesses and asymmetrical niches filled with images of movement. For one critic, the murals of the Sala $O$ presented "an almost vertiginous dynamism, moving the viewer onwards in a kind of frenzy that mimics the hysteria of the legendary March on Rome of October 1922" (Schumacher, 1991., p. 173). Here, the critic identifies not only a montaging of images, but also a montaging of subject matter over representational technique, the "hysteria" of the march (subject) being layered over the "frenzy" of images (technique).

The concept of 'montage' in the design of the Sala $O$ starts to define its architecture entirely within the realm of representation (as technique). Historical photographs of the Sala $O$ suggest a similarity to the two-dimensional prouns, abstract works of the Constructivist architect El Lissitzky. Like Lissitzky's drawings, the overlay of contradictory perspectival messages in Terragni's exhibit denied the space of the room. The static walls seemed to 'move' to encounter the visitor, flattening the space into that of a multi-layered drawing, perhaps relating back once again to Terragni's preparatory studies in designing the room (McLaren, 1992, p. 104).

Ultimately, Terragni combined modern techniques of photography with cubist/futurist overlaps and transparencies, resulting in a sequence of spaces/images relying on juxtapositions of media material to serve the organisers' political agendas. The spatial configuration of the Sala $O$ provides an example of an important effect that techniques of production and reproduction such as montage have on architecture: The process of production is and makes the architecture, in that it becomes the source of and influence on the architecture itself.

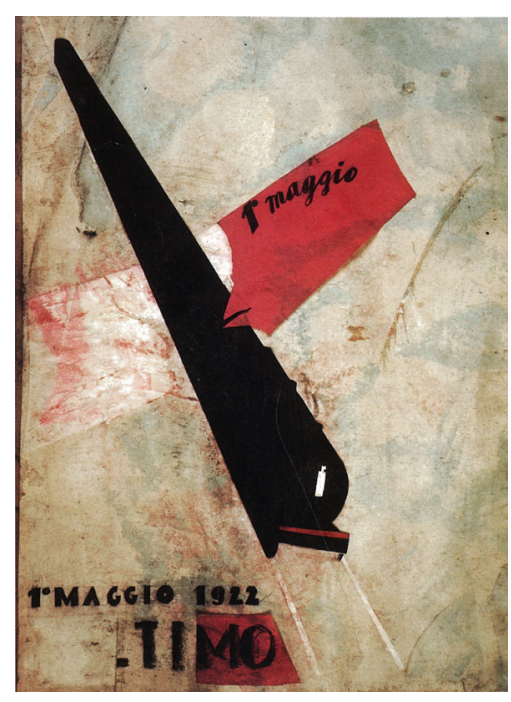

fig. 6.XIII. Giuseppe Terragni, preparatory drawing for the Sala O (c.1933).

\section{Ideologies in the Mostra and Sala O}

Any study of Terragni's Sala $O$ and the Mostra della Rivoluzione Fascista exhibition in general cannot ignore the fact that the whole production was a carefully conceived work of Fascist propaganda, with the aim of promoting particular ideologies: most obviously politically, socially, but also culturally. As the historian Marla Stone writes in her essay, The anatomy of a propaganda event: the Mostra della rivoluzione fascista, this exhibition revealed Fascism's ability, in the middle years of its rule, to respond to Italian cultural needs: "With the exhibition, the regime produced the first event of a shared national culture", created using the institutions, techniques, and products of the culture industry (Stone, 1992, p. 37). The architecture 


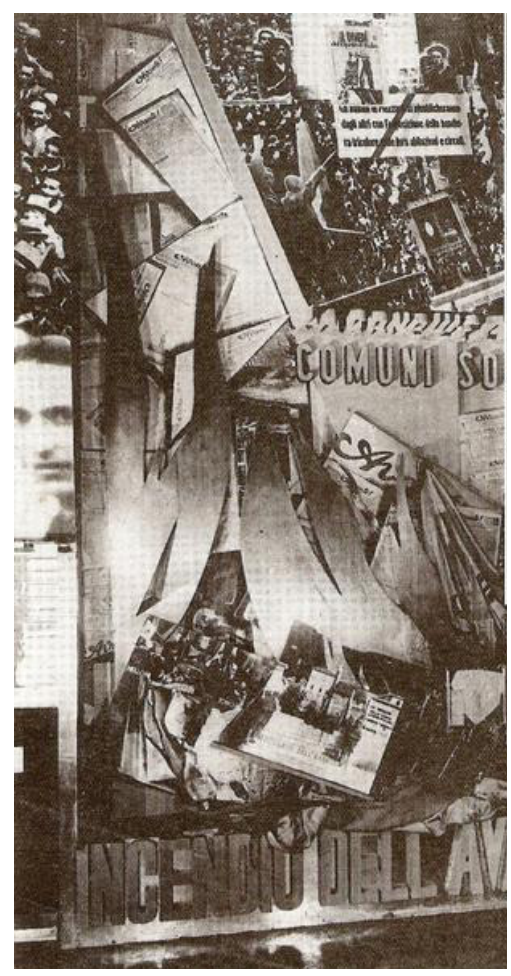

fig. 6.XIV. Sala O, 1933. Collage entitled "Incendio dell'Avanti" ("Burning of the Avanti").

6.8. For Benjamin's concept of the aestheticisation of politics, refer to the second version his essay, The work of art in the age of its technological reproducibility, first published 1989. (Benjamin, 2008)

6.9. For Benjamin's discussion of the 'atrophy of experience' due to new forms of technology, refer to his unfinished 'Arcades Project' (Benjamin, 2002).

6.10. The philosopher Benedetto Croce, quoted in Schumacher (1991), p.13. Discussions of the role of politics in the personal lives and creative works of Terragni and other architects prominent during the Fascist regime often reveal a profound discomfort with the idea that such architecture can be as modern as it is Fascist, many writers trying to explain away the Fascism of the Italian Rationalist architects. As the architectural historian Diane Ghirardo details, the earliest argument was that the architects "played Fascist in order to do architecture". However, her historical studies contend that Terragni and other Rationalist architects were ardent Fascists, even if by 1942 they had renounced Fascism (Ghirardo, 1980, p. 109). swept the visitor up in the representation of a history designed to contribute to the creation of an Italian national consciousness, and allowed artists to participate in the construction of that history. "In return, artists and spectators gave their continued consent to Fascist rule", the ideologies promoted by the exhibition working to legitimise and entrench the dominance of Fascist culture (Stone, 1992, p. 40).

More than just a didactic device for 'brainwashing', the exhibition was an architectural and cultural 'event', an actualisation of Fascist historical ideology. It didn't just 'tell' the public of the successes of Fascism, it tried to 'show', 'prove' and 'demonstrate' this. The architecture of the Mostra can therefore be seen as an extremely focussed media event: it illustrates the way in which the Fascist regime created new cultural 'spaces' (including architecture and spatial settings) to promote its message. In attempting to control the context in which people interpreted the ideologically-'loaded' exhibition material, the Fascists sought to leave no room for alternate interpretations, synchonysing the message of the exhibition with its architectural medium.

The exhibition is a prime example of the potential of architecture to affect the viewer on a subconscious level, and acts as testimony to some of the most pervasive cultural phenomenon of the period. This includes what Walter Benjamin called Fascism's "aestheticisation" of politics ${ }^{6.8}$ and the "atrophy of experience" ".9 that accompanied the spread of new means of mass communication. Writing on the architecture of the Mostra as a "media event", historian Libero Andreotti considered its exhibits "to promote a set of mimetic and contagious practices: slogans, gestures, ways of dressing and moving that were at the heart of fascism's aesthetic, more than political, appeal" (Andreotti, 2005, p. 9).

\section{The "unfortunate" question:Terragni and Fascism}

Terragni's architectural work is intrinsically tied to the cultural ideologies of his day, most obviously Fascism. If architecture is concerned with meaning, in Terragni's architecture Fascism formed a big part of this meaning. It is interesting to note that early post-war architectural historians tried to separate this aspect of meaning (Fascism) from his architecture in an attempt to 'salvage' the best architects and their architecture from what has been discreetly described as the "unfortunate episode" of the Fascist era. ${ }^{6.10}$ But as my earlier discussion of the architecture culture industry (Chapter 5) has shown, making architecture is an intrinsically political act, linked inextricably to issues of social power. State-funded buildings and projects constructed during the Fascist period were intended for particular (political) settings and designed to serve particular (political) functions. As the architectural historian Diane Ghirardo points out, "because they had patrons with definite political programs, they could not but serve as 
vehicles of that political ideology" (Ghirardo, 1980, p. I I0). The Mostra was certainly no exception to this 'aestheticisation of politics', the organising committee carefully tapping into the existing institutional structure of the Italian art world to gain as much credibility as possible for the implementation of its particular visual culture. The list of contributors to the exhibition reads like a roll-call of leading inter-war Italian artists, with representatives of all the predominant Italian modern movements,. ${ }^{6.11}$ so Terragni was certainly not alone in producing work which celebrated the regime. Indeed, the mere selection of Terragni by the organisers as one of the contributing designers to the exhibition suggests that his ideological leanings were in keeping with the strict agenda of the regime and its supporting culture industry. This arrangement would not have been without its benefits: in completing a commission for the dominant cultural group (the Fascist regime), Terragni's creative prestige would have been enhanced, adding to his credentials both as a Fascist and as a designer of Fascist projects.

Fascist ideology informed part of the context in which Terragni was working in and the frames of reference visitors to the Mostra used to place meanings on the exhibition's architectural spaces. Although fascism is widely considered a discredited political system by contemporary society, the nature of Terragni's work as 'Fascist' should not dilute its significance as an example of the way politics and ideologies influence the creation and interpretation of cultural products. Nor should it require a 'down-playing' of the Fascist aspects of his work for us to reach useful conclusions from it. It is important to understand that every cultural product is embedded within the particular cultural contexts of its production, and everything we produce expresses our political outlook to some extent.
6.11. Futurism being represented by Enrico Prampolini, Gerardo Dottori, Antonio Santagata, and Aldo Carpinetti; Novecentro by Mario Sironi, Achille Funi, Adalberto Libera, and Mario De Renzi; "Return to order" and the regionalist Strapaese movement by Mino Maccari and Leo Longanesi; and of course Terragni for the Rationalists. 


\section{Conclusion}

Giuseppe Terragni's Sala $O$ exhibit provides a useful example of an architecture influenced by, produced from, and literally constructed with the products of the culture industry. Examining its production, design, messages, and interpretation has shown how the institutions seeking to boost and secure the Fascist regime operated within the context of a creative, spatial practice such as the architectural design of this exhibit. The ideologies employed in its production conflated readers-of-media with visitors-of-architecture. I contend that Terragni's architectural work in this context provides some lessons for contemporary architects: his work demonstrates several ways for the architect to engage with processes of the architecture culture industry in order to explore the substance of their ideas, their own ideologies, and the particular cultural contexts in which they practice.

The Sala $O$ design used media techniques in a spatial manner to create a new architecture in the minds of its audience. It was also a designed environment exemplifying the relationship between politics and culture in forming the culture industry. Political ideas were promoted via the products of the culture industry, and the architecture culture industry was supported through association with the dominant social powers. This project also reveals a reversal in the traditional relationship between a built work and the print media, in that the representation began to influence the conception and the content of the architecture. It demonstrates a way of practicing architecture which cannot be separated from its representation, and reveals architecture's dependence on the culture industry and its products such as print material, which so significantly feed our perception of architectural meaning. 


\section{conclusion summary}

- The 1933 Exhibition of the Fascist Revolution as work of blatant propaganda is a useful reminder that acts of cultural production (including the creation of architecture) are intrinsically political acts.

- People's perception of cultural products cannot be separated from the ideologies that influence their interpretations.

- The use of media techniques in the design of architectural space utilises the ability of print media to engage people in the communication of ideas and the attribution of meaning in culture.

- Print media products (and their associated techniques and processes) can be seen to not only influence and help produce architecture, but be a sort of architecture in themselves. 


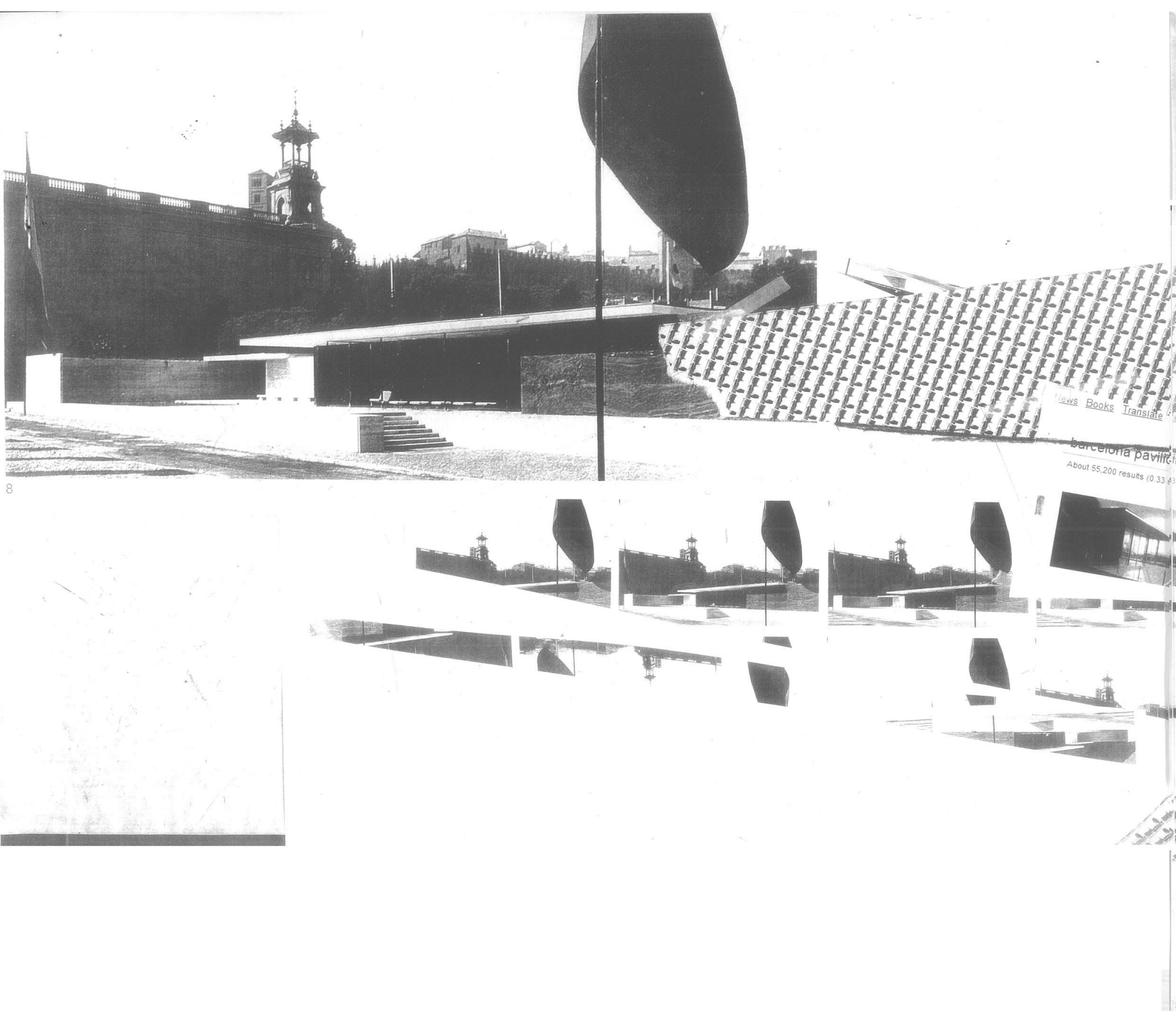




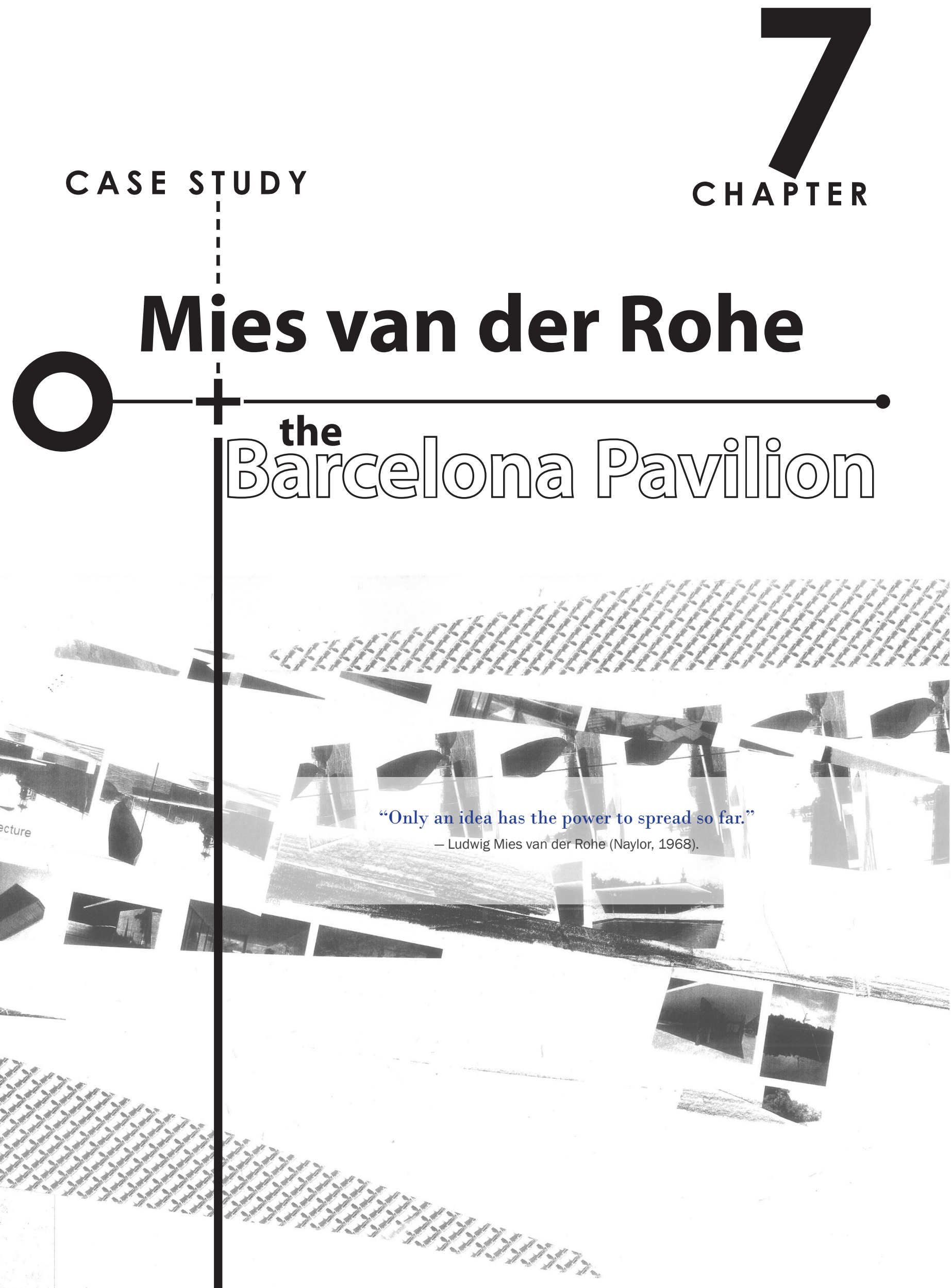




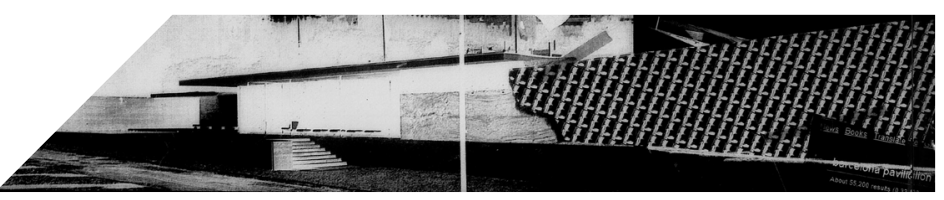

Introduction

SECTION I:The Barcelona Pavilion and Architectural Media

\& Representation

- Mies and the media space of architectural production

- The Berliner Bild-Bericht photographs:A focus

- The concept of 'montage' or 'collage' in the Barcelona

Pavilion

- Problematic plans

SECTION 2:The Barcelona Pavilion and the Culture Industry

- The pavilion and ideology: canonical interpretations

- The 'International Style' exhibition \& book

- The pavilion and ideology: myths

- Mies' factual manipulation: misstatements and inaccuracies

SECTION 3:The Barcelona Pavilion and Meaning

- A 'compromised' construction: "architecture” vs.

"building"

- Priorities

- Idea and image:The pavilion and dreaming

- "architecture" or "architectonic"?

- [re]production and [re]construction

\section{Conclusion}




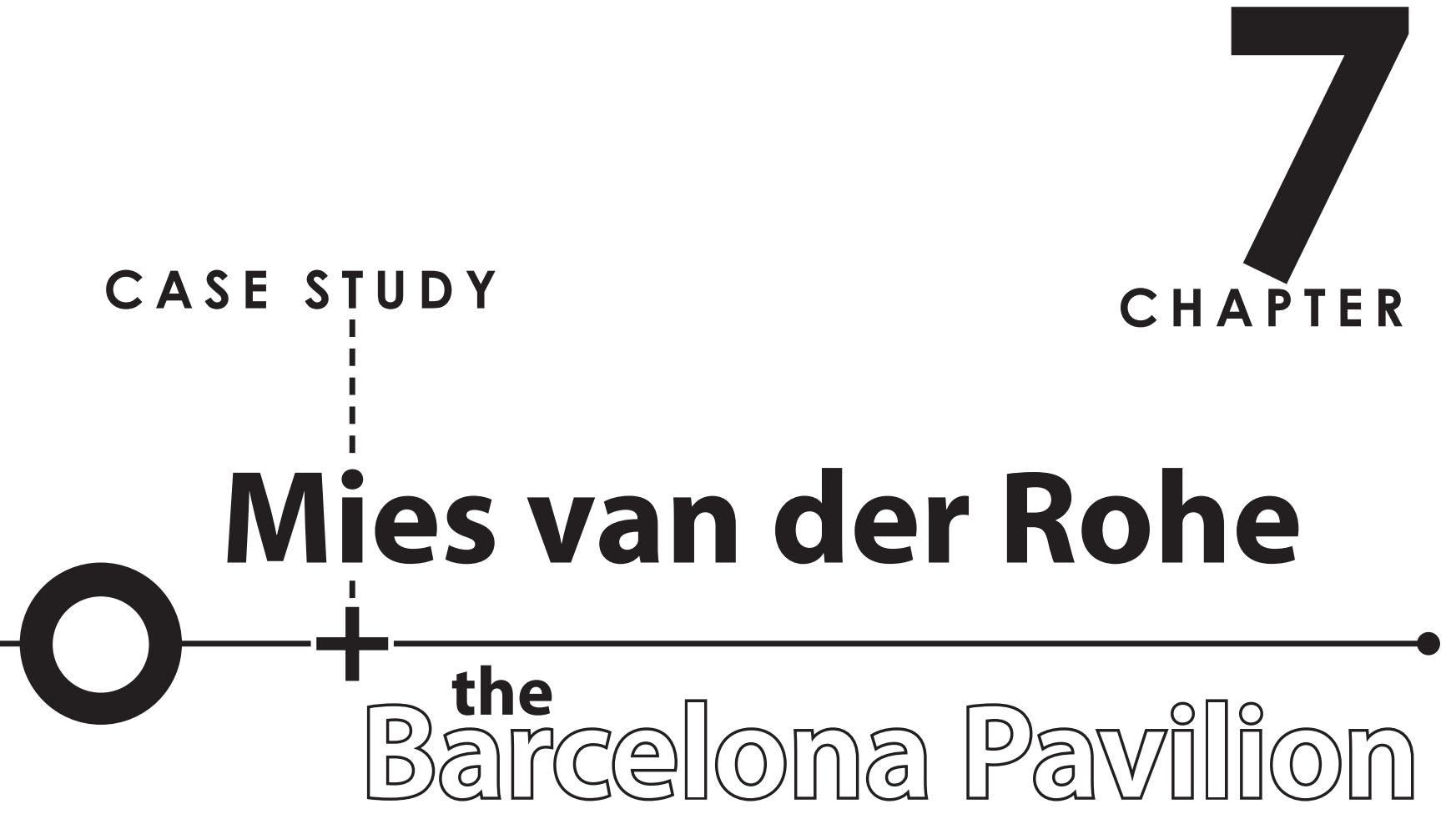

\section{Introduction}

My final case study is situated at the overlap of the three research areas discussed: architectural meaning, print media and representation, and the architecture culture industry. It ties together the ideas discussed in the earlier chapters, and extends the discussion of the first two case studies, (of Le Corbusier's publishing activities, and Terragni's Sala $O$ design). This chapter focuses on the Barcelona Pavilion, a work which can be interpreted to challenge conventional understandings of architecture, while simultaneously being identified as an exemplar by the very institutions of architectural culture which such interpretations question.

The Barcelona Pavilion was a work of architecture by the architect Ludwig Mies van der Rohe designed as the national pavilion of Germany for the 1929 International Exposition in Barcelona, Spain. Constructed as a temporary building, the pavilion had only a fleeting physical existence, lasting only for nine short months from May 1929 until its demolition at the end of the exposition in January 1930. Hailed by many architectural historians as an icon of modernism and an exemplar of the "International Style" of the 1920s and '30s, the pavilion has been much publicised by the architecture culture industry, becoming part of mainstream architecture's key reference points in Western architectural history. 7.1 In 1986 a team of Spanish architects, led by Ignasi de Solà-Morales, rebuilt the pavilion in a 'permanent' form on the original site.

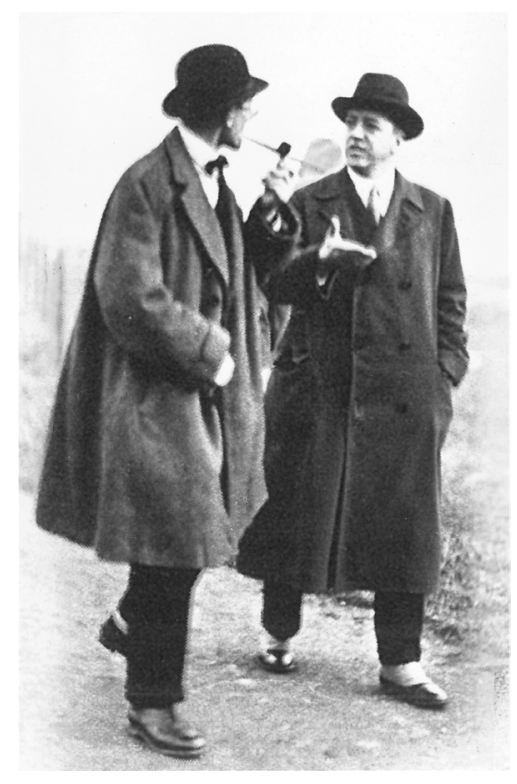

fig. 7.I. Le Corbusier and Mies van der Rohe, photographed together in StuttgartWeissenhof, 1927.

7.1.

See for example, Henry-Russell Hitchcock's Architecture: Nineteenth and Twentieth Centuries (Baltimore: Penguin Books, 1958); Sigfried Giedion's Space, Time \& Architecture: the growth of a new tradition (Cambridge, MA: Harvard University Press, 1941); and Nikolaus Pevsner's Pioneers of Modern Design (Baltimore: Penguin Books, 1960). 

vilion is contradictory, unstable and complicated. Some writers have cautioned against using it to inform generalisations on the entirety of architectural historiography, the pavilion being seen as a particularly anomalistic and irregular example of architecture (for example, see Dodds, 2005, p.35-40). However, while acknowledging the details of the pavilion's situation may be unique, I consider the general patterns of its story to be indicative of more widespread activities in architectural culture.

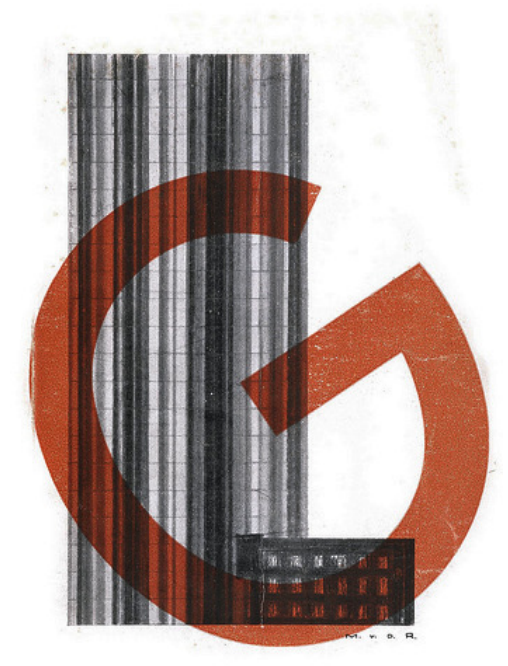

fig. 7.II. "G" magazine, no.3 (June 1924). Cover featuring a charcoal drawing of Mies' own 1922 Friedrichstrasse Glass Skyscraper project.

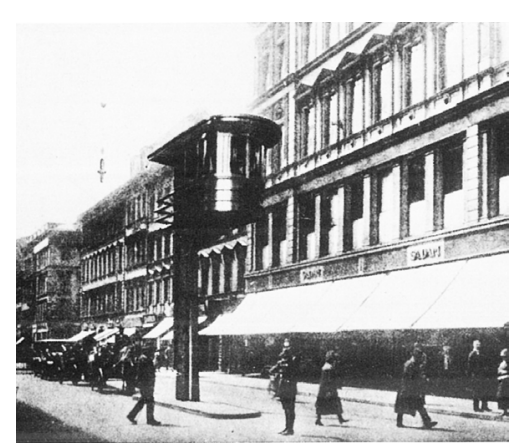

fig. 7.III. Mies van der Rohe, Traffic Tower project (1924). Photomontage.

7.3. For example, his photomontage of physical models into street views, such as in his 1924 Traffic Tower project (Honey, 1986, p. 42).
In this chapter I consider the Barcelona Pavilion from three thematic 'angles': its representation in printed media (SECTION I), its promotion by institutions of the architecture culture industry (SECTION 2), and the lessons its history might offer to an understanding of architectural meaning (SECTION 3). My discussion of the Barcelona Pavilion aims to explore how an architect's conscious use of architectural media techniques has influenced the interpretation of their work by the architecture culture industry and others, and resulted in a highly significant (that is, meaningful) architecture. ${ }^{7.2}$

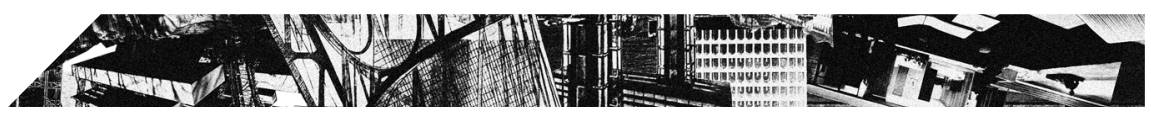

\section{SECTION I:The Barcelona Pavilion and Architectural Media \&} Representation

As discussed in Chapter 6, architectural culture is implicated in the processes of media in wider culture. The Barcelona Pavilion is one of the most widely published works of architecture, and processes of media and representation have been integral to its significance and status.

\section{Mies and the media space of architectural production}

Paralleling the experience of Le Corbusier with the journal L'Esprit Nouveau, Mies also engaged in print media processes of the architecture culture industry to explore the 'media space' as a space of architectural production. He was intimately familiar with the influential and propagandistic impact of print media through his role as an author, editor, and publisher of the Expressionist periodical "G", originally founded in 1923 by Werner Gräff, the avant-garde architect El Lissitzky, and artist Hans Richter. From 1924, the journal " $G$ " was published by Mies from his own architectural office, suggesting that it became an extension of his architectural practice. During the early part of his career, he graphically represented in print media far more projects than he ever built. He used hand-made models, architectural drawings, photomontage and collages rather than building materials as he explored the image of new materials and new methods of construction independent of building. In this way, Mies used the media to help create his career, with his fame and reputation largely arising, not through the result of built works, but via publications, temporary exhibitions, and a few brief and cryptic texts. As Mies' early career shows, he was skilled at inserting artificially-created elements into photographs to explore his ideas. ${ }^{7.3}$ In his book on the Barcelona Pavilion, the architectural historian George Dodds explains Mies' use of print media material and representation as tools for his ideas to emerge through "the act of making” (Dodds, 2005, p. 128). Dodds asserts that Mies made things (and not just physical buildings), including drawings, photographs of drawings, photographs of temporary buildings. The relation of these representations to built form was often complicated, most interestingly in the photographs of the Barcelona Pavilion. 


\section{The Berliner Bild-Bericht photographs: A focus}

Most architects, in thinking of the Barcelona Pavilion probably call to mind black-and-white images showing an ambiguously-scaled, empty-seeming building with a reflecting pool or two and dramatic perspective vistas formed from planar, richly-textured walls and floors. What triggers these images are a set of sixteen photographs, taken by the Berliner Bild-Bericht company soon after the opening of the pavilion at the 1929 Barcelona International Exposition. The Berliner Bild-Bericht master prints from Mies van der Rohe's personal collection are arguably the most historically significant and permanent traces of the 1929 building. ${ }^{7.4}$ Reproductions of selected master prints are in virtually every monograph and article on the work of the German architect Ludwig Mies van der Rohe (1886-1969), as well as in most surveys of modern architecture. So pervasive is their influence that there are only a handful of instances where other photographs of the pavilion were published during Mies' career, all of which were prior to his emigration to the United States in 1937. After his relocation to Chicago, and until his death in 1969, the only photographic images of the pavilion that Mies gave permission to be printed were copies of the Berliner Bild-Bericht prints. My case study of the Barcelona Pavilion focuses on the influence of these photographs in the development of the pavilion's meaning. In contrast to many others writing on the pavilion who treat it as a single fixed, immutable work in architectural history, I consider the story of the Barcelona Pavilion to contain three distinct works: the Barcelona Pavilion of 1929 which visitors were able to walk through; the Barcelona $\mathrm{Pa}$ vilion as created through the set of 16 Berliner Bild-Bericht photographs; and the 1986 physical reconstruction of the Barcelona Pavilion. Each is a separate and discrete work, all having their own unique claim to authenticity. However, while all equally "authentic", they are not all equal. The 1986 pavilion is but a 'permanent' reconstruction of the temporary 1929 building, and this 'original' was arguably largely made for the purposes of its translation into photography, through the Berliner Bild-Bericht prints. This argument highlights the significance of the Berliner Bild-Bericht images in the development of architectural meaning for the pavilion.

Through examining these photographs, their use by Mies, and the relationship they hold to the various published plans of the pavilion, I attempt to show how Mies explored design via the techniques and processes of print media and architectural representation.

\section{Manipulated images}

The sixteen Berliner Bild-Bericht prints representing fourteen distinct views of the 1929 Barcelona Pavilion are extraordinary works of art and fittingly, the original sepia-toned gelatin prints are held in the archives of the Museum of Modern Art, New York. However, the master prints show evidence of manipulation, as Mies cropped, airbrushed and masked elements of the photos which did not fit his idea of how the pavilion should
7.4. The dismantling of the original pavilion in 1929 has undoubtedly contributed to the significance of the Berliner BildBericht prints, which became historical records of an absent built object. The master prints are therefore the most important surviving documents of one of the most famous works of twentieth century architecture. As a group, they are far more important than any one of Mies' surviving drawings of the pavilion, and far more illuminating than his published comments on the project. The pavilion's photographic fame even pre-dates, by many decades, any publication of Mies' drawings of the building. 

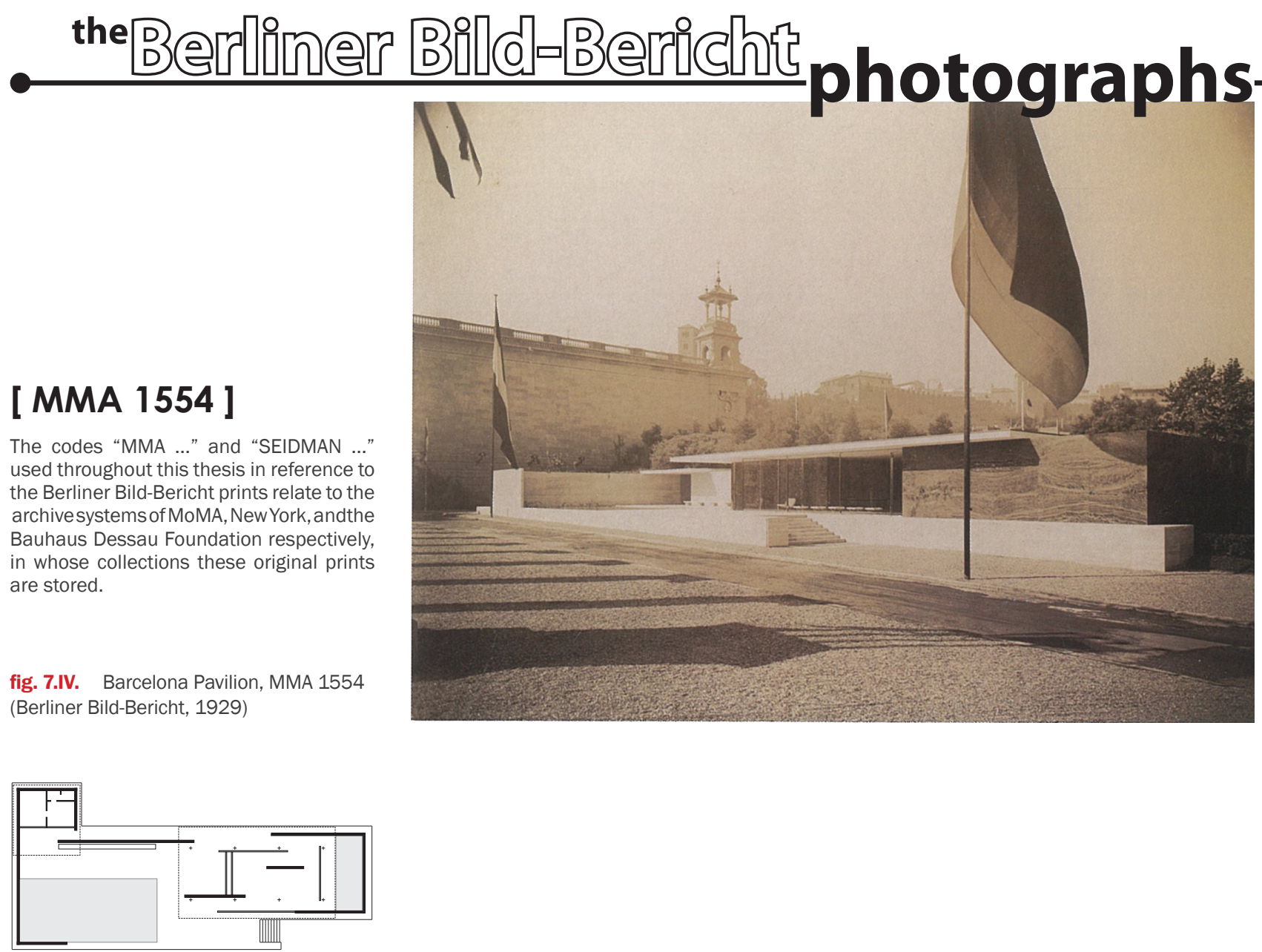

[ MMA 1197]

fig. 7.V. Barcelona Pavilion, MMA 1197 (Berliner Bild-Bericht, 1929)
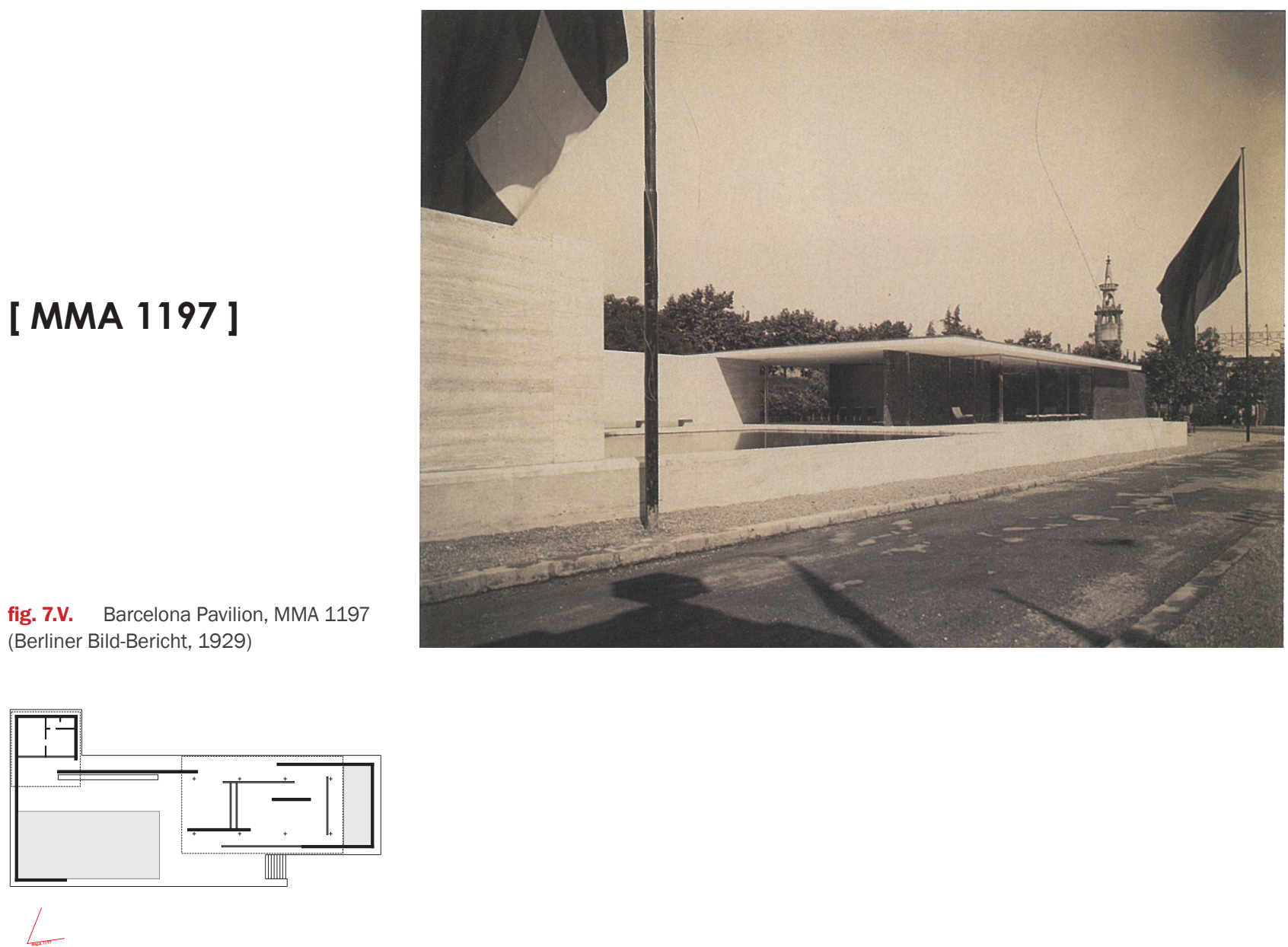


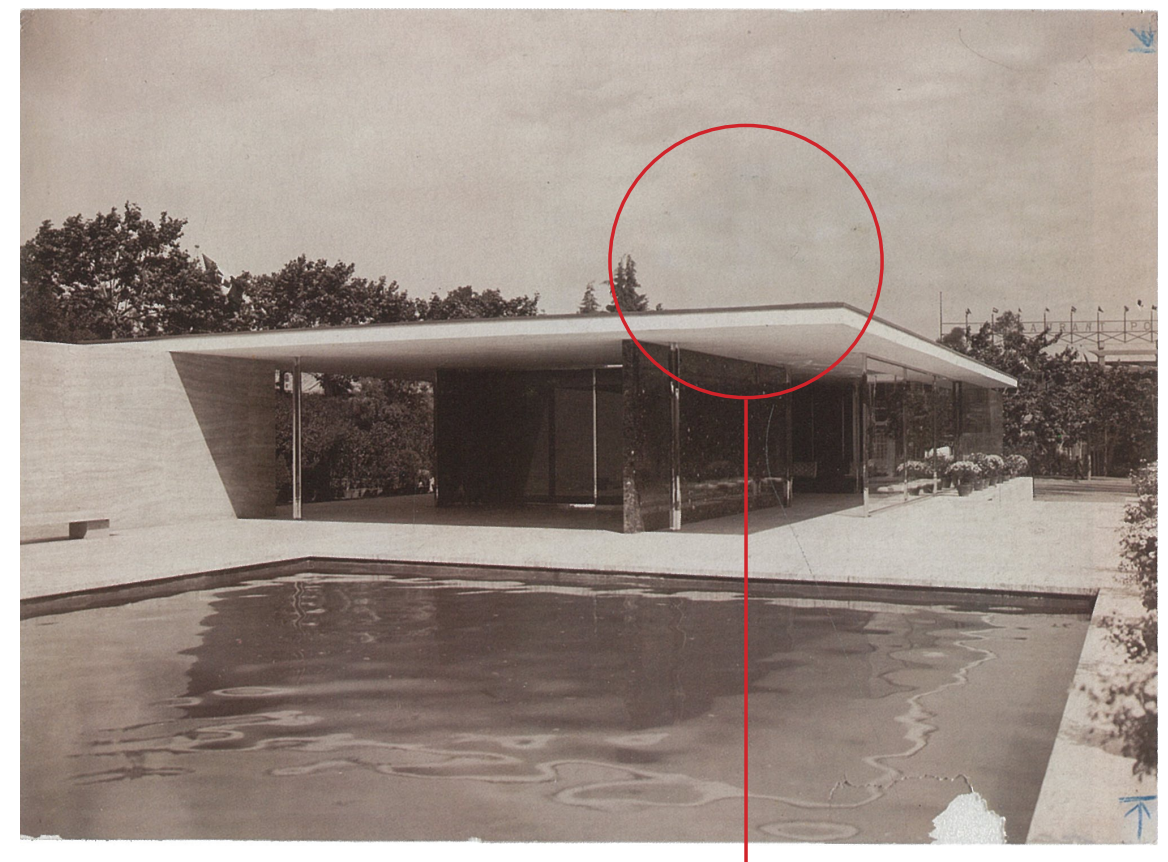

[ MMA 1437]

fig. 7.VI. Barcelona Pavilion, MMA 1437 [manipulated] (Berliner Bild-Bericht, 1929)

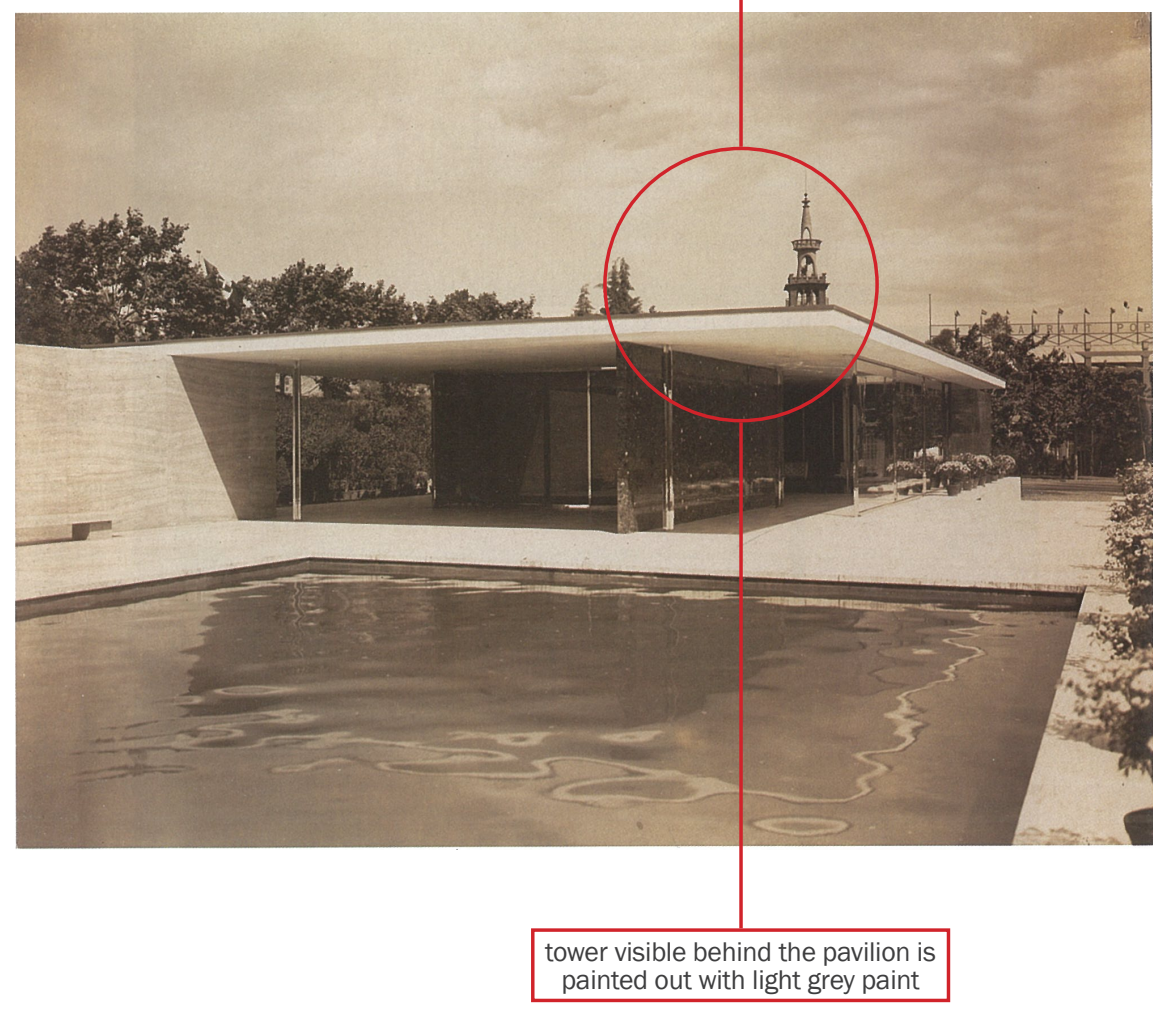

fig. 7.VII. Barcelona Pavilion, MMA 1437 (Berliner Bild-Bericht, 1929)

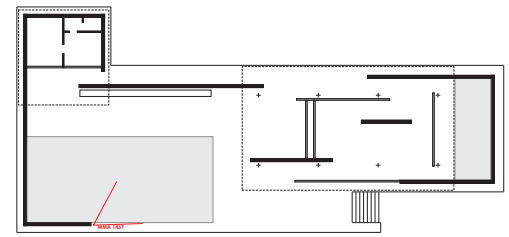




\section{[ SEIDMAN 248 ]}

fig. 7.VIII. Barcelona Pavilion, SEIDMAN 248 (Berliner Bild-Bericht, 1929).

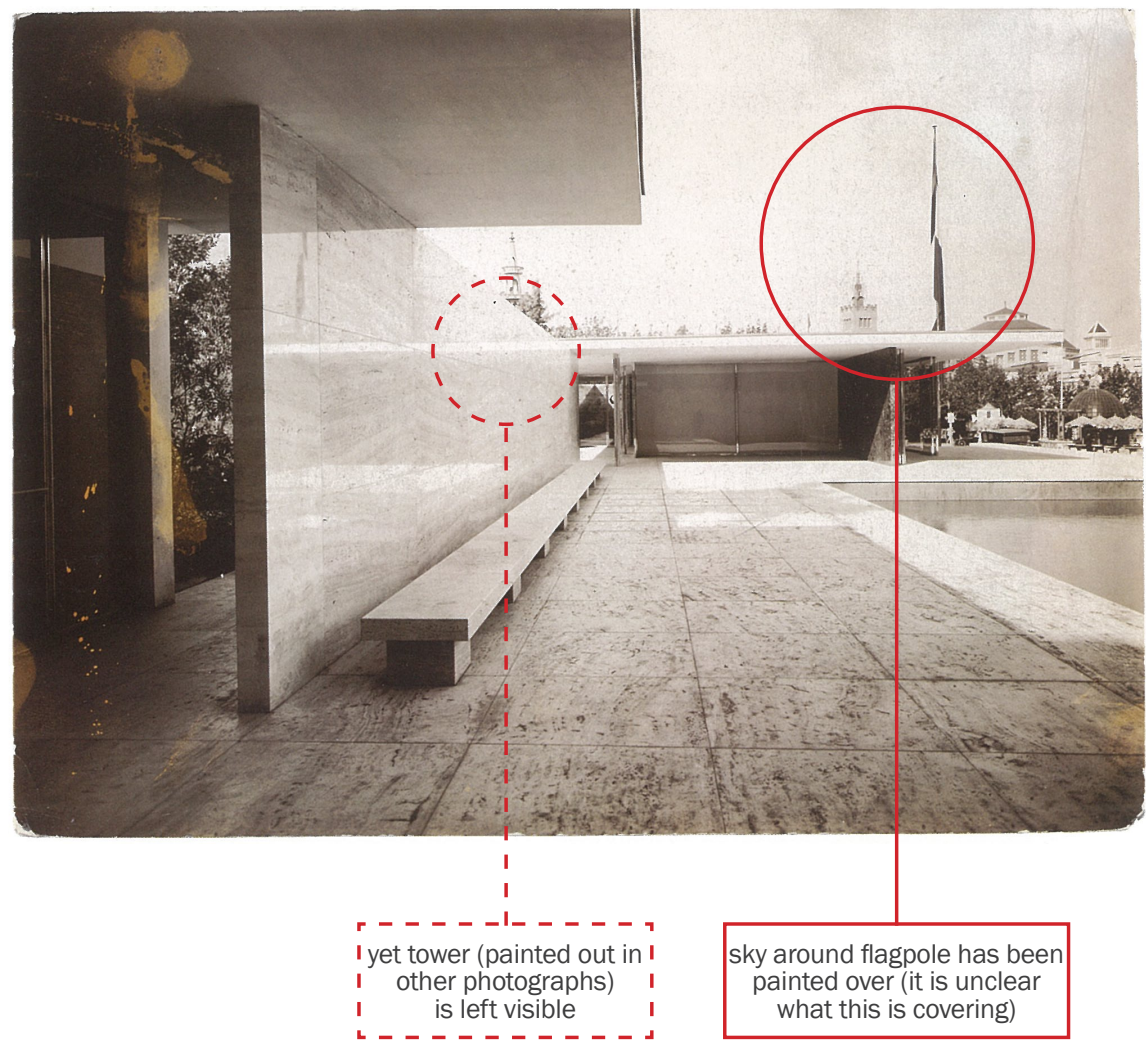

[ MMA 7360]

fig. 7.IX. Barcelona Pavilion, MMA 7360 (Berliner Bild-Bericht, 1929).
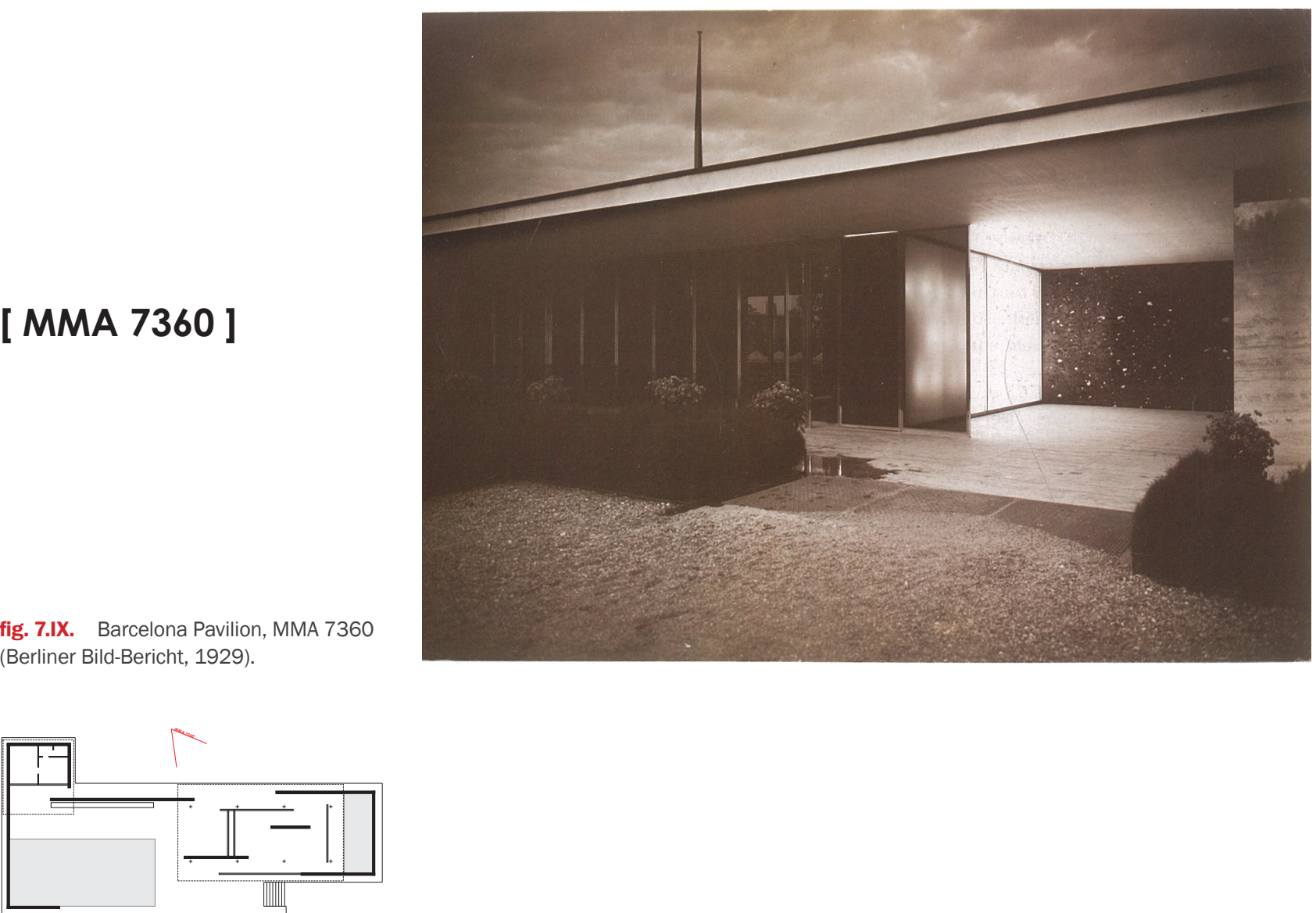


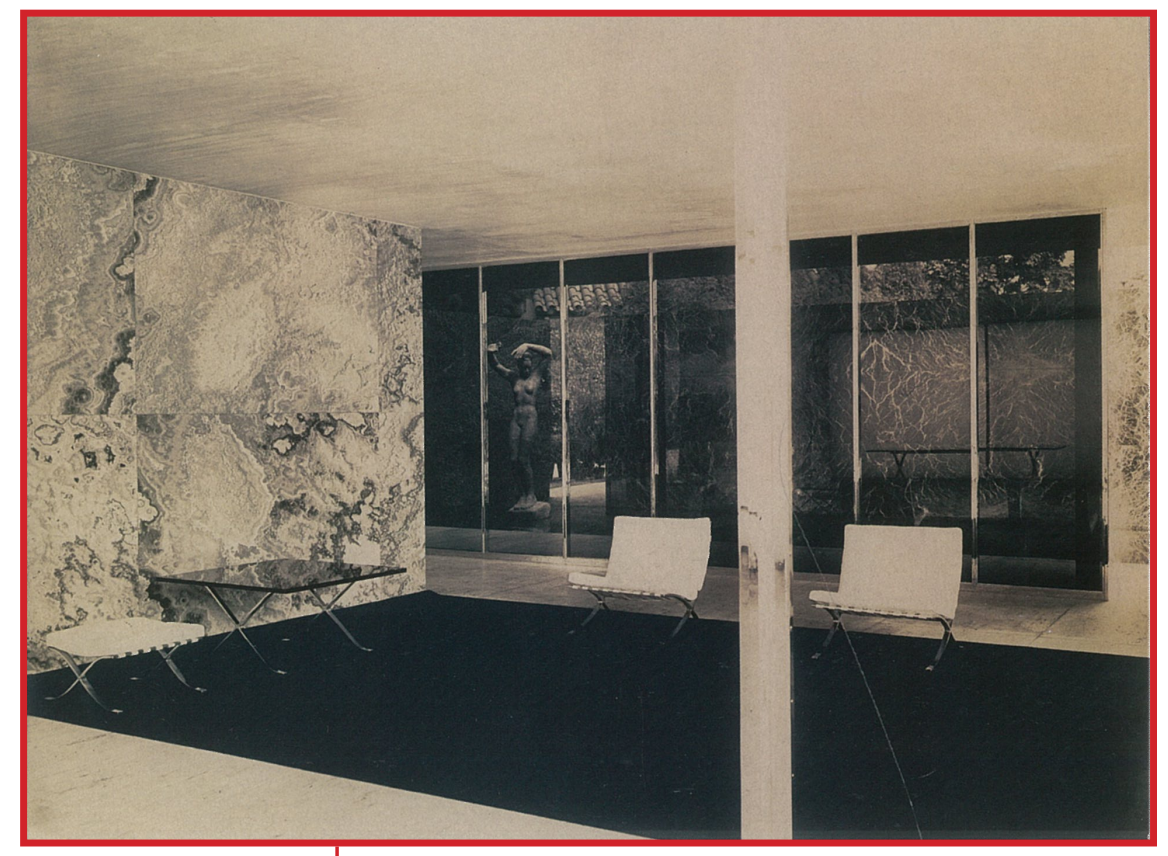

[ SEIDMAN 167 ]

fig. 7.X. Barcelona Pavilion, SEIDMAN 167 (Berliner Bild-Bericht, 1929).

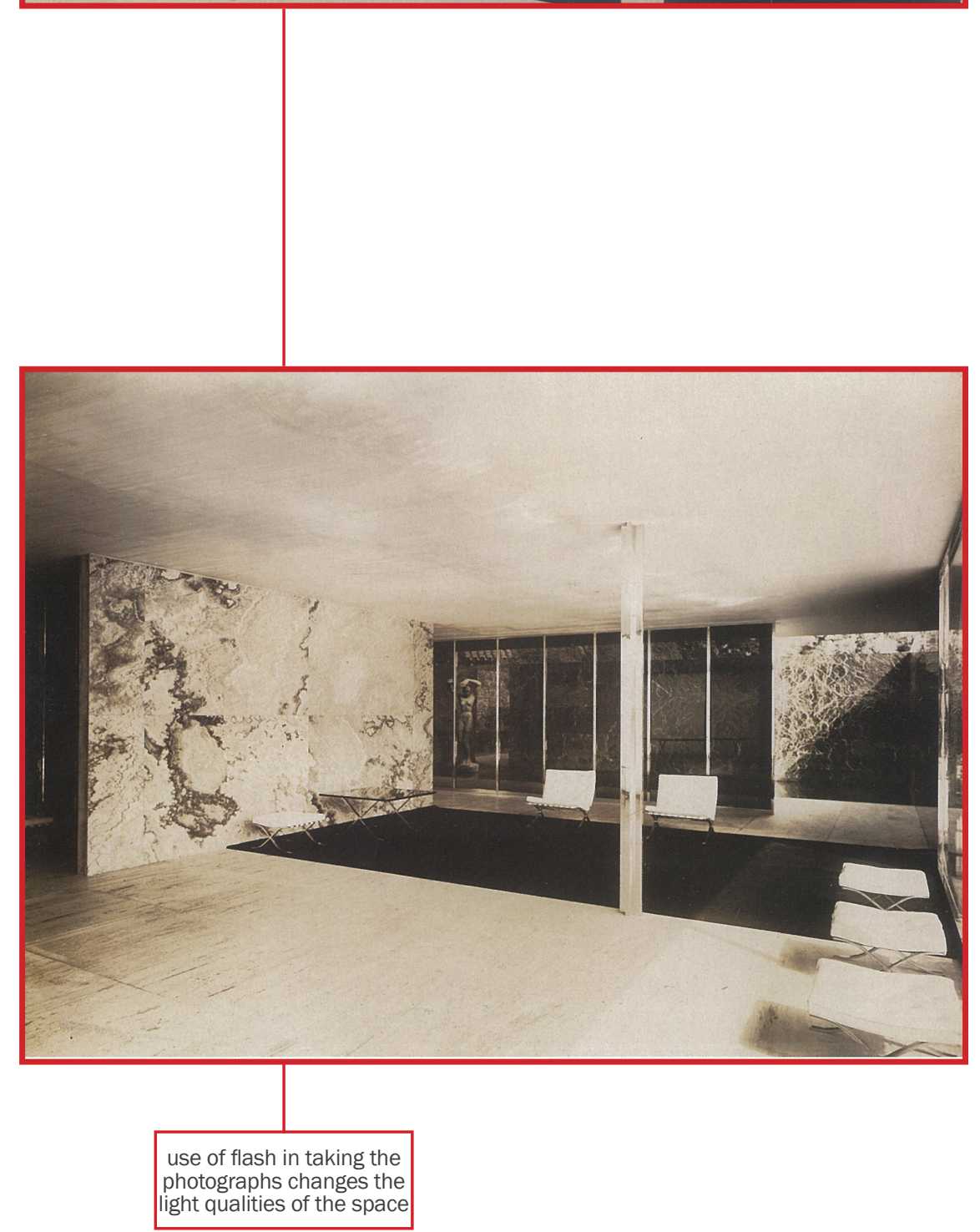

fig. 7.XI. Barcelona Pavilion, MMA 1814 (Berliner Bild-Bericht, 1929).

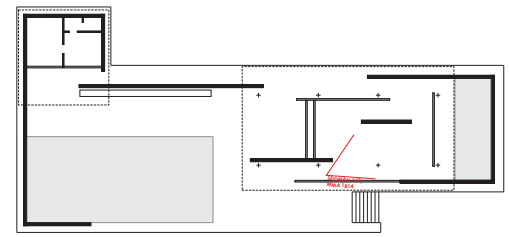




\section{[ MMA 299]}

fig. 7.XII. Barcelona Pavilion, MMA 299 (Berliner Bild-Bericht, 1929).
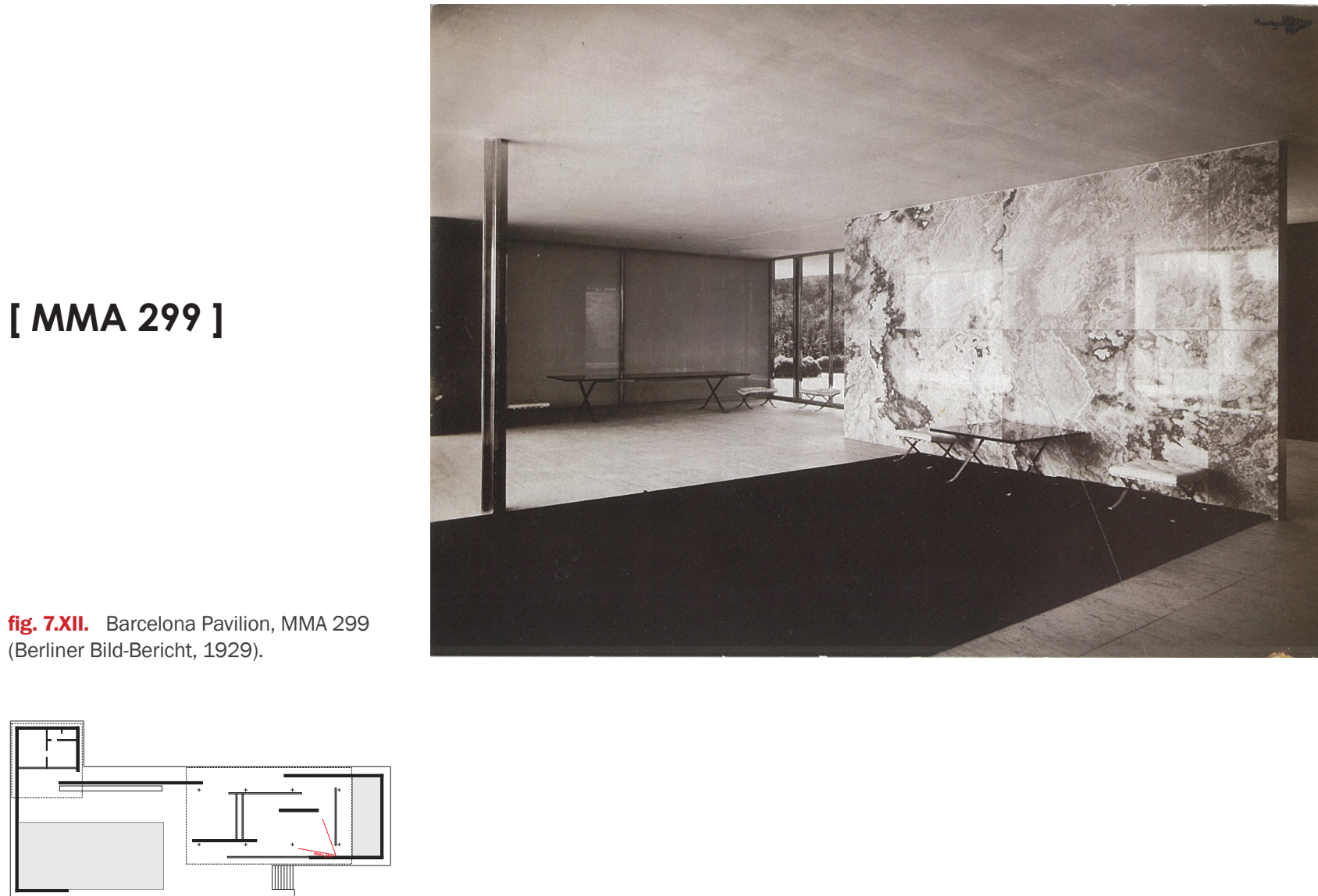

\section{[ MMA 298 ]}

fig. 7.XIII. Barcelona Pavilion, MMA 298 (Berliner Bild-Bericht, 1929).
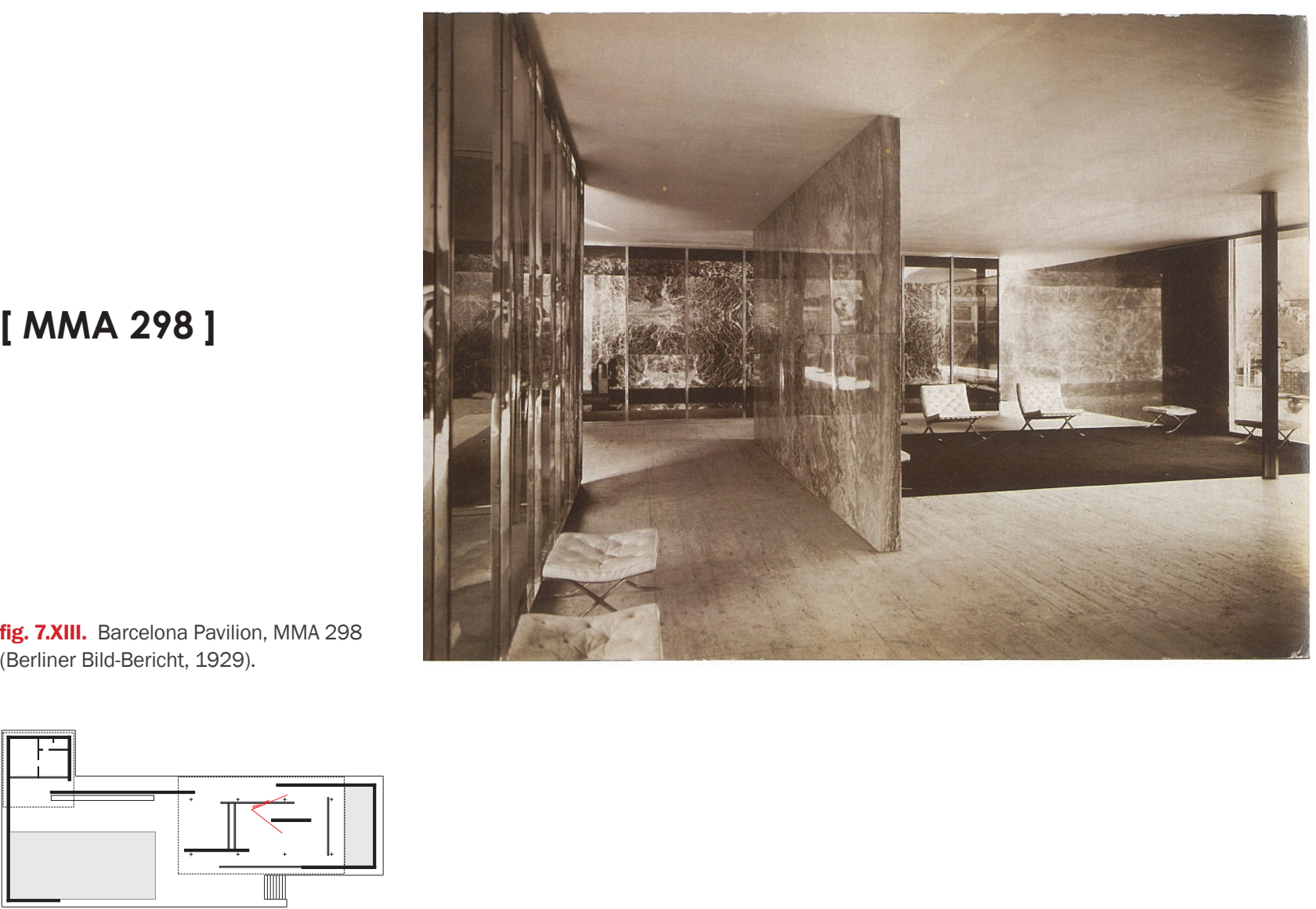


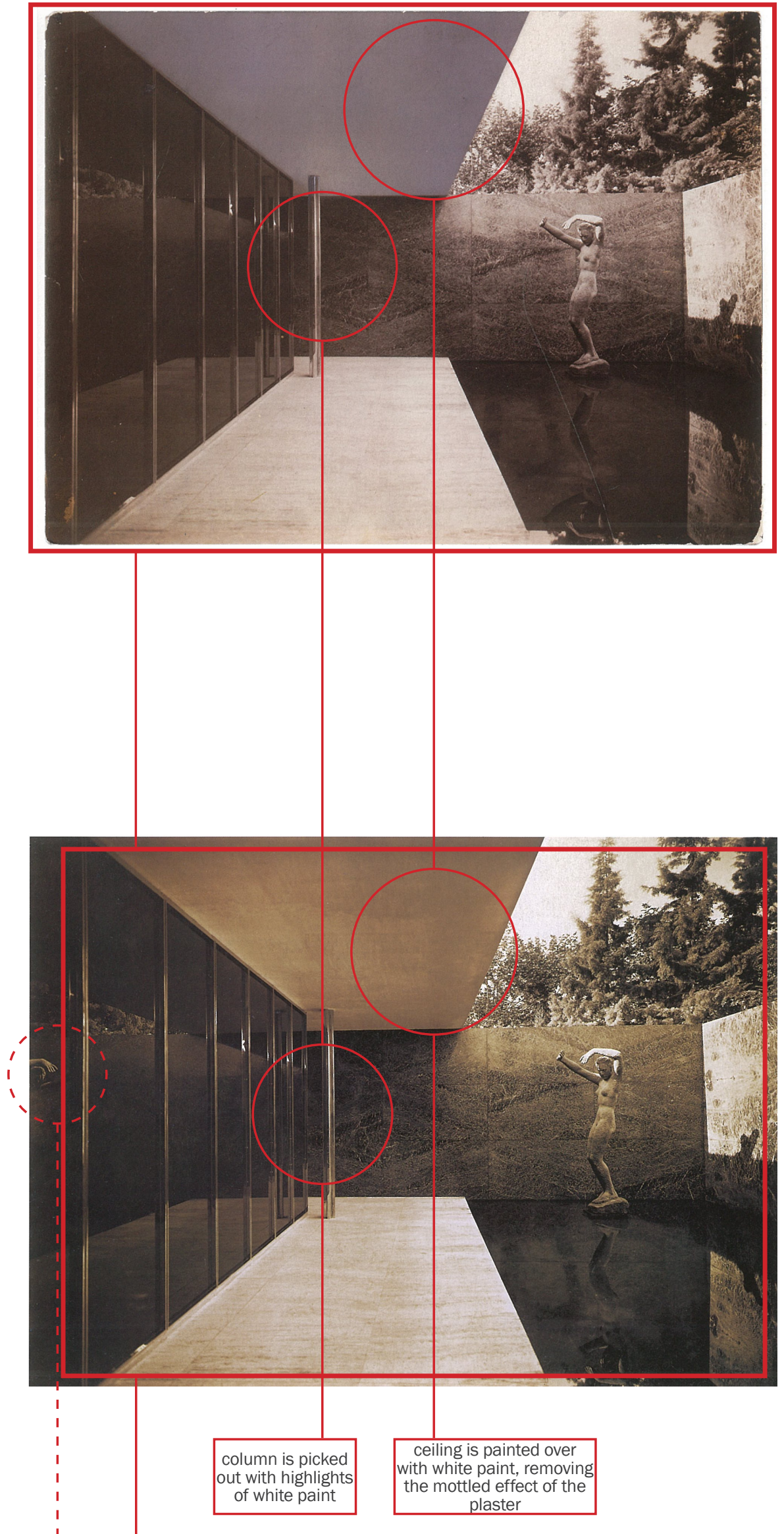

[ MMA 1180]

fig. 7.XIV. Barcelona Pavilion, MMA 1180 [manipulated] (Berliner Bild-Bericht, 1929).

\section{[ MMA 1180]}

fig. 7.XV. Barcelona Pavilion, MMA 1180 (Berliner Bild-Bericht, 1929).

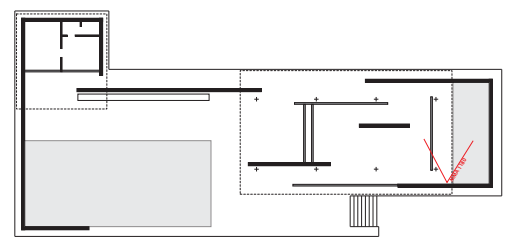




\section{[ SEIDMAN 247 ]}

fig. 7.XVI. Barcelona Pavilion, SEIDMAN 247 (Berliner Bild-Bericht, 1929).
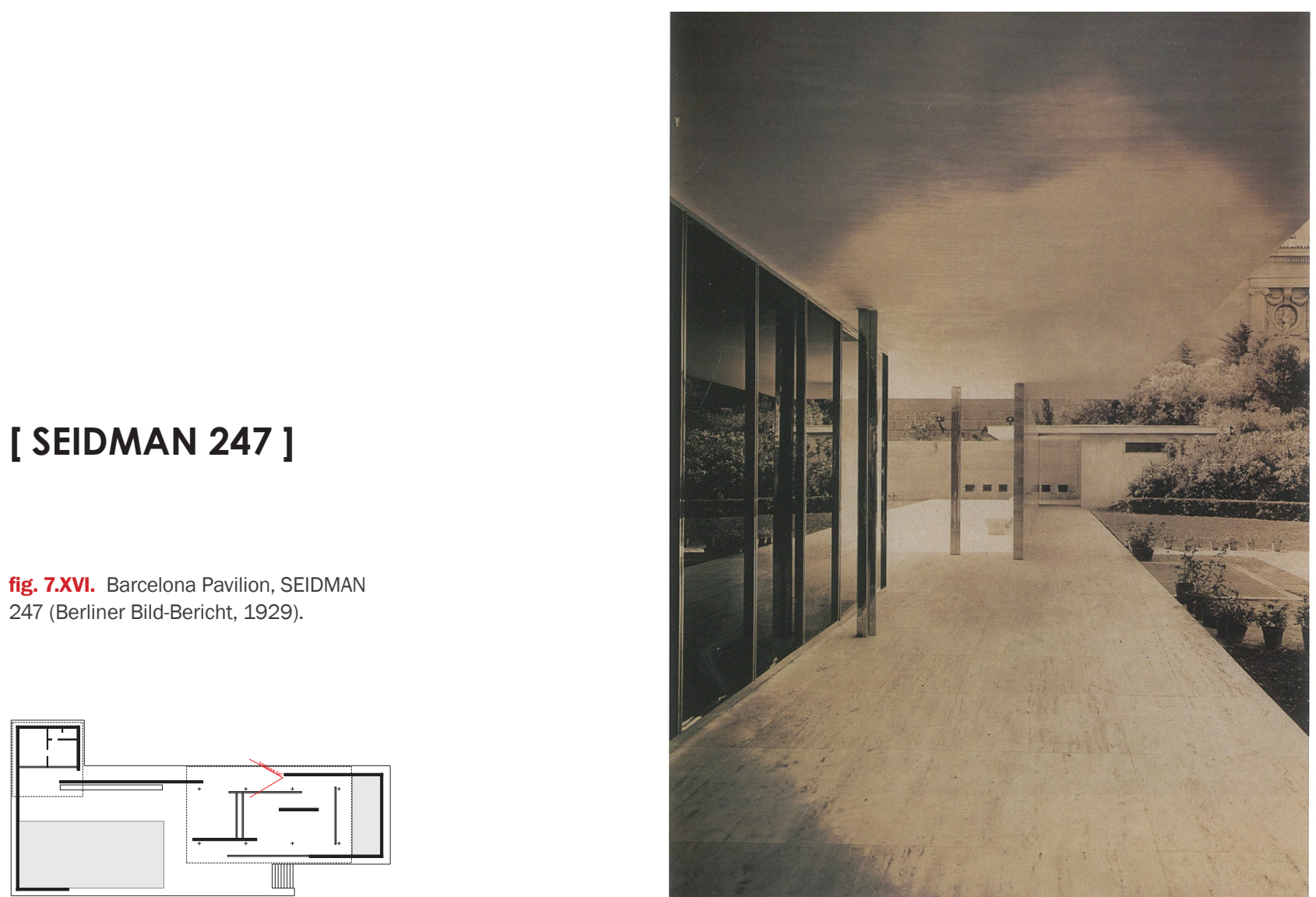

\section{[ SEIDMAN 249 ]}

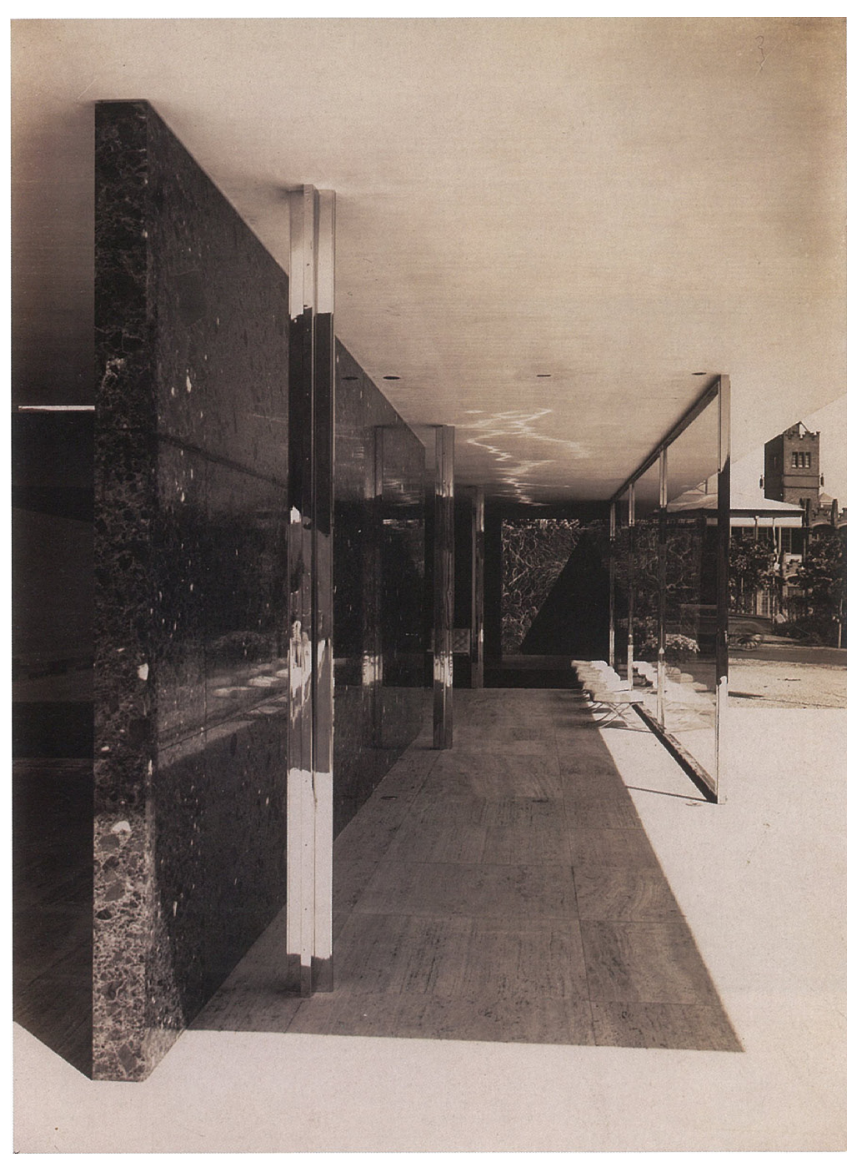




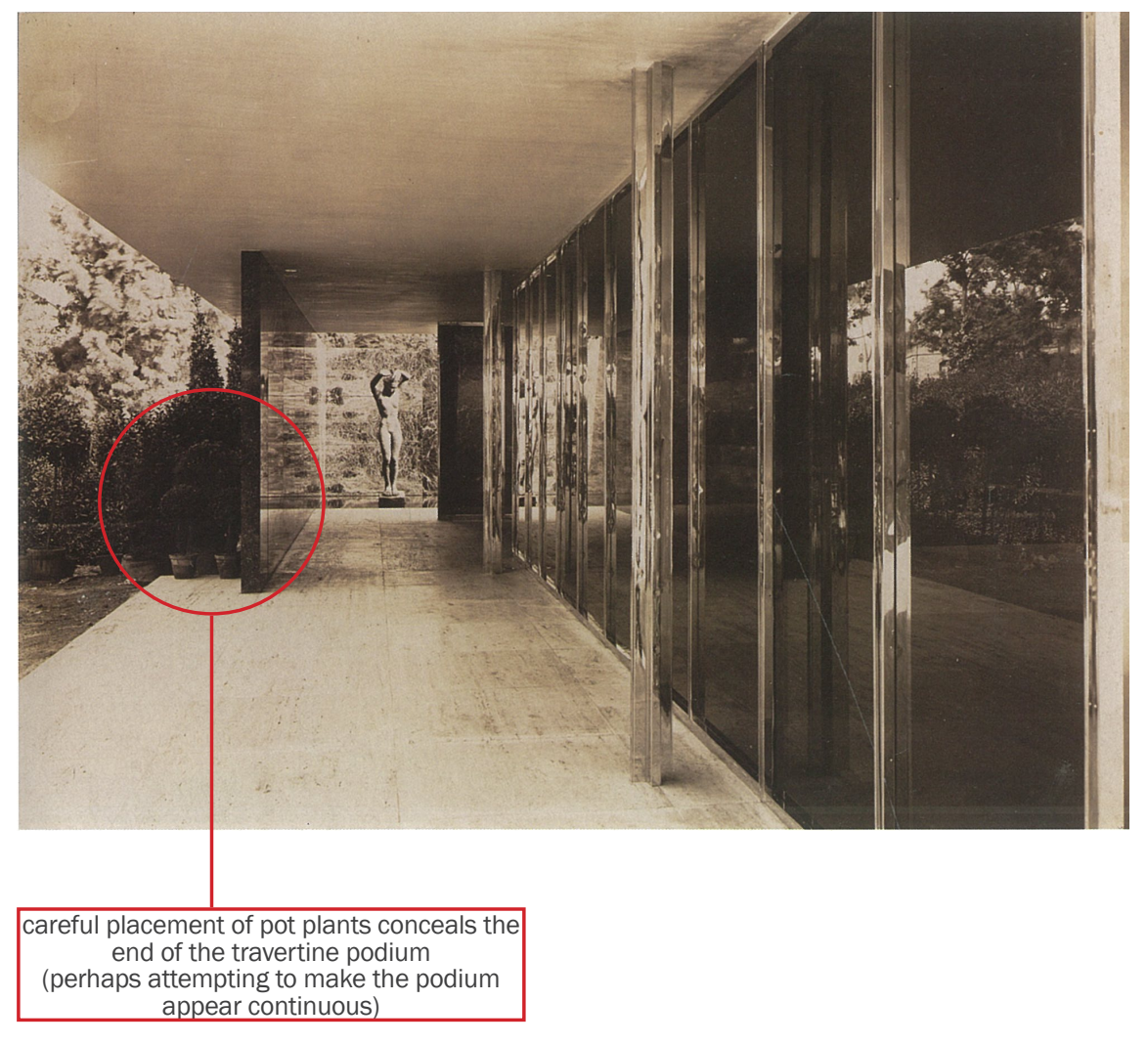

\section{[ MMA 11254 ]}

fig. 7.XVIII. Barcelona Pavilion, MMA 111254 (Berliner Bild-Bericht, 1929).
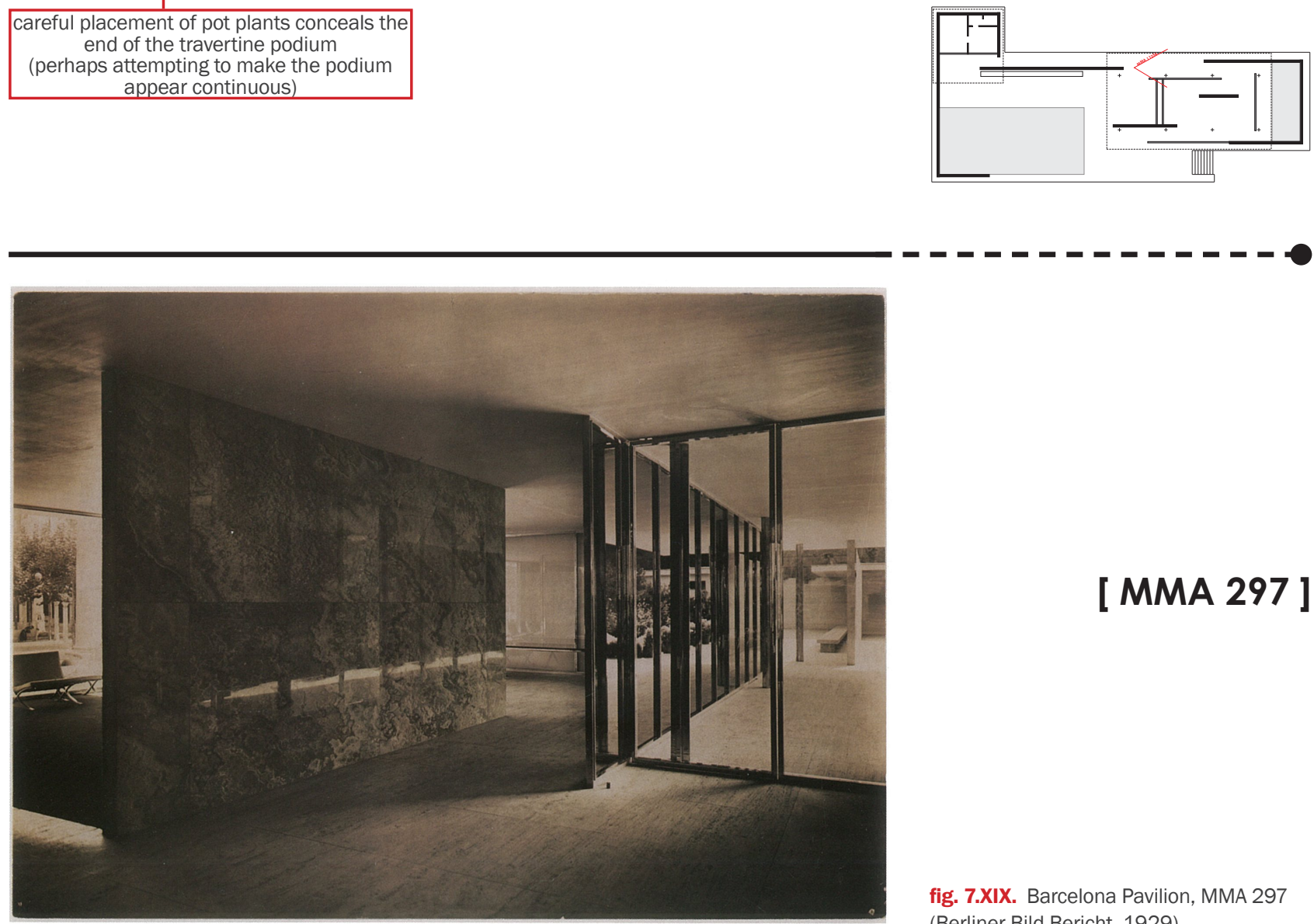

[ MMA 297]

fig. 7.XIX. Barcelona Pavilion, MMA 297 (Berliner Bild-Bericht, 1929).

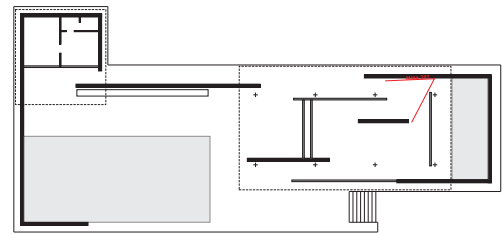


look in these printed media images. For example, aspects of the surrounding site are painted over in certain views, the stainless steel columns are highlighted in others, and each view is carefully framed, positioned or cropped once developed.

\section{The 'authentic' image?}

While Walter Benjamin argued that the mechanical reproduction of artworks effectively banished the 'aura of authenticity' of the original, the case of the Berliner Bild-Bericht prints seems to provide a reversal of this argument. "From a photographic negative," Benjamin writes, "one can make any number of prints; to ask for the 'authentic' print makes no sense" (Benjamin, 2008, pp. 24-25). However, in the case of the Barcelona Pavilion, "original" becomes a complex term: the 'original' 1929 pavilion was 'compromised' as a work of construction in several ways (as discussed later in Section 3 of the chapter), and did not reflect the ideas Mies seems to have explored in its 'mediated' form. The 'original' negatives of Berliner Bild-Bericht prints themselves have been lost, all reproductions being produced from the same set of reproduction prints, yet these carry traces of 'authentic' artistic manipulation through painting and cutting (see Dodds, 2005, pp. 19, 24-25). The manipulated photographic reproductions of the 1929 pavilion can be considered as 'producing' the original built Barcelona Pavilion. They seemingly carry the essence of Mies' intent much more than the pavilion's physical form, whether that of 1929 or 1986. The media 'aura' of the Barcelona Pavilion is therefore situated in the gap between the Berliner Bild-Bericht photographs and viewers' ability to interpret the material reality of their reproduction (images made from dots of ink on paper) as somehow a work of architecture.

\section{The concept of 'montage' or 'collage' in the Barcelona Pavilion}

In the Berliner Bild-Bericht prints, viewers confront a very special work of art, constantly in flux. At odds with the many documentation efforts, various reconstructions, and copious scholarship on Mies and his work, the Barcelona Pavilion remains a fluid, unfixed and changeable work. While the images may be physically present, the architecture they represent remains a promise unfulfilled, being not so much a real documentation of an architectural place as, to use Walter Benjamin's terms, surreal images of ruinous spaces, "residues of a dream world" suggesting a possible architecture (Benjamin, 1973, p. 176). Similar to Terragni's use of the concept of montage in the Sala O, Mies exploited the capacity of photographic film to "break down and to reconstruct, and ultimately to remake the [physical] material... [thereby creating] a new earthly terrain that did not exist anywhere..." except in the media space of montage (Kuleshov, 1974). In terms of its reception via publication, the effectiveness of the Berliner BildBericht photographs can also be attributed to the montage and collage-like 
characteristics of their perception. The consistent and distinctive style of their photography, the similarities between individual shots, as well as the tendency for them to have been published in sets of three or more images at once, contributes to their reading as sets or series of views, rather than as separate or isolated representations. Our eyes flick constantly back and forth between the prints, in effect constructing a montage of mental images as we form connections between the views. Even at the level of individual photographs, the Berliner Bild-Bericht prints operate as kaleidoscope-like collections of reflected and fragmented views rather than straightforward depictions of space, as seen for example in the print MMA 298. Like the drawings of Constructivist architect El Lissitzky and the photocollages of Terragni's Sala 0 , the overlay of ambiguous perspectival messages in Berliner Bild-Bericht photos such as the MMA 298 image seem to deny the space they depict. The aesthetic collision of separate elements and the resulting overlay of independent associations in effect transform the photographs into collages. Juxtaposing contradictory representational information in a way which subtly subverts our perception of physical space, the complementary concepts of montage and collage contribute to the fluid ambiguity of the Barcelona Pavilion's representation and architecture.

\section{Problematic plans}

Similar to the disjunction between the physical and represented realities displayed in the Berliner Bild-Bericht photographs, various and differing plans of the pavilion have emerged in published discourse.

\section{The 1929 publication plan of the pavilion}

The plan submitted by Mies in the official guide to the 1929 Barcelona Exposition was the standard plan accompanying the Berliner Bild-Bericht prints in most accounts of the Barcelona Pavilion until the 1960s. It is a highly-stylised plan, simplifying the pavilion down to an intersection of black lines and boxes. However, there are several inconsistencies between this plan and the Berliner Bild-Bericht photographs. Most significant among these are: the podium of the pavilion being drawn as continuous around the exterior; the absence of the Kolbe statue; and the lack of furnishings. Dodds argues that these absences are "most disquieting as they are essential to the mise-en-scène of the interior" (Dodds, 2005, p. 24 n2I.19a). It is unclear what Mies' motivations were in excluding the sculpture and furnishings from the plan, given that they feature so prominently in the Berliner Bild-Bericht prints and their obvious effect on visitors' experience of the physical spaces. However, one possible explanation could be that Mies was attempting to conceal his careful 'staging' and manipulation of the Berliner Bild-Bericht photographs: As well as the 'post-production manipulation' of the printed photographs, Mies organised the careful rearrangement of the furniture for each Berliner Bild-Bericht view, so perhaps not presenting a fixed furniture layout in the 1929 plan was an attempt

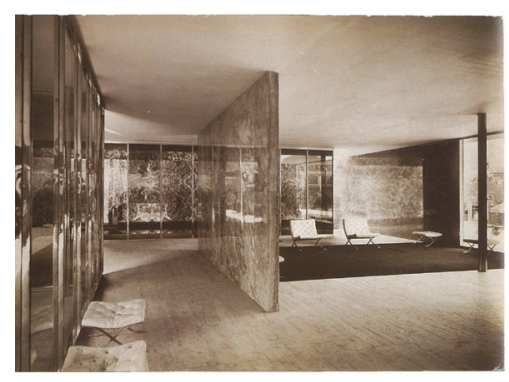

fig. 7.XX. Barcelona Pavilion, MMA 298 (Berliner Bild-Bericht, 1929).

Taken from next to where the exterior glass wall meets the frosted glass of the Light Wall, in this photo nearly every vertical surface is compromised by multiple reflections: the facing plane of the glass wall to the reflecting pool appears to extend through the right-hand wall of the building, just as it penetrates the central onyx wall running directly toward the camera in the foreground. "The flat planarity of the surfaces and the insistence of the horizontal reflection that dominates the centre of the image are visually incompatible. We cannot recognise them as co-existent in space" (Zimmerman, 2005, p.149), an effect paralleling, like Terragni's Sala O, the avant-garde collages of El Lissitzky.

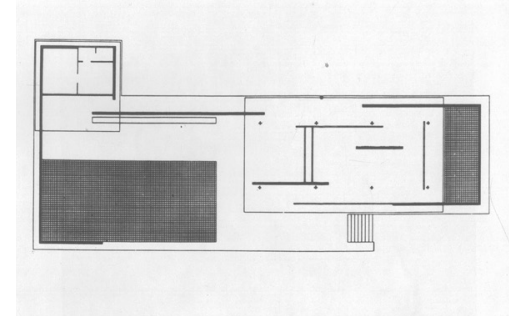

fig. 7.XXI. Mies van der Rohe, Plan of the Barcelona Pavilion (published 1929). 


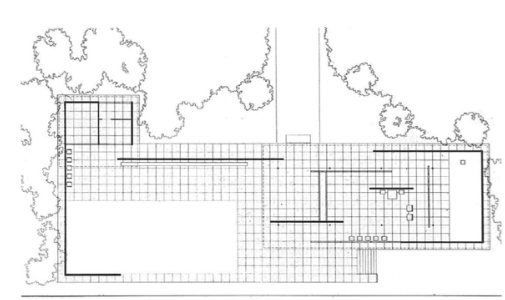

fig. 7.XXII. Werner Blaser, Plan of the Barcelona Pavilion (drawn 1964).
7.5. The influence of these plans can be demonstrated through the debate on the grid of the travertine flooring. Not represented at all in the 1929 published plan, and then drawn as an unvarying and homogenous one metre square grid in the 1964 Blaser plan, many historians have since argued that it was an organisational and proportional module for Mies (and the Berliner Bild-Bericht photographs certainly don't provide any clear evidence to refute this claim)(Tegethoff, 1985, pp. 81-82). The 1986 reconstruction seems to have followed this interpretation, using a regular grid of square slabs measuring $109 \mathrm{~cm}$. Yet workshop drawings from the original marble sub-contractor on the 1929 pavilion document that the slabs actually varied from $81.6 \mathrm{~cm}$ to $114.5 \mathrm{~cm}$, depending on their placement. This, and the fact that the grid does not appear in any of Mies' developmental plans, suggests that the grid was an afterthought, and that Mies adjusted the grid to suit his needs rather than letting it organise the space. to preserve the authority of the photographs. Interestingly, the plan also floats abstractly on a blank white background, further decontextualising it from its siting in the exposition grounds and complementing the abstract qualities of the setting as portrayed in the Berliner Bild-Bericht prints. Despite these discrepancies, visible to anyone looking carefully at the photographs, the plan remained unchallenged for half a century, until the publication of Wolf Tegethoff's Mies van der Rohe: the Villas and Country Houses in 198I (Dodds, 2005, p. 24 n2I.19a).

\section{The 1964 Blaser plan}

In 1965 a new plan of the Barcelona Pavilion was published to accompany Werner Blaser's Mies van der Rohe:The Art of Structure. This was an 'officially sanctioned' plan, produced by Blaser in 1964 while working in Mies' Chicago office. Mies approved this plan for publication, not only in Blaser's book, but in several others from the mid-1960s on. However, like the 1929 publication plan, the Blaser plan is inaccurate (in terms of representing both the built 1929 pavilion, and the pavilion as seen in the Berliner Bild-Bericht prints) in at least three key areas: The roof (drawn as a dashed line) is drawn extending over the small reflecting pool to rest on the Alpine marble perimeter walls. The podium is again drawn as extending uninterrupted around the building. The grid of the travertine paving is drawn as unvarying and homogenous. Further, although some of the furniture and the plinth for the Kolbe statue has been included, the second, larger table is missing from in front of the Light Wall, as well as the area of black carpet which so many interpreters of the pavilion have described as a significant feature of the interior space. Because Blaser was working under Mies' supervision, Mies must have known these inaccuracies were not a true reflection of the built pavilion. Mies also knew that he had carefully managed (via the placement of plantings, the cropping of master prints, etc) the appearance of a continuous podium in the Berliner Bild-Bericht prints. Therefore, the objective accuracy of the plan seems to have been, for Mies, less important than its relation to his ideal of the plan. The correspondence between truth and fact seems to have been the correspondence of idea and image for Mies, a connection which will be further discussed later in the chapter. These two influential plans ${ }^{7.5}$ provide an example of how Mies made conscious choices to present a highly-filtered version of the pavilion's design to the media, one not corresponding to the physical 1929 pavilion but supporting certain attributes of the pavilion produced through the Berliner Bild-Bericht photographs. In doing so, I argue Mies was seeking intentionally to influence the interpretations people were able to make of his architecture. 


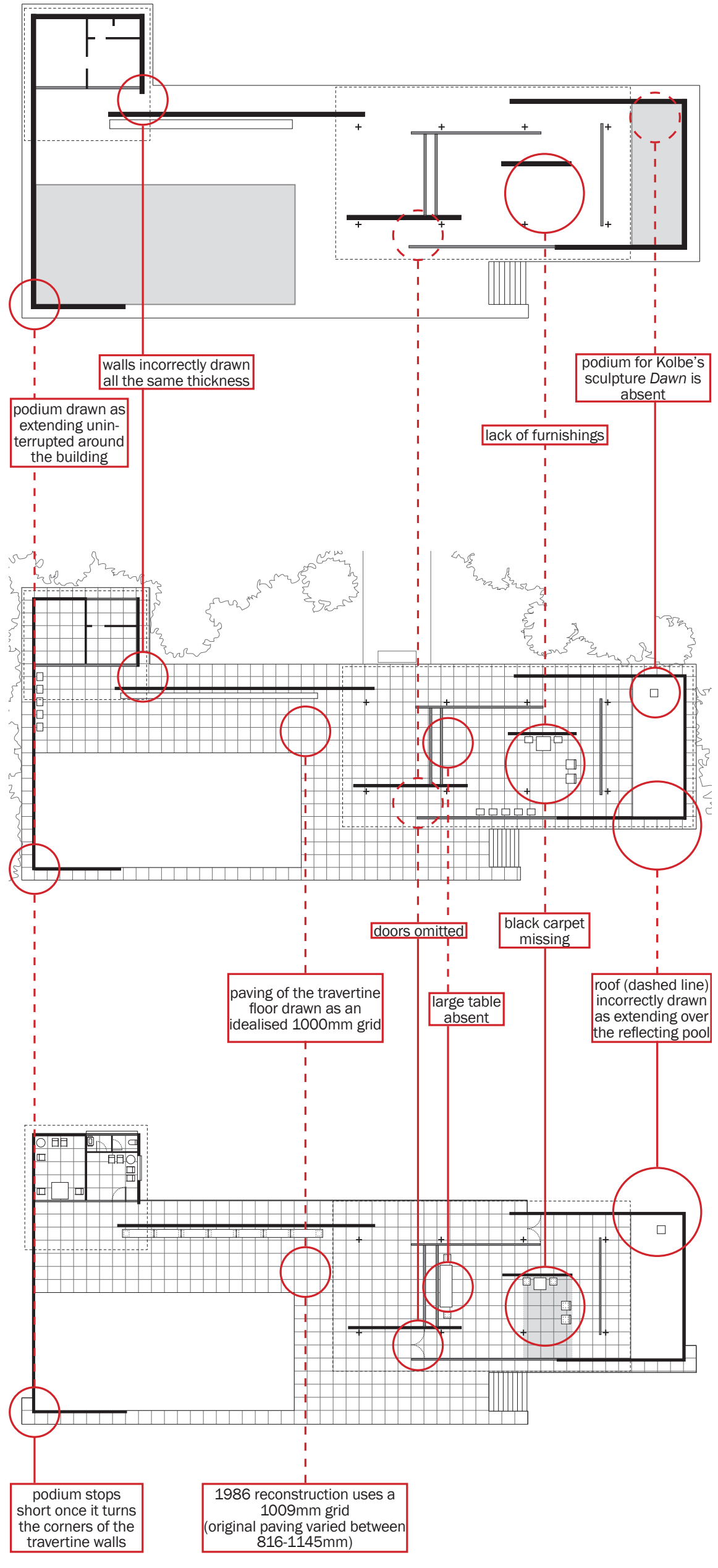

fig. 7.XXIII.

Plan of the Barcelona Pavilion (as published 1929).

Author's own drawing based on the plan drawn by Mies to accompany the offical catalogue of the 1929 Barcelona Interna tional Exposition.

Note the extreme simplification, lack of furnishings, and podium.

fig. 7.XXIV.

Plan of the Barcelona Pavilion (as published 1965).

Author's own drawing based on Werner Blaser's plan drawn under the supervision of Mies in his Chicago office in 1964.

Note the podium, indications of site context, and roof lines.

fig. 7.XXV. Plan of the Barcelona Pavilion (as published 1986).

Author's own drawing based on the plan of the 1986 reconstruction by Ignasi de Solà-Morales, Cristian Cirici, and Fernando Ramos.

Note the podium, furnishings, doors, and roof lines.

The design of the service annexe to the rear of the large reflecting pool is one of the leastdocumented aspects of the pavilion, with no interior photographs having yet been discovered. Given that each of the plans above shows a slightly different configuration for the annexe, uncertainty remains. 


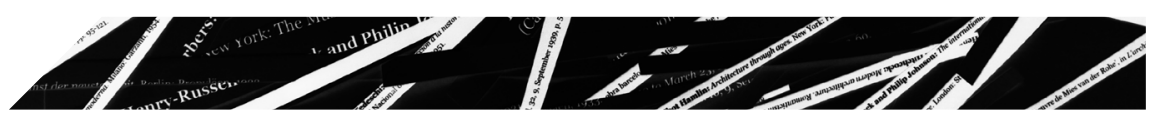

SECTION 2:The Barcelona Pavilion and the Culture Industry

As a cultural product, particularly one whose significance is intrinsically tied to the publication of certain architectural media and representations, the Barcelona Pavilion is implicated in the processes of the architecture culture industry. Privileging certain understandings - canonical interpretations - the culture industry has advanced certain myths, misstatements and inaccuracies to do with the pavilion, revealing the use of the Barcelona Pavilion as a vehicle for architectural ideology.

\section{The pavilion and ideology: canonical interpretations}

Among the many books, essays and critiques of the Barcelona Pavilion, the first critic to focus on the published life of the pavilion as opposed to its physical existence was the semiotician and historiographer Juan Pablo Bonta. He chronicled the publication history of the pavilion in two books published in 1975 and 1979 respectively, proposing a series of stages to the interpretation of historically significant buildings. Bonta's fourth stage of interpretation is "Canonic Interpretation", which he describes as a sort of "crystallisation" of influential interpretations into a cohesive understanding which is then propagated throughout sections of a community. What mainstream architecture understands of the Barcelona Pavilion is the result of such canonical interpretations promoted by the architecture culture industry. Bonta collated a pastiche of points from an extensive survey of published material on the pavilion to identify what its canonical interpretation might include. It covered things such as the fluidity of space provided by the "free" plan; the non-structural walls contrasting with the independently-arranged structural columns; and the commonly-made assertion that the building was a work of art, the leading building of the decade, perhaps the best of the century. Bonta was careful to note that a difference exists between interpretations based on first-hand experiences of the 1929 pavilion, and those of critics who could only see photographs and other published material. However, as he identifies the emergence of 
the canonic interpretation with the appearance of a number of influential critiques of the Barcelona Pavilion around 1960-1961,7.6 (three decades after the physical building was demolished) this canonic understanding is more an interpretation of the Berliner Bild-Bericht prints than of a firsthand spatial experience. Once again reinforcing the significance of the Berliner Bild-Bericht prints in almost every interpretation of the pavilion, the canonical interpretations themselves developed the power to shape, inform and to a certain extent restrict future interpretations. Canonical interpretations are extremely difficult to escape, as even 'alternate' or 'oppositional' interpretations are positioned in response to mainstream or prevalent views.

\section{The 'International Style' exhibition and book}

The canonical status of the Barcelona Pavilion was aided by the inclusion of an enlarged Berliner Bild-Bericht photograph and an idealised plan of the pavilion in MoMA's Exhibition 15, Modern Architecture: International Exhibition, 1932. Curated by Henry-Russell Hitchcock, Philip Johnson, and Lewis Mumford, this exhibition and the book, "The International Style:Architecture since 1922”, written by Hitchcock and Johnson to accompany it, defined the emergence of a new architectural 'style' characterising architectural production in the third decade of the twentieth century. In both the exhibition and the book, special attention was drawn to the Barcelona Pavilion, which was cited as a paradigm of the new style, despite none of them having seen the building physically in 1929. Their coverage of the pavilion was based entirely on second-hand media material, including several Berliner Bild-Bericht prints and an incorrect plan. The written description of the building in the book is packed with misstatements of fact and uncited restatements of others. Given how influential this book became in helping shape the course of $20^{\text {th }}$ century modernism, the authors can be held responsible in part for establishing certain 'myths' of the Barcelona Pavilion for several generations of architects.

\section{The pavilion and ideology: myths}

The Berliner Bild-Bericht prints of the pavilion have been published and reproduced so often, and in so many different situations, that they cannot be considered independently of their history of interpretation. Part of this history is a set of ideological interpretations of the pavilion's architecture which have been promoted by the architecture culture industry as being “accepted" truths. However, as I will attempt to explain, these apparent "truths" are in fact highly-artificial perceptions of the pavilion, deriving from the manipulated reality of Mies' Berliner Bild-Bericht images. In promoting these "false truths" as "facts", the architecture culture industry has created a mythic pavilion, further cementing its cultural significance to the fabric of mainstream architecture culture. These myths are always linked to ham, Arthur Drexler, Peter Blake Leonardo Benevolo and Vincent Sully as among those critics published 1960-1961 who cemented the canonical interpretation of the pavilion in place.

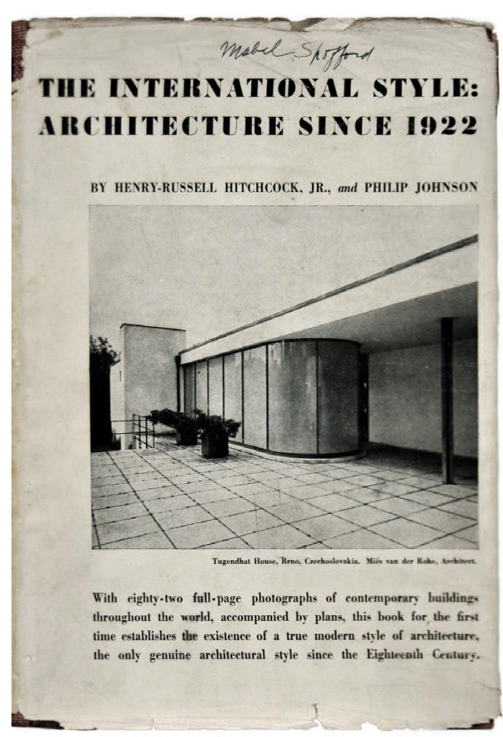

fig. 7.XXVI.

Henry-Russell Hitchcock \& Phillip Johnson, The International Style: architecture since 1922. Cover, Octavo, 1932.

Featured on the dustjacket is the Tugendhat House, Brno, which Mies was designing as he worked on the Barcelona Pavilion. 


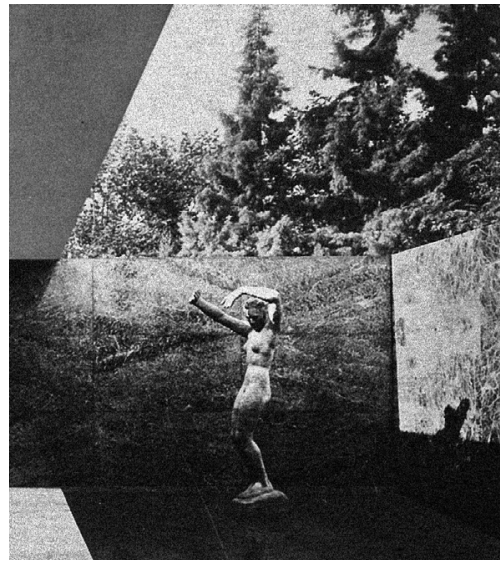

fig. 7.XXVII. reproduction of MMA 1180

Note how the grainy texture of this black-andwhite print makes the veining of the marble wall appear similar to the vegetation visible above the wall.

Tegethoff writes: “Nature here extended almost symbolically onto the structure itself, causing the boundaries to blur... The dark green veining of the Tinos marble blended visually with the surrounding cypresses and conifers, appearing to be the architectural crystallization of their organic forms. In the surviving photographs this is particularly apparent from the way in which the plants on the shadowed north side can scarcely be distinguished from the wall" (Tegethoff, 1985, p. 87) the intrinsic qualities of photographic reproductions of the pavilion, chiefly of the BBB prints.

\section{Myth of the new "free plan" and "free facade"}

Mies' comments on his work, including the pavilion, often seem to have been delivered with a politician's grasp of propaganda and mythmaking. As an architect who professed to be apolitical, he nevertheless appears to have been skilled in all of politics' most important arts, including the art of laying claim to "new" ideas previously "discovered" by others. A famous example of this is his sudden revelation while designing the Barcelona $\mathrm{Pa}$ vilion - that walls no longer had to be load bearing. "One evening as I was working late on the [pavilion] I made a sketch of a free-standing wall, and got a shock. I knew it was a new principle" (6 Students Talk with Mies, I952, p.28). Mies' comments have led generations of architects to believe in the 'new honesty' of the pavilion's structural system, with the slender chromeplated columns promoted as the only structural elements. Yet three years earlier, Le Corbusier had already published his ideas on the "free plan" and "free facade" in an article in L'Esprit Nouveau, “Les 5 points d'une architecture nouvelle" (Dodds, 2005, p. 25). And ironically, despite his professed revelation, Mies was forced to make many of the walls in the pavilion load-bearing because its slender columns were too thin to adequately support the roof. (Dodds, 2005, p. $59 \mathrm{n79}$ ). The gap between the reality of the pavilion and its portrayal by Mies and the culture industry allowed this myth to emerge, largely as a result of the apparent clarity of structural distinction presented by the Berliner Bild-Bericht photographs.

\section{Myth of site specificity}

Initially interpreted as a relatively self-referential and isolated project, recent influential interpretations have inverted this notion, claiming the Barcelona Pavilion as a careful and subtle site-specific work. Writers such as Glaeser (1979), Hays (1984), Tegethoff (1985), and Neumeyer (I99I) interpreted the pavilion to have been strategically designed for its site within the masterplan, topography, and physical context of the Exposition on the lower slopes of the Montjuic hillside. This is despite most traces of the surrounding context of the pavilion in the BBB prints typically being painted over, kept out of frame, or blurred to abstraction. Tegethoff in particular argues for the intrinsic connection of the pavilion to its setting because of the way the green marble walls blend into the surrounding foliage.

However, the photograph Tegethoff uses to illustrate his claim is a grainy photo based on the MMA I I80 Berliner Bild-Bericht print, showing the small reflecting pool with the Kolbe statue. In his book, the foliage and wall appear similar in texture and tone, and reproductions of the print in other publications indicate that the larger and grainier the enlargement, 
the closer in tonal value the wall and vegetation appear. Yet in clear reproductions of the BBB prints, as well as in colour photographs of the 1986 reconstructed pavilion, this similarity is reversed. The similarity between three-dimensional vegetation and the two-dimensional veining of the $\mathrm{Al}$ pine (not Tinian, as Tegethoff claims) marble wall is largely a function of the homogenising effect of the black-and-white photographic image, as well as of the loss of detail in the processes of mechanical print reproduction. This example illustrates how the peculiarities of media material can inform people's perceptions of architecture, in this case allowing Tegethoff and others like him to interpret a connection between the pavilion and its physical context.

\section{Myth of symmetry}

The qualities of photography, particularly its qualities of distance and abstraction, are the source of another "mythic" interpretation of the pavilion. Robin Evans' essay, Mies van der Rohe’s Paradoxical Symmetries(first published 1990) is a widely cited analysis of the pavilion's hidden 'horizontal symmetry'. 7.7 Evans claims that Mies consciously eliminated obvious symmetry in the plan and elevation of the pavilion, only to slyly reintroduce it back into the design via an "optically constructed" symmetry along a horizontal axis between floor and ceiling, and then finally readmit symmetry "into its normal orientation as a family of fictions (in reflections)" off the shiny finishes of the pavilion's materials (Evans, 2002, p. 412). Yet by his account, this 'horizontal axis of symmetry' was only apparent to Evans when studying photographs of his visit to the reconstructed 1986 pavilion, not during the actual visit itself."Perusing the slides I had taken of the reconstructed pavilion, I found it difficult to decide which way up they went - an artifact of photography no doubt. Then I changed my mind. It was not an artefact of photography, but a property of the pavilion itself, a property of which I had not been conscious while there [but which] the photographs had made it easier to discern"(Evans, 2002, p. 409).This myth of the pavilion's horizontal symmetry seems therefore based entirely upon the kind of framed, static views of an abstract visual field particular to the photographic image, and further, on a reading of such images disregarding signs of Mies' own ideas on the matter.

\section{Mies' factual manipulation: misstatements and inaccuracies}

Right from the very start of its history, misstatements and inaccuracies have accompanied virtually all publications of the Barcelona Pavilion. For example, in Sheldon Cheney's The New World Architecture (1930), one of the Berliner Bild-Bericht photographs is captioned, "The German Pavilion at the Seville Exposition.” Demonstrating the crucial dependence between image and text, this example seems to show that it is the caption which determines the 'truth' of the picture. Dodds has written on this gap between
7.7. For further interpretations of horizontal symmetry and the idea of "horizon" in the pavilion, see Randall Ott, "The Horizontal Symmetry of Mies van der Rohe", Dimensions, vol. 6 (Ann Arbor, MI: University of Michigan, 1993), and Caroline Constant, "The Barcelona Pavilion as Landscape Architecture: Modernityand the Picturesque", AA Files, vol. 20 (Autumn, 1990).

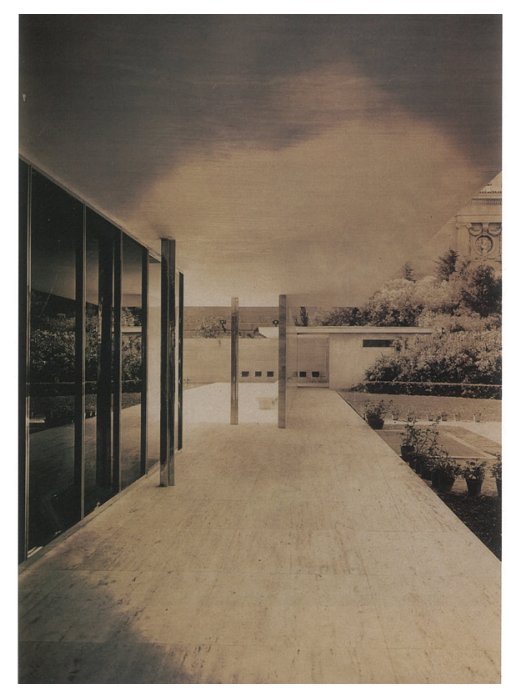

fig. 7.XXVIII.

Barcelona Pavilion, SEIDMAN 247 (Berliner Bild-Bericht, 1929).

Evans writes: "Notice the difficulty of distinguishing the travertine floor, which reflects the light, from the plaster ceiling, which receives it. If the floor and the ceiling had been of the same material, the difference in brightness would have been greater. Here, Mies used material asymmetry to create optical symmetry, rebounding the natural light in order to make the ceiling more sky-like and the ambiance more expansive" (Evans, 2002, p. 409) 


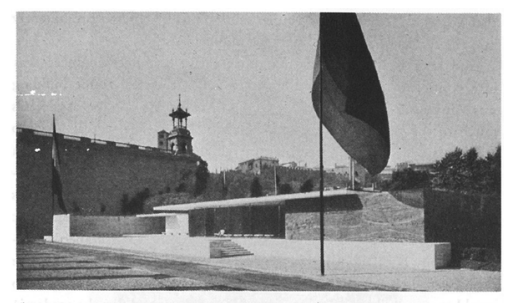

fig. 7.XXIX.

Image of the Barcelona Pavilion from Sheldon Cheney's The New World Architecture (1930).

A reproduction of the Berliner Bild-Bericht print MMA 1554 is mis-captioned "The German Pavilion at the Seville Exposition." Further, the image is incorrectly attributed not to Mies van der Rohe or to Berliner Bild-Bericht, but to a completely separate author, Frederick Kiesler. "truth" and "fact" in Mies' work and discourse, noting how the things he said often seeming to be in conflict with the projects and buildings he made (Dodds, 2005, p. 126). During the 1960s, when Mies was asked about the pavilion, his recollections grew increasingly vague, often sounding more like repetitions of what others (who knew the building primarily through the Berliner Bild-Bericht prints and the few (inaccurate) plans) had to say. His comments on the pavilion seem to confuse more than explicate. These included confusion on its dimensions, materials, configuration, and even what happened to the pavilion after its physical deconstruction. Yet Mies appears not to have made any corrections or clarifications of the many textual and graphical errors in the accounts of the pavilion published during his lifetime, many of which were made with his direct involvement. This suggests that Mies was employing a strategy of deliberate misinformation, taking advantage of the ambiguous state of the pavilion to advance ideas he approved of, or strategically remove others which conflicted with his vision. He also seems to have been content for the architecture culture industry to appropriate the pavilion as an icon of modern architecture, especially given the cultural prestige this bestowed upon him as architect. Seemingly to maximise this personal benefit, it could be argued Mies was prepared to alter his original ideas on the pavilion to conform to the canonical interpretations which the culture industry was busy manufacturing and promoting. However, what Mies' involvement with the culture industry's canonical interpretations and mythmaking activities certainly demonstrates is the influence which the architecture culture industry exerts over all individuals engaging with the field of architecture: users, interpreters, critics and architects. People shape their architectural meanings around the cultural contexts they are situated in, people's ideas constantly evolving in response to those around them. 


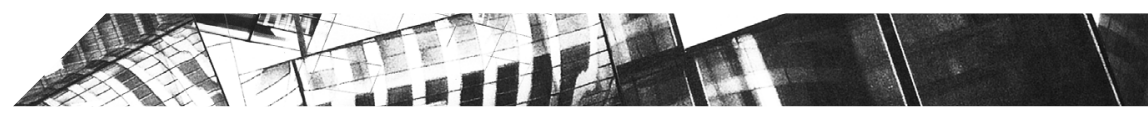

\section{SECTION 3:The Barcelona Pavilion and Meaning}

My study of the entwining of the pavilion's existence with its representation in print media, as well as of the associated influence of the architecture culture industry in its widespread conception and understanding, has produced several lessons for an understanding of architectural meaning.

\section{A 'compromised' construction: "architecture" vs. "building"}

The design of architecture and the construction of buildings are often two completely separate things. The design of architecture involves the subtle manipulation of many elements, ideas and concepts, whereas its construction is often an act of compromise, failing to realise the potential of many aspects of the design. The Barcelona Pavilion can be seen as a clear example of this distinction between architecture and building. The physical reality of the 1929 pavilion was "compromised" in terms of Mies' vision by the extreme limitations of time and budget imposed on the project, as well as its position as only a temporary construction. Mies employed many halfmeasures ${ }^{7.8}$ to complete the pavilion, but even these did not allow the construction to be finished on time, the pavilion opening late a few weeks after the official start to the exposition. However, the canonical interpretations of the pavilion converge repeatedly on Mies' use of precious materials and construction techniques that were built to last. The myths of the culture industry support these ideas, allowing for the 'edited' Barcelona Pavilion of canonical interpretation to emerge, unified and appraised through carefully framed and cropped photographs. By Mies' transformation of a building into a photograph of a building, the compromised 1929 pavilion was "freed from the unsubtlety of construction and imbued with the nuance of the architect's hand" (Dodds, 2005, p. 78). While the 'building' itself appears to have been unsatisfying for Mies, he was nevertheless still able to create 'architecture' through a conscious separation of these two distinct acts. Our interpretations of the Barcelona Pavilion ought to take this separation into account.

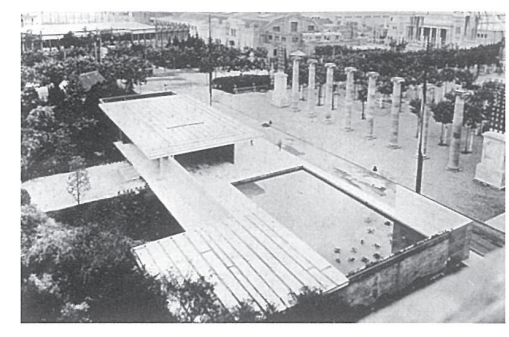

fig. 7.XXX. Barcelona Pavilion seen from above, showing the cheap tarpaper roofing (visible as black lines) used in the 1929 construction.

7.8. Among such "short-cuts" were: exterior walls crudely covered with painted rough stucco, a podium base which stops just out of the primary views of the building, an unevenlyfinished plasterceiling, periodic flooding of the interior, and a curtain track that rarely worked for a curtain that, as Dodds argues, Mies probably never wanted (Dodds, 2005, pp. 110-125). 


\section{Priorities}

Having thus conceptually separated 'building' from 'architecture', Mies was able to focus his attention on those avenues of production which most effectively fed his explorations of architectural meaning. Historic personal correspondence between Mies and his close collaborator on the BarceIona Pavilion, Lilly Reich, suggests that Mies placed more value on the Berliner Bild-Bericht photographs than on the 1929 building itself. Documents in the Mies van der Rohe Archive at the Museum of Modern Art, New York, show that by the time of the official opening of the German Pavilion in May 1929, Mies was already absorbed in the design of the Tugendhat house in Brno. "Although the correspondence between Mies and Reich reveals that the pavilion had numerous problems requiring resolution, Mies was inattentive to them and quickly lost interest in the temporary building" (Dodds, 2005, p. 82). At the end of the exposition, a serious offer to the German authorities from a local businessman in Barcelona to convert the pavilion into a restaurant was, tellingly, left unconcluded: when given an opportunity to save the building from demolition, Mies seems to have decided not to intervene. Dodds argues that, in Mies' eyes, the prolonged existence of the pavilion (especially if it was reprogrammed with an 'ordinary' function) would diminish much of what the Berliner Bild-Bericht photographs had achieved. "After all, the Berliner Bild-Bericht photographs had been published throughout Europe and the United States; Mies had what he wanted. Given the choice of preserving the master prints of the building, Mies chose the photographs" (Dodds, 2005, p. 82).

\section{Idea and image:The pavilion and dreaming}

As suggested by his deliberate sanctioning of inaccurate plans of the Barcelona Pavilion, it seems for Mies, the correspondence of 'truth' and 'fact' in architecture was the correspondence of 'idea' and 'image'. Mies explored his architectural ideas in the media space of architecture, in drawings, photographs of drawings and photographs of temporary buildings. The relation of such 'media-makings' to built form was often unclear. However, this seems to have been deliberate: through consistent verbal opacity, and over-simplified statements of intent, Mies seems to embrace the manipulative potential of ambiguous information. By saying one thing, yet showing people another, Mies set up a creative tension in his work which allowed people to read many more things into the pavilion than he ever conceived of. It also allowed the pavilion to act as a sort of 'blank slate', a medium for interpreters to project their own ideas, agendas and desires onto. In his book Building Desire, George Dodds discusses this trait of the pavilion, seeing it as inspiring an oscillation between waking and dreaming. Dodds sees the pavilion as "a threshold to a recurring dream of modernity that, over time, has become so familiar to historians and critics that their memories of photographs are often confused with waking experiences of an inhabited architecture" (Dodds, 2005, p. 42). Seeing this as an indication 
of the fundamentally surreal character of the BBB prints, Dodds uses the pavilion to suggest we question other works of architecture, particularly those where our knowledge of which depends almost exclusively on photographic evidence. ${ }^{7.9}$

\section{"architecture" or "architectonic"?}

As the Berliner Bild-Bericht prints of the Barcelona Pavilion show, even without direct access to the physical object, people are able to attribute architecture with meaning and value. However, in studying architecture through media reproductions, architectural researchers must recognise that there is a difference in the qualities of space identified through photographs, compared to spatial qualities identified through two-dimensional drawings of a building or by physically inhabiting the space. Alternatively, they could identify that for the purposes of their argument, they are suspending the distinction between the two (photographically produced space and physical space).

Recognition of this difference is fundamental in understanding the influence print media exerts over our interpretation of architecture, but need not privilege the physical space over the media space. As the Berliner BildBericht prints of the Barcelona Pavilion show, the merely architectonic (that which resembles architecture) may be given equal (or indeed sometimes even greater) status with physical architecture; the metaphor of space produced by the media becoming meaningful as an architecture of the simulacrum. . $^{10}$

\section{[re]production and [re]construction}

The history of the Barcelona Pavilion is centred around the sixteen Berliner Bild-Bericht prints, but also to a certain extent on people's desire to reconstruct the space of these photographs. Even before the 1929 pavilion had been dismantled, discussions about how the physical pavilion could be preserved were entered into (including, as mentioned, a proposal from a Barcelona entrepreneur to convert it into a restaurant). Despite Mies' apparent reluctance to preserve the original pavilion, there were a number of initiatives, both during Mies' life and after, to physically reconstruct the pavilion (de Solà-Morales, Cirici, \& Ramos, 1993, p. 26) ${ }^{7.11}$. Only some of these initiatives have been aware of the "slipperiness" of the pavilion, most feeding blindly off the labyrinthine myths and interpretations which have accumulated around the pavilion over the past eighty-two years.

\section{985 OMA reconstruction}

One physically-realised reconstruction which cleverly played on the mythical status of the pavilion, as well as the irregularities and 'missing pieces' of its history was that completed for the 1985 Trienalle in Milan by Rem
7.9

Dodds gives the work of Eileen Gray and Le Corbusier's little-discussed Beistegui apartment in Paris as examples of architecture in which we are reliant primarily on photographs to know about. Other buildings in this category include structures built like the Barcelona Pavilion for various exhibitions: Paxton's Crystal Palace, Le Corbusier's Swiss Pavilion, and Alto's Finnish Pavilion.

7.10. In his essay Simulacra and simulation (first published 1981), the French philosopher Jean Baudrillard discussed people's perception of reality as being conditioned by various historical "simulacra." (See Jean Baudrillard, Simulacra and Simulation (Ann Arbor: University of Michigan Press, 1994). He saw “modern" reality (arising from the Industrial Revolution) as a simulacrum where the distinctions between image and reality broke down due to the proliferation of the mass-reproduction of items. In this historic period, the massproduced object's ability to imitate reality threatened to replace the original version, a sentiment evident in the contemporaneous writings of Walter Benjamin. However, in Baudrillard's "post-modern" reality of today, the simulacrum becomes one of a model preceding the original, eliminating the distinction between reality and representation: today there is only the simulacrum, and originality becomes a totally meaningless concept. The Barcelona Pavilion, a product created within the timeframe of Baudrillard's “modern” reality, yet continuing to be reproduced and used as an exemplar in today's "post-modern" reality, crosses the boundary between simulacrum-as-product and simulacrum-as-model, in particular through the various acts of its reconstruction since 1929. It is for individual interpreters to decide whether such reconstructed simulacra still offer meaning to contemporary architecture culture.

7.11. These include initiatives by the rationalist Catalan architectural movement Grup R (1959), architect Juan Bassegoda Nonelli (1964), and the architect Fernando Ramos (1974), none of which were realised, before the 1986 reconstruction led by Ignasi de Solà-Morales. 


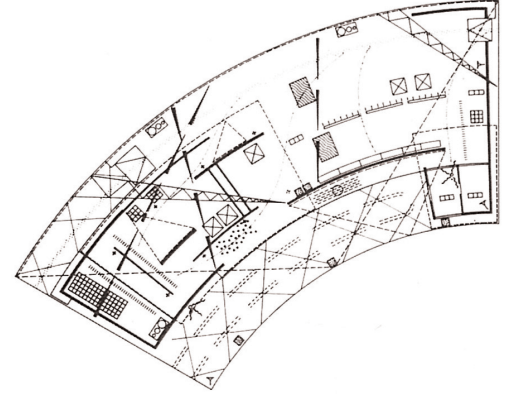

fig. 7.XXXI.

OMA Barcelona

Pavilion reconstruction at the 1985 Milan Trienalle.

The plan of the pavilion was warped to fit the curve of the exhibition space.

7.12. Koolhaas' story started with the arrival of the dismantled pavilion arriving back in Germany just after Mies had left for Chicago. The narrative described how parts of the pavilion's materials were used alternately in the construction of: a set for a propaganda film, the floor of a German ministry duringthe war, and a locker room for the never-to-be-realised 1952 Olympic Games in East Germany. According to the end of this story, the pieces of the pavilion were finally 'rediscovered' by a visiting scientist from the West, who managed to secure the fragments off the East German authorities "in return for one medium-sized computer and the secret design of a new machine gun" (Koolhaas \& Mau, 1995, pp. 46-61).

7.13. The concept of the empowered "emancipated spectator" of works of art comes from the French philosopher Jacques Rancière, and is discussed in his 2009 book of the same name.
Koolhaas and his Office for Metropolitan Architecture (OMA). Recognising both the need for critical recovery and the impossibility of replication, the OMA version of the Barcelona Pavilion was based on the hazy details concerning what happened to the pieces of the pavilion once it was dismantled in 1930. Koolhaas created a fictional narrative whereby parts of the dismantled pavilion formed unlikely backdrops to various historical events of twentieth century Germany. ${ }^{7}$.12 While mostly an exercise in 'tongue-incheek', the OMA reconstruction demonstrates that the meaning of the Barcelona pavilion is not fixed or static. The Berliner Bild-Bericht photographs and the stories that have grown up around them oscillate between documentation, depiction, and a 'virtual production' of the Barcelona Pavilion. They are incitements to dream, and the inspiration of many potential architectures and meanings.

\section{I986 Barcelona reconstruction}

\section{An "official" reproduction}

However, the reconstruction which has (most) complicated and challenged the meanings of the Barcelona Pavilion is the 1986 reconstruction effort by a team of Spanish architects, led by Ignasi de Solà-Morales, Cristian Cirici, and Fernando Ramos. Coinciding with the one hundred-year anniversary of Mies' birth, this project can be interpreted as the "officially-sanctioned" reconstruction, being promoted by the architecture culture industry as being "true" to the original 1929 pavilion. Writers on the reconstruction have commented excitedly on finally being able to walk "through the pavilion itself", at last being able to experience "the real thing" (Cohen, 1994, p. 52). The implications of comments like these are significant in that they reveal an ideology equating replica with reality. Further, recent monographs on Mies have colour photographs of the 1986 reconstruction intermingled with Berliner Bild-Bericht prints, all alarmingly designated as the 1929 building. Small misstatements such as these may not appear suspicious as isolated incidents, but through the cycles of publishing, interpretation, reproduction and reinterpretation which occur with all print media products to some degree, they multiply and can become established as patterns of misinformation. Fitting into Herman \& Chomsky's "propaganda model" of mass media (as discussed in Chapter 5), misinformation is able to be used by institutions of the culture industry to advance interpretations of architecture supporting their own ideologies and agendas. While these processes are largely inevitable and beyond the control of the general public, or indeed, of architects, we still have the opportunity as the "emancipated spectators" of cultural products to critically interpret their meanings, and to challenge the cultural ideologies they seek to promote. ${ }^{7.13}$ 


\section{A physical reproduction}

The architects of the reconstruction project soon discovered that the specifics of actual design of the 1929 pavilion were essentially unknown, given that the Berliner Bild-Bericht photographs were manipulated, that they showed only certain attributes of the building and obscured or confused the determination of others, and that the plans published by Mies and his scholars contained significant differences in dimensions and detailing (de Solà-Morales, et al., 1993, p. 26). In order to proceed with the project and resolve the many discrepancies, as well as to elaborate necessary information which could not be based on any historical documents, the reconstruction architects found it was necessary to develop a set of "priority criteria" to help guide their process of interpretation. As they put it, "no reconstruction can avoid acknowledging the existence of certain specific criteria, according to which the problems it poses are resolved. In the case of the reconstruction of the German Pavilion, the criteria were not drawn up in isolation, but in an attempt to balance the various interests to be satisfied by the project as a whole" (de Solà-Morales, et al., 1993, p. 28). Chief among such priorities was "the concept of a reconstruction that would interpret as faithfully as possible the idea and the material form of the 1929 pavilion...Our fidelity to Mies van der Rohe's idea was by no means gratuitous or merely speculative, but was contrasted point by point with the available information on the concrete solutions employed in the original building" (de Solà-Morales, et al., 1993, p. 29) Yet the biggest flaw in the 1986 pavilion is the reconstruction architects' insistence that a physical building is able to recreate the significance of the Barcelona Pavilion.As I have argued, Mies did not treat built form as an end in itself, but rather as another available technique in his quest to explore his ideas in the media space. Where the reconstruction architects saw in Mies' manipulation of the Berliner Bild-Bericht prints attempts to "correct" the flaws of the "compromised" physical building, Mies was in my view extending the potential of the photographs to stimulate the sort of architecture which he dreamed of. Considering the role manipulated media material seems to have played in Mies' conception of the Barcelona Pavilion, I believe he was never actually interested in attaining a state of final perfection of the physical pavilion, instead recognising this was much more easily and effectively achieved within the media space of architecture.

\section{A superficial reproduction}

Despite being rebuilt on exactly the same site as the 1929 pavilion, what the reconstruction architects constructed in 1986 was a merely visual replica (Newton, 2005, p. 64). The essence of the original pavilion was interpreted as being contained within the carefully-duplicated visible surfaces."The rebuilding of the pavilion does not so much enable us to walk freely and unencumbered through the real thing, as it has given us fresh insights into the photographs from 1929 and their often tenuous relation

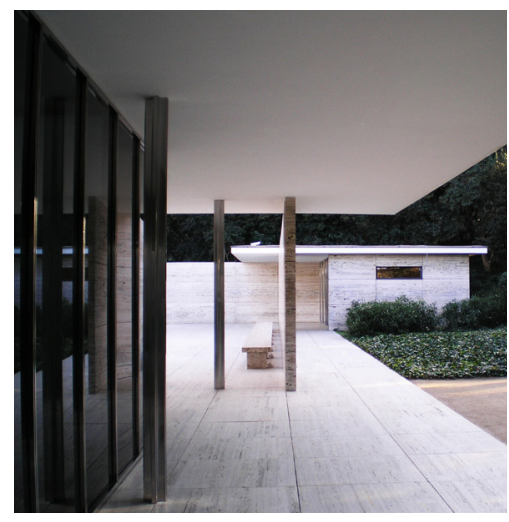

fig. 7.XXXII. 1986 reconstruction of the Barcelona Pavilion, Barcelona. (author's own photograph, 2010).

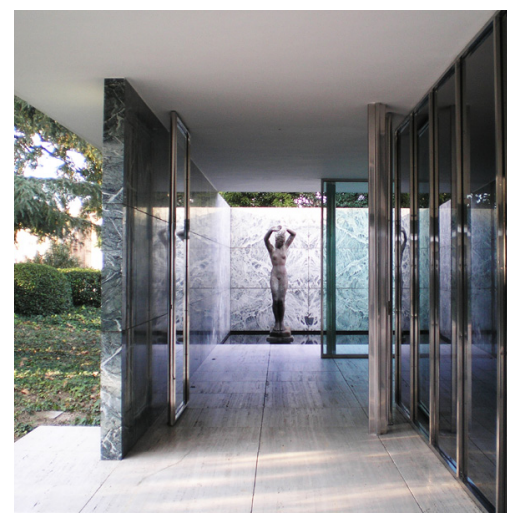

fig. 7.XXXIII.

1986 reconstruction of the Barcelona Pavilion, Barcelona. (author's own photograph, 2010). 

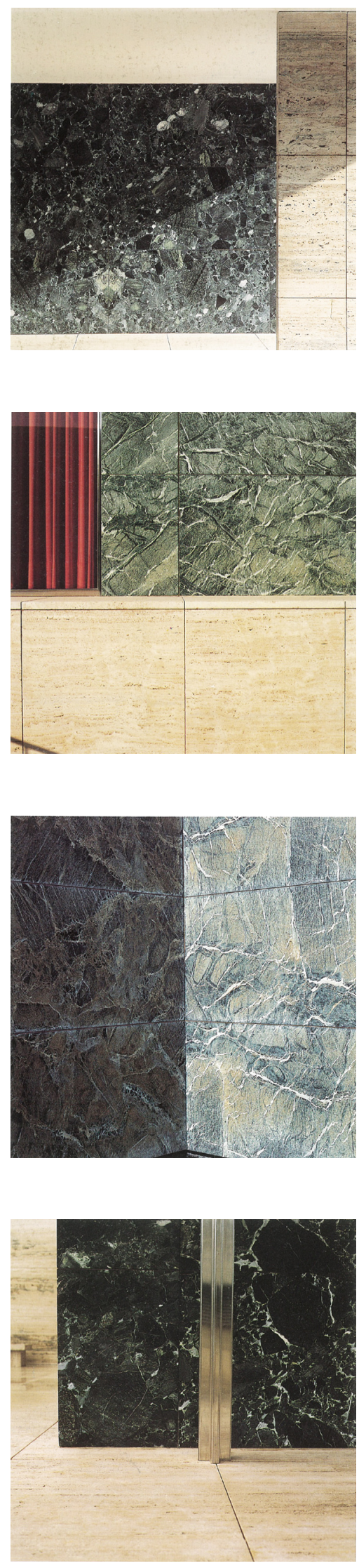

to occupiable space" (Dodds, 2005, p. 38).The 1986 project reconstructed the Barcelona Pavilion in material and visual terms, but as I have argued, without the weight of the meanings layered onto the Berliner Bild-Bericht photographs, it can only be seen as a superficial architecture. It mimics appearance without being able to engage very deeply with the substance of what makes the Barcelona Pavilion significant for architectural culture, its meaning.Along this line of thought, Dodds makes the comment that the intent behind the 1986 reconstruction seems strangely similar to the "cargo cults" of the post-World War II era in the South Pacific (Dodds, 2005, p. 63 $\mathrm{n}$ 1 19). These were religious practices where the native inhabitants of now isolated island military outposts made replicas of the various items used by the military "gods" such as radio transmitters, in order to bring the gods back to the island. By making this association, Dodds infers that the physical reconstruction is but a futile attempt to channel the imaginary "magic" of the Barcelona Pavilion, and potentially just an exercise in social power exploiting our gullibility to believe what we are told.

\section{Last words on [re]production/construction}

While the 1986 pavilion may offer the opportunity to reassess what we thought we knew about the physical characteristics of the Barcelona Pavilion, it also provides an opportunity to consider how much of our understanding of this work is not simply reproduced by photography, but produced by it. The 1929 pavilion, a setting for ceremonial and photographic events, did exist physically, but just barely. The 1986 reconstructed pavilion seems to not only raise serious questions about the role physical reconstructions play for architectural meaning, but also reveals the dominant thinking in architecture culture which ties meaning to built forms.

fig. 7.XXXIV

fig. 7.XXXV.

fig. 7.XXXVI.

fig. 7.XXXVII.

1986 reconstruction of the Barcelona

Pavilion, Barcelona.

Photographic details of the materials.

Seeming to support the idea of the 1986 pavilion as a superficial reproduction, the 1993 book on the reconstruction project written by the project architects features a set of photographs which seem to linger lovingly on its material surfaces and textures. 


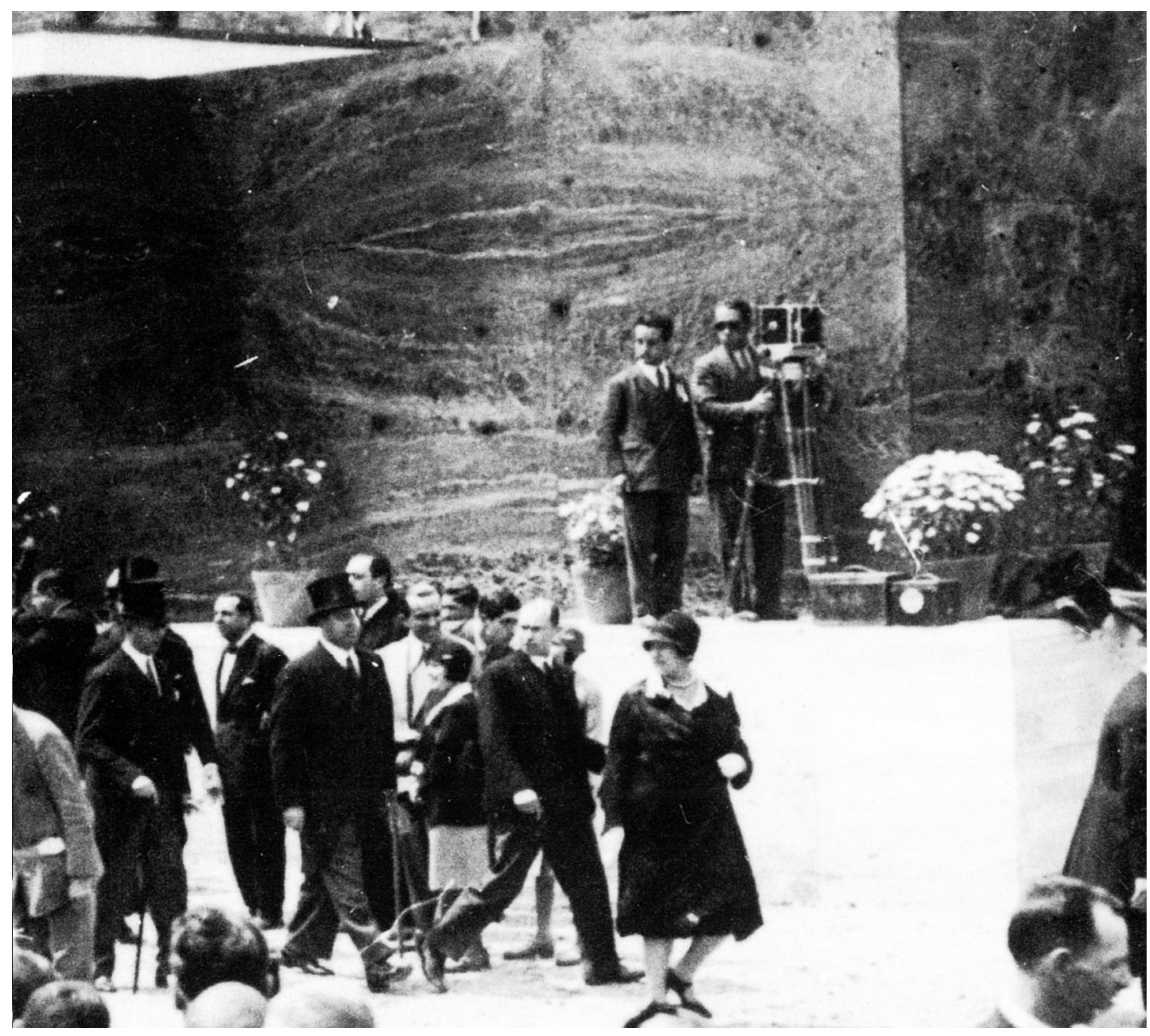

fig. 7.XXXVIII. Opening ceremony for the German National Pavilion at the Barcleona International Exposition, May 26, 1929. (Detail of MMA 7361, MoMA).

Mies (in top hat, centre left) can be seen striding away from the pavilion, as a photographer and his assistant watches next to a tripod camera.

While most of the crowd looks back to watch the departure of the Spanish King Alfonso XIII, Mies strides briskly away from the pavilion. With the ceremonies complete and the carefully-constructed Berliner Bild-Bericht photographs made, Mies was apparently finished with the physical pavilion, and never seemed to look back. 


\section{Conclusion}

7.14. For example in one article, the art critic Rosalind Krauss quotes Hays, who is quoted by Evans, who also quotes Quetglas, who in turn is commented on by Hays, demonstrating the dizzying swirl of "verbal traditions" which arise around the pavilion. (Rosalind Krauss, "The Grid, the /Cloud/, and the Detail", in The Presence of Mies, ed. Detlef Mertins (Princeton: Princeton Architectural Press, 1994), p.134)
7.15. " $[\mathrm{In}]$ the Barcelona Pavilion, Mies van der Rohe constructed a scenic space whose neutrality shares profound similarities with...the sets of [architect and stage designer Adolphe] Appia and [scenic designer Edward Gordon] Craig... In a place that refuses to present itself as space and that is destined to vanish like a circus tent, Mies gives life to a language composed of empty and isolated signifiers, in which things are portrayed as mute events. The sorcery of the theatre of the avant-garde dies out in the wandering without exits of the spectator of Mies's pavilion..." (Tafuri, 1987, pp. 111-112)
The Barcelona Pavilion has often been used as one of the defining case studies in biographies of Mies and surveys of architectural modernism. The pavilion's complicated history generates whole kaleidoscope-like pictures of criticism, interpretation and discussion. ${ }^{7.14}$ However, the story of the Barcelona Pavilion may tell us less about Mies' oeuvre and the origins of modern architecture than about the culture of the 'diffused image' and its implications for architectural meaning. Being restricted to a limited set of historic photographs and previous interpretations of the three pavilions (the 1929 pavilion, the BBB print pavilion, and the 1986 pavilion), any reading of the work of architecture we call "The Barcelona Pavilion" is largely determined by our own frames of reference. With this in mind, the pavilion can be considered both as an object for, and simultaneously a surface of reflection, in that it is able to act as a mirror capturing the desires and dreams of its audience without giving up its own elusive essence. The Berliner Bild-Bericht prints do not document a building; they anticipate an architecture. It may be more productive to ask not what this dream means, but rather what it provokes us to do - which may be its meaning after all.

Manfredo Tafuri comes closest perhaps, to what seems to be essential to the meaning of the Barcelona Pavilion when he compared it to a stage set. 7.15 Forming not only a physical set for the 'performance' of the 1929 International Exposition, but a "filmic" set for the staging of the Berliner Bild-Bericht photographs, the physical building, like the carefully controllable viewpoint of the camera and the manipulable photographic film which it uses, was arguably only a tool in Mies' production of this architecture of theatrical intangibility. Through producing the Berliner Bild-Bericht photographs, Mies was constructing an alternative reality rather than representing an existing world. This architectural reality took its place alongside the "real world", clearly sharing temporal and certain (filtered) spatial conditions of that world, but subverting its absolute authority as the location of the 'work of architecture'. As eloquently put by the architectural theorist K. Michael Hays, "A participant in the world and yet disjunctive with it, the Barcelona Pavilion tears a cleft in the continuous surface of reality,'(Hays, 1984, p. 25) but in doing so opens the way to the possibilities offered for architectural meaning in the 'media space of architecture'. 


\section{CHAPTER conclusion summary}

- The Barcelona Pavilion is a work of architecture considered significant for mainstream architecture culture, yet this architecture is based largely on a set of photographs and media space.

- The architecture culture industry promotes canonical interpretations; myths promoted seemingly as fact.

- The built form need not be an end in itself, being able to be used by architects as a stepping stone to more significant cultural production in the media space of architecture. I argue that Mies used the physical 1929 pavilion as a maquette to generate a set of photographs to publish, this being how Mies explored, promoted and developed meaning of his architecture. 


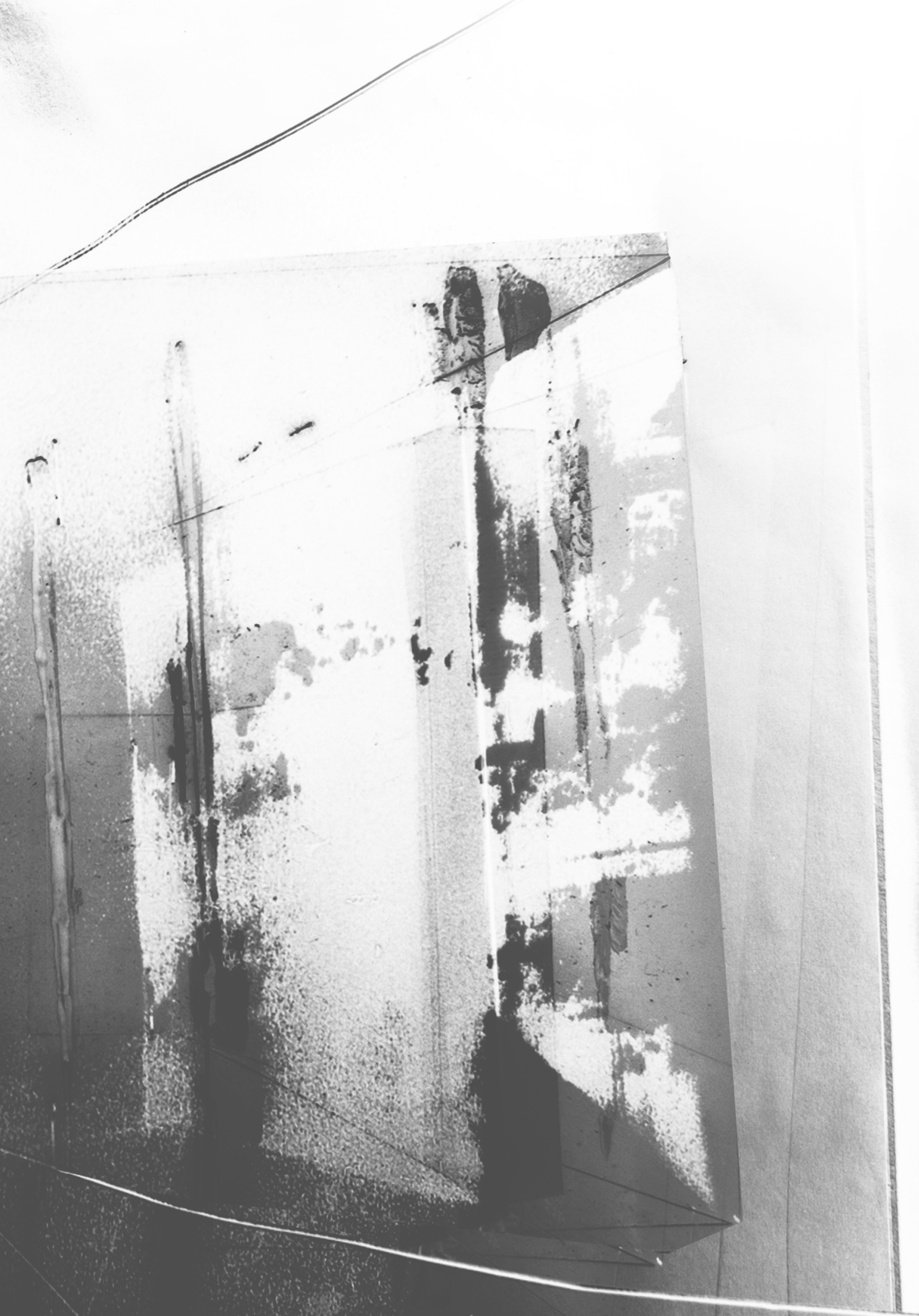

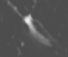




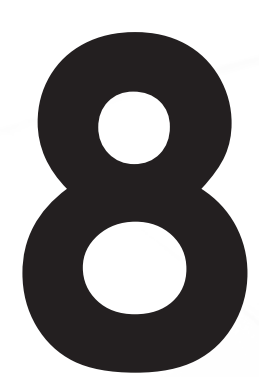

CHAPTER

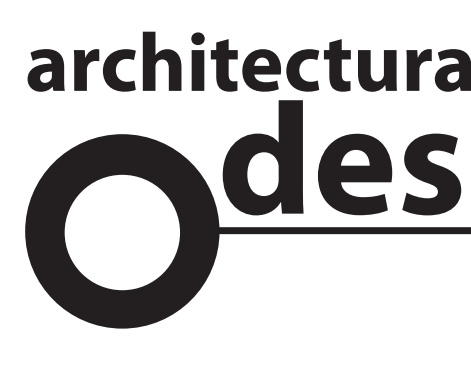

of the

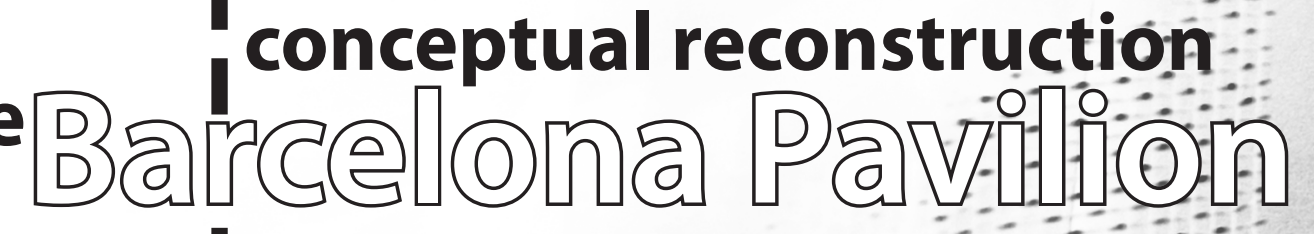

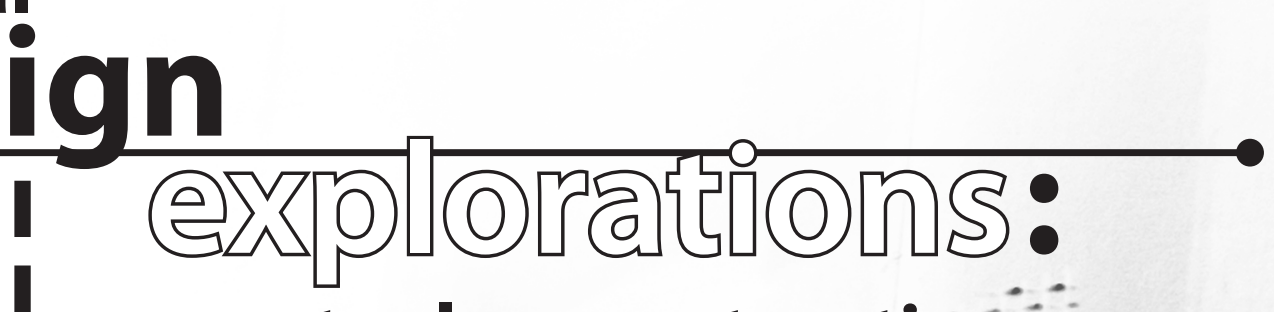

ign

I

(1)

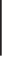

conceptual reconstruction 
SECTION I:The Publication Exhibition piece

-

- Writing down: Description

- Writing out: Intentions

- Writing through: Critical Interpretation

- Summation

SECTION 2: The September Installation

- Writing down and out: Description and Intentions

- Writing through: Critical Interpretation

- Summation

SECTION 3:The 'new work' installation

- Writing down: Description

- Writing out: Intentions

- Writing through: Critical Interpretation

- Summation

Conclusion: a post-structuralist work of architecture 


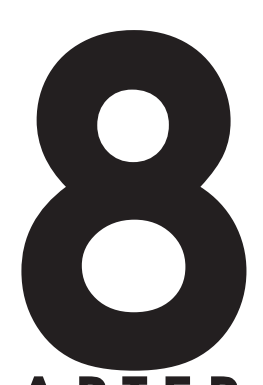

CHAPTER

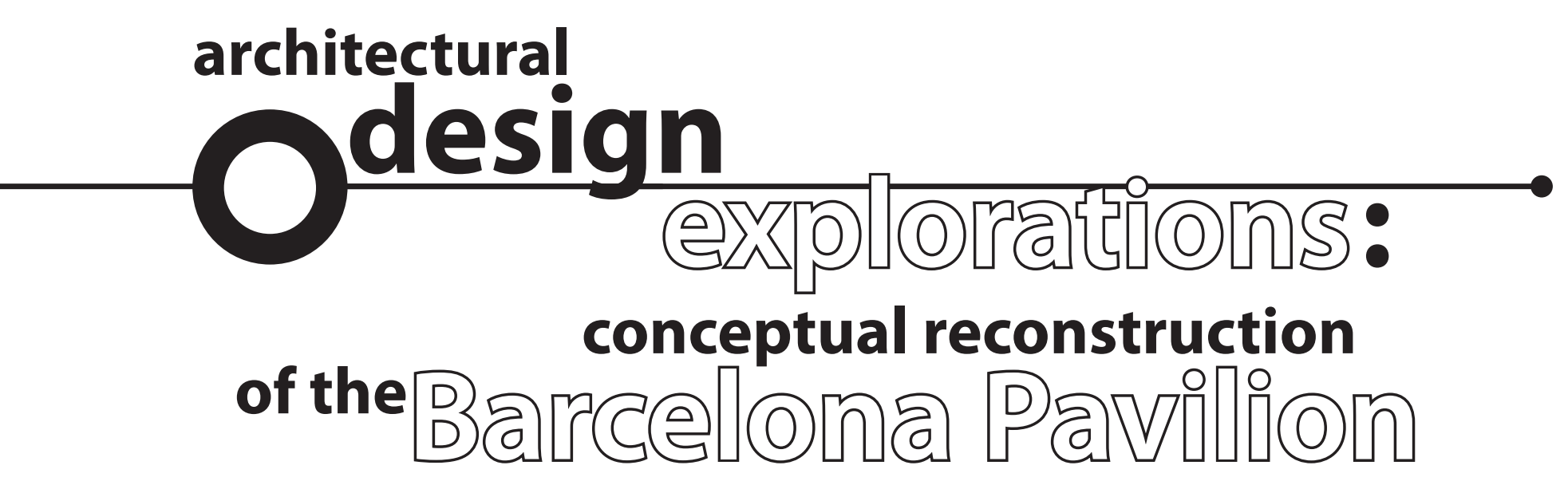

\section{Introduction}

Having developed key theoretical positions of architectural meaning, the influence of the culture industry on architecture, ${ }^{8.1}$ and ways of engaging with processes of print media, this chapter now focuses on the exploration and extension of these ideas via the activity of design. The project of this design study is the reconstruction, within the 'media space' of architecture, of Mies van der Rohe's Barcelona Pavilion. Linear in process but nonlinear in content and ideas, the design project of this research has been discussed in three major sections: In Section I, I discuss the design and implementation of an exhibition piece for the 20I I "Publication" exhibition of creative architectural work, in Wellington, New Zealand. In Section 2, I discuss the design and implementation of an installation for the September 2011 Design Review at the School of Architecture, Victoria University of Wellington. Finally, in Section 3, I discuss the conceptual design of a further installation work, provisionally entitled "A new work", as a further refinement of the ideas explored in the first and second stages. However, in order to provide some specific context to these discussions, I first consider the role of the 'project', and explain some aspects of my design method and design criteria.
8.1. It is important to note that the culture industry is nota separate entity from the field of architecture: architecture constitutes a part of culture, with architects and others championed by the culture industry simultaneously making culture and being made by it. 
8.2. The simplicity of this idea becomes complicated when examining the 1986 reconstruction of the Barcelona Pavilion: because no record of the interior of the pavilion's service annexe exists, the reconstruction architects designed a conjectural interior based on his treatment of American interiors in later projects of his career. This use of a future precedent for Mies' pavilion is a highly artificial move, and one fraught with debates on assumption of intent. (See de Solà-Morales, Cirici, \& Ramos, 1993, p. 35).

8.3. Definingsuch contextual criteria is crucial for an understanding of the architectural meanings I explore: The design explorations ought to be considered within the conceptual context established by this thesis, as meaning resides in people's interpretation of cultural gestures, and the context in which it is located. Like Duchamp's Fountain by R. Mutt (1917), the context of the work is what makes it significant.

8.4. "All architectural production is inherently 'fictional' in that it refers to the possible - possible forms of building and potential forms of actions in response to a building" (Leatherbarrow, 1993, p. 215).

\section{The role of the 'project', and aims of the design process}

Unlike most architectural design projects, the 'project' of this research takes an existing (in the loosest sense of the word) work of architecture, the Barcelona Pavilion, as its starting point and subject matter. It explores a critical, alternative reading of this already-designed and widely-discussed work of architecture. The new project does not set out to 'design' or even 're-design' an object or space as a primary aim, seeking more to act as a visual process of mediation, exploring (both visual and theoretical) perspectives and understandings of this project which traditional plans, sections and other visualisations could not have offered. By definition, "to project" literally means to throw forward. But in order to throw something forward, both thrower and projectile must be situated in a position behind the conceptual event. Every 'project' is therefore a representative from the past. ${ }^{8.2}$ The design explorations discussed in this chapter act as 'projections' of my written research and study into a different, spatial format. Defining my own frame of reference for these design explorations, ${ }^{8.3}$ I consider the success of this project in being interpreted as 'architecture' to be dependent on the ability of the result to suggest the "something becoming" of the work: the potential it evokes for its audience or the possibilities we seem to find within it. ${ }^{8.4}$ In particular, the design explorations seek the potential of engaging with print media processes for the development of architectural meaning, of the Barcelona Pavilion specifically and of architecture as a creative practice generally.

\section{Indeterminacy as a part-method}

The design process of this research utilised the concept of 'indeterminacy' as a part-method, in order to work within the definition of meanings as social products established in Chapter 2 (meanings are personal interpretations placed by humans as active agents interpreting cultural objects in specific contexts and according to cultural frames of reference). The design process evolved in an ad hoc manner, deliberately avoiding an overall 'vision' or plan, and was not formulated as part of a larger structure of production working towards an established end-product. Instead, design 'situations' were created in which single-staged design moves could be taken. These moves were conscious and deliberate in what they were intended to explore, but specifically avoided predicting what the critical outcome of each stage would be: each step had to be taken independently, and the results considered for what they were rather than what they should have been. Once finished, each stage led to a new and different situation from that before it. This meant the productive context of each design stage constantly evolved and was reconfigured in parallel to its progress. In being conscious of and taking advantage of this, the design process echoed the constantly shifting context of cultural products, where each new addition may reconfigure people's understanding of the collective whole in a small but crucial manner. 
This process of 'indeterminate control', where I could only "see" one step ahead of myself in terms of the design process was developed to parallel the extent to which architects can "control" the reproduction and dissemination of their work via the media. As demonstrated clearly through Mies van der Rohe's tight grip on the photographic reproduction of his work during his career, architects have the ability to influence some aspects of how the media portrays their work. ${ }^{8.5}$ Yet this influence only extends to the first 'generation' of media output: once a book on Mies' work was published with all his 'approved' photographs inside, further situations of interpretation would have been beyond his direct control. For example, such a book could have been critiqued by editors of an architectural journal, and in doing so, indirectly critique Mies' work in ways unanticipated, and unable to be mitigated by Mies. In my design process, I could only directly influence the next 'generational output' of each stage to a certain extent before I used the indeterminacy of the method to produce the next result.

Nevertheless, the method of indeterminate control does not erase or replace the intentions I had in making each stage of the design. The process was not left "up to chance" and was not aligned with 'automatic' art production practices. ${ }^{8.6}$ As the creator of the works at each stage, I had specific ideas I was attempting to explore at each point, and made conscious decisions about how best to approach these on an immediate level as I was completing each stage. As an active human agent interpreting the cultural products of each design stage, I attributed them with meanings and then explored these meanings for myself in creating the next design stage. The important point to note again was that I avoided trying to anticipate what each stage would produce, and specifically did not try to fit these products into an overall structure of production seeking a pre-planned result. Consequently, results from the design stages were fragmentary, partial, and incomplete by themselves.

\section{Interpretation: retrospective analysis}

But remembering the poststructuralist ideas of relational art, works of art are only partial objects. They provide a link between perception and other possibilities. The beholder is the joint creator of the work, venturing into the mysteries of creation through the gap offered between the intent of the artist and the interpretation of their work by viewers. In being both the 'artist' and 'audience' of my own work in this process, my own interpretations became an important aspect of my design method, these interpretations always occurring, like the act of 'projecting', from an historical point of consideration. Having finished each stage, I engaged in a moment of retrospective analysis, considering the product in light of potential interpretations, as well as how it might be received as part of the previous set of products. In doing so, I was able to identify threads of ideas
8.5. See Chapter 7 on Mies van der Rohe and Chapter 4 on Le Corbusier for discussions on the careful influence exercised by these architects over how architectural media presented their work.

8.6. However, this was not a process driven byasarbitrarya conceptas "chance". Bourriaud actually contends that, "If there is an area where chance does not exist, it is indeed the realm of artistic creation" (Bourriaud, 2002, p. 84). He explains that chance is an important factor in art, but only in relation to its production: once exhibited (whether to a public audience or only to the artist themselves), for Bourriaud, the work leaves the world of the arbitrary and everything in it starts to stem from an interpretation. 
from the case studies which were influencing my design work, as well as work on developing my own personal conclusions to do with meaning in architecture.

\section{Reconstructing the Barcelona Pavilion}

\section{On the act of reconstruction}

Any cultural product is tied to the conditions and context of its production. An object of reproduction is not exempt from this, especially as any reproduction is a 'new' cultural product to a certain extent. The reconstruction of a work of architecture is a form of reproduction, and as such, is not only a reflection of the original object, but of the ideologies of those individuals participating in the reconstruction.As Dodds puts it, "Any attempt at historically reconstructing the Barcelona Pavilion, or any other building, results in a reproduction of the image of a building, and more importantly, an image of its builders" (Dodds, 2005, p. I35). This is exactly what the French philosopher PaulValéry unexpectedly learnt from his study of Leonardo da Vinci: while Valéry thought he was writing on the genius of Leonardo, he realised that what he wrote was only a reflection of his own mind and the image of the artist which his mind's eye had constructed."In the end...," Valéry wrote, "I dared to discuss myself using his name and his character," projecting himself onto the study he was creating (Valéry, 1929, Pp. 26-27). A Barcelona Pavilion in 20II is a different creature to either the 1986 pavilion or the 1929 pavilion: although undeniably related, they are nevertheless separate and discrete works. Given the overall goal of this thesis as working towards a philosophy of meaning in architecture, my reconstruction of the Barcelona Pavilion is necessarily a product of this search, and its success ought to be considered within this context.

\section{Design criteria for my reconstruction}

Derived from the theoretical positions I developed in Chapters 2 (Meaning), 3 (Media) and 5 (Architecture Culture Industry), and learning from my case studies in Chapters 4 (Le Corbusier), 6 (Terragni) and 7 (Mies van der Rohe), several criteria for my exploratory theoretical 'reconstruction' of the Barcelona Pavilion emerge. Seeking to avoid the limitations of the studied architects, particularly their attempts to prescribe architectural meaning, these criteria nevertheless stem from the examples which Le Corbusier, Terragni, and Mies van der Rohe set in their conscious and productive engagement with the print media processes of the architecture culture industry. The criteria also aim to eschew the way in which others have made attempts at reconstructing the Barcelona Pavilion, transcending their dependence on visual similarity to engage with the deeper substance of its architecture: the meanings which people place on it. Given these aims, I proposed that my reconstruction of the Barcelona Pavilion be: 
- A non-physical reconstruction: it could use physical elements along the way, but these were not the end product or result.The 'reconstruction' was not to be limited to a built form.

- It should use the ability of media techniques and processes to access the way we attribute meaning to what we see.

- But it should move beyond a visual replica: it needed not look like the pavilion of the Berliner Bild-Bericht photographs.

- It should not fall into the category of 'propaganda', in the sense of advancing a manipulative agenda contributing to the architecture culture industry's 'mythmaking' on the pavilion.

- Rather, its primary motivation should focus on the way the pavilion was and is produced through print media: It should work to question and critique this phenomenon.

- My work of reconstruction should aim to remain open to interpretation by people in different ways, and be composed to allow for this variety of meanings to occur: it should not seek to prescribe meaning.

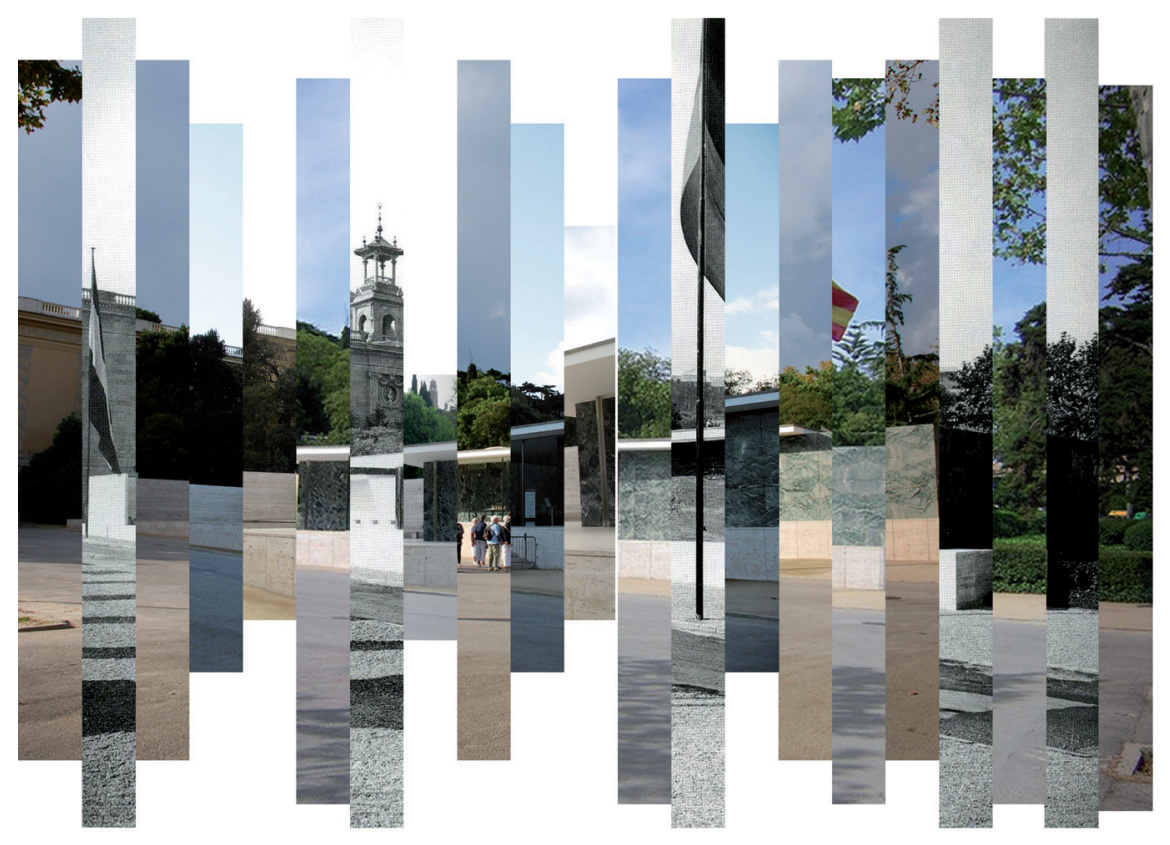

fig. 8.I. Barcelona Pavilion, digital photocollage. 

black and white and placed facing each other within the exhibition space, lit with ceiling-mounted floodlights. The Seidman 247 image was hung on the wall of the gallery, whereas the MMA II 254 image was adhered to a cardboard backing sheet and hung from ceiling beams in the middle of the room, forming a hanging partition in the gallery space.

\section{Writing out: Intentions for the Publication Exhibition piece}

Affixed to the wall next to these two images was the following statement, giving some context to the work, and what my intentions were in creating this exhibition piece:

this is architecture

Matthieu Mereau

"The Barcelona Pavilion, designed by architect Ludwig Mies van der Rohe as the national pavilion representing Germany at the 1929 Barcelona International Exposition, is one of the most recognizable and influential works of architecture of the 20th Century. Its significance is surely without question, but its particular history, interpretation and representation via different media forms raises questions about the way we think about the way meaning is produced and communicated in architecture. The original pavilion existed physically for less than I year, yet due to a set of 16 photographs commissioned by Mies after the completion of the pavilion in May 1929, the architecture culture industry has continued to promote, discuss and use the pavilion as a 'masterpiece of modernism, as if the physical structure still existed. My work in this exhibition explores this idea and attempts to challenge the cultural hegemony of architecture-as-built-object.

Two plates from the set of 16 Berliner Bild-Bericht photographs are enlarged to near-life size. The photos show two opposing views of the rear passage of the original pavilion, taken from almost the same spot. In placing them opposite each other, analogous to the spatial configuration of the original pavilion, a space is created between them for the spectator: the imagined space of the photographic plate in the camera, or in other words, the media space of the architecture.

In inhabiting the space between these two reproductions of architecture, this space is 'charged' with the power of media to influence the way we interpret meaning in architecture." 


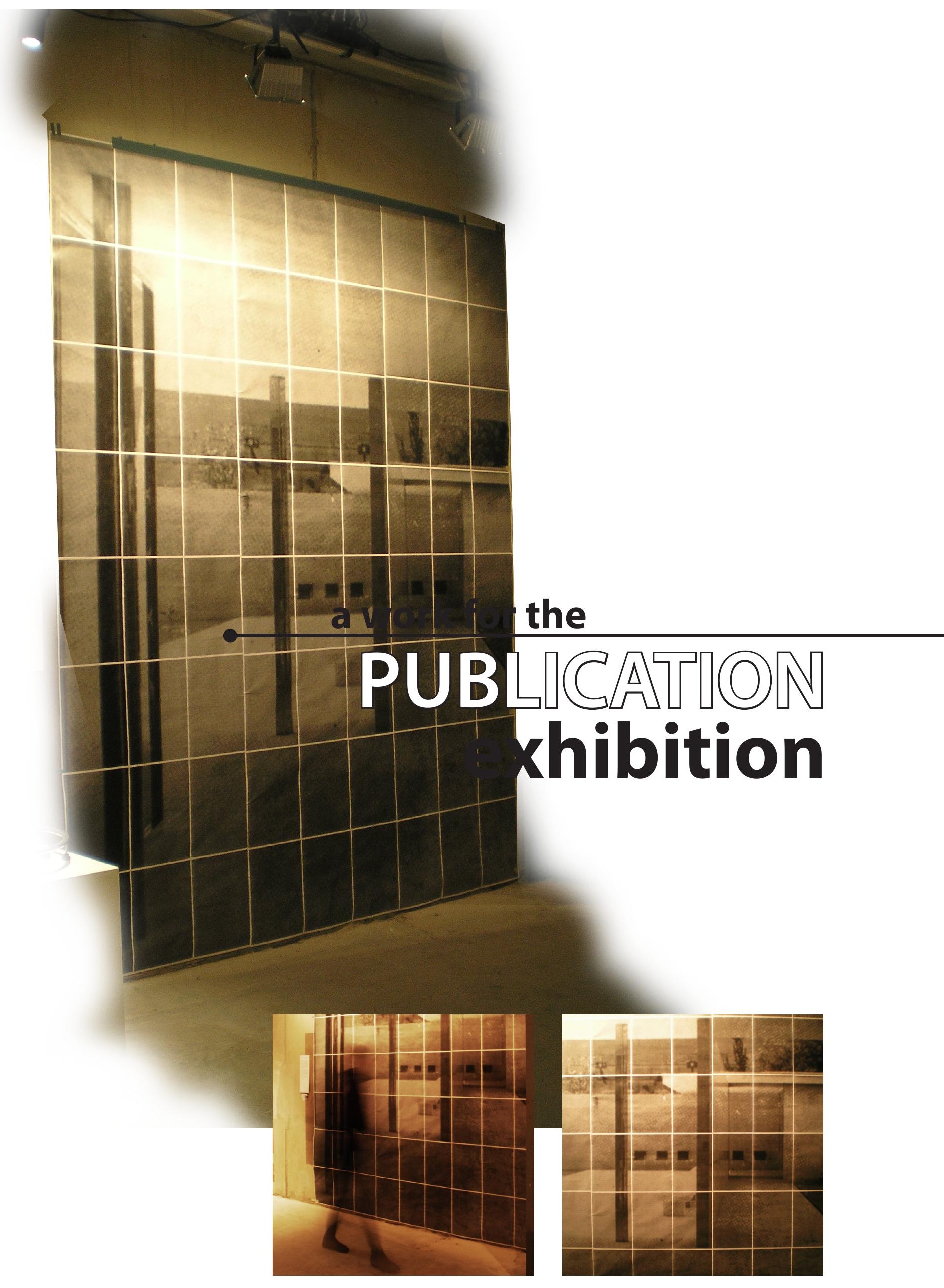




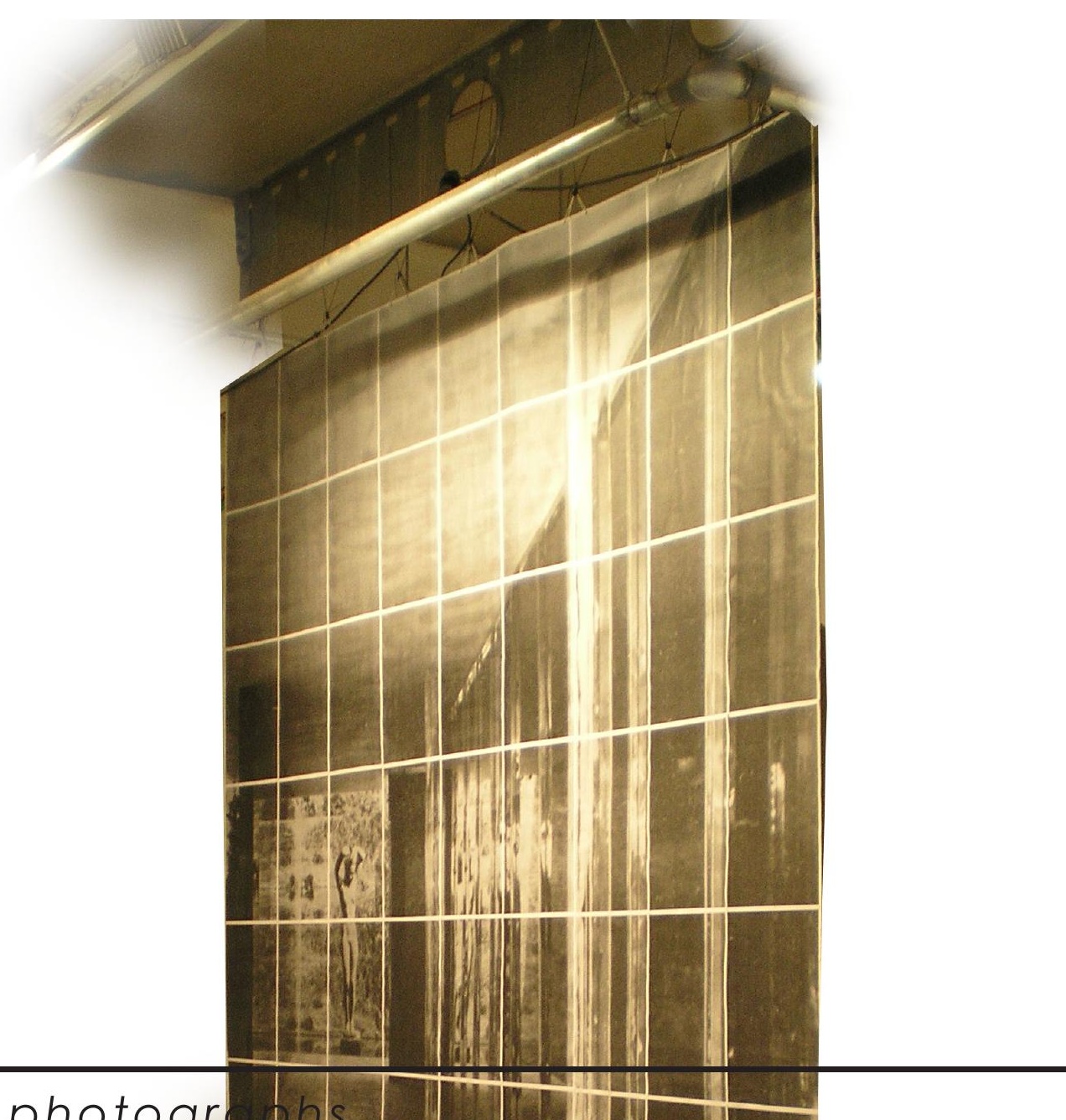

full-scale photogr phs

spatial relationships

inhabiting the space of the reproduction
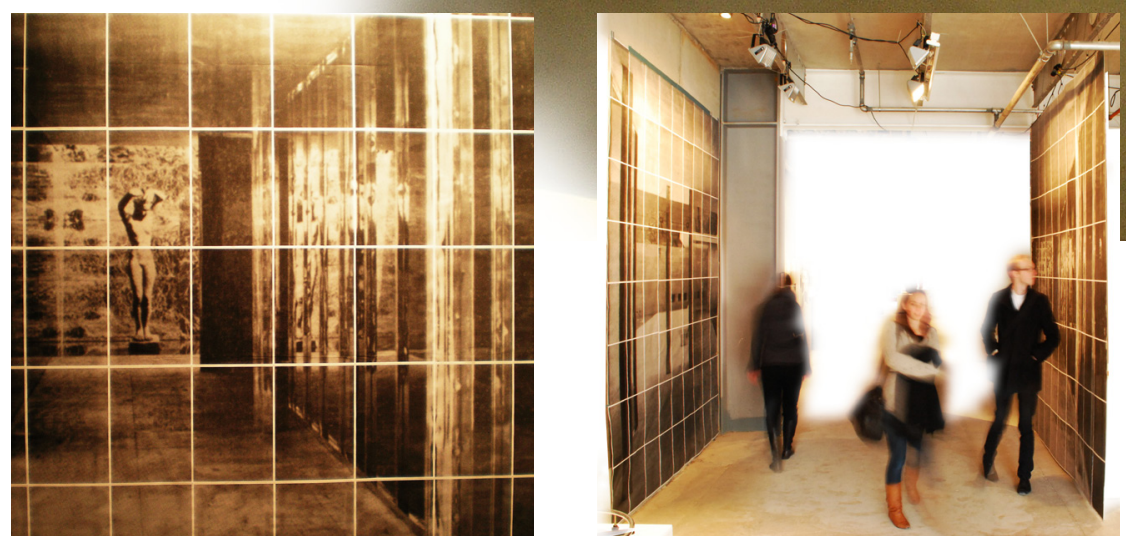

fig. 8.III. installation, Publication Exhibition, 23-27 July 2011, Wellington. 
Writing through: Critical Interpretation of the Publication Exhibition piece

The act of reproducing these two canonical images of the Barcelona Pavilion, at an 'architectural' scale, and within the context of an exhibition, in a manner 'reconstructed' the Barcelona Pavilion in Wellington. Joining the field of several other 'reconstructions' of the pavilion in different forms since 1929, the Publication work could be interpreted to hold as much validity as the 1989 reconstruction in Barcelona, both being but different manifestations of the architecture of the canonical photographs. Further, since the Publication reconstruction was a fleeting, temporary event, lasting only one week, it is arguably more closely connected than the 1989 pavilion to the original pavilion's short physical existence, which itself lasted only for the May 1929-Jan 1930 duration of the Barcelona International Exposition.

\section{The size}

In enlarging the Berliner Bild-Bericht photos to life-size, the Publication reproductions were given some of the properties of the built architecture. Through its new, large scale, the space depicted in the photo became more accessibly imagined as inhabitable, being able to be read in similar terms to a visitor's experience of walking around the gallery space. The Publication work also shifts potential perceptions of the space referred to in the original photographs: The Berliner Bild-Bericht plates are notoriously deceptive about the actual scale of the pavilion's spaces, their smoothing of the pavilion's surfaces and lack of human presence giving little reference for us to judge how large or small the pavilion may be. Further complicating matters is that the sole visible 'occupant' of the pavilion, Kolbe's Dawn statue, is actually slightly larger than life-size, giving the impression the pavilion is smaller than is really the case. By reinstating the physical scale of the 1929 pavilion to the Berliner BildBericht plates, such ambiguities are dispelled and people's conventionallyaccepted interpretations of the pavilion's spaces subtly questioned.

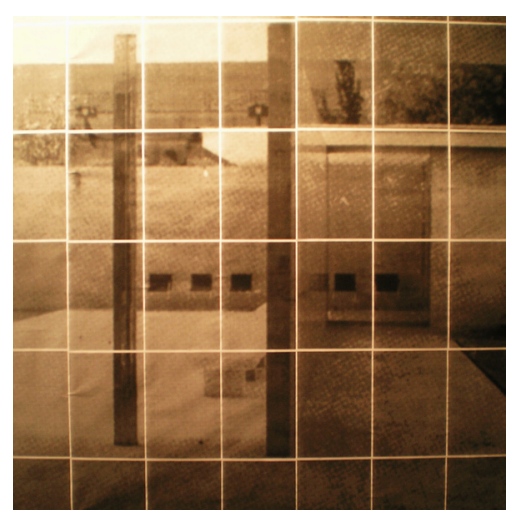

fig. 8.IV. detail of installation panel, Publication Exhibition.

Note the white grid formed through the tile-print reproduction process.

\section{The grid}

All reproductions leave some trace of the processes used to create them. Even the most high-quality art print will be limited in communicating the texture and depth of brushstrokes of the original, flattening them through the method of photographic reproduction into the surface of the printed image. In the Publication exhibition piece, the tile-print method of reproduction resulted in a white grid dividing up the image where two adjacent printed paper sheets met. Acting as a clear reminder of its status as a reproduced image, as well as its method of construction, the grid also forms a link to the 1929 pavilion, where Mies gave each material in the pavilion its own ordering grid pattern (Tegethoff, 1985, pp. 8I-82). With most people's understandings of the Barcelona Pavilion being a construction of the media space of architecture (as discussed in Chapter 
7), this new reproduction acknowledges print media as the material of the pavilion's reconstruction, and the white grid becomes the ordering factor of the physical printed photographs.

\section{The pixelation}

Another trace of the process and method of reproduction in the Publication work was the subtle pixelation of the image, created through the process of digitally scanning the small source images and reproducing them at a significantly increased size. When viewing the surface of the image panels at close range, the image visually dissolved into patterns of small circles, like the halftone dots used in print media. This pixelation encouraged the viewer to stand back and engage with the image from a distance, not only within the space formed through the pairing of the image panels, but approaching the piece from the other areas of the gallery. It linked the piece more closely to stage sets and advertising billboards, which deal with the performative and eye-catching properties of images, than to documentary photography in books and journals, which rely on ideologies of 'objective' or 'true' depictions of tangible, physical space. As such it subverted the potential for the image to act purely as a referent to the physical space of the 1929 pavilion, instead bringing the visitor's awareness to the surface and texture of the reproduced image as a design object in itself, and correspondingly, to its qualities as a work of architecture.

\section{The perspective points}

One of the aspects characterising the sixteen Berliner Bild-Bericht photographs as a set is their strong composition relying on deep single-point perspectives. The Seidman 247 and MMA II 254 plates are no exception, and their sense of perspective featured strongly in the Publication work. Due to the geometries of perspectival distortion and the scaling up of each image, the horizon line of each image corresponded with the eye level of the visitor to the gallery. This tied perception of the image panels to an experience of standing in the 1929 pavilion (yet not attempting to pretend they were directly equivalent). The vanishing points of the perspective for each image also aligned across the space between the two panels, situating the viewer at a point of perspectival climax: the perspectives of both views diminish from the point the visitor occupied, heightening the significance of the 'media space' between them as well as correlating each image panel with the other. Adding to the criss-crossing relationship between the panels, the correspondence of perspectives established a sort of visual 'reverberation' of each image against the other.

\section{Summation}

In my investigation of the ability for print media to provide enough interpretive material for the conceptual reconstruction of the Barcelona Pavilion in Wellington, the Publication exhibition piece played a significant

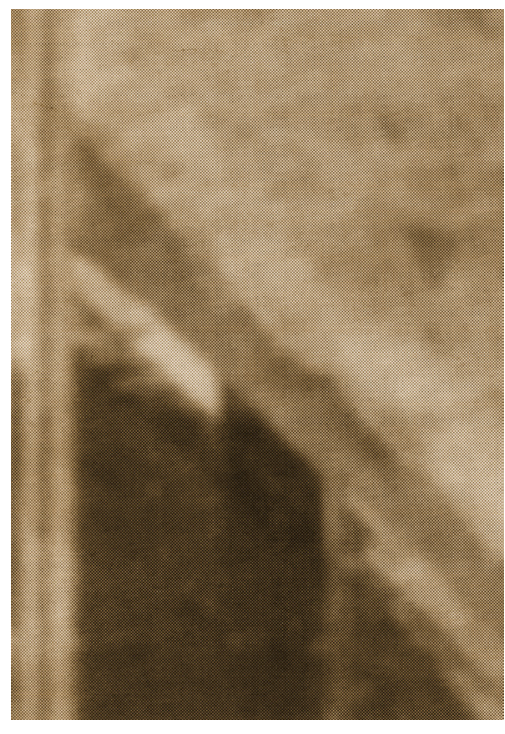

fig. 8.v. detail of installation panel surface, Publication Exhibition.

Note the pixelation of the image as a result of the enlarging reproduction process. 
role in shaping the direction of my further design explorations. The nature of its design elements (mechanically-reproduced and manipulated imagery, presented on panels, arranged to shape space and involve the presence of viewers engaging with them) provided material stimulating enough questions of interpretation to show that this approach would be useful in moving toward a philosophy of meaning in architecture.

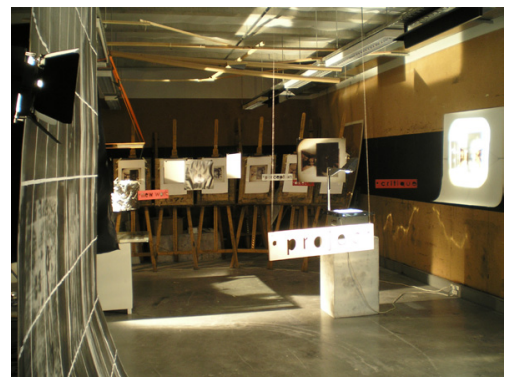

fig. 8.VI. The September Installation, School of Architecture, Victoria University of Wellington, 2011.
8.7. The sequence of the BerlinerBild Bericht plates in the 'context' stage took the visitor on a visual tour of the 1929 pavilion, from overall views of the pavilion from the front facade and the main reflecting pool, views through the front 'entranceway' to views of the interior, Kolbe statue and the second reflecting pool, finally to views of the rear passageway and back facade.

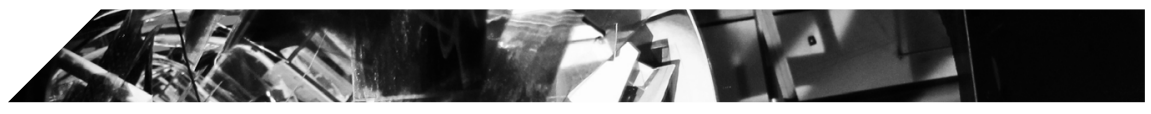

\section{SECTION 2:The September Installation}

Using the ideas explored the Publication exhibition piece as a key point, the second set of design explorations involved the design and implementation of an installation for the September 20II Design Review at the School of Architecture, Victoria University of Wellington.

The following discussion of this stage of my design explorations covers each of the seven parts of the installation, discussed in the order which visitors to the installation would move through them. To maintain the flow of the written discussion, I have structured it by keeping the 'writing down' (descriptions) and 'writing out' (intentions) for each part of the installation together, before moving on to the more holistic 'writing through' analysis, critically interpreting the installation as a whole.

\section{Writing down and out: Description and Intentions for the Septem- ber Installation}

\section{'a context'}

The installation took place in a studio in the Wigan Building of the Faculty of Architecture and Design, Victoria University of Wellington. From the doorway of the room, the visitor was drawn into a long narrow space upon whose floor was arranged a sequence ${ }^{8.7}$ of the reproduction Berliner Bild-Bericht photographs, printed in the sepia tones and dimensions of the original plates and fixed to shiny backing stands to make them freestanding. Seeming to 'spill' from the dominant perspective lines in each image was a collage and photomontage of printed media material, including tile pattern-prints of each photo, titles of key articles and essays on the pavilion and Mies, and reproductions of the various plans of the pavilion showing where each view was taken from. As this 'shadow' of the image got larger and longer, amateur photographs of the 1989 pavilion started to appear, mimicking the framing and viewing angle of each Berliner BildBericht plate. 


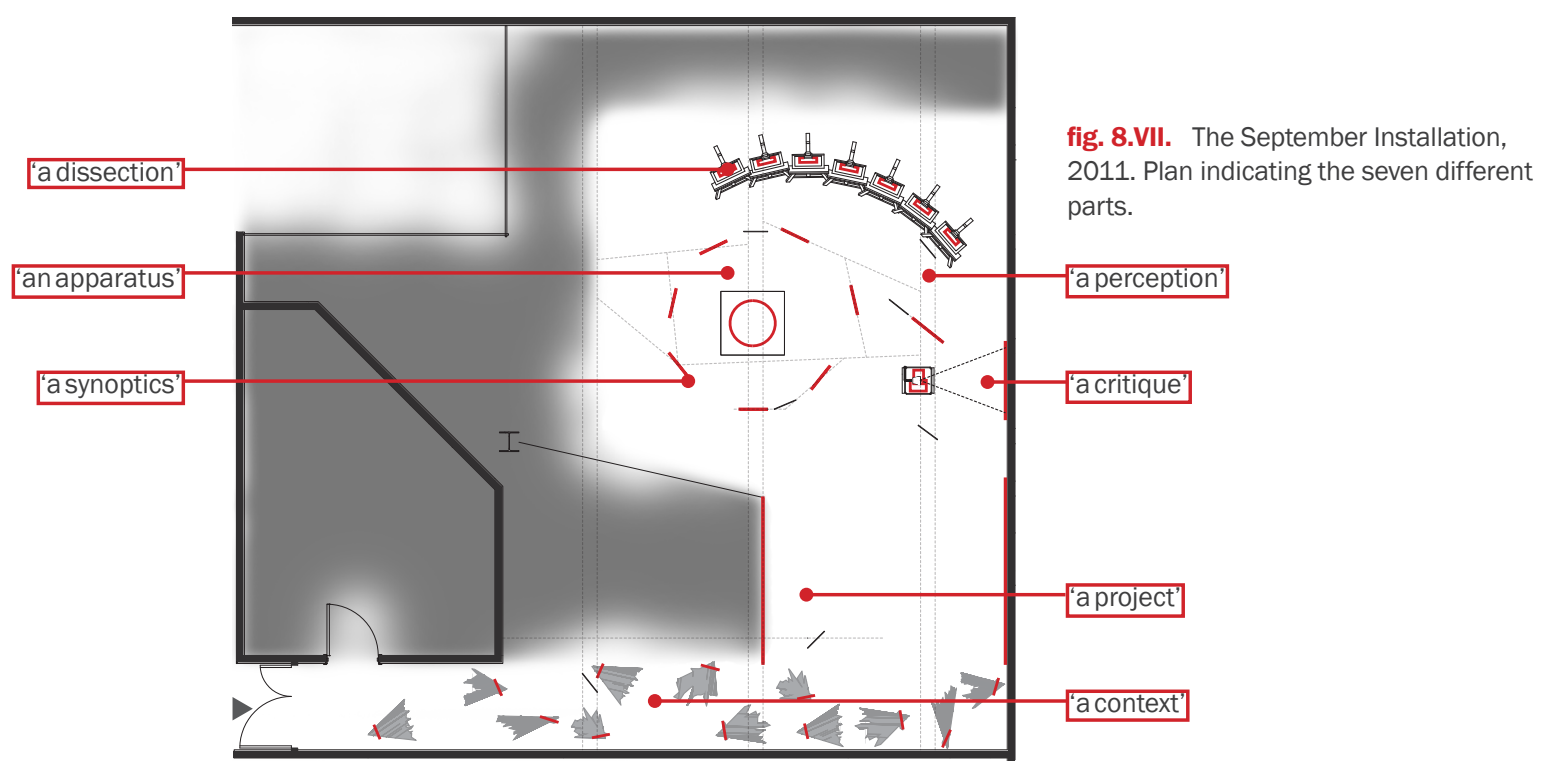

As discussed in Chapter 7, the Berliner Bild-Bericht photographs occupy a particularly influential position in the history of the Barcelona Pavilion, and in people's interpretations of its architectural meanings. As such, they cast a 'cultural shadow' over everything to do with the pavilion, be that critical discussion, personal interpretation, or media and physical reproduction. The 'shadow-collages' created in the 'context' stage of the installation sought to show something of this influence. They created a sort of frame of reference for the rest of the work to be situated in and stem from, also providing some of the 'raw material' in terms of the techniques of collage and manipulation of print media material for later stages.

\section{'a project'}

Having followed this trail of canonical photographs to its end, the visitor found themselves in the main space of the installation. First to draw their attention was one of the large-scale Berliner Bild-Bericht reproductions from the Publication Exhibition. As in the exhibition, two large panels represented the act of 're-constructing' the Barcelona Pavilion in Wellington. However, in this re-installation, only the MMA II 254 panel was included, as the Seidman 247 panel was destroyed in the course of the Publication exhibition pack-down. Instead, a 'place holder' of a sheet of shiny aluminium foil acted as a referent to the original exhibition piece, as well as making reference to the silver-coated negatives used in early photography. This large silver panel dazzled under the installation lighting, shimmering slightly as the visitor walked past, its large size contrasting with its delicacy. The fact of the Seidman 247 panel's destruction and the obvious impermanence of its substitute further pointed to the fleeting nature of the physical image, and its detachment from the more enduring substance of its meanings, which, if they prove to be culturally significant, may be shared and last for hundreds of years. Meanings are fluid and able to be morphed and merged by people in different ways, being distorted by the vagaries of context just as visitors' reflections were distorted by the silver panel.

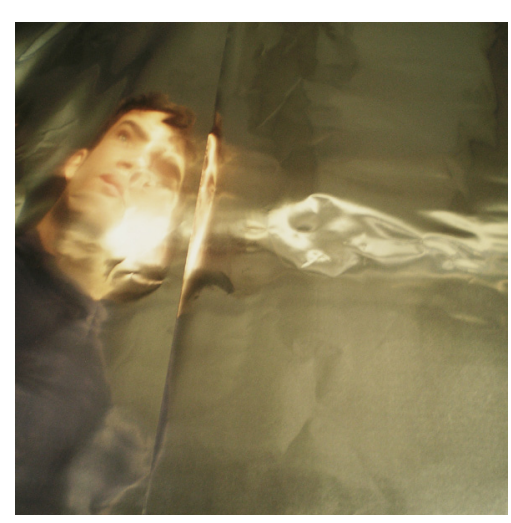

fig. 8.VIII. 'a project', The September Installation. The distorted reflections of visitors in the shiny foil panel. 

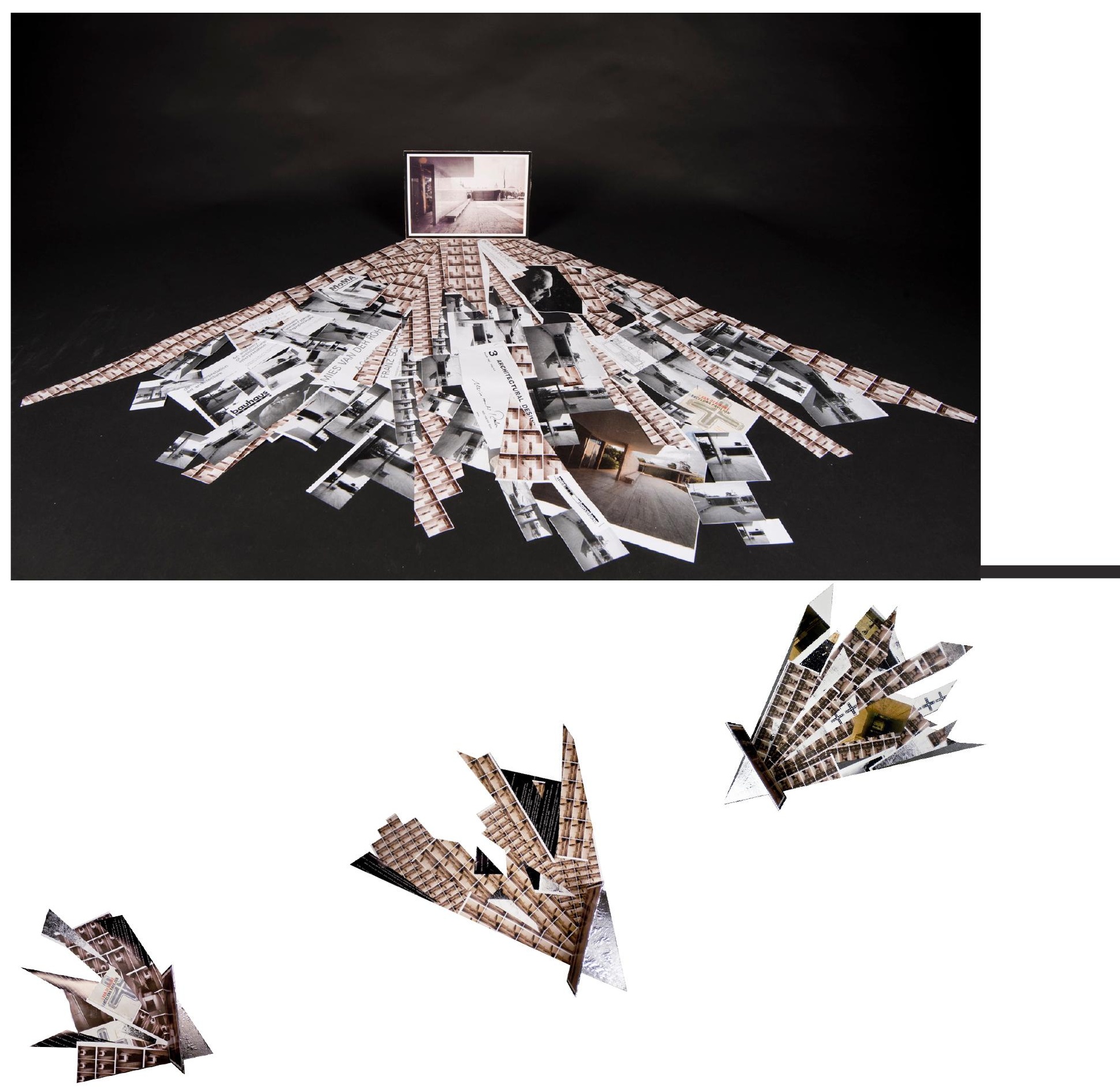


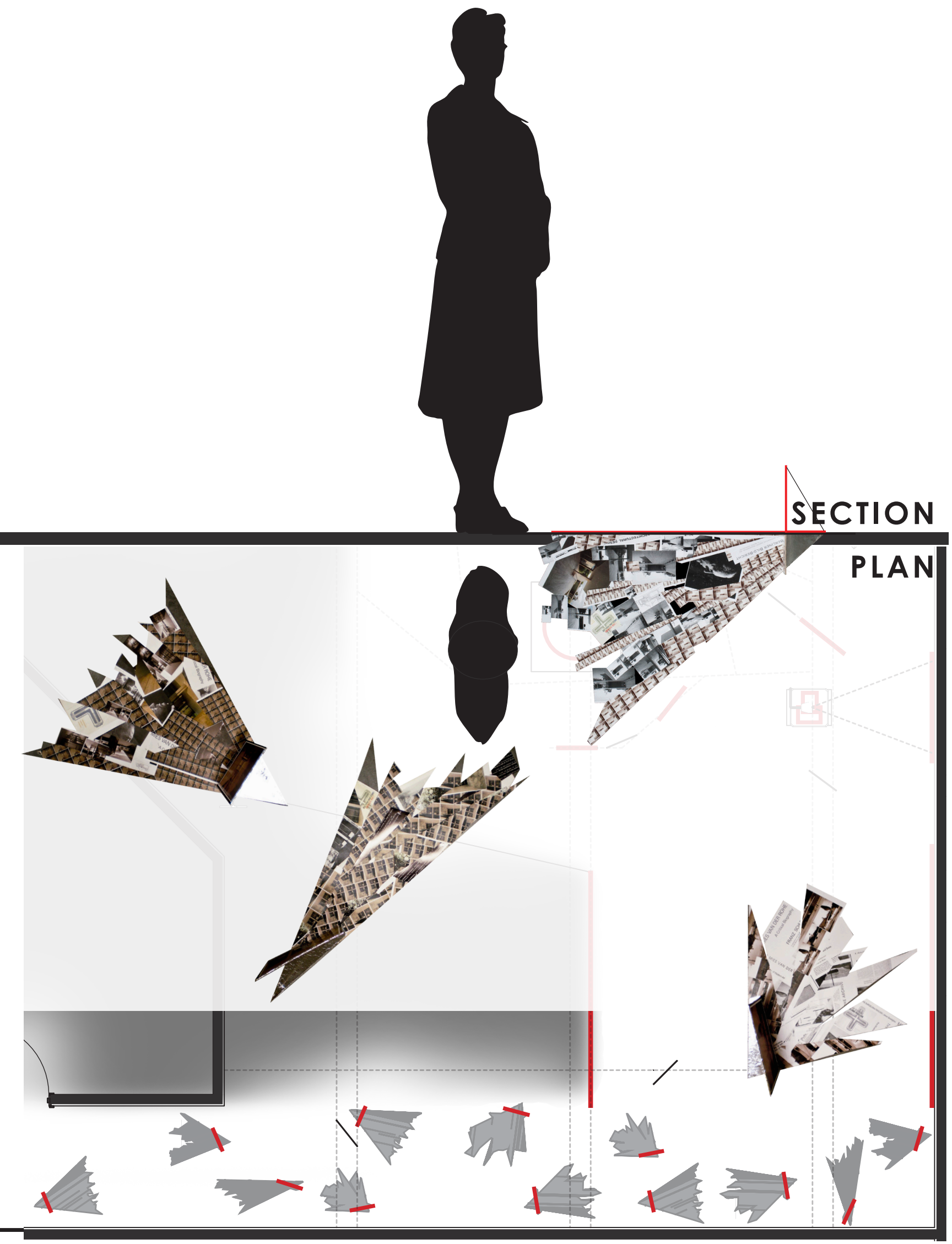




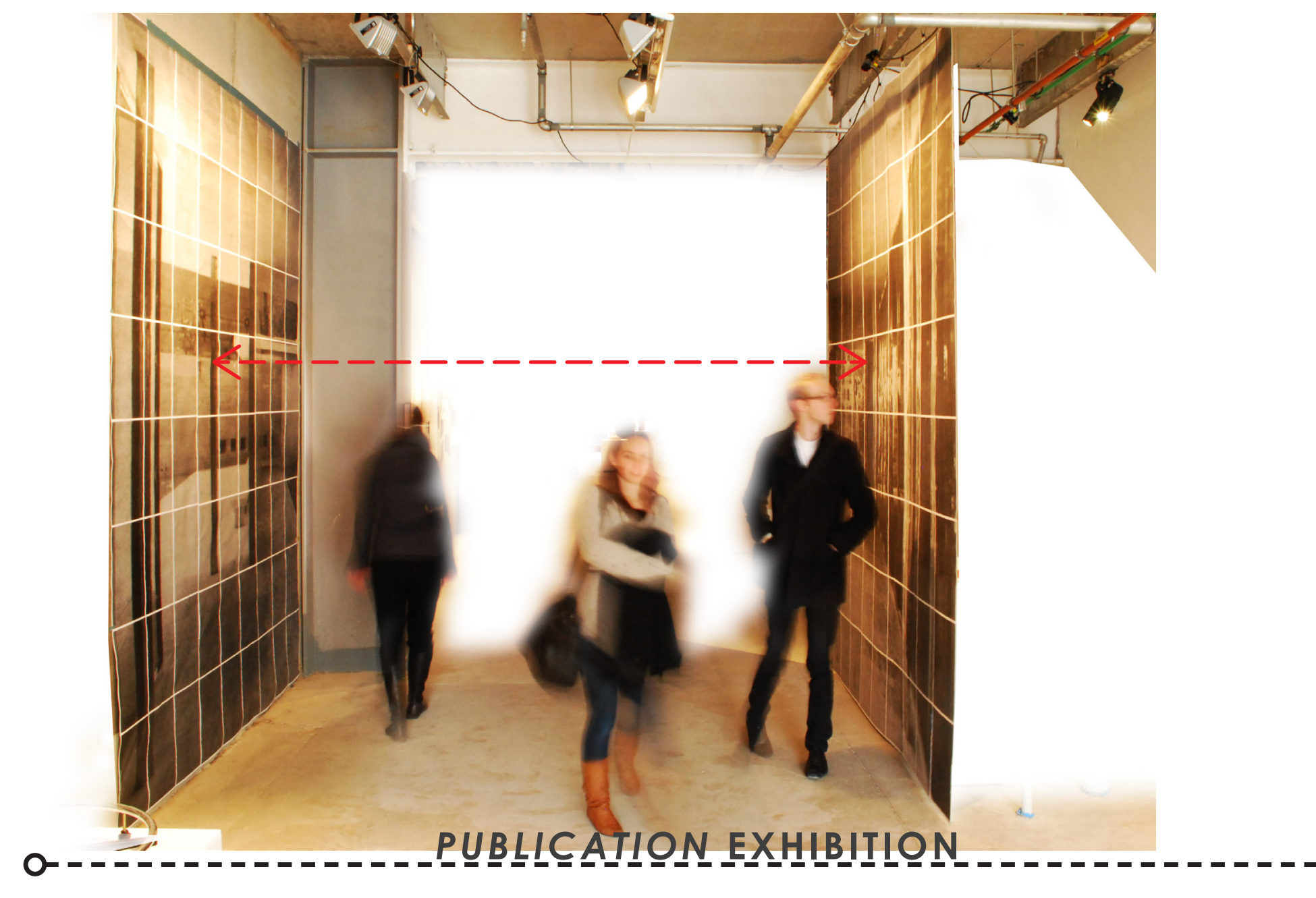

full-scale photographs

spatial relationships

a project $\begin{aligned} & \text { inhobiting the spoce } \\ & \text { of the repoduction }\end{aligned}$

fig. 8.X. 'a project', The September Installation. 

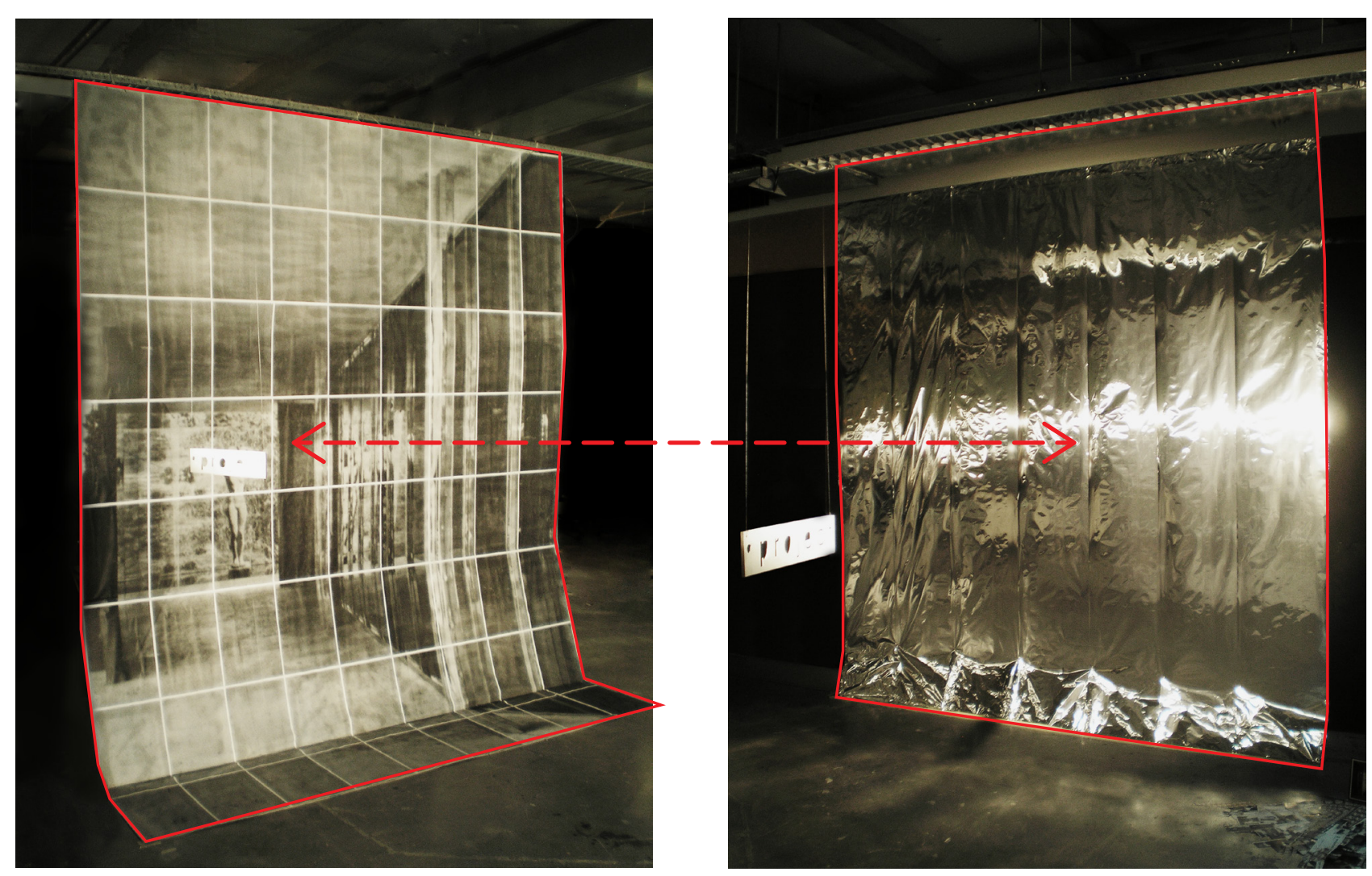

SEPTEMBER INSTALLATION

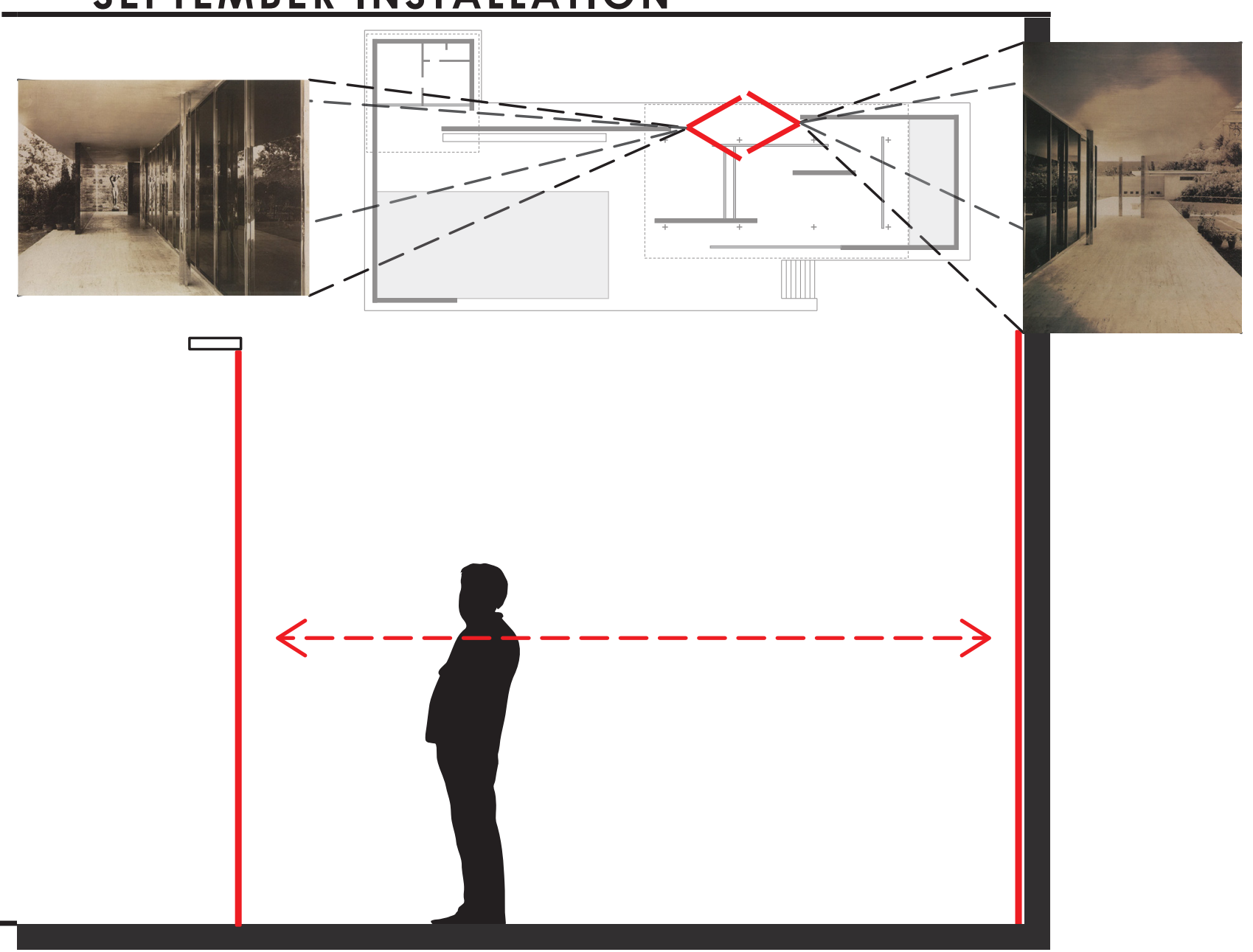




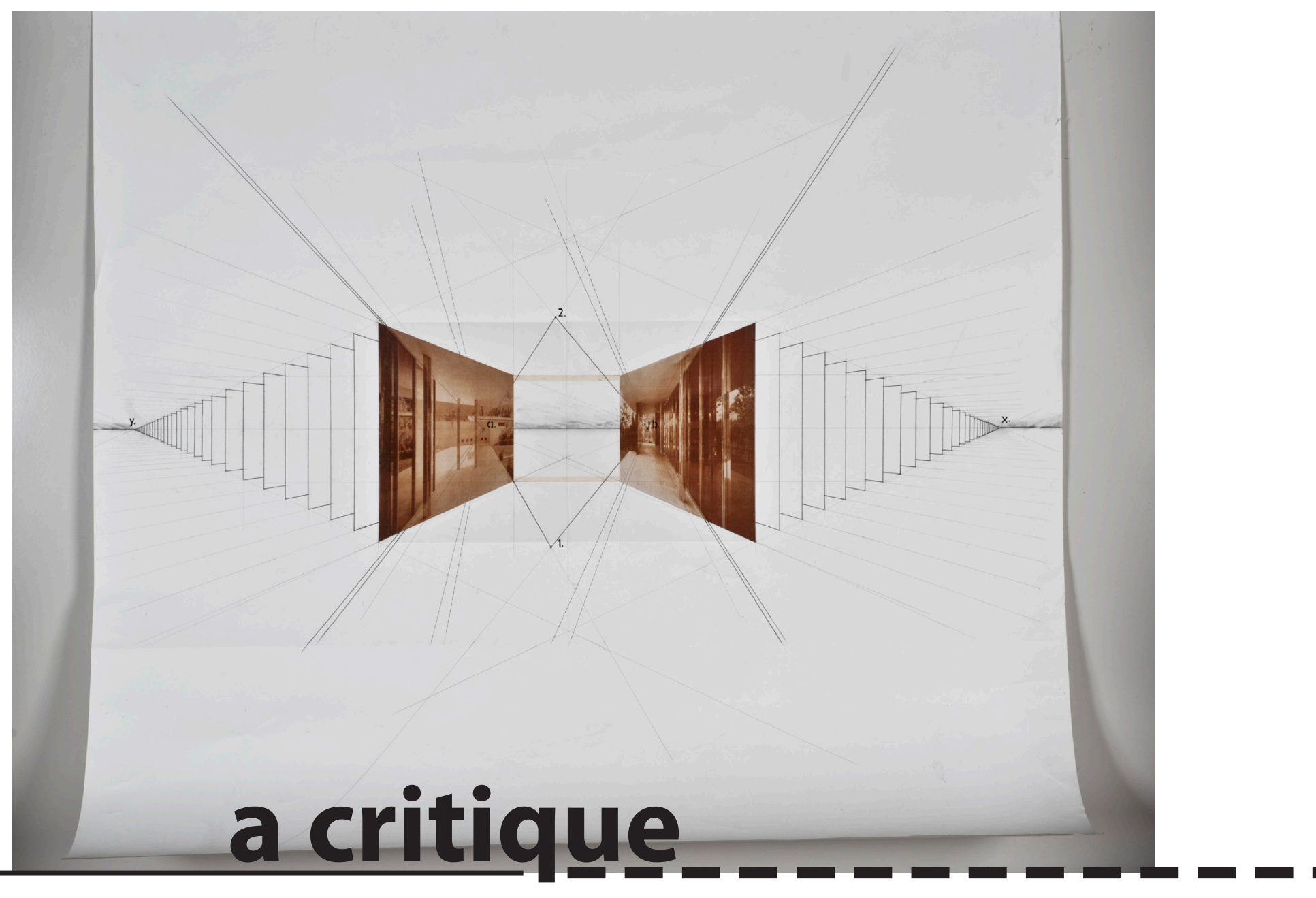

fig. 8.xı. 'a critique', The September Installation. architectural drawing collage
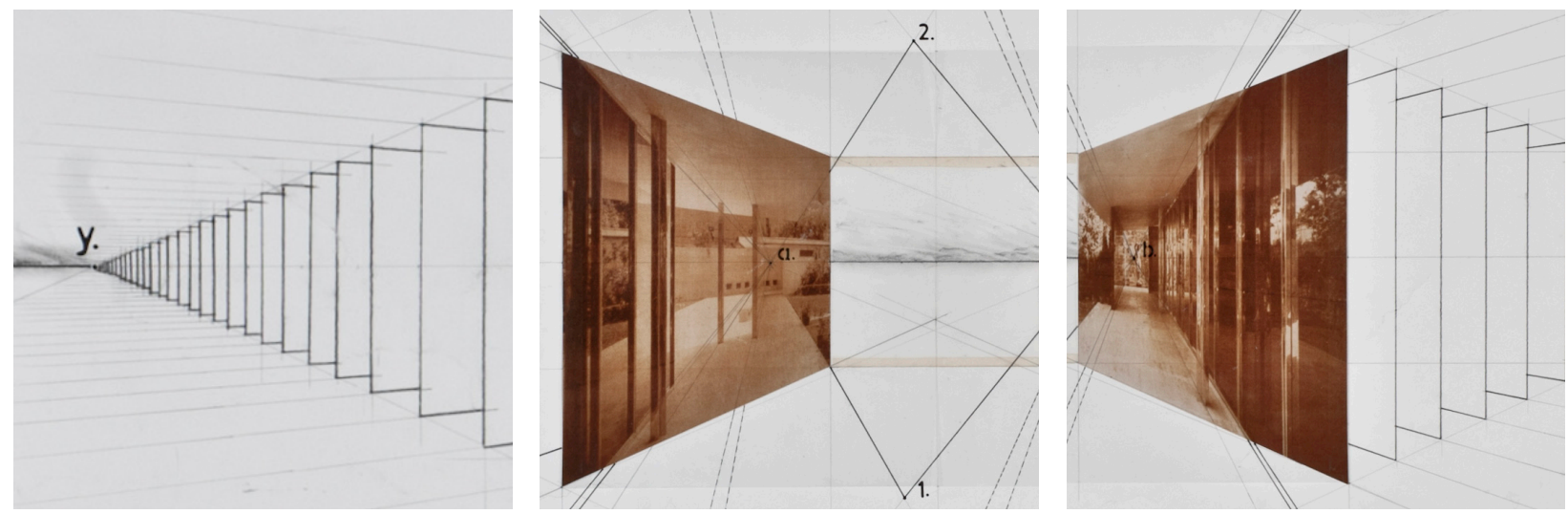


\section{'a critique'}

Moving from the 'media space's.8 reverberating between the panels of ' $a$ project', the visitor arrived at a large drawing fixed to the adjacent wall. It analytically explored the Publication Exhibition piece via architectural drawing, visually investigating the idea that each panel was 'reverberating' against the other, and attempted to 'draw out' potential implications for architectural meaning of creating such a space. The pair of panels were drawn using two-point perspective projection, from an abstract vantage point placing them in the middle of an empty landscape. Perspective lines from the distorted photographic image on each panel were drawn out, contrasting with the two-point perspective of the panels themselves. The 'bouncing' of the viewer's eye back and forth along the invisible yet implied connections between the two panels the drawing was supported and accentuated by the 'echoing reverberations' of the panels repeating the panels infinitely into the distance of the drawing. The conflicting spatial information of these elements of the drawing deliberately broke down the formal relationship between the drawn panels, creating shifts and misreadings of the pictorial space between them.
8.8. I am referring here to the physical space between the panels as 'media space' only symbolically, as 'actual' media space is an abstract concept describing the way people imagine space and architectural meaning as they interpret architectural media. The 'project' work and other aspects of the September installation are attempts to produce a physical, experiential manifestation of the 'media space of architecture' concept.

\section{'a perception'}

Situated in front of the 'critique' drawing was an overhead projector, casting two black-and-white transparencies of the Seidman 247 and MMA I 254 plates onto the drawing. These were so arranged to display the Seidman 247 transparency over the drawn panel representing the MMA I 254 reproduction, and the MMA I I 254 transparency over the Seidman 247 drawn panel, using the vanishing point of each image as the common anchor point for each transformation. The inversion of the established pictorial order of the drawing layered further 'reverberations' onto this analytical work, as well as introducing an external 'media' element onto what was a conventional architectural-style drawing operating within the traditional representational confines of the discipline. Hanging next to the projector was a photographic print of the projection/drawing combination. This display of original architectural work (the drawing), media influence (the projection) and the mediatised reproduction (the photograph), attempted to reveal the way media build upon their own output, as well as presenting a certain interpretation ('a perception') of the primary work ('a project') which all of these elements referenced. 


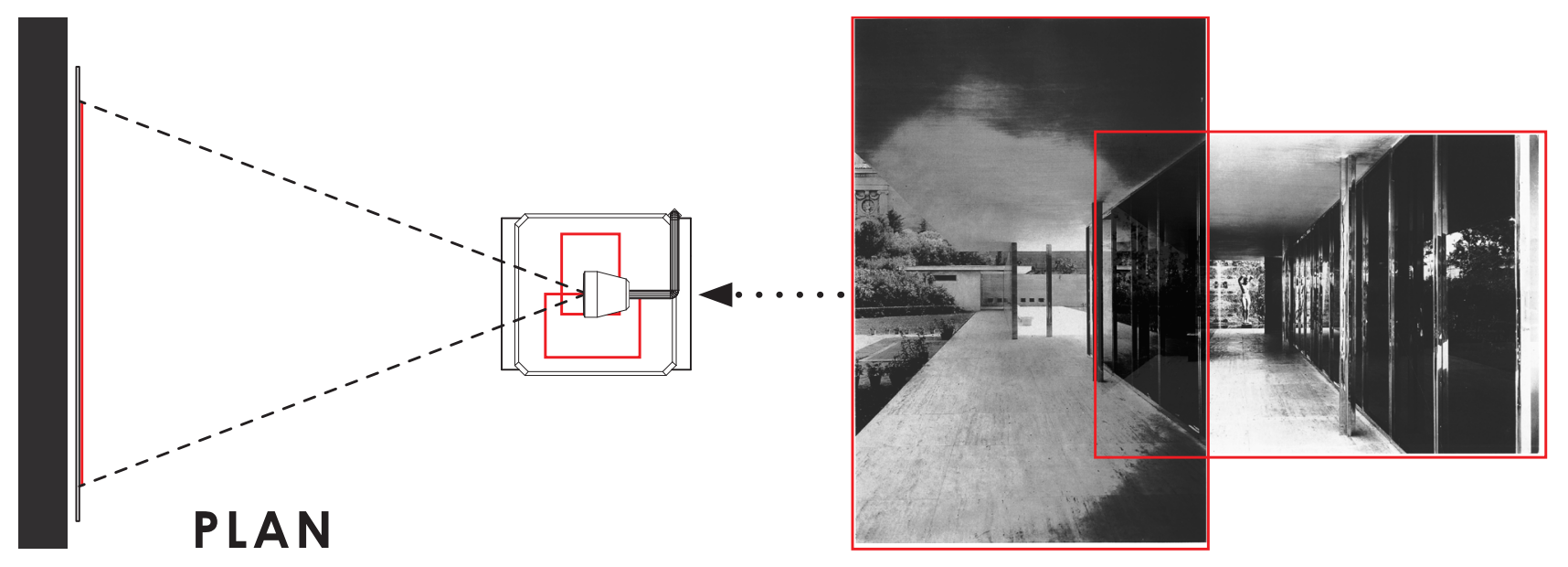

a perception projection over drawing

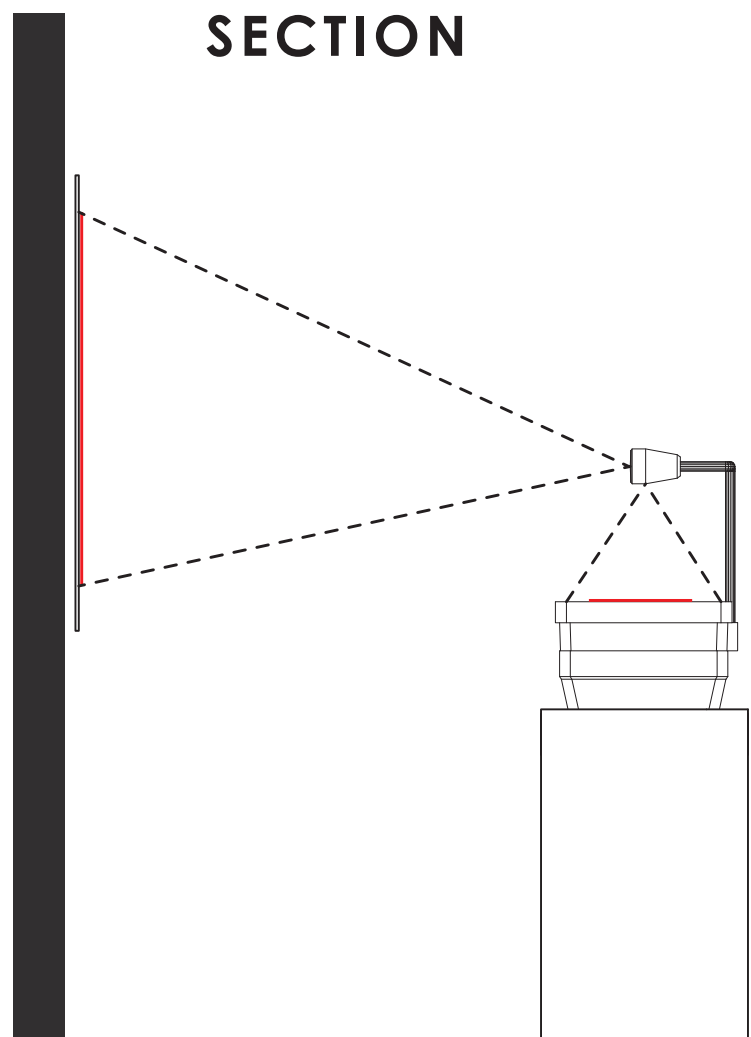

photograph

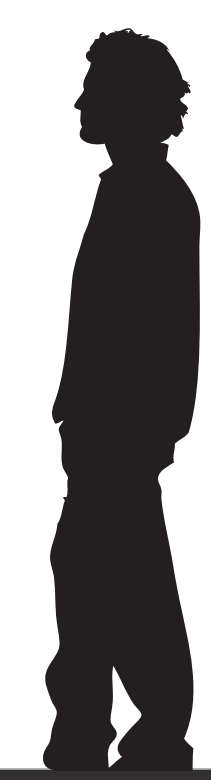




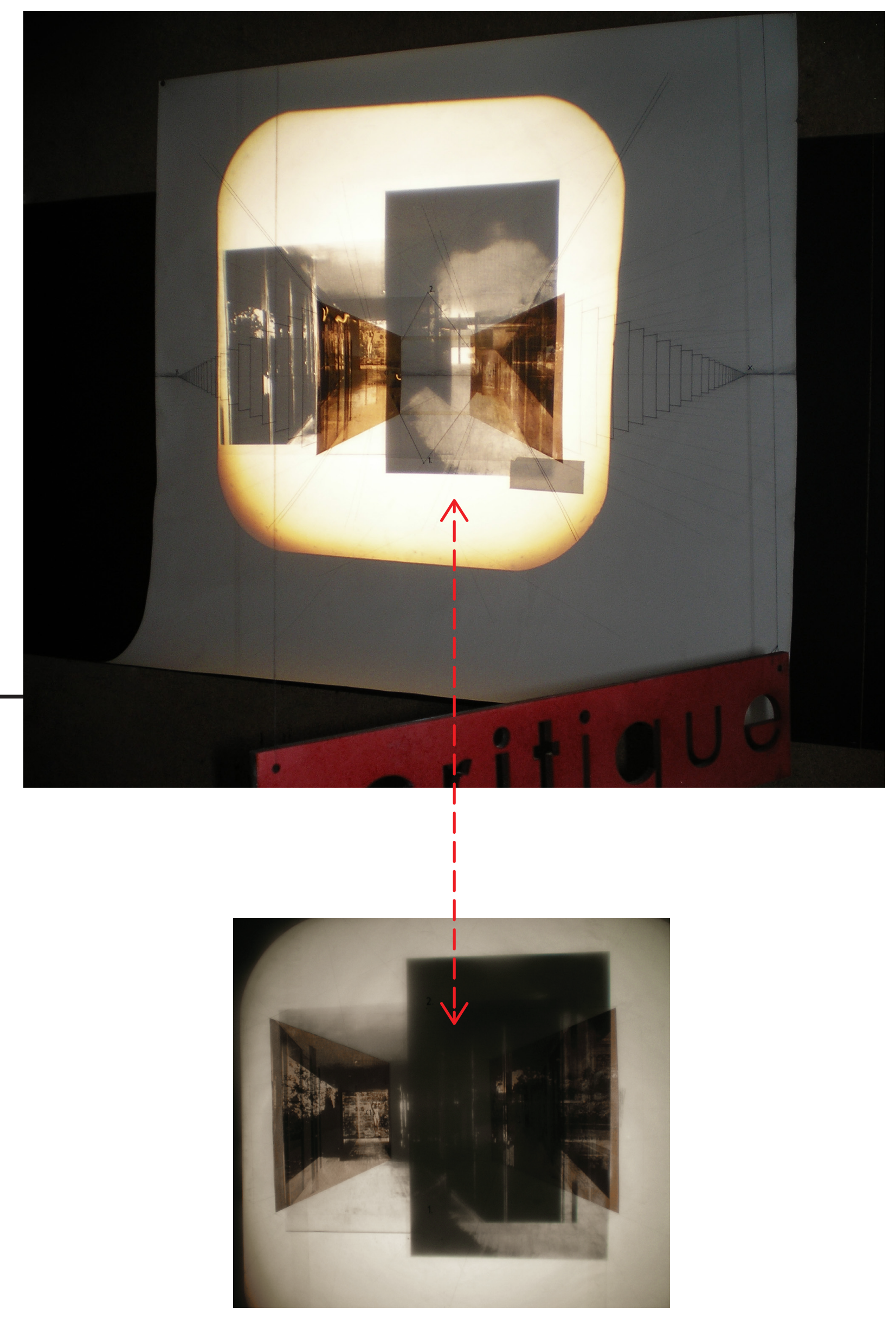


8.9. Small details of the 'dissection' work's configuration, such as the way the easel legs crossed each other were specific design decisions made towards linking them as one body of work in this manner.

8.10. The name 'an apparatus'seems appropriate for the way this setup seemed to instantly reproduce and 'explode' into the 'media space' whatever as placed into it (in this case, the set of seven 'dissection' images).

8.11. Having considered the linear arrangement of the 'dissection' images as they stood on their easels, I discovered that they could be linked in a cyclical pattern, from darker-toned images to lighter ones and back to darker ones. This discovery informed the circular design of the 'apparatus' ring model.

8.12. My intentions in designing the 'apparatus' ring model were to explore the relation of the 'dissection' images as they faced each other across the diameter of the cardboard ring. Considering each image independently, I identified the strongest elements of each view: the major perspective lines, light and dark areas, and some of the key architectural elements visible in the distorted photographs such as the columns, the Kolbe statue and the wall panels. Using modelling techniques of collage, cut-outs, and the layering of different materials and effects, these aspects were 'extracted' into the space of the circle via three-dimensional additions to the image surface. In positioning these modelled elements, I used a specific vantage point above the rim, directly opposite the image in question. (This position was also used as the photographic perspective of the camera in photographing each part of the model for the 'new work' image set.)

\section{'a dissection'}

Having distilled the efforts of the previous stages of the installation into the highly potent medium of a photograph, the next stage considered this image as a new source of inspiration and space of exploration. This photo seemed to me layered with different meanings and definitions of architectural space, so this next stage performed a sort of visual 'dissection' on it, extracting seven iterations or versions of the master image. Digital image manipulation processes (in Photoshop) were used to alter the shadows and highlights of the master image in incremental steps, allowing different parts of the image to recede or advance within the visual field as they became darker or lighter.The resulting 'sections' were printed onto colour transparencies and pinned to easels like strange art $\mathrm{x}$-rays, drawing visitors along the curving arrangement to examine their display. A graduated sequence of change from one transparency to the other was noticeable, different parts of the original image receding from or advancing into prominence in each reproduction. The individual images seemed to be an extracted layer from the different depths of the master image, pulling us deeper and deeper into its image field. Each image could be considered for its meanings independently, on the scale of a single easel, but also in relation to the entire sequence of easels as an image series. 8.9 Printed in subtle tones of amber, sepia, greys and blacks, these images had a sense of melancholy and history to them, evoking the spirit of the Barcelona Pavilion as something immaterial and ghostly, tied to a specific moment in time (the moment of the Berliner Bild-Bericht photographs) yet living on through the mechanical alchemy of the architecture culture industry's continued reproductions.

\section{'an apparatus'}

Upon reaching the last easel, the visitor was drawn back towards the centre of the room by the climactic moment of the installation, entitled 'an apparatus' 8.10 This consisted of a model in ring form, its interior face lined with the same set of seven images from the 'dissection' sequence.".11 Bursting out of each image toward the centre of the circle were variously modelled 'extractions' of aspects in each photograph. Bits of wire, transparent plastic sheets, wire gauze and cut and folded card manipulated parts of each image and 'spatialised' them each in a different way. ${ }^{8} .12$ The exterior face of this model was sheathed in shiny silver foil as used in the 'project' stage, and the whole was lit dramatically with a small spotlight. But the most dramatic aspect to this part of the installation was the fact that the ring-shaped model was suspended in space between two large mirrors, one hung above it and the other resting below it. These two reflective surfaces multiplied the effect of the model, reproducing it infinitely along a virtual vertical axis and transforming the single, independent ring into an infinitely-long 'tunnel' stretching into the reflected depths of the mirrors. The 'apparatus' seemed to me to explore which elements were significant in defining 'architecture', its mechanism being used by the viewer to extract these essential 
moments and intensifying their impact through their reflected repetition.

\section{'a synoptics'}

As a final element to the installation, a set of seven new photographs encircled the mirror and model 'apparatus'. These showed views of the ring model from different angles, each photo taken from a set vantage point directly across the circle from the particular section of the ring it showed. Lit dramatically, these photographs had an abstract and ambiguous nature to them, blurring the viewer's ability to judge their scale or exact spatial configuration. Full of possibility, and open to a multitude of divergent interpretations, this stage of the installation was given the title 'a synoptics', an invented word suggesting a "seeing together" of these photographs, and an elaboration of their meaning as a collected image set. ${ }^{8.13}$ This name also related to the way each photo was hung in a direct visual line with the part of the model forming the subject of each photograph. In doing so,

8.13. Rationalised as: syn- = "together"; -optics = "a way of seeing." the intention was to allow the visitor to make visual connections between what they were seeing in the 'synoptics' photographs and the original 'apparatus' model. As they circled these photographs, peoples' attentions were drawn in a full circle back to the Berliner Bild-Bericht photographs of the 'context' stage, visible once more from this part of the room, as the starting point for this design exploration. 

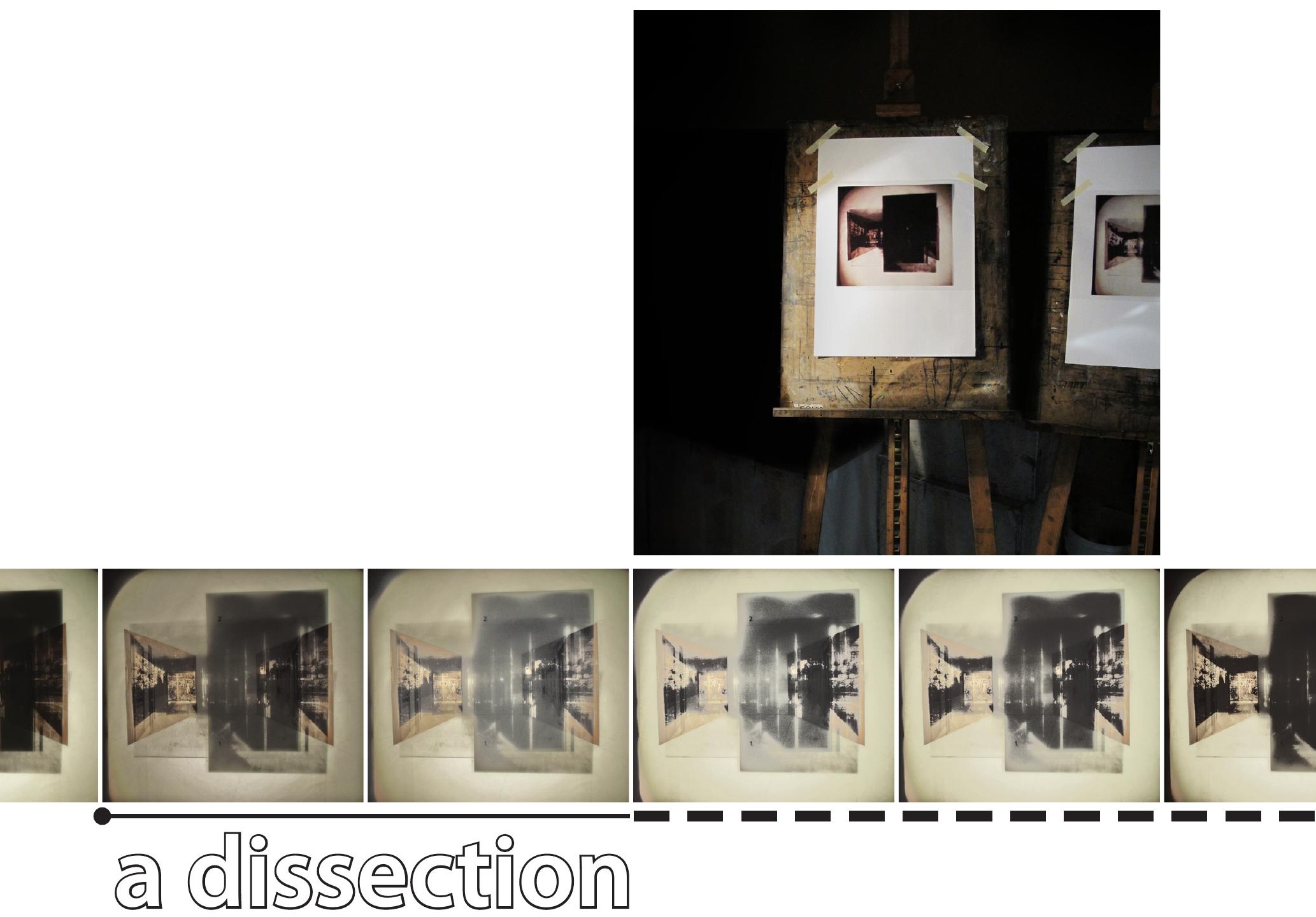

photographic manipulations

iterative changes

colour transparencies

easels 


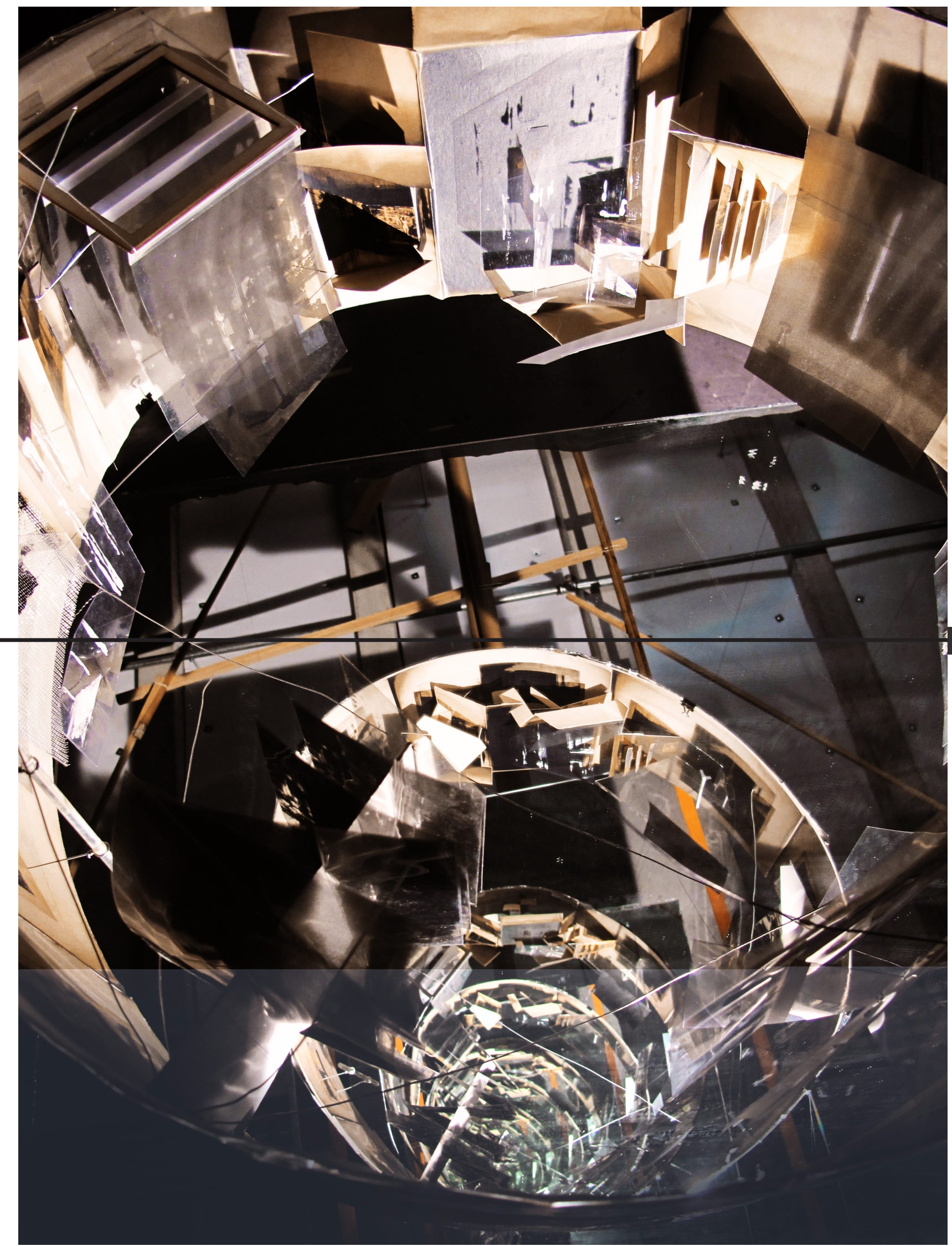

fig. 8.XIV. 'an apparatus', The September Installation. 


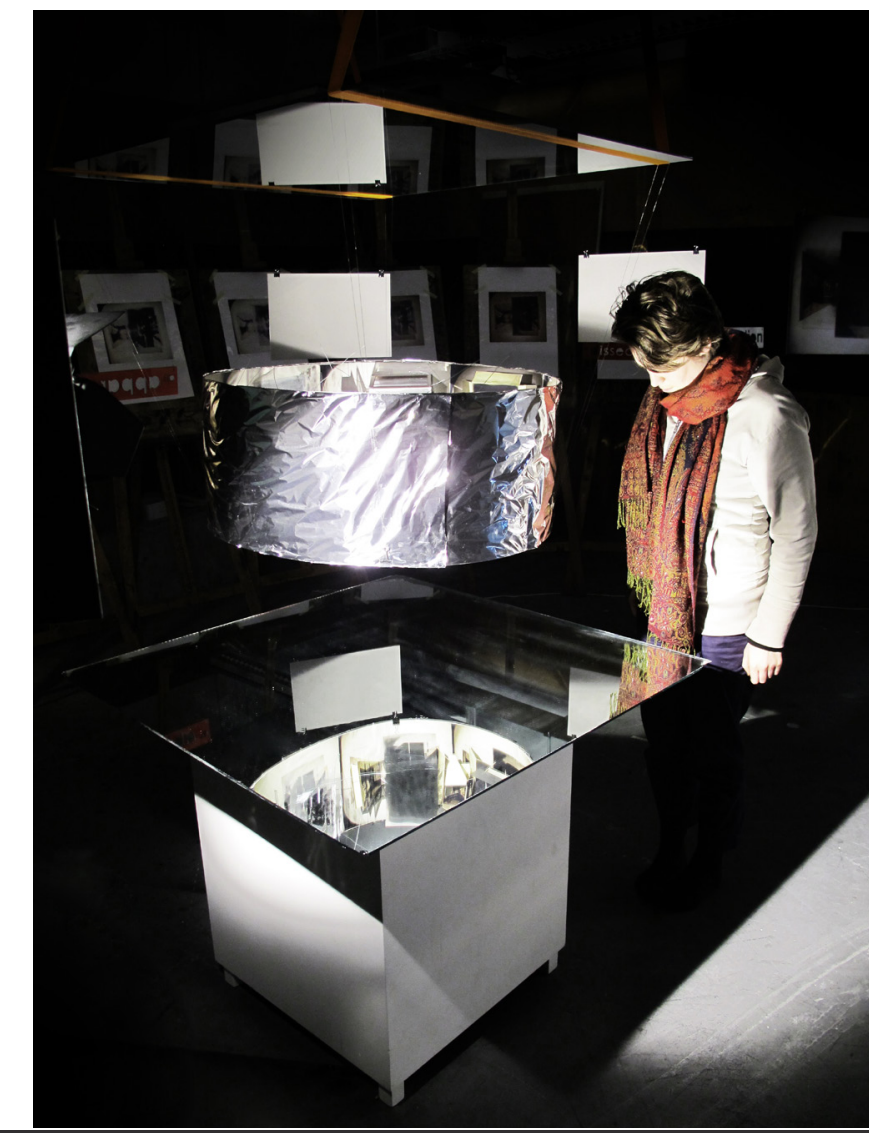

mirror

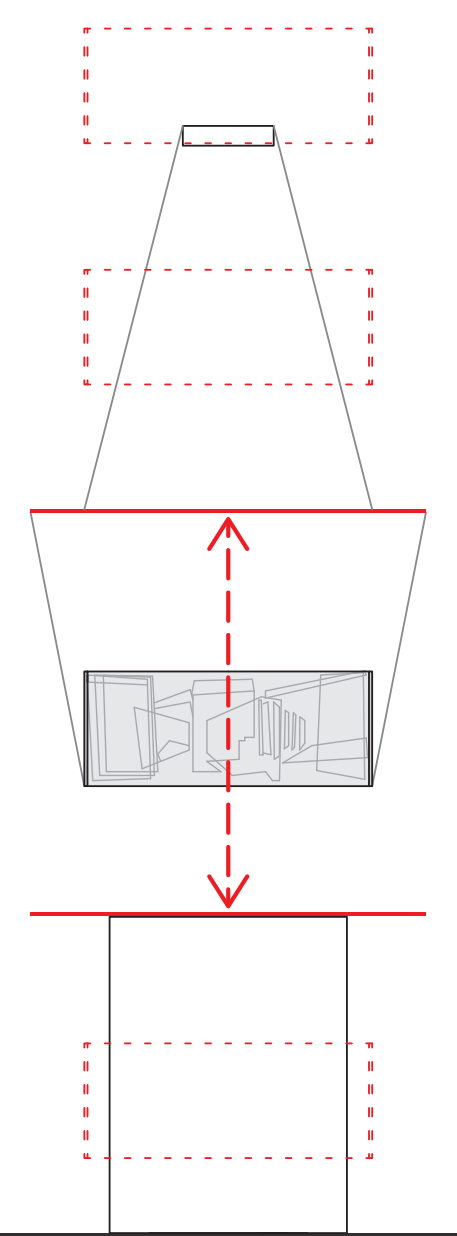

an apparatus 

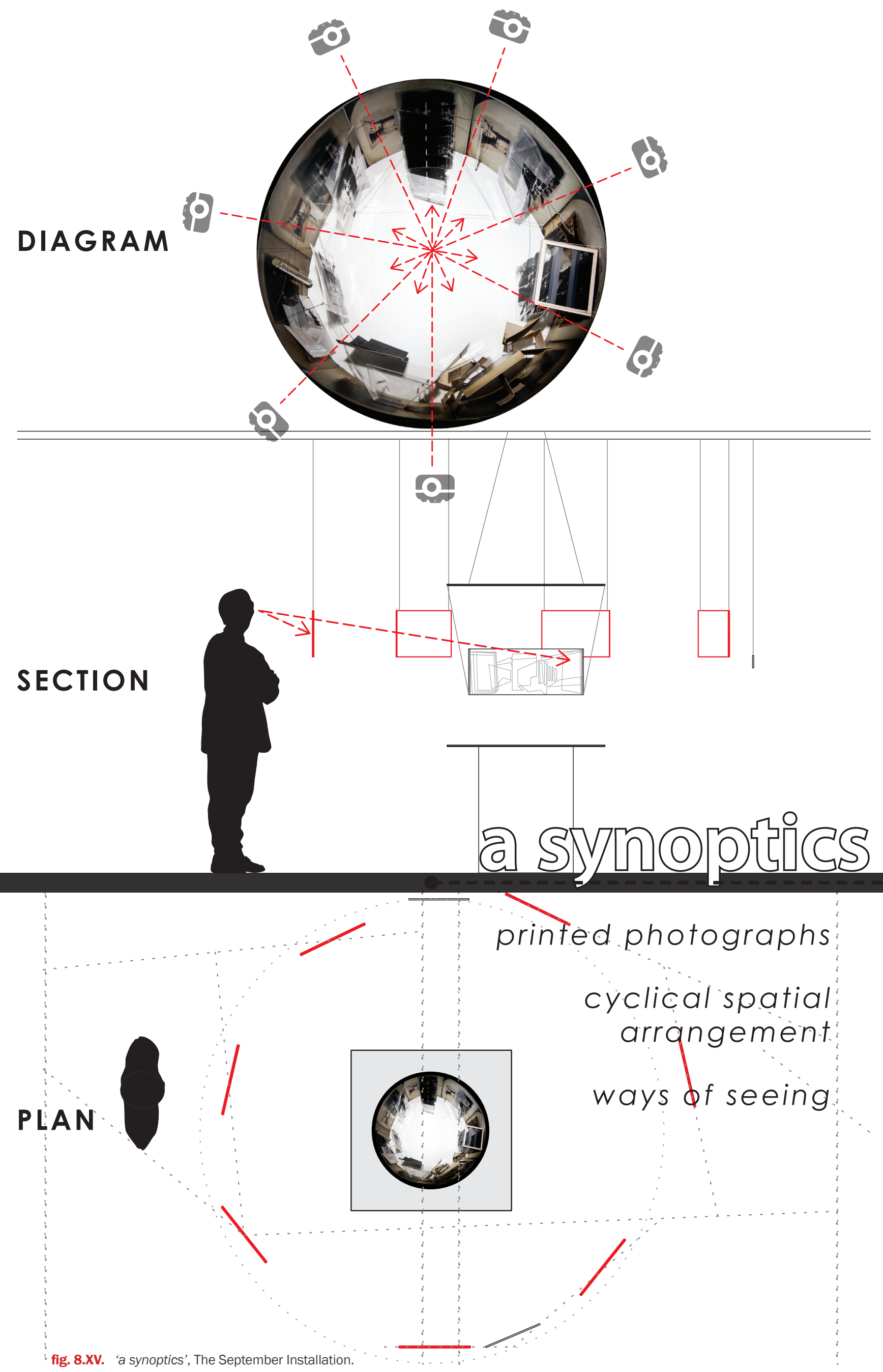


\section{Writing through: Critical Interpretation of the September Installation}

\section{Meanings from processes of reproduction}

The work displayed in the installation revealed a fluid attitude to the status of 'original' and 'reproduced' cultural product.At different stages, work was produced and then reproduced in various ways, the reproduction often changing status to become the new 'original work'. Referencing Walter Benjamin's ideas on the death of the aura of the original, this condition provokes us to reconsider the point where the cultural product is 'produced' and shifts it from the hands of the artist-creator to the media processes of the architecture culture industry (see Benjamin, 2008, Pp. $2 \mathrm{I}-22$ ). I used each of its stages as the 'raw' conceptual material for the subsequent one, in ways which relate to Le Corbusier's publishing of his own work in L'Esprit Nouveau (see Chapter 4). Yet where Le Corbusier promoted himself and his ideas, my installation used it as a means of exploring potentially shifting interpretations as material was changed from one media format to another. As elements were reproduced, interpreted, and reproduced again, there arose the possibility of interpreting potentially different meanings, just as others might be obscured or 'lost in translation', illustrating the impossibility of 'fixed' or 'static' meaning.

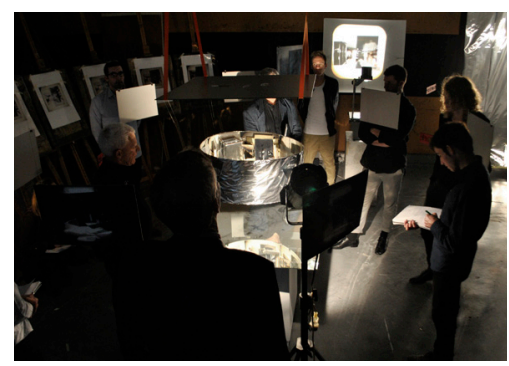

fig. 8.XVI. The September Installation. The design review in progress.

\section{Others' interpretations: the design review}

The installation was created for the situation of a design review as part of the thesis-by-design programme at the VUW School of Architecture. It was presented to a panel of guest reviewers, comprised of internal and external critics who were guided by the format of the design review to give critical 'feedback' on whatever they considered the 'design project' to consist of. Considering the 'event' of the installation as being the substance of the thesis design project, my presentation ${ }^{8.14}$ stood in distinct contrast to the more standard design documentation and conventional architectural representations of building projects which the reviewers had been discussing. The sort of feedback which the review generated ${ }^{8.15}$ was interesting in the way it seemed to reflect certain ideologies of mainstream architectural education, and more generally, of mainstream architecture culture. This was demonstrated most obviously through comments from the reviewers seeking to know what the 'message' of the installation was, as well as how I was proposing to generate a building design from the

8.14. My presentation started in a room separate from that of the installation, with a short overview of my thesis, major conceptual ideas and the theoretical positions I had been developing. I then invited the reviewers and assembled audience to explore the room of the installation for a short time withoutany initial directions from me. I then proceeded to explain my intentions through each stage of the room, and opened the floor to discussion.

8.15. Some questions I received from the reviewers: "What is it all about?" “I can't make head nor tail of the meaning [of your installation]" "What is your next step? How will it become architecture?" 

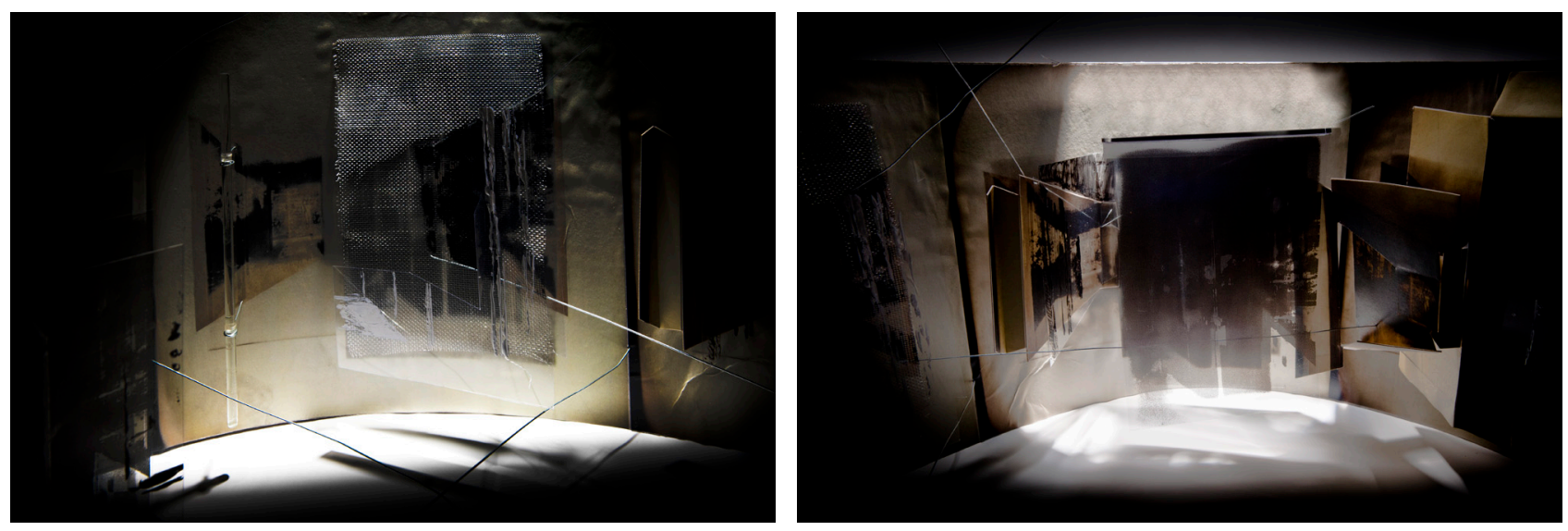

a synoptics

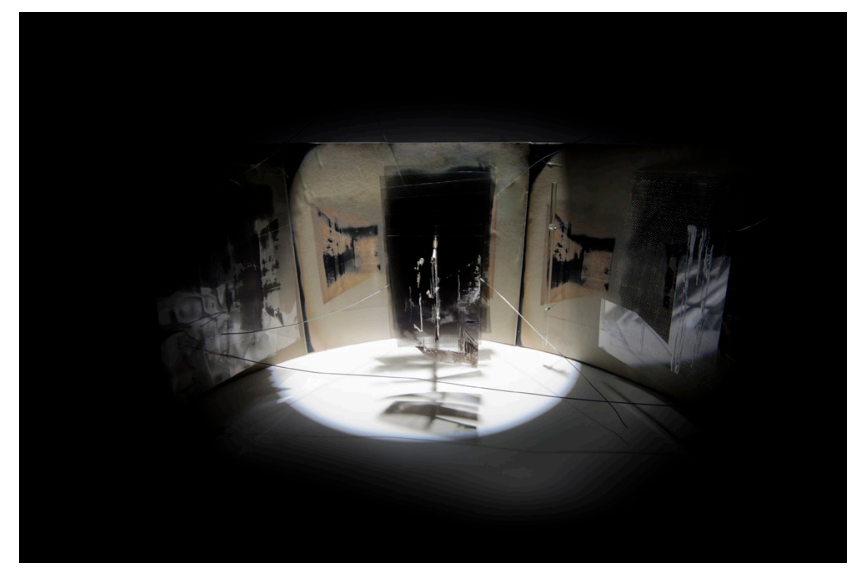

syn- = "together"

-optics = "a way of seeing" 

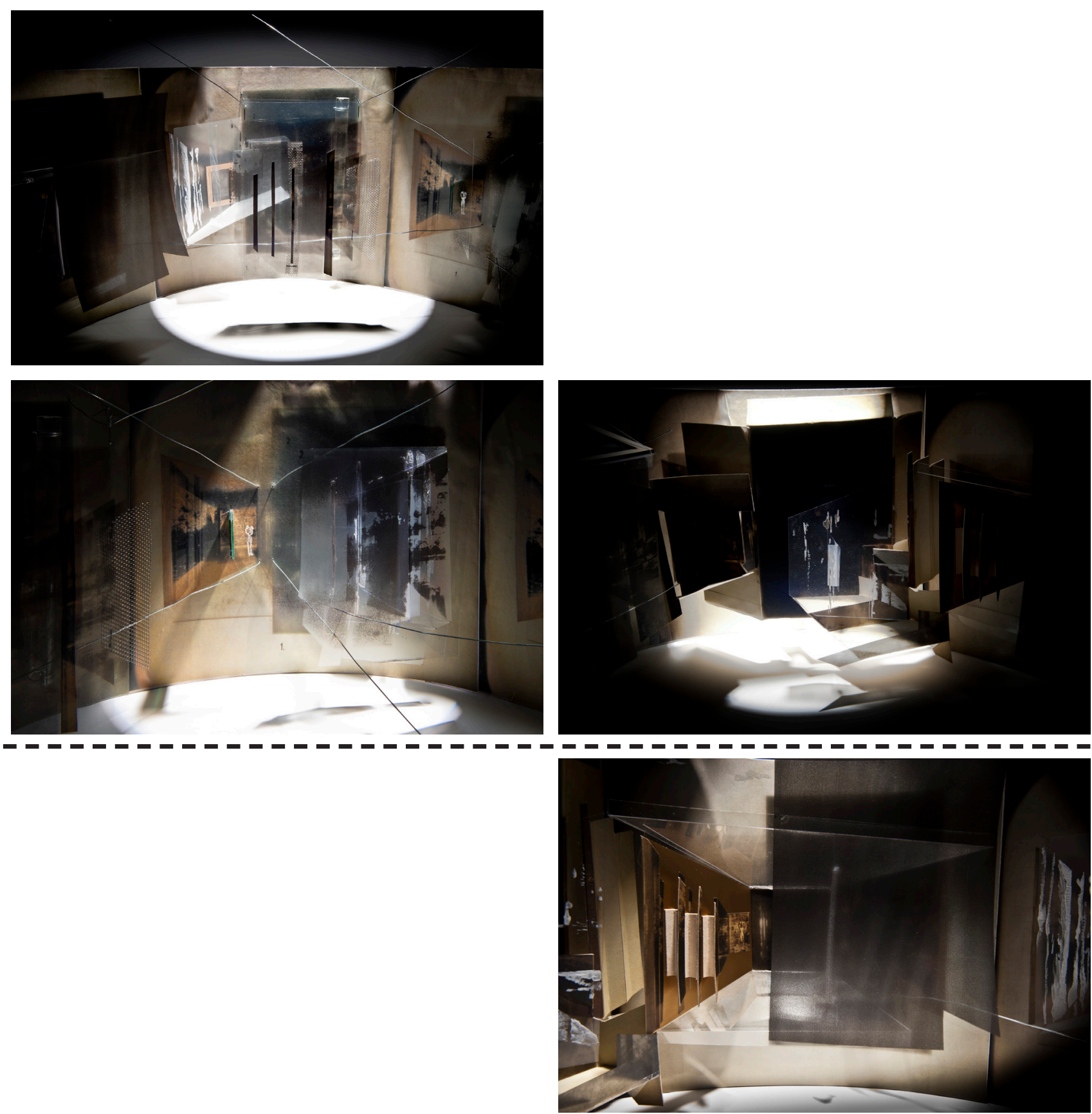

fig. 8.XVII. 'a synoptics', The September Installation. The 'synoptics' photographs. 
8.16. See Jacques Rancière, The Emancipated Spectator (2009), for an expanded discussion of these ideas.

8.17. The reviewers also started a discussion about the formal aspects of the installation (for example criticising the chipped edges of one of the mirrors). Mainstream understandings of aesthetic meaning often talk about "formal beauty", referring to a sort of inventive fusion of 'style' and 'content'. However, as Bourriaud points out, this is a confusion of form (a physical trait) with meaning: "The most common criticism to do with new artistic practices consists...in denying them any 'formal effectiveness', or in singling out their shortcomings in the 'formal resolution'” (Bourriaud, 2002, p. 21). Criticism from the reviewers on formal aspects of the installation reveals for me their ideological bias towards romantic hermeneutical understandings of meaning, treating it as somehow 'embedded' within these formal attributes of the work. In contrast, post-structuralism, through the concept of relational aesthetics, shows that meaning only exists in the encounter and in the dynamic relationships of people to their cultural contexts and personal frames of reference. 'process-work' which the installation, for them, seemed to show. Questions from the reviewers on the 'message' of the installation demonstrated that they were still subscribing to a form of the 'romantic hermeneutics' model of meaning, seeking what they considered the 'original' or 'true' meaning of the work from its creator (myself), rather than realising the potential power of their own position as 'emancipated spectators' of the work, able to activate and 're-create' the work through their own act of viewing and interpreting it. ${ }^{8} 16$ Despite my pre-installation talk presenting the attribution of meaning as a personal, individual activity taking place within each person's own frame of reference and cultural context, the hegemony of mainstream institutional thinking prevailed. ${ }^{8.17}$ Comments from the reviewers seeking to understand how I was going to 'realise' the ideas of the installation via translation into built form demonstrated the hegemony of architecture-asbuilding, and a lack of recognition for the role that print media products of the architecture culture industry play in shaping and developing architectural meaning, even in the most conventional of building projects.

\section{The installation as the Barcelona Pavilion reconstructed}

For me, the production of this installation could be seen as the creation of an alternative reality, a place in which the intentional, the planned and the logical were brought together with the chance, the unpredictable and the inexplicable. The idea of a self-contained, closed and 'complete' work of art was replaced with a fragmentary, open-ended, and collaged work-inperpetual-progress:the 'Barcelona Pavilion' of the September Installation was not an ordered assembly of component parts in a tidy relational hierarchy, as mainstream architecture culture would have us believe Mies' 1929 pavilion to be, but an assemblage of disparate (media) materials - a piece of collage - whose actual existence is still continually being produced, even through the relation of the text of this very thesis to the accompanying images.

\section{Summation}

Considered through a mainstream (romantic hermeneutics) understanding of the role the project plays for architectural meaning, the feedback I received from the reviewers might be considered generally negative and problematic, finding a lack of obvious and decisive meaning, and confused and conflicting 'aesthetic decisions'. However, because the installation was produced with a post-structuralist understanding of meaning, the measure of its success is not in the clear communication of a prescribed 'message'. Instead, it ought to be critiqued in regard to the way it may be interpreted in very ambiguous ways, a complete contrast to 'propaganda', and the way it may be seen to reveal the media phenomenon by which the meanings of the Barcelona Pavilion (in all its incarnations) are produced through the media space of architecture. Ultimately, the representational material (drawings, photographs and models) of the installation were used not only in exploring the theoretical positions proposed by my research, but also 
as a mechanism for finding, inventing and treading new design research paths. In particular, the final set of seven 'synoptics' photographs were identified as having the potential for further development as "speculative instruments", 8.18 in both the visual and contemplative senses, for a more focussed reconstruction of the Barcelona Pavilion in the media space.
8.18. phors: Studies in Language and Philosophy. (Ithaca, N.Y.: Cornell University Press, 1962), 237

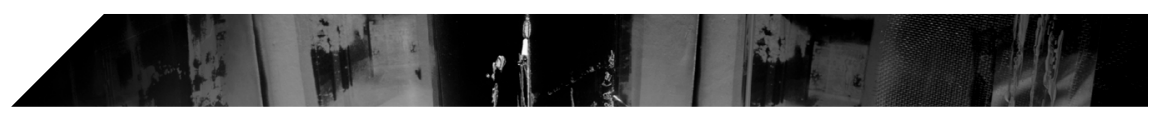

SECTION 3:The 'new work' installation- a product of the design experiment process

\section{Writing down: Description of the 'new work' installation}

The final design exploration in my process of conceptually reconstructing the Barcelona Pavilion took the form of a proposal for a further installation, as a refinement and extension of the design moves made in the Publication Exhibition piece and the September Installation. Conceptually located in a dark gallery setting, the 'new work' installation proposal comprises seven large screen-walls, each 5.1 metres wide $\times 3.4$ metres tall, arranged around a central space in which seven digital projectors hang, angled to project onto each of the screen walls. The projectors display the seven 'synoptics' photographs on the freestanding screen-walls, which are viewable from both inside and outside the ring of screens. The projectors are set to one-minute periods, after which they change to show another of the photographs. The image sequence for each projector is randomly determined, limited only by the requirement for each of the seven photographs to be shown once at any one time on the screens. 


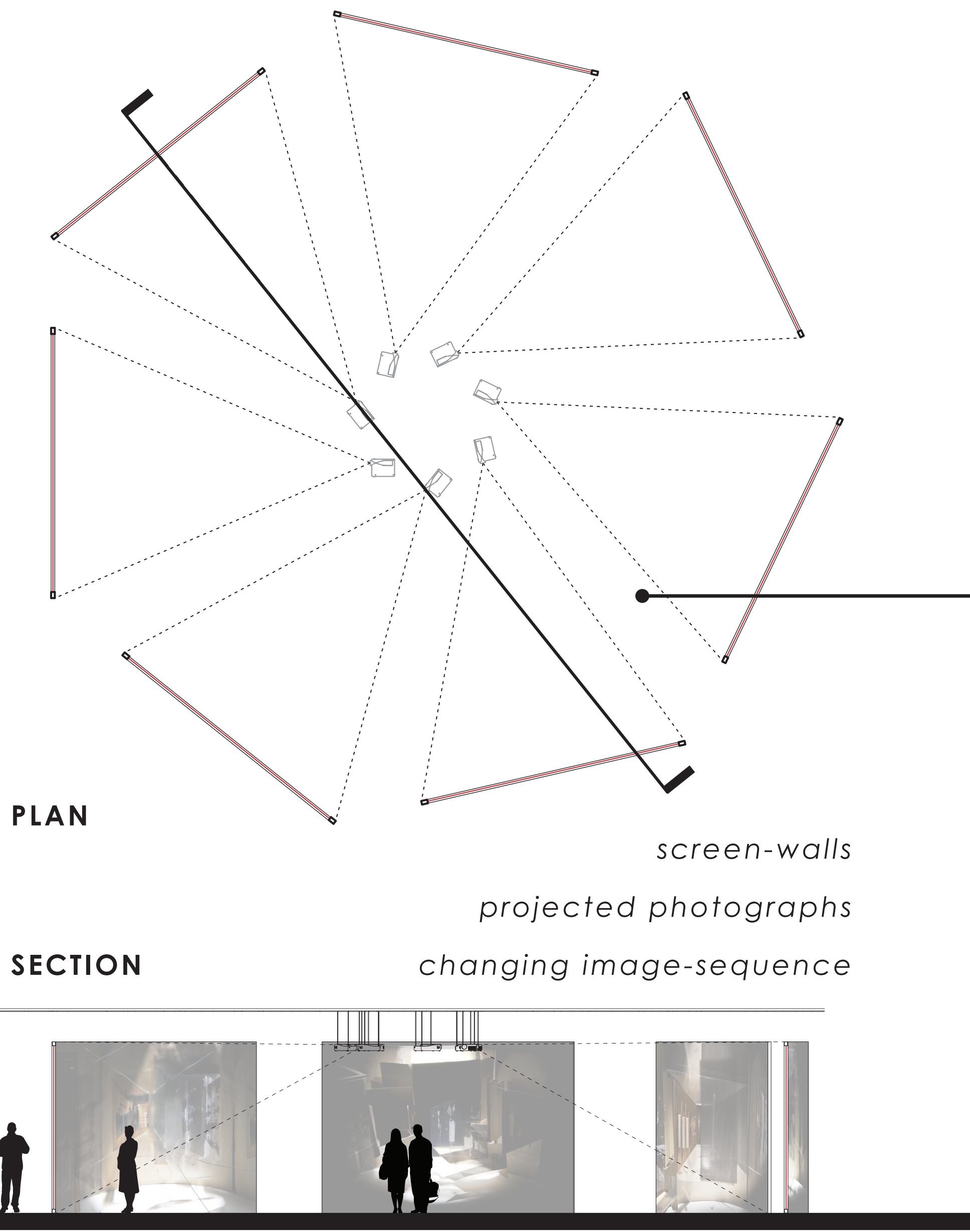




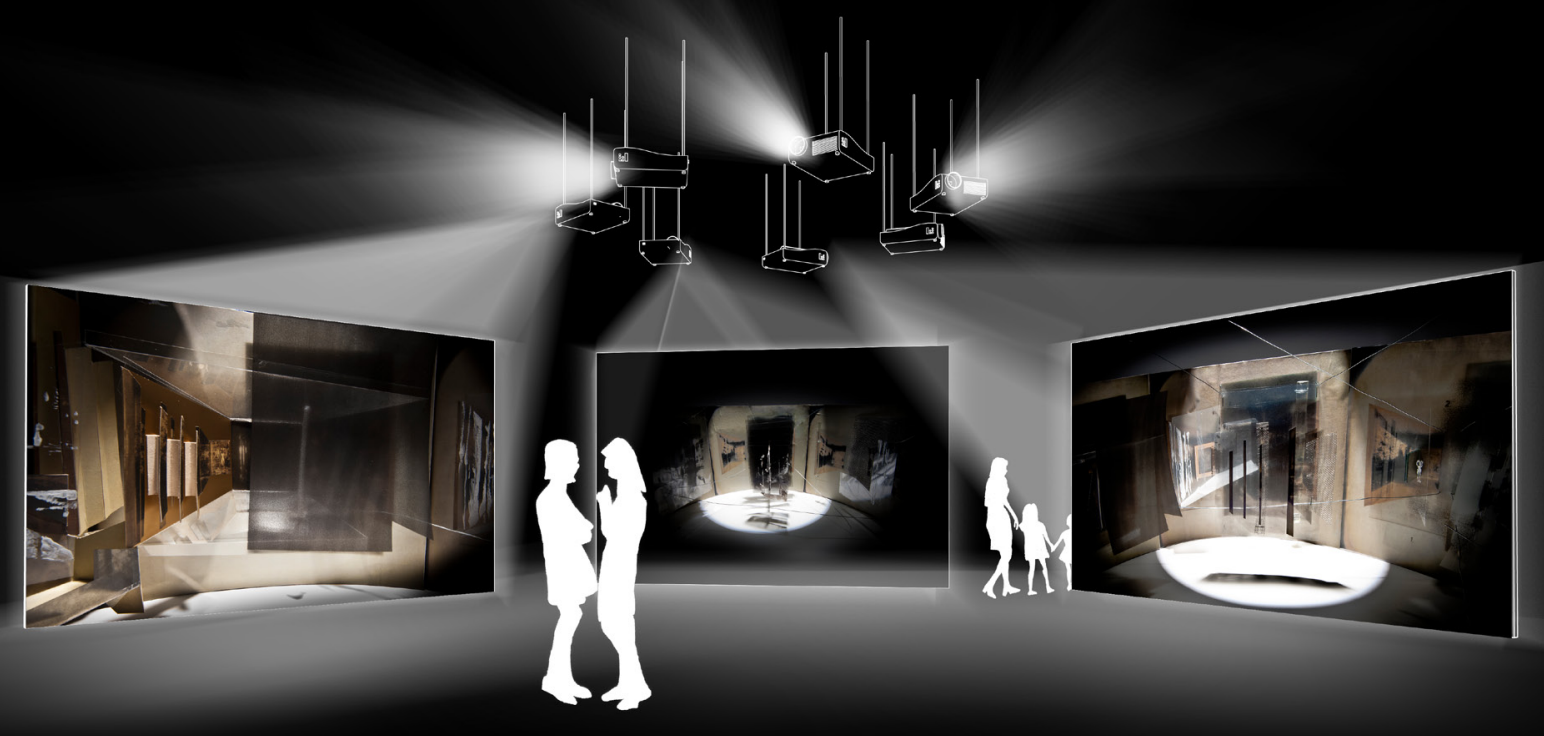

INSTALLATION PROPOSAL

\section{a new work}

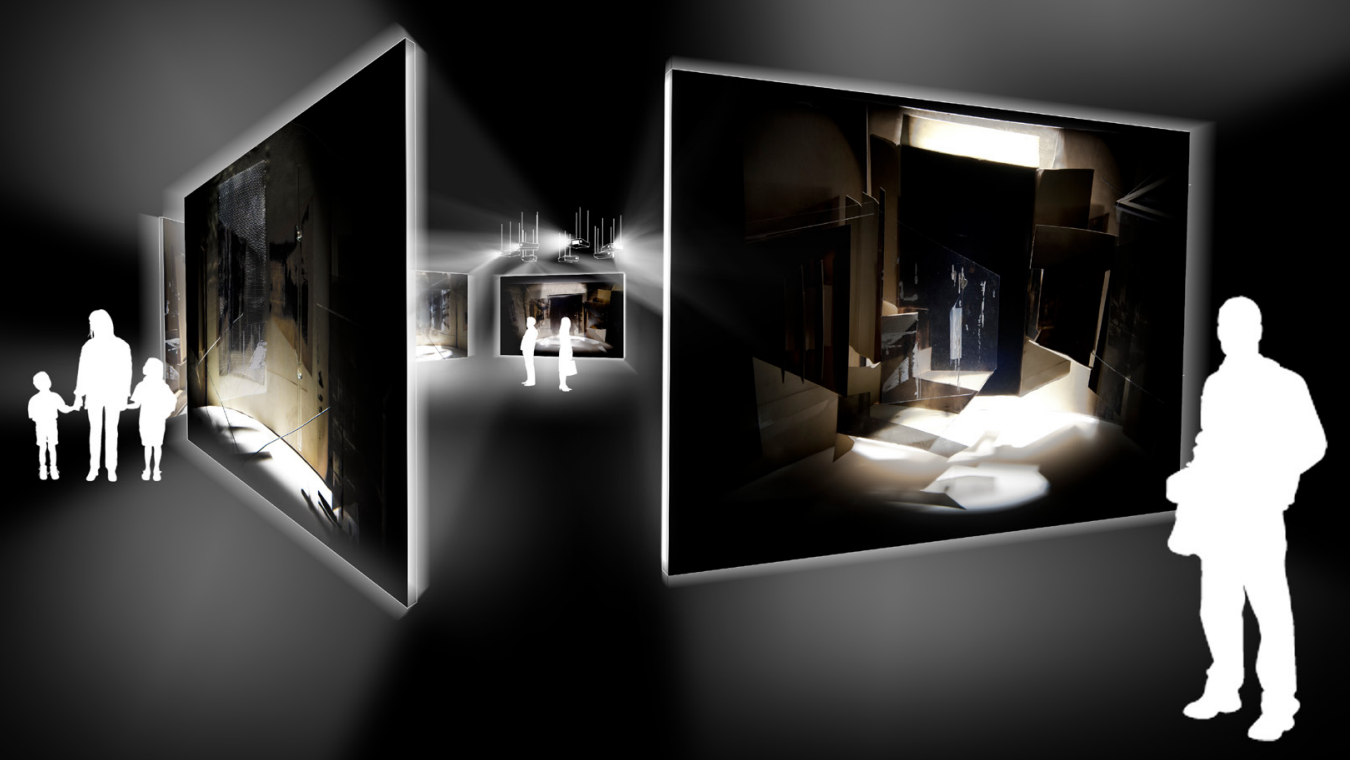


The 'new work' installation proposal seeks to give the extremely emotive 'synoptics' photographs some of the powerful presence and impact of the Publication Exhibition and 'project' works. In explaining my intentions for this proposed installation, further description of these particular images is important:
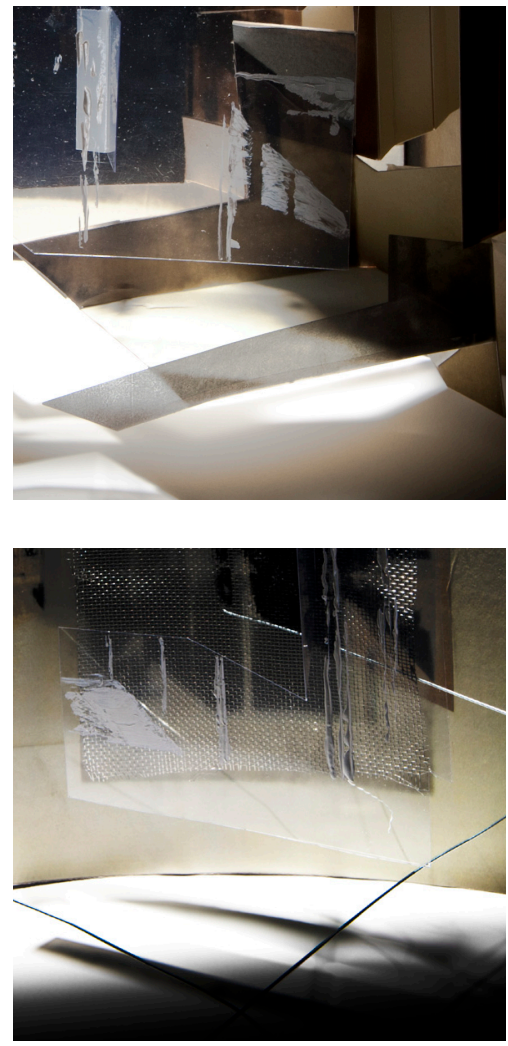

fig. 8.XIX.

fig. 8.XX.

Details of the 'synoptics' photographs.

8.19. See Chapter 7: Case Study The Barcelona Pavilion of Ludwig Mies van der Rohe.

8.20. The 'apparatus' model itself employed techniques derived from Le Corbusier's and Terragni's print media explorations. Generated using base images appropriated from the 'dissection' sequence of the installation, the basic image ring of the 'apparatus' was then manipulated through collage, cut-outs and modelled additions mounted to its surfaces. (see Chapters 4 and 6 for discussions on Le Corbusier's and Terragni's use of media techniques in their architectural work).

\section{The 'synoptics' photos as an image set}

The seven 'synoptics' model photographs are one of the significant products of the process of my design explorations. They are characterised by ambiguity and possibility: it is not clear what they actually depict, or at what scale they operate. They have dramatic qualities of light and shadow, solid and void. They evoke shimmering, translucent materialities, as well as dense, textured surfaces. Parts of the images appear highly structured, clear, and planar, whereas other parts dissolve into insubstantial blurs and fine, spidery lines. It is these ambiguous qualities and simultaneous contrasts which make these seven photographs so meaningful for me. They seem to be 'flexible' enough to accommodate many different interpretations, yet still be decisively 'architectural' in some way.As individual images, they don't provide nearly as much impact as when seen in a series, their association strengthening their interpretive effect. Particularly in this respect, I consider the set of seven photographs to be comparable to the sixteen Berliner Bild-Bericht prints of the 1929 Barcelona Pavilion.The significance of the Berliner Bild-Bericht image set as the crucial influence on people's understanding of the Barcelona Pavilion's meanings has been discussed in Chapter 7. In using a series of photographs as the primary material for a conceptual reconstruction of the Barcelona Pavilion, I contend that my 'synoptics' image set may be seen as inheriting the place of the Berliner BildBericht prints in influencing people's attribution of meanings to this work.

\section{The 'synoptics' photos in relation to the Berliner Bild-Bericht prints}

The process by which the 'synoptics' photos were produced also parallels aspects of the critical understanding of the Berliner Bild-Bericht prints. As I concluded in my discussion of the role the physical pavilion had for Mies, the 1929 pavilion was used as a maquette for the staging of a set of photographs produced with the aim of their public dissemination. ${ }^{819}$ The 'apparatus' mode ${ }^{8.20}$ made for the September Installation operated in a similar manner: it mostly became significant after being reproduced, first in the reflections of the mirrors it was placed between, and then most importantly, in the set of seven photographs. The 'apparatus' model had in my view extremely limited potential for interpretation as a work of architecture, and it was only through the act of photographic reproduction that potential architecture really became possible. The 'work' in this case was the exploration of the process leading to the 'objects' of the 
photographs and the meanings which people attribute to them, rather than the built form of the model itself: it did not represent the logical end of the work, but an 'event' in the work's production in the media space of architecture.

\section{Writing through: Critical Interpretation of the 'new work' instal- lation}

\section{'Architecting' meaning}

During the design exploration process, I have had to come to terms with the intent I had as the 'artist' of the work and the potentially dangerous temptation of pretending that such intentions were able to be discerned by an audience. The interesting thing has been to find a way of 'managing' this irrepressible intent against the post-structuralist need to allow the audience of my work to attribute their own meanings to it, to not attempt to prescribe meaning. I hold that in order to address these seemingly conflicting desires, all that is needed is a small shift in the attitude of designers: instead of designing specific 'things', they design 'situations'. Meanings in architecture are social products, interpretations of culturallyproduced environments, and are made by active human agents, in specific cultural contexts. While attempting to prescribe set meanings ought to be understood as untenable, what designers are able to influence and take control over is the tangible 'environment' or 'situation' which may become the subject of meaning, of people's interpretations. This follows the conventional pattern of creative production, in that a design 'situation' is merely another way of thinking about the cultural product: drawn sketches on a page, physical buildings, or printed images in journals. Architects cannot control the meanings which people attribute to such products, but they can control the products themselves, in terms of their particular qualities or characteristics. With this position in mind, architects are placed to influence the 'situation' which people attribute with meaning. I consider this to involve the design of the 'overall schema' of the cultural product, related to Barthes' first and second levels of meaning; the informational and the symbolic. ${ }^{8.21}$ To reflect this distinction of the activity of architects in designing 'situations' (cultural products), the verb "to architect" has been useful. Architects design situations. These situations may have meanings attributed to them by people interpreting them, including the architect, but the architect has not 'designed' these meanings. In designing situations stimulating the attribution of meanings, architects can only 'architect' meanings. By this I mean they provide material for people to interpret; providing the overall framework of Barthes' informational and symbolic levels of 'simple' meanings, for people to process and then perhaps reach Barthes' third, obtuse level of meaning, the most influential and significant. The 'architecting' of meaning as opposed to the 'designing' of meaning is a concept which may be applied to many cultural products, whether built form or the intangible architecture of the 'media space'.
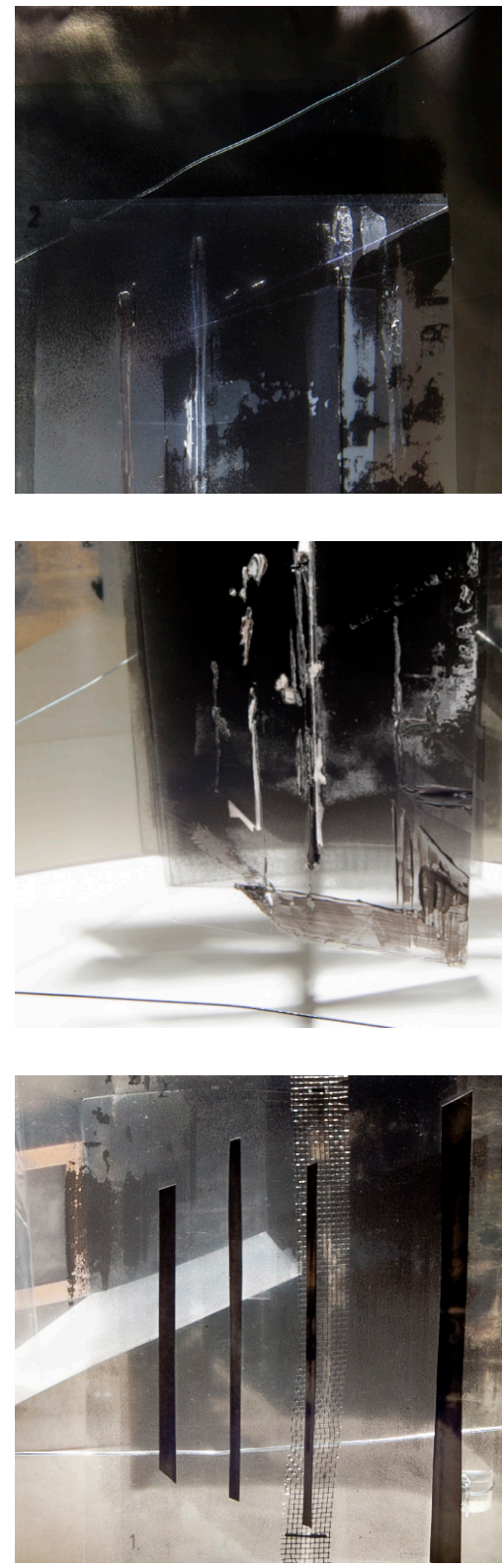

fig. 8.XXI.

fig. 8.XXII.

fig. 8.XXIII.

Details of the 'synoptics' photographs.

8.21. Refer to Chapter 2 for my discussion of Barthes' three levels of meaning. 


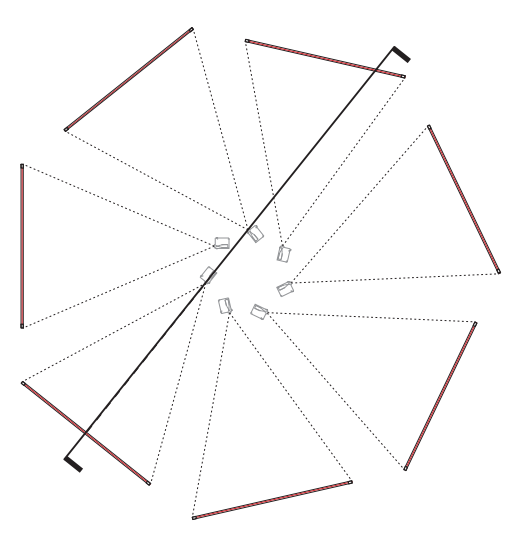

fig. 8.XXIV. 'new work' installation.

8.22. See Chapter 2 for a discussion of Bourriaud's "relational aesthetics".

\section{Productive superficiality}

In my discussion of the 1986 reconstruction of the Barcelona Pavilion in Chapter 7, I criticise this project for being a 'superficial reproduction', contending it to be a replica of the pavilion in merely material and visual terms. I argued it mimics appearance without being able to engage very deeply with the substance of what makes the Barcelona Pavilion significant for architectural culture, its meaning. My own project of reconstructing the Barcelona Pavilion in the 'new work' installation might at first seem to fall into a similar 'superficiality', using visual material (the 'synoptics' photographs) as its primary elements. However, I would argue that my design proposal engages in a 'productive superficiality', consciously utilising the tension between the uncompromising flatness of the screen-walls and the irrepressible perspectival depth of the projected photographs. This tension reveals the limitations of the physical screens as any sort of 'bearer' of meaning, being (for all intents and purposes) empty forms. 'Activated' through their receiving of the projected photographs, the physicality of the screens is subverted through the viewer's visual penetration of the surface of the projected image.

\section{"relational" images}

The arrangement of the screen walls is designed to avoid prioritising any particular screens in the group. Configured around the edges of a regular heptagon, I have arranged the plan to avoid axial symmetry and direct relationships between pairs of screens across the central area. Instead, each screen is placed to almost 'slip' past the next and not close the central area off as a 'contained' space, splaying to accept the movement of visitors in and out. The plan is also designed to provide wide sightlines for visitors: from almost any vantage point within or surrounding the installation, a visitor should be able to see at least two screens, meaning that their visual perception of the work is shaped through readings of multiple rather than singular projected photographs. In this, the 'new work' installation proposal can be considered against Bourriaud's "relational aesthetics" in that it produces open-ended conditions which invite the viewer to participate in the conceptual construction of the work. ${ }^{8.22}$ The 'looseness' of the plan, the double-sided visibility of the screens, the ability of the visitor to see more than one screen from each position, all co-operate to define the work as a partial object, a 'situation' which can only be activated through the audience's engagement.

\section{Faceted interpretations: Giedion's anonymous history}

The separate images of the installation work together to create a multifaceted experience for visitors, allowing them to interpret the work personally and independently through a collating of individual perceptive 
moments. This experience parallels what the architectural historian and critic Sigfried Giedion called "anonymous history": "History is a magic mirror. [He] who peers into it sees his own image in the shape of events and developments. It is never stilled. It is ever in movement like the generation observing it ...The ideal in anonymous history would be to show simultaneously the various facets [of history] as they exist side by side, together with the process of their interpenetration... [Like in an insect's eye] - a lens of multiple facets - fusing its distinct images of the outer world into an integrated picture" (Giedion, 1948, pp. 2-4). Like Gideon's anonymous history, the reproduced Barcelona Pavilion of the 'new work' installation is never still.The changing of the projected images, and the 360 degree views afforded those inside the ring of screens encourage the viewer to construct a 'montage' of meaning fragments, a shifting mosaic of interpretation which filters pieces of historic understanding according to personal frames of reference to produce faceted possibilities of meaning for the future.

\section{Summation}

"Can we create a parallel between the emergence of photography and the present-day spread of screens in contemporary exhibitions? For our age is nothing if not the age of the screen."

— Nicolas Bourriaud, Relational Aesthetics (2002), p.66.

Bourriaud writes that "the exhibition has become the basic unit from which it is possible to conceive of relationships between art and ideology ushered in by technologies” (Bourriaud, 2002, p. 72). 'Exposition', a synonym of 'exhibition', is even related to representational technologies via the exposure of a film negative. And like a film negative, which is created through the act of displaying light-sensitive paper to a view (albeit for a fraction of a second), the exhibition is produced through an act of showing and the effect this act has on its substance. With this idea in mind, the 'new work' installation design may be considered as a 'photogenic space', a space which encourages a photographic way of seeing. The space of the installation becomes that of a virtual darkroom within which viewers rove like a camera, called upon to frame ways of perceiving the work, developing a personal montage of views, and editing out particular viewing angles and fragments of meaning. 


\section{Conclusion: a post-structuralist work of architecture}

The design explorations conducted as part of this research have been an attempt at creating architecture which is open to post-structuralist understandings of meaning, that is, meanings as social products, personal interpretations placed by humans as active agents interpreting cultural objects in specific contexts and according to cultural frames of reference. Through these works, in particular the 'new work' installation proposal, I have tried to explore architectural production as a post-structuralist architect, creating work which remains open to interpretation by people in different ways. My work does not seek to prescribe meaning. However, it has nevertheless attempted to communicate certain ideas and concepts. In architecturally modelling processes of media production and reproduction, my work has tried to reveal the way print media may influence the production of architecture in the abstract 'media space' of people's imaginations. I have interpreted my spatial, media works as together being a conceptual 'reconstruction' of one of the most significant works of modern architecture, the Barcelona Pavilion. In presenting these works as 'another' Barcelona Pavilion, despite its visual divergence, I question viewers on their conventional understandings of the pavilion, being the result of cultural 'myth-making' and possibly a sort of ideological propaganda by the mainstream architecture culture industry. Finally, the design decisions and methods of presentation used in the 'new work' installation proposal have attempted to challenge the hegemony of the built form as the dominant site of architectural meaning; presenting a work which is "at once persistent and fleeting, smooth and elusive" (to quote Barthes on his third level of meaning) (Barthes, 1982, p. 320). I attempt to show how meaning is an intangible mental construction which exists separate from built form. Transcending physical materiality, meaning arguably becomes the ultimate substance of architecture, and indeed of all cultural products. For what transforms even piles of stone and mortar into cathedrals making people's spirits soar is our attribution of meaning to them, and the cultural frames of reference through which we make our interpretations. 


\section{conclusion summary}

- Built forms may be explored through media processes of representation and reproduction to deal with questions of architecture in meaningful ways.

- A work of architecture can be constructed in the media space (using a set of photographs for example), one open to meanings produced under a post-structuralist understanding of meaning.

- A post-structuralist work of architecture is a work which does not prescribe meaning, instead having the potential to be interpreted in a various ways while still remaining compelling for future interpretations.

- A post-structuralist work of architecture requires the acknowledgement of its architect that they are not the sole creators of the work.

- Particularly, in regards to architecture reproduced in forms of print media, viewers play a significant role in 'collaging' fragments of experience into a mental construction, in effect 'making' an architecture in the media space as they form interpretations of architectural meaning. 


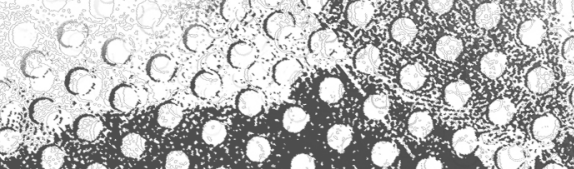

F.

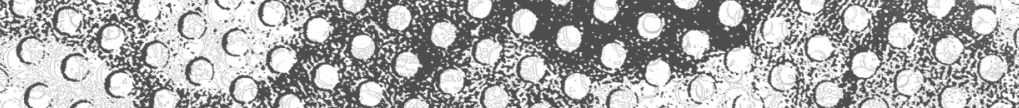

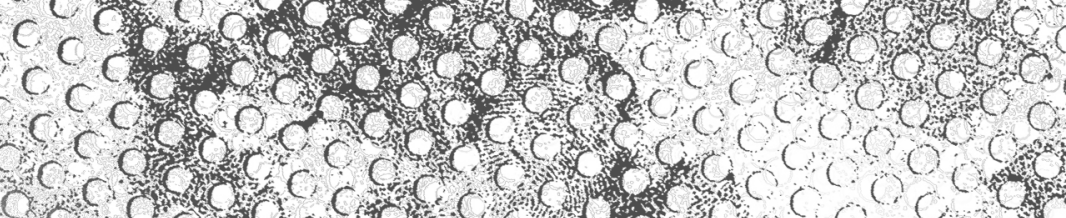

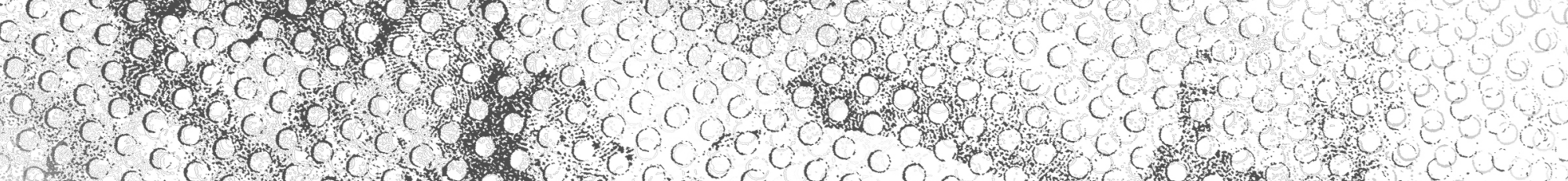

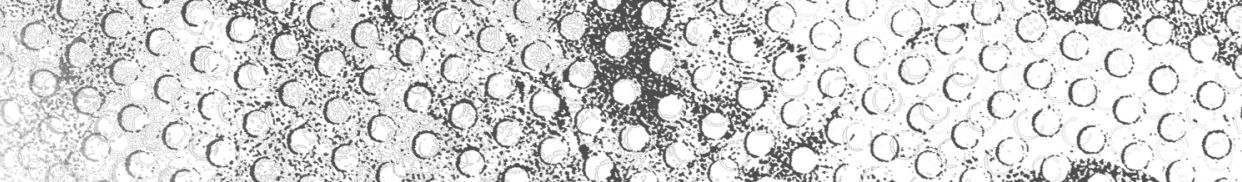

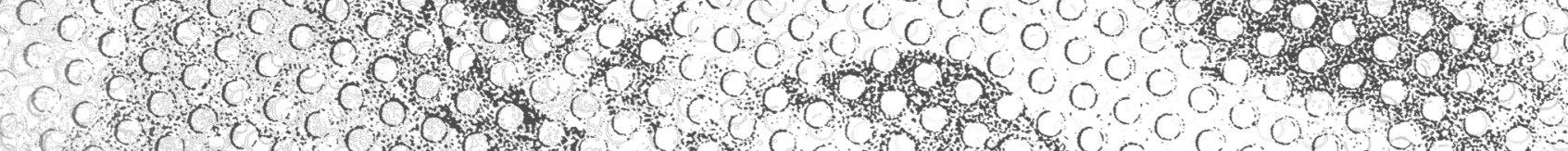

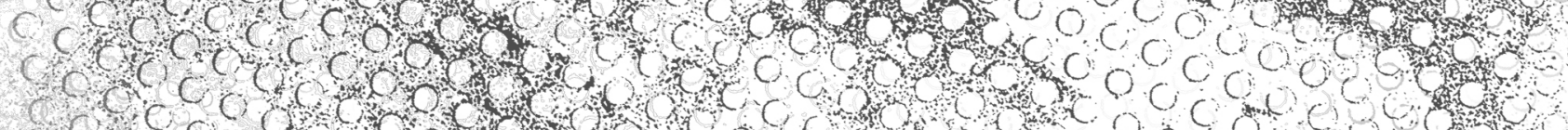

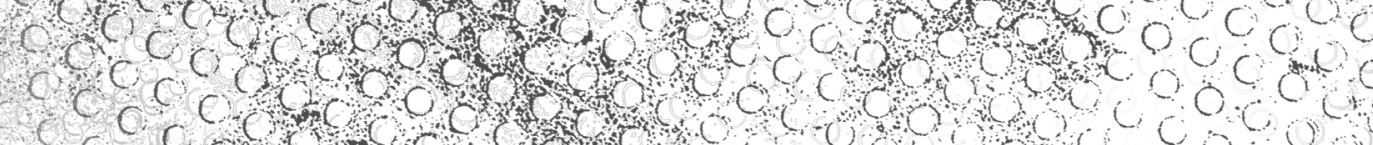

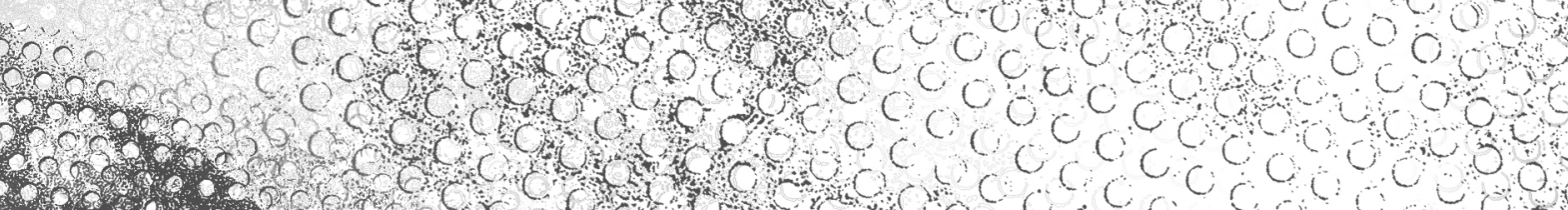
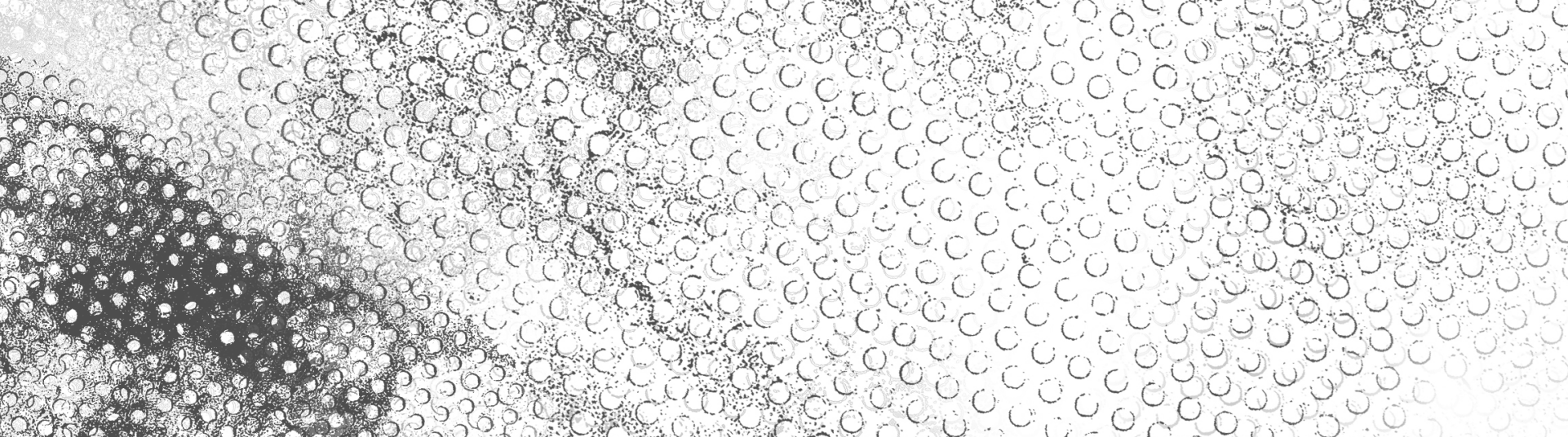

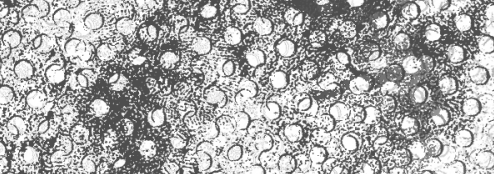

H.

(1)

W.

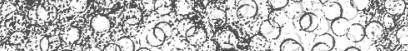

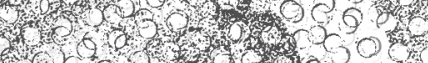

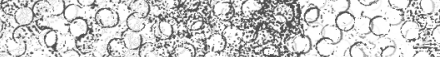

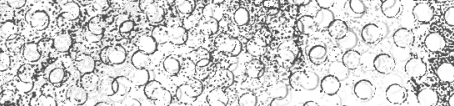

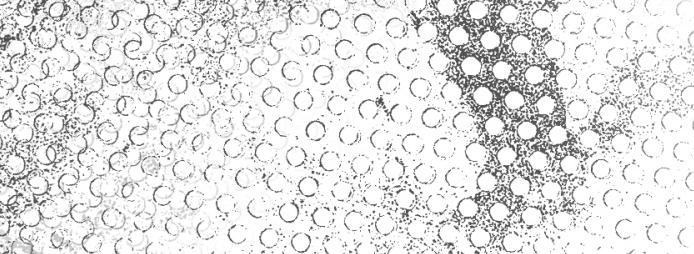

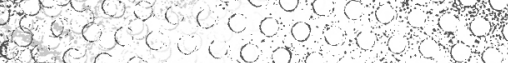

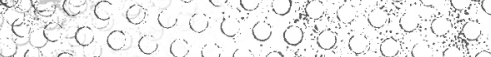

Q

eccoud O OCOACO 


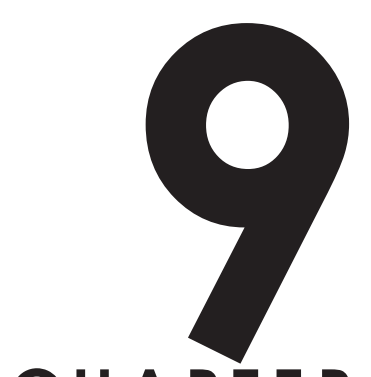

CHAPTER

\section{conclusions}

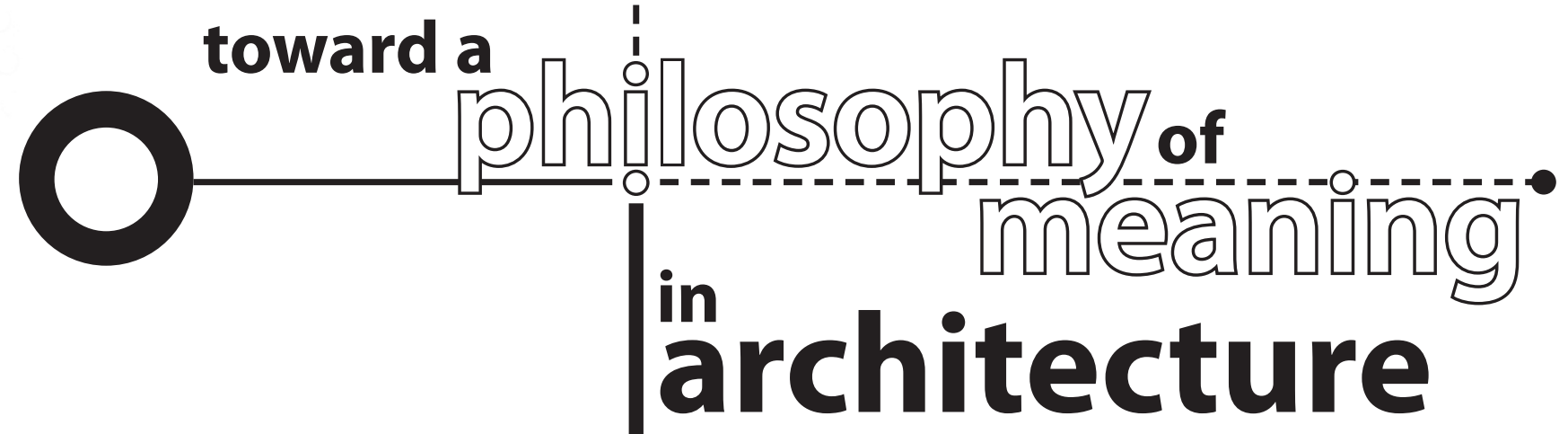


Introduction

Significance of this research

Conclusions toward a philosophy of meaning in architecture

- Last words 


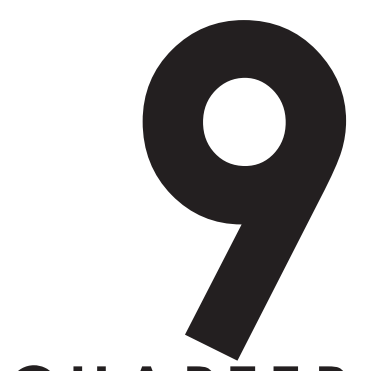

\section{conclusions}

toward a

CHAPTER

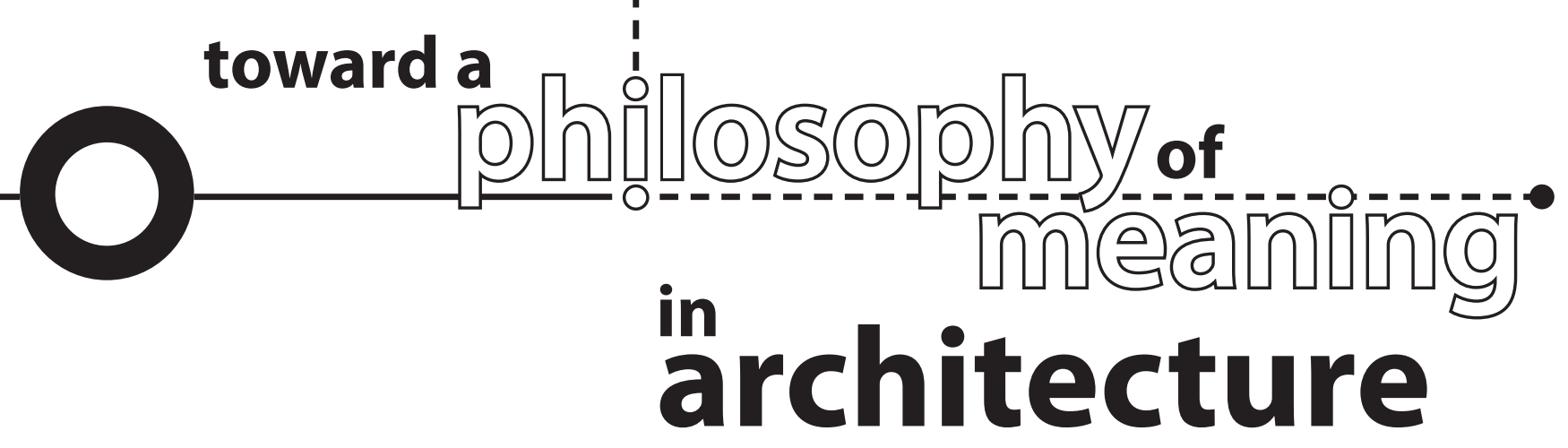

\section{Introduction}

This research has been a personal, interpretive, exploration of meaning in architecture. As such, it is necessarily limited by my personal frames of reference, the values I hold, and the particular cultural context in which I am situated. Because of this, the findings of this research may consequently be seen as limited in their scope for immediate 'application' by other architects. However, I have not sought a universally-applicable 'manifesto' for architectural production as many famous architects promoted by the architecture culture industry have done. Rather, I reject the idea that any set of ideas are 'universally-applicable', as the idea that one individual has the authority to prescribe certain values for acts of cultural production (such as architectural design) is both deterministic and strongly associated with securing positions of social power. Considering this research as a form of critical practice, I have sought instead to enable reflection and emancipative action against the cultural hegemony of dominant social powers rather than reinforce their existing ideologies. I invite readers to consider these conclusions as critiques of these mainstream attitudes prevalent in architecture culture. 


\section{Significance of this research}

The relation of architecture to the visual nature of culture in the contemporary age has not been widely discussed in mainstream architecture culture. As awareness of architecture as a strongly 'mediatised' practice increases, its relationship to the mechanisms of the culture industry ought to be critically considered in order to establish architecture's role in the greater context of cultural meaning.

In this research I have been interested in the place of print media and contemporary conditions of representation and image-production in the development of architectural meaning. Necessarily, this has been a concern with some of the cultural activities that sustain this production:mass media discourse, including the publicity and promotion of certain cultural ideas over others.

What this research has helped refute is the idea and the reality itself of a singular, unique space of 'the architectural' as material built substance. My re-assessment of architecture dissolves the distinction between the physical and the cultural trace of architecture, in terms of a proliferation of radically new spaces and different dimensions of architectural production. Using contemporary media technology, forms of architecture can be produced which defy conventional perceptions of 'substance' or 'shelter'. Confronted by this, people ought to relinquish the category of 'architecture' as a unified physical and material presence if they are to understand the diversity of potential significance it may offer.

The discussions of this research, informed by theoretical positioning and by case studies of architectural production engaging with the media space, have allowed me to develop conclusions towards a philosophy of meaning in architecture, including some indication of new potential for the roles of architects. 
CONCLUSIONS TOWARD A PHILOSOPHY OF MEANING IN ARCHITECTURE

From my research on meaning in architecture, I have discovered and explored a number of key notions about the cultural production of architectural meaning. These interrelated notions are as follows:

\section{Architectural meaning resides in people's heads, not in built forms.}

The reification of objects with meaning is arguably one of the biggest misconceptions of mainstream architecture culture, and a significant part of dominant architectural ideology. The institutions of mainstream design practice, design discourse, and architectural education seem to treat meaning as though it is embedded in and able to be retrieved from objects. However, I find meanings in architecture are social products, interpretations of culturally-produced environments, made by active human agents, in specific cultural contexts. As the complex story of the Barcelona Pavilion shows, a material existence or otherwise is no barrier to our attribution of meaning.

The regime of 'true' meaning is a myth perpetuated by mainstream architecture culture for reasons of social power.

Ideologies of cultural institutions influence people's interpretations of cultural products, including architecture. They do this to promote specific ideas and agendas, including those of 'truth' and 'objectivity' which transform certain people's interpretations'. ${ }^{9}$ into so-called 'fact'. This ideology works to mask the way these institutions tend to manipulate and influence people's interpretations, whether intentionally or not. Yet people cannot escape the 'ways of seeing' which our cultural frames of reference influence, attributing or placing interpretations on cultural products in accordance with their ideologies. For example, considering a design like Terragni's Sala $O$ exhibit, what one visitor may interpret as inspiring and patriotic, another person might interpret as repressive and imperialist. This shows how meanings are subjective, and how cultural communication is a constant negotiation of partial understandings in a state of flux between people.
9.1. The people whose interpretations of meaning are privileged and promoted by the architecture culture industry are more often than not members of the 'architectural intelligentsia': famous architects, editors, critics, or academics, whose interpretations secure and maintain the established positions of social power in mainstream architecture culture. 


\section{Architectural representations are not 'neutral depictions of reality', but ideologically-charged interpretations.}

The publishing of print media is the public communication of certain ideas and representations from varied viewpoints, values and stances of selfinterest. It is a media process by which people, as cultural agents, share their understandings and exercise social power. The representation and reproduction of architectural images are inherently political acts. Techniques of modern architectural media can exploit certain 'ways of seeing' which media material prompt, particularly people's tendencies to visually scan series of architectural images and conceptually assemble these perceived fragments into an imagined whole.

Architectural design theory (aesthetic meaning) can be developed through exploration of the media space of architecture.

Print media products (and their associated techniques and processes), through representation and reproduction, can influence the meanings people attribute to works of architecture. Architectural representations can be seen to not only affect the way people perceive built forms, but can be seen to produce a sort of architecture in themselves. For example, the Barcelona Pavilion is a work of architecture considered significant for mainstream architecture culture, yet this significance is based on people's perception of a set of photographs, and the 'media space' people may create in their heads while looking at them. This (non-physical) space has been shown to be highly important for the production of architectural meaning. 
Acknowledging that the 'media space of architecture' exists has the potential to expand, if not redefine the roles of architects.

Given that print media material engages people's imaginations in the fabrication of personal architectural realities, the act of representation can be understood as an act of architectural design. Released from the ideological reification of objects with meaning, architects ought not to limit themselves to the design of built forms. The (mostly under-acknowledged) potential of architects as skilful media operatives allows them to design cultural products open to meanings developed under post-structuralist understandings. Engaging in this manner with processes of mass media and representation, architects have the opportunity to develop a creative, productive space within which to practice architecture in the pursuit of conceptual self-development and to explore their own interpretations of architectural meaning.

\section{Architects 'architect' architecture, but do not have absolute con- trol of people's meanings.}

While in some periods of architectural history, people have considered architecture to have a 'language of meaning', in my view buildings are extremely poor vehicles for communication. Architects have little control of the meanings which people attribute to objects or 'design situations', but they can influence the 'situations' themselves. In designing situations, architects can act to 'architect' meanings, that is, provide people with the actual cultural material to attribute with meanings.

Following the philosopher Roland Barthes' theory of three levels of meaning, designers can engage in the 'informational' and 'symbolic' levels of communication through this act of 'architecting'. However, the most significant level, the third, obtuse meaning, remains out of architects' control, this being the emotive evaluation of the space between the image of architecture and its description, allowing us to believe in the potential of ink dots on paper to offer significance to our culture as works of architecture.

The statement "architects architect architecture" represents, for me, a new way of thinking about the role of the architect in contemporary culture. 


\section{last words}

Architectural objects do not anchor meanings. Meaning is not a static phenomenon. Meanings move, slide and change as they are produced in people's heads, and as people attempt to communicate their ideas through cultural products. Built forms have no more stable an interpretation than images of such forms. Buildings, texts, and representations are constructed things with ambiguous status - both depending on and creating architectural culture and the architecture in which culture is played out.

Following my research, I am now very much of the view that representations of architecture in print media can have a significant influence on people's interpretations of built forms. I find that the 'media space of architecture' has a particularly important role in the production of meaning in architecture.

Further, my research has shown that in engaging with processes of mass media and representation, architects have the opportunity to create a space in which they can explore questions of architectural meaning for themselves and others. The special focus of the architecture culture industry is and can further be the stimulation of architectural meanings and the spread of architectural interpretations in society. 


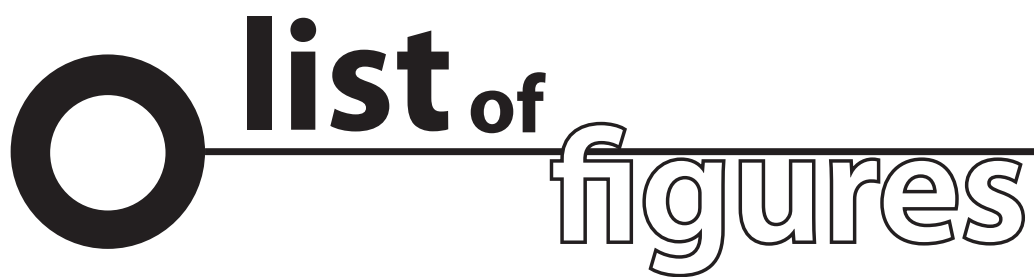

\section{CHAPTER I}

fig. 1.I Research areas.(diagram by the author, 20I I).

fig. 1.II Critical interpretations are reflections of the ideologies and ideas of their authors. (drawing by the author, 20I2).

fig. 1.III Diagram of this thesis. (diagram by the author, 20I I).

\section{CHAPTER 2}

fig. 2.I Logo of the New Zealand Institute of Architects.

(Reproduced from: www.nzia.org.nz, accessed I8.01.2012)

fig. 2.II Roland Barthes' three levels of meaning for the interpretation of cultural products (including architecture). (drawing by the author, 20I I).

fig. 2.III Firemen's Memorial, Christchurch, 2009. (author's own photograph).

fig. 2.IV Nicolas Bourriaud, Relational Aesthetics. Cover, Les Presses du réel, 1998. (Image: Les Presses du réel)

fig. 2.v A romantic hermeneutical understanding of meaning-production in architecture. (drawing by the author, 20l I).

fig. 2.vı A post-structuralist understanding of meaning-production in architecture. (drawing by the author, 20II).

\section{CHAPTER 3}

fig. 3.I The circuit of culture.

(diagram redrawn by the author from Hall, I997, p. I).

fig. 3.II Early twentieth century picture postcard featuring Notre Dame de Paris. (Image: Levy Fils \& Co., collection of the author)

fig. 3.III Kester Rattenbury (ed.), This is not architecture. Cover, Routledge, 2001.

fig. 3.Iv Collage of print media material on the Barcelona Pavilion: a representation of bildwelt. (collage by the author, 20II).

fig. 3.v Cropped photo-fragments, suggestive of the 'technological' image. (author's own photographs, 2010).

fig. 3.vI Window reflections in mirrored glass. Prague, 2010. (author's own photograph).

fig. 3.VII Photographic study of a wax form. (author's own photograph, 2009)

fig. 3.VIII Manipulated photo of the Villa Schwob, designed by Le Corbusier (1916). (Reproduced from: Le Corbusier, 2008, Plate IX. Photo: Fondation Le Corbusier, Paris).

fig. 3.vIX Manipulated photo of the Barcelona Pavilion, designed by Mies van der Rohe (1929). (Reproduced from: Dodds, 2005, Plate I4. Photo: SCALA/ Museum of Modern Art, New York). 


\section{CHAPTER 4}

fig. 4.I Le Corbusier's French identity card. (Reproduced from: Boyer, 20 I I, p.687. Image: Fondation Le Corbusier, Paris).

fig. 4.II L'Esprit Nouveau, all covers 1920-1925. (Reproduced from: de Heer, 2009, p.24. Images: Fondation Le Corbusier, Paris).

fig. 4.III Page from L'Esprit Nouveau 20 (I924).

(unpaginated. Image: Fondation Le Corbusier, Paris).

fig. 4.IV Marcel Duchamp, Fountain by R.Mutt (19|7). (Reproduced from: The Blind Man, no.2, 1917. Photo:Alfred Stieglitz).

fig. 4.v Spread from L'Esprit Nouveau 19 (1923).

(unpaginated. Image: Fondation Le Corbusier, Paris).

fig. 4.VI Manipulated photograph of the Villa Schwob, as published in L'Esprit Nouveau 6 (192I). (Reproduced from: Le Corbusier, 2008, Plate IX. Photo: Fondation Le Corbusier, Paris).

fig. 4.VII Villa Schwob, detail of the pergola. Original photograph (c. 1920). (Reproduced from: Colomina, 1994, p. I I0. Image: Fondation Le Corbusier, Paris).

fig. 4.VIII Manipulated photograph of the Villa Schwob, as published in L'Esprit Nouveau 6 (192I). (unpaginated. Image: Fondation Le Corbusier, Paris).

fig. 4.IX Villa Schwob, showing hillside site context and neighbouring houses. Original photograph (c. 1920). (Reproduced from: Colomina, 1994, p. I I 3. Image: Fondation Le Corbusier, Paris).

fig. 4.X Advertisement for the Innovation luggage company, featuring an architectural drawing by Le Corbusier. L'Esprit Nouveau 20 (1924). (Reproduced from:Troy, 199I, p.217. Image: Fondation Le Corbusier, Paris).

fig. 4.XI Le Corbusier reading at home in Paris, 1946. (Reproduced from: LIFE, 59(II) (10.09.1965), p.40. Photo: Nina Leen/Time Life Pictures).

\section{CHAPTER 5}

fig. 5.I Max Horkheimer \& Theodor Adorno, Dialectic of Enlightenment, (first published 1944). Cover of the 2002 edition, Stanford University Press. (Image: Stanford University Press).

fig. 5.II Edward Herman \& Noam Chomsky, Manufacturing Consent. Cover, Pantheon Books, 1988.

fig. 5.III Roland Barthes, Mythologies (trans. Annette Lavers). Cover of the Ist English edition. Paladin, 1972). (Image: Paladin).

fig. 5.IV Nikolaus Pevsner, Pioneers of Modern Design, (first published 1936). Cover of the $|96|$ edition, Penguin. (Image: Penguin).

fig. 5.v Sigfried Giedion, Space, Time and Architecture, (first published 194I). Cover of the 1943 edition, Harvard University Press. (Image: Harvard University Press).

fig. 5.VI Leonardo Benevolo, History of Modern Architecture (first published in Italian 1960). Cover of the 1977 edition, MIT Press. (Image: MIT Press).

fig. 5.VII Reyner Banham, Theory and design in the first machine age, (first published 1960). Cover of the 1980 edition, MIT Press. (Image: MIT Press). 


\section{CHAPTER 6}

fig. 6.I Exhibition of the Fascist Revolution, 1933. Entrance facade designed by Adalberto Libera and Mario de Renzi.

(Reproduced from: Domus 6, 1933. Image: Central State Archives, Italy).

fig. 6.II Exhibition of the Fascist Revolution, 1933. Plan of the exhibits.

(Reproduced from:Andreotti, 2005, p. I 2. Image: G. Terragni Archive, Como).

fig. 6.III Sala O, 1933. Collage entitled "Me ne frego" ("I do not care") combining slogans and text from the II Popolo d'Italia newspaper. (Reproduced from:Alfieri \& Freddi, 1933. Image: G. Terragni Archive, Como).

fig. 6.IV Sala O, 1933. Collage entitled "lene umane" ("Human hyenas") using material from II Popolo d'Italia. (Reproduced from:Alfieri \& Freddi, 1933. Image: G. Terragni Archive, Como).

fig. 6.v Plan of the Sala O, designed by Giuseppe Terragni. Rome, 1933. (author's own drawing, 20II).

fig. 6.VI Sala O, 1933.View towards the "Me ne frego" collage. (Reproduced from: Terragni, 2004, p.388. Image: G. Terragni Archive, Como).

fig. 6.VII Sala O, 1933. In the centre foreground is the "forze giovanili" collage. (Reproduced from:Terragni, 2004, p.389. Image: G. Terragni Archive, Como).

fig. 6.VIII Sala O, 1933.View towards the "Adunate" photomontage. (Reproduced from: Marciano, 1987, p.77. Image: G. Terragni Archive, Como).

fig. 6.IX Sala O, 1933. Part of the "scioperomania" collage. (Reproduced from: Marciano, 1987, p.76. Image: G. Terragni Archive, Como).

fig. 6.x Sala O, 1933. Detail of the "Adunate" photomontage. (Reproduced from: Alfieri \& Freddi, 1933. Image: G. Terragni Archive, Como).

fig. 6.XI Giuseppe Terragni, photomontage (date unknown). (Reproduced from: Schumacher, 1991, p. 173. Image: G. Terragni Archive, Como).

fig. 6.XII El Lissitzky, Proun I9D (1922). (Image:Artstor/Museum of Modern Art, New York).

fig. 6.XIII Giuseppe Terragni, preparatory drawing for the Sala $O$ (c. 1933). (Reproduced from: Marciano, 1987, p.75. Image: G. Terragni Archive, Como).

fig. 6.xIv Sala O, 1933. Collage entitled "Incendio dell'Avanti" ("Burning of the Avanti”). (Reproduced from:Alfieri \& Freddi, 1933. Image: G. Terragni Archive, Como).

\section{CHAPTER 7}

fig. 7.I Le Corbusier and Mies van der Rohe, photographed together in Stuttgart-Weissenhof, 1927. (Reproduced from: Honey, 1986, p.I0. Image: Fondation Le Corbusier, Paris).

fig. 7.II "G" magazine, no.3 (June 1924). Cover featuring Mies' charcoal drawing of his 1922 Friedrichstrasse Glass Skyscraper project. (Reproduced from: Neumeyer, 1991, p. 16. Image: SCALA/Museum of Modern Art, New York

fig. 7.III Mies van der Rohe, Traffic Tower project (1924). Photomontage. (Reproduced from: Honey, 1986, p.42. Photo:Werner Graff).

fig. 7.IV Barcelona Pavilion, MMA 1554 (Berliner Bild-Bericht, 1929).I (Reproduced from: Dodds, 2005, Plate I. Image: Bauhaus Dessau Foundation). 
fig. 7.v Barcelona Pavilion, MMA I 97 (Berliner Bild-Bericht, 1929).

(Reproduced from: Dodds, 2005, Plate 2. Image: Bauhaus Dessau Foundation).

fig. 7.VI Barcelona Pavilion, MMA I 437 [manipulated] (Berliner Bild-Bericht, 1929). (Reproduced from: Dodds, 2005, Plate 4. Image: SCALA/Museum of Modern Art, New York).

fig. 7.VII Barcelona Pavilion, MMA 1437 (Berliner Bild-Bericht, 1929). (Reproduced from: Dodds, 2005, Plate 3. Image: Bauhaus Dessau Foundation).

fig. 7.vIII Barcelona Pavilion, SEIDMAN 248 (Berliner Bild-Bericht, 1929). (Reproduced from: Dodds, 2005, Plate 7. Image: SCALA/Museum of Modern Art, New York).

fig. 7.IX Barcelona Pavilion, MMA 7360 (Berliner Bild-Bericht, 1929). (Reproduced from: Dodds, 2005, Plate 16. Image: SCALA/Museum of Modern Art, New York).

fig. 7.X Barcelona Pavilion, SEIDMAN 167 (Berliner Bild-Bericht, 1929). (Reproduced from: Dodds, 2005, Plate 10. Image: Bauhaus Dessau Foundation).

fig. 7.XI Barcelona Pavilion, MMA I8I4 (Berliner Bild-Bericht, 1929). (Reproduced from: Dodds, 2005, Plate 9. Image: Bauhaus Dessau Foundation).

fig. 7.XII Barcelona Pavilion, MMA 299 (Berliner Bild-Bericht, 1929). (Reproduced from: Dodds, 2005, Plate 12. Image: SCALA/Museum of Modern Art, New York).

fig. 7.XIII Barcelona Pavilion, MMA 298 (Berliner Bild-Bericht, 1929). (Reproduced from: Dodds, 2005, Plate I I. Image: SCALA/Museum of Modern Art, New York).

fig. 7.XIv Barcelona Pavilion, MMA I I 80 [manipulated] (Berliner Bild-Bericht, 929). (Reproduced from: Dodds, 2005, Plate I 4. Image: SCALA/Museum of Modern Art, New York).

fig. 7.xv Barcelona Pavilion, MMA I I80 (Berliner Bild-Bericht, 1929).

(Reproduced from: Dodds, 2005, Plate I 3. Image: Fundació Mies van der Rohe, Barcelona).

fig. 7.XVI Barcelona Pavilion, SEIDMAN 247 (Berliner Bild-Bericht, 1929). (Reproduced from: Dodds, 2005, Plate 6. Image: Bauhaus Dessau Foundation).

fig. 7.XVII Barcelona Pavilion, SEIDMAN 249 (Berliner Bild-Bericht, 1929). (Reproduced from: Dodds, 2005, Plate 5. Image: Bauhaus Dessau Foundation).

fig. 7.XVIIIBarcelona Pavilion, MMA I I 254 (Berliner Bild-Bericht, I929). (Reproduced from: Dodds, 2005, Plate 8. Image: Bauhaus Dessau Foundation).

fig. 7.xIX Barcelona Pavilion, MMA 297 (Berliner Bild-Bericht, 1929). (Reproduced from: Dodds, 2005, Plate I5. Image: SCALA/Museum of Modern Art, New York).

fig. 7.xx Barcelona Pavilion, MMA 298 (Berliner Bild-Bericht, 1929). (Reproduced from: Dodds, 2005, Plate II. Image: SCALA/Museum of Modern Art, New York).

fig. 7.XXI Mies van der Rohe, Plan of the Barcelona Pavilion (published 1929). (Reproduced from: Drexler, 1986, p.226. Image: SCALA/Museum of Modern Art, New York). 
fig. 7.XXII Werner Blaser, Plan of the Barcelona Pavilion (drawn 1964).

(Reproduced from: Bonta, 1975, p.55. Image: Collection of Werner Blaser).

fig. 7.XXIIIPlan of the Barcelona Pavilion (as published 1929). (drawing by the author, 20II).

fig. 7.xxIvPlan of the Barcelona Pavilion (as published 1965). (drawing by the author, 20II).

fig. 7.xxv Plan of the Barcelona Pavilion (as published 1986). (drawing by the author, 20II).

fig. 7.xxvıHenry-Russell Hitchcock \& Phillip Johnson, The International Style: architecture since 1922. Cover, Octavo, 1932. (Image: Octavo).

fig. 7.XXVII Detail of a grainy reproduction of MMA I I80. (Reproduced from: Dodds, 2005, Plate 14. Image: SCALA/Museum of Modern Art, New York).

fig. 7.XXVIII Barcelona Pavilion, SEIDMAN 247 (Berliner Bild-Bericht, 1929). (Reproduced from: Dodds, 2005, Plate 6. Image: Bauhaus Dessau Foundation).

fig. 7.XxIX Image of the Barcelona Pavilion from Sheldon Cheney's The New World Architecture (1930). (Reproduced from: Cheney, 930, p. 127. Image: Longmans).

fig. 7.xxx Barcelona Pavilion seen from above, showing the cheap tarpaper roofing used in the 1929 construction. (Reproduced from: de Solà-Morales, et al., 1993, p.20. Image: SCALA/Museum of Modern Art, New York).

fig. 7.xxxI OMA Barcelona Pavilion reconstruction at the 1985 Milan Trienalle. (Reproduced from: Dodds, 2005, p.87. Image: Rem Koolhaas, Office of Metropolitan Architecture).

fig. 7.xxxII I 986 reconstruction of the Barcelona Pavilion, Barcelona. (author's own photograph, 2010).

fig. 7.XXXIII I 986 reconstruction of the Barcelona Pavilion, Barcelona. (author's own photograph, 2010).

fig. 7.xxxIv I 986 reconstruction of the Barcelona Pavilion, Barcelona. Photographic detail of the materials. (Reproduced from: de SolàMorales, et al., 1993, p.64. Photo: Eloi Bonjoch).

fig. 7.XXXV I $\quad 986$ reconstruction of the Barcelona Pavilion, Barcelona. Photographic detail of the materials. (Reproduced from: de SolàMorales, et al., 1993, p.66. Photo: Eloi Bonjoch).

fig. 7.XXXVI I 1986 reconstruction of the Barcelona Pavilion, Barcelona. Photographic detail of the materials. (Reproduced from: de SolàMorales, et al., 1993, p.64. Photo: Eloi Bonjoch).

fig. 7.XXXVII $\quad$ I 986 reconstruction of the Barcelona Pavilion, Barcelona. Photographic detail of the materials. (Reproduced from: de SolàMorales, et al., 1993, p.66. Photo: Eloi Bonjoch).

fi.g 7.xxxvIII Opening ceremony for the German National Pavilion at the Barcelona International Exposition, May 26, 1929. (Reproduced from: Schulze, 1985, p. I62. Image: SCALA/Museum of Modern Art, New York). 


\section{CHAPTER 8}

fig. 8.I Barcelona Pavilion, digital photocollage. (collage by the author, 20I I).

fig. 8.II advertising poster, Publication Exhibition, July 20 I I. (Image: Geordie Shaw).

fig. 8.III installation, Publication Exhibition, 23-27 July 20 I I, Wellington.

(author's own photographs).

fig. 8.Iv detail of installation panel, Publication Exhibition.

(author's own photograph, 20II).

fig. 8.v detail of installation panel surface, Publication Exhibition.

(author's own photograph, 20II).

fig. 8.VI The September Installation, School of Architecture, Victoria University of Wellington, 20II. (author's own photograph).

fig. 8.VII The September Installation, 20 I I. Plan indicating the seven different parts. (drawings by the author).

fig. 8.VIII 'a project', The September Installation. The distorted reflections of visitors in the shiny foil panel. (author's own photograph, 20II).

fig. 8.IX 'a context', The September Installation. (drawings and photographs by the author, 20I I).

fig. 8.x 'a project', The September Installation. (drawings and photographs by the author, 20I I).

fig. 8.XI 'a critique', The September Installation. (drawings and photographs by the author, 20II).

fig. 8.xII 'a perception', The September Installation. (drawings and photographs by the author, 20II).

fig. 8.XIII 'a dissection', The September Installation.

(drawings and photographs by the author, 20I I).

fig. 8.xIv 'an apparatus', The September Installation.

(drawings and photographs by the author, 20II).

fig. 8.xv 'a synoptics', The September Installation.

(drawings and photographs by the author, 20II).

fig. 8.xvI The September Installation. The design review in progress. (Photo: Marita Hunt, 20II).

fig. 8.xVII 'a synoptics', The September Installation. The 'synoptics' photographs. (author's own photographs, 20II).

fig. 8.xVIII 'a new work', installation proposal. (drawings and photographs by the author, 20I I).

fig. 8.xIx Detail of the 'synoptics' photographs. (author's own photograph, 20I I).

fig. 8.xx Detail of the 'synoptics' photographs. (author's own photograph, 20I I).

fig. 8.XXI Detail of the 'synoptics' photographs. (author's own photograph, 20I I).

fig. 8.xxII Detail of the 'synoptics' photographs. (author's own photograph, 20I I).

fig. 8.XxIII Detail of the 'synoptics' photographs. (author's own photograph, 20I I).

fig. 8.xxiv Plan of the proposed 'new work' installation. (drawing by the author, 20II).

fig. 8.xxv 'a project', The September Installation. Detail of the shiny foil panel, rippling like Giedion's "magic mirror" of history.

(author's own photograph, 20II). 


\section{Obibliography}

“6 Students Talk with Mies" (1952). Master Builder, 2(3). (School of Design, North Carolina State College, Spring, 1952).

Abrams, J. (199I). 'Available for viewing'. In M. Caiger-Smith \& D. Chandler (Eds.), Site work: architecture in photography since early modernism. London:The Photographic Gallery.

Alfieri, D., \& Freddi, L. (1933). 'Mostra della Rivoluzione Fascista' Guida Storica. Rome: Partita Nazionale Fascista.

Andreotti, L. (2005). 'Architecture as media event: Mario Sironi and the Exhibition of the Fascist Revolution', 1932. Built Environment, 3I(I), 9-20.

Banham, R. (1960). Theory and design in the first machine age. London: Architectural Press.

Barthes, R. (1972). Mythologies (A. Lavers, Trans.). London: Paladin.

( I 982). 'The third meaning'. In S. Sontag (Ed.), A Barthes reader (pp. 317 333). New York: Hill and Wang.

(1 999). 'Myth today.' In J. Evans \& S. Hall (Eds.), Visual culture: the reader (pp. 5I-58). London: Sage.

Benevolo, L. (197 I). History of modern architecture. Cambridge, MA.: MIT Press.

Benjamin,W. (1 973). Charles Baudelaire:A lyric poet in the era of high capitalism. London: NLB.

(2002). The Arcades Project (H. Eiland \& K. McLaughlin, Trans.). New York: Harvard University Press.

(2008a). 'News about flowers'. In M.W. Jennings, B. Doherty, T.Y. Levin \& E. F. N. Jephcott (Eds.), The work of art in the age of its technological reproducibility, and other writings on media (Pp. 27I-273). Cambridge, MA.: Harvard University Press.

(2008b). 'The work of art in the age of its technological reproducibility'. In M.W. Jennings, B. Doherty, T.Y. Levin \& E. F. N. Jephcott (Eds.), The work of art in the age of its technological reproducibility, and other writings on media (pp. 19-55). Cambridge, MA.: Harvard University Press.

Bourriaud, N. (2002). Relational aesthetics (S. Pleasance, F.Woods \& M. Copeland,Trans.). Dijon: Les Presses du réel. 
Boyer, M. C. (20 I I). Le Corbusier: homme de lettres. New York: Princeton Architectural Press.

Carpo, M. (200 I). Architecture in the age of printing : orality, writing, typography, and printed images in the history of architectural theory. Cambridge, MA.: MIT Press.

Chekhov, A. (1921). Notebooks (S. Koteliansky \& L. Woolf, Trans.). New York: B.W. Huebsch.

Cheney, S. (1930). The new world architecture. London: Longmans.

Cohen, J.-L. ( 1 994). Mies van der Rohe. Paris: Hazan.

Colomina, B. (1988). 'More about reproduction: in response to McLeod and Ockman'. In B. Colomina \& J. Ockman (Eds.), Architectureproduction (pp. 232-239). New York: Princeton Architectural Press.

(1994). Privacy and publicity: modern architecture as mass media. Cambridge, MA: MIT Press.

De Frede, C. (1983). 'Il giudizio di Mussolini su Croce'. Storia e politica, 22(I).

de Heer, J. (2009). The architectonic colour: polychromy in the purist architecture of Le Corbusier (G. Hall, Trans.). Rotterdam: 010 Publishers.

de Smet, C. (2005). Le Corbusier: architect of books (D. Dusinberre, Trans.). Baden: Lars Müller Publishers.

de Solà-Morales, I., Cirici, C., \& Ramos, F. (1993). Mies van der Rohe: Barcelona Pavilion. Barcelona: Gustavo Gili.

Dodds, G. (2005). Building desire : on the Barcelona Pavilion. New York: Routledge.

Drexler, A. (Ed.). ( 1 986). The Mies van der Rohe Archive (Vol. 2). New York: Garland Publishing.

Du Gay, P. (Ed.). ( 1 997). Production of culture/cultures of production. London: Sage/The Open University.

Dutton,T.A. (1996). 'Cultural studies and critical pedagogy: cultural pedagogy and architecture'. In T.A. Dutton \& L. H. Mann (Eds.), Reconstructing architecture: critical discourse and social practices. Minneapolis: University of Minnesota Press. 
Elwall, R. (2004). Building with light: the international history of architectural photography. London: Merrell.

Evans, R. (2002). 'Mies van der Rohe's paradoxical symmetries'. In T. Gannon (Ed.), The light construction reader (pp. 399-4 I9). New York: Monacelli Press.

Fogu, C. (2005). 'To make history present'. In C. Lazzaro \& R. Crum (Eds.), Donatello among the Blackshirts: history and modernity in the visual culture of Fascist Italy (pp. 33-49). Ithaca, NY.: Cornell University Press.

Gadamer, H.-G. (1975). Truth and method. New York: Continuum.

Ghirardo, D.Y. (1980). 'Italian architects and Fascist politics:An evaluation of the rationalist's role in regime building'. Journal of the Society of Architectural Historians, 39(2), 109-127.

Giedion, S. (194I). Space, time and architecture: the growth of a new tradition. Cambridge, MA: Harvard University Press.

(1948). Mechanization takes command: a contribution to anonymous history. New York: Oxford University Press.

Goldberger, P. (2009). Why architecture matters. New Haven:Yale University Press.

Habermas, J. (1 984). The theory of communicative action: reason and the rationalization of society (T. McCarthy, Trans. Vol. I). Cambridge: Polity.

Hall, S. (1997). Representation: cultural representations and signifying practices. London: Sage.

Hays, K. M. ( I 984). 'Critical architecture: between culture and form'. Perspecta, 2 I, I4-29.

Herman, E. S., \& Chomsky, N. ( 1 988). Manufacturing consent: the political economy of the mass media (Ist ed.). New York: Pantheon Books.

Higgott, A. (2007). Mediating modernism: architectural cultures in Britain. New York: Routledge.

Hill, J. (2003). Actions of architecture: architects and creative users. New York: Routledge.

Hollein, H. (1968). 'Alles ist Architektur'. Bau, I (2), I-32. 
Honey, S. (Ed.). ( 1 986). Mies van der Rohe: European works. London:Academy Editions.

Horkheimer, M., \& Adorno,T. (2002). Dialectic of enlightenment: philosophical fragments. Stanford, CA: Stanford University Press.

Illich, I. (1995). 'Guarding the eye in the age of show'. RES:Anthropology and Aesthetics(28), 47-6I.

Jennings, M.W. (2008). 'The production, reproduction, and reception of the work of art'. In M.W. Jennings, B. Doherty, T.Y. Levin \& E. F. N. Jephcott (Eds.), The work of art in the age of its technological reproducibility, and other writings on media (pp. 9-18). Cambridge, MA.: Harvard University Press.

Kearney, R. ( 199 I ). Poetics of imagining: from Husserl to Lyotard. London: Harper Collins Academic.

Kearney, R. (1994). The wake of imagination. London: Routledge.

Koolhaas, R., \& Mau, B. ( 1 995). Small, medium, large, extra-large. New York: Monacelli Press.

Krier, L. (2009). The architecture of community.Washington, D.C.: Island Press.

Kuleshov, L. (1974). 'Art of cinema'. In R. Levaco (Ed.), Kuleshov on film: writings by Lev Kuleshov. Berkeley, CA: University of California Press.

Le Corbusier. ( 1926$)$. Almanach d'architecture moderne. Paris: Les Éditions G. Crès et Cie.

(1954). The Modulor (P. de Francia \& A. Bostock, Trans.). London: Faber and Faber.

(2008). A Study of the decorative art movement in Germany (A.T.

Anderson, Trans.).Weil am Rhein:Vitra Design Museum.

Leatherbarrow, D. ( 1993). The roots of architectural invention: site, enclosure, materials. Cambridge: Cambridge University Press.

Louridas, P. (1999). 'Design as bricolage: anthropology meets design thinking'. Design Studies, 20(6), 517-535.

Marciano,A. F. ( 1 987). Guiseppe Terragni: opera completa, 1925- / 943. Rome: Officina. 
McLaren, B. ( 1992). 'Under the sign of the reproduction'. Journal of Architectural Education, 45(2), 98-106.

Mertins, D. (20 I I). Modernity unbound: other histories of architectural modernity. London:Architectural Association.

Mitchell,W.J.T. (1994). Picture theory: essays on verbal and visual representation. Chicago: University of Chicago Press.

Naylor, G. (1968). The Bauhaus. London: Studio Vista.

Nead, L. ( 1 988). Myths of sexuality: representations of women in Victorian Britain. Oxford: Basil Blackwell.

Neppi,A. ( 1 932). 'L’opera degli artisti alla Mostra della rivoluzione fascista'. Rassegna istruzione artistica(November-December 1932).

Nesbitt, K. (1 996). Theorizing a new agenda for architecture: an anthology of architectural theory 1965-1995. New York: Princeton Architectural Press.

Neumeyer, F. (199I). The artless world: Mies van der Rohe on the building art (M. Jarzombek, Trans.). Cambridge, MA: MIT Press.

Newton, C. (2005). 'The phoenix pavilion: interpreting the black and white memory of the Barcelona Pavilion'. Fabrications, I5(2), 63-76.

Pallasmaa, J. (20I I). The embodied image: imagination and imagery in architecture. Chichester:Wiley.

Parkes, P. I. (1 986). Post-modern architecture theory: a critique. Ph.D Dissertation, University of Wales Institute of Science and Technology, Cardiff.

Pevsner, N. (1960). Pioneers of modern design: from William Morris to Walter Gropius (third ed.). Baltimore: Penguin Books.

Porphyrios, D. ( I 985). ‘On critical history'. In J. Ockman (Ed.), Architecture, criticism, ideology (Pp. 16-2I). Princeton, NJ: Princeton Architectural Press.

Publication Collective. (20 I I). 'Statement of intent'. PUBLICATION Architectural Exhibition, 20I I, from http://publicationexhibition.blogspot. com/ 
Rattenbury, K. (Ed.). (2002). This is not architecture: media constructions. London: Routledge.

Schulze, F. ( 1 985). Mies van der Rohe: a critical biography. Chicago: University of Chicago Press.

Schumacher, T. L. (199 I). Surface \& symbol: Giuseppe Terragni and the architecture of Italian rationalism. New York: Princeton Architectural Press.

Schwarzer, M. (2004). Zoomscape: architecture in motion and media. New York: Princeton Architectural Press.

Staub, P. (20I I). '2D or not 2D:What's lost in translation between the dimensions?' In T. Lorenz \& P. Staub (Eds.), Mediating Architecture. London:AA Publications.

Stone, M. (1992). 'The anatomy of a propaganda event: the Mostra della rivoluzione fascista'. Carte Italiane, I (I2), 30-40.

Tafuri, M. (1987). The sphere and the labyrinth: avant-gardes and architecture from Piranesi to the 1970s (P. d'Acierno \& R. Connolly, Trans.). Cambridge, MA: MIT Press.

Tegethoff,W. (1985). Mies van der Rohe: the villas and country houses. Cambridge, MA: MIT Press.

Terragni, A., Libeskind, D., \& Rosselli, P. (2004). The Terragni atlas: built architectures. London:Thames \& Hudson.

Troy, N. (1991). Modernism and the decorative arts in France: art Nouveau to Le Corbusier. New Haven:Yale University Press.

Valéry, P. (1 929). Introduction on the method of Leonardo da Vinci (T. McGreevy, Trans.). London: John Rodker.

von Moos, S. (1979). Le Corbusier, elements of a synthesis. Cambridge, MA: MIT Press.

Watney, S. ( 1 999). 'On the institutions of photography'. In J. Evans \& S. Hall (Eds.), Visual culture: the reader (pp. I4I-I6I). London: Sage.

Weder, A. (2007). 'An interview with Beatriz Colomina'. The Canadian Architect, 52(7), I3-I4.

Wilde, O. (1969). 'The decay of lying'. In R. Ellmann (Ed.), The artist as critic: critical writings of Oscar Wilde (pp. 230-320). New York: Random House. 
Williams, R. (1977). Marxism and literature. London: Oxford University Press.

Williams, R. (198I). Keywords : a vocabulary of culture and society. London: Flamingo.

Žaknić, I. (2007). The final testament of Père Corbu. New Haven:Yale University Press.

Zimmerman, C. (2005). Modernism, media, abstraction: Mies van der Rohe's photographic architecture in Barcelona and Brno (1927-3I). Ph.D dissertation, City University, New York. 


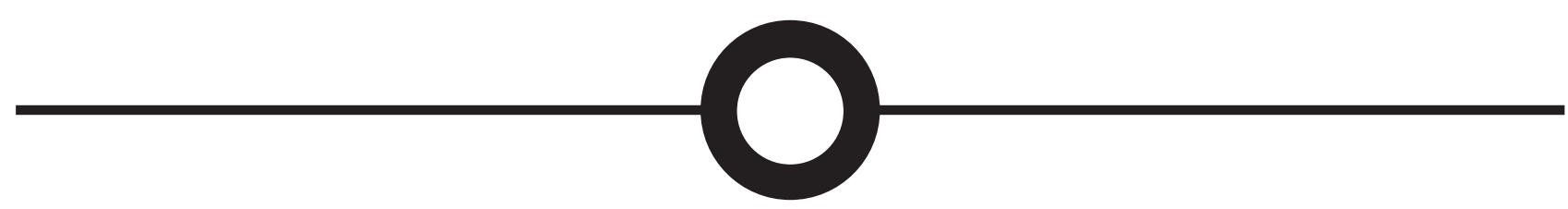

$\triangle 188$ 